Zweiter Beratungsgegenstand:

\title{
Rechtliche Optimierungsgebote oder Rahmensetzungen für das Verwaltungshandeln?
}

1. Bericht von Prof. Dr. Thomas Würtenberger, Freiburg

Inhalt

Seite

A. Fragestellung . . . . . . . . . . . . . . 141

B. Gegenwärtige Erscheinungsformen rechtlicher

Optimierungsgebote . . . . . . . . . . . . . . 143

I. Optimierung der Freiheit als Prinzip der Verfassungsauslegung? . . . . . . . . . . . . . . . . . 143

II. Spezifisch verwaltungsrechtliche Optimierungsgebote im Planungs-, Umweltschutz- und Wirtschaftsverwaltungsrecht ...............

C. Die historische Entwicklung des Optimierungsdenkens . . . 147

I. Traditionslinien des Optimierungsdenkens . . . . . . 147

II. Von ordnungsrechtlichen Rahmensetzungen zu

Optimierungsgeboten als Weg zu einer demokratischen und am Umweltschutz orientierten Verwaltung . . . . 151

1. Ordnungsrechtliche Rahmensetzungen für das Verwaltungshandeln .............. 151

2. Demokratisierung der Verwaltung durch rechtliche Rahmensetzungen und Zielsteuerung . . . . . . 152

3. Rechtliche Optimierungsgebote als Mittel zur Verwirklichung des Umweltschutzes . . . . . . 153

D. Die entscheidungstheoretische Problematik von Optimierungsgeboten . . . . . . . . . . . . . 154

I. Unsicherheit über die Wirkungszusammenhänge . . . 154

II. Schwierigkeiten der rechtlichen Bewertung . . . . . . 155

III. Zwang zur situativen Konkretisierung des Rechts . . . . 157

IV. Keine Garantie optimaler Entscheidung . . . . . . . 157 
E. Verfassungsrechtliche Grenzen von Optimierungsgeboten . . 158

I. Grenzen der verfassungsrechtlichen Optimierungsprinzipien . . . . . . . . . . . 158

II. Begrenzung durch die Garantie kommunaler Selbstverwaltung . . . . . . . . . . . . . . . . 159

III. Bedenken gegen eine Ausgestaltung der Kontrollerlaubnis als Optimierungsentscheidung . . . . . . . . . . . 160

IV. Grenzen richterlicher Kontrolle bei optimierendem Abwägen und rechtlichen Optimierungsgeboten . . . . 162

F. Optimierung durch Verwaltungsverfahren . . . . . . 166

I. Zur Neuorientierung des Verwaltungsverfahrens . . . . 166

II. Zur Rücknahme rechtlicher Optimierungsgebote und des Rechtsschutzes . . . . . . . . . . . . 168

G. Schlußbemerkung . . . . . . . . . . . . . . . . 170 


\section{A. Fragestellung}

Durch die Subsumtion eines Lebenssachverhalts unter eine Verwaltungsrechtsnorm wird herkömmlicherweise das rechtlich Gesollte bestimmt. Neben diese Rechtsfindung durch Subsumtion tritt die Rechtskonkretisierung durch Abwägung. Hier leitet sich die rechtliche Entscheidung nicht aus der Auslegung einer Norm, sondern aus einer Abwägung zwischen gegenläufigen Rechtsprinzipien oder öffentlichen und privaten Interessen her. Dieses Abwägen zielt auf Minimierung von Lasten und Kosten, auf Maximierung von Erfolg und Ertrag oder auf den optimierenden gewichtsproportionalen Ausgleich widerstreitender Prinzipien². Die prinzipienrechtliche Abwägung sucht Rechtsprinzipien entsprechend ihrem Geltungsanspruch und ihrer Wertigkeit nach den jeweiligen tatsächlichen und rechtlichen Möglichkeiten in einem möglichst hohen und damit optimalen Maß zu verwirklichen ${ }^{3}$. Eine solche Auflösung von Kollisionen zwischen Rechtsprinzipien oder zwischen rechtlich verfestigten öffentlichen und privaten Interessen ist eine rechtsschöpferische Leistung.

Der moderne Staat ist ein Abwägungsstaat. Sein Verfassungsrecht ist durch Abwägung unter der Leitidee einer optimalen Verteilung von Freiheit, von staatlichen Funktionen ${ }^{5}$ oder von optimaler Ressourcenalloka-

1 Subsumtion und Abwägung sind allerdings keine Alternativen, sondern bezeichnen eher Übergänge in der juristischen Argumentation. Während unter eindeutige Rechtsbegriffe nur subsumiert wird, erfordert die Auslegung unbestimmter Rechtsbegriffe in der Regel die Bewertung und Abwägung zwischen widerstreitenden Interessen. Aber auch soweit der Rechtsfindung lediglich Prinzipien vorgegeben sind, kann das besondere Gewicht eines Prinzips Abwägungsvorgänge (weitgehend) entbehrlich werden lassen (vgl. Stück ARSP 84 (1998) 405, 413 ff.). - Allgemein zur Rechtsfindung durch Abwägung: Hubmann Wertung und Abwägung im Recht, 1977; Erbgutb u.a. (Hrsg.), Abwägung im Recht, 1996; Schlink Abwägung im Verfassungsrecht, 1976; Leisner Der Abwägungsstaat. Verhältnismäßigkeit als Gerechtigkeit?, 1997; Rubel Planungsermessen, 1982.

2 Zu Definitionsversuchen Bischof NJW 1991, 2323.

${ }^{3}$ Alexy Theorie der Grundrechte, 1985, 75, 146; ders. in: ders./Dreier/Neumann (Hrsg.), Beiheft 44 zum ARSP (1991) 30, 42; Enderlein Abwägung in Recht und Moral, 1992, $87 \mathrm{ff}$; zur hier nicht weiter zu verfolgenden Kritik an diesem Ansatz: Scherzberg Grundrechtsschutz und „Eingriffsintensität der Grundrechte“, 1989, 169ff., 181 ff.; Penski JZ 1989, 105, $110 \mathrm{ff}$.

4 Hierzu die Nachw. in Fn. 1 und 3; Sieckmann ARSP 81 (1995) 164; ders. Rechtstheorie 26 (1995) 45.- Zur rechtlichen Regel als Ergebnis von Abwägungen zwischen Prinzipien: Sieckmann ARSP 83 (1997) 14, $17 \mathrm{f}$.

s In Zeiten eines knapper werdenden Finanzrahmens bedarf es der Optimierung der die Freiheit schützenden und stützenden staatlichen Institutionen. In den Kommunalwissenschaften sucht man nach optimalen Organisationsformen (vgl. Wabl in: Henneke (Hrsg.), Organisation kommunaler Aufgabenerfüllung. Optimierungspotentiale im Spannungs- 
tion geprägt. Weite Partien seines Verwaltungsrechts sind durch Abwägungsgebote und durch das Gebot, bestimmte Rechtsprinzipien zu maximaler Wirksamkeit kommen zu lassen (rechtliche Optimierungsgebote), beherrscht.

Normative Gebote zu optimierendem Abwägen sind eine besondere Facette deutscher Rechtskultur. Die deutsche Tradition ist einer rechtsstaatlichen Optimierung der Freiheit verpflichtet und sieht hierin die Vollendung des Rechtsstaates. Das Wissen um die rechtskulturelle Bedingtheit eines am Optimierungsdenken orientierten Rechtsstaates mag jenes historische Bewußtsein schaffen, das Distanz zum Gewordenen ermöglicht und Grundlage von Rechtsreform aus Anlaß der europäischen Integration sein kann ${ }^{6}$.

Die Frage nach rechtlichen Optimierungsgeboten oder Rahmensetzungen für das Verwaltungshandeln führt in die neuere Steuerungsdiskus$\operatorname{sion}^{7}$ : Zu welchen Steuerungsleistungen ist das Recht im Bereich des abwägenden und optimierenden Verwaltungshandelns faktisch in der Lage? Zugleich ist ein klassisches Thema der Staats- und Verwaltungsrechtslehre und auch früherer Staatsrechtslehrertagungen ${ }^{8}$ angesprochen: Welche Verrechtlichung der Verwaltung durch klare rechtliche Rahmensetzungen fordert der demokratische Rechtsstaat? Welche Verwaltungszwecke kön-

feld von Demokratie und Effizienz, 1998, $15 \mathrm{ff}$.). Im Bereich der Rechtspflege orientiert sich die Prozeßrechtsreform auch an den ökonomischen Grenzen staatlicher Leistungsfähigkeit und sucht die Justizverfassung im Spannungsfeld von rechtlich gebotener Effektivität und abnehmenden finanziellen Ressourcen zu optimieren (Würtenberger in: Justizministerium Baden-Württemberg (Hrsg.), Ist unser Rechtsstaat noch bezahlbar?, 1994, 33 ff.; Hoffmann-Riem Die Verwaltung 30 (1997) 481 ff.; Pitschas ZRP 1998, 96 ff.). Zu einem Optimierungsgebot im Bereich der Staatsaufgaben: Sachverständigenrat "Schlanker Staat" (Hrsg.), Abschlußbericht Bd. 1, 2. Aufl. 1998, 45.

${ }^{6}$ Zum Erfordernis einer gemeineuropäischen Dogmatik des Verwaltungsgeschehens", die eine zumindest partielle Distanz zu nationaler Tradition erfordert: Bachof VVDStRL 30 (1972) 193, 236; Heyen ARSP 62 (1976) 475, 488, $494 \mathrm{f}$.

${ }^{7}$ Schmidt-Aßmann Das allgemeine Verwaltungsrecht als Ordnungsidee, 1998, $19 \mathrm{ff}$; Grimm (Hrsg.), Wachsende Staatsaufgaben - sinkende Steuerungsfähigkeit des Rechts, 1990; Huber Die entfesselte Verwaltung, in: Staatswissenschaften und Staatspraxis 8 (1997) $423 \mathrm{ff}$ - Ein Überblick über die Steuerungsdebatte in der Politikwissenschaft bei von Beyme Der Gesetzgeber, 1997, $19 \mathrm{ff}$.

${ }^{8}$ Becker/Rumpf VVDStRL 14 (1956) $96 \mathrm{ff} ., 136 \mathrm{ff}$. zum Verhältnis von Verwaltung und Verwaltungsrechtsprechung; Vogel/Herzog VVDStRL 24 (1966) $125 \mathrm{ff}$., $183 \mathrm{ff}$. zum Verhältnis des Gesetzgebers zur Verwaltung; Scholz/Schmidt-Aßmann VVDStRL 34 (1976) $145 \mathrm{ff}$., $221 \mathrm{ff}$. zum Verhältnis von Verwaltungsverantwortung zur Verwaltungsgerichtsbarkeit; Wabl/Pietzcker VVDStRL 41 (1983) 151 ff., 193 ff. zur Neubestimmung des Verwaltungsverfahrens; Maurer/Scbnapp VVDStRL 43 (1985) $135 \mathrm{ff}$., $172 \mathrm{ff}$. zum Verwaltungsvorbehalt. 
nen und sollen „ohne starke Bindung an Rechtssätze ${ }^{{ }_{9}}$ durch Rechtsschöpfung aufgrund optimierenden Abwägens realisiert werden? Welche exekutivischen Vorbehaltsbereiche gibt es im Bereich optimierenden Abwägens gegenüber der Judikative? Die klassische Thematik der Balancierung des demokratischen Rechtsstaates erhält durch die stärkere Betonung des Verfahrensgedankens im Europäischen Verwaltungsrecht einen neuen Akzent. Der deutschen Konzeption der Steuerung der Verwaltung durch Recht und rechtliche Optimierungsgebote stellt sich das europäische Konzept der Optimierung durch Verfahren entgegen. Verfahrensrechtliche Optimierung im Spannungsfeld von gesetzlicher Steuerung und Selbststeuerung der Gesellschaft, also die demokratische Qualität der Verwaltung, ist die abschließende Fragestellung.

\section{B. Gegenwärtige Erscheinungsformen rechtlicher Optimierungs- gebote}

Das Verwaltungshandeln unterliegt in vielfältiger Form verfassungsrechtlichen und gesetzlichen Optimierungsgeboten ${ }^{10}$ :

\section{Optimierung der Freiheit als Prinzip der Verfassungsauslegung?}

Optimierung liegt, in ihrer Reichweite umstritten, der Verfassungsauslegung zugrunde ${ }^{11}$. Bei der Bestimmung der Grundrechtsschranken findet eine Abwägung kollidierender Verfassungsgüter statt, die Freiheit abgrenzt und zuordnet ${ }^{12}$. Der Verhältnismäßigkeitsgrundsatz ${ }^{13}$ und der Grundsatz praktischer Konkordanz ${ }^{14}$ sind Auslegungsregeln, die auf eine

9 Stier-Somlo in: FG Laband, Bd. II, 1908, 443, 499; m.w.N. bei Remmert Verfassungsund verwaltungsgeschichtliche Grundlagen des Übermaßverbotes, 1995, 124 ff.; ScbmidtAßmann in: FS Stern, 1997, $745 \mathrm{ff}$.

${ }^{10}$ Seitens der Verwaltungswissenschaften wird Entscheidungsrichtigkeit als Produkt von Rechtmäßigkeit, Optimalität und Akzeptabilität ${ }^{4}$ definiert (Hoffmann-Riem DVBI. 1994, 1381, 1382). Hier geht es weniger um derartige verwaltungspolitische bzw. verwaltungspraktische Forderungen, sondern um normative Optimierungsgebote.

${ }^{11}$ So der Ansatz von Alexy Theorie (Fn. 4) 75 ff, - Bedenken gegen diese Konzeption: Stem Das Staatsrecht der Bundesrepublik Deutschland, Bd. III/1, 1988, 502; Bd. III/2, 1994, 621 ff.; Lerche in: FS Stern, 1997, $197 \mathrm{ff}$.

12 Seit dem Lüth-Urteil, BVerfGE 7, 198.

${ }^{13}$ Starck Der demokratische Verfassungsstaat, 1995, 121; Dechsling Das VerhältnismäBigkeitsgebot, 1989, $56 \mathrm{ff}$.

14 Hesse Grundzüge des Verfassungsrechts, 20. Aufl. 1995, Rdn. 71 f.; BVerfGE 83, 130, 143: Kollidierende Grundrechte müssen ,mit dem Ziel der Optimierung zu einem angemessenen Ausgleich gebracht werden"; Scholz in: Maunz/Dürig, Art. 20a GG, Rdn. 42: Der Grundsatz der Einheit der Verfassung fordert ... den stetigen Interessen- und 
optimale Realisierung von Grundrechten, also auf eine Optimierung der Freiheit ${ }^{15}$, zielen ${ }^{16}$. Das Verwaltungsrecht steht unter dem Gebot einer bisweilen übersteigerten verfassungsorientierten Optimierung. Leitet man aus der objektiven Bedeutungsschicht der Grundrechte Optimierungsgebote und hieraus Handlungspflichten $a b^{17}$, so verstärkt dies die problematische Tendenz, das Verwaltungsrecht als "Verwirklichung " der Grundrechte zu sehen ${ }^{18}$. Wie für den Gesetzgeber entwickelt, aber wesentlich enger, soll es für optimierende Verwaltungsentscheidungen nur den Korridor zwischen Übermaß- und Untermaßverbot geben ${ }^{19}$. Eine Belastungen und Begünstigungen in einem multipolaren Rechtsverhältnis verteilende Verwaltungsentscheidung soll im Sinne einer Gesamtverhältnismäßigkeit ${ }^{20}$ die Interessen sachgerecht abwägen und in optimaler

Schutzgüterausgleich (Vorbehalt der praktischen Verfassungskonkordanz) ${ }^{\alpha}$; der Grundsatz der Verhältnismäßigkeit soll das "maßgebende Regulativ“ sein.

${ }^{15}$ Neben diesen Auftrag tritt der Zwang zu ökonomischer Optimierung. Gemeinwohlverwirklichung durch optimale Ressourcenallokation ist eine teils verfassungsrechtliche, teils politische Zielsetzung. Der in Art. 114 Abs. 2 S. 1 GG geregelte Wirtschaftlichkeitsgrundsatz zwingt die Verwaltung zu einer ökonomischen Optimierung. Ob und in welchem Umfang die Verwaltungstätigkeit einer ökonomisch orientierten Wohlfahrtsmaximierung unterworfen wird, entscheidet sich bei der Rechnungshofskontrolle (Degenbart VVDStRL 55 (1996) 190, 208 ff.; Schulze-Fielitz ebd. S. 231, 254 ff., 262 ff.; Sierig Die Grenzen der staatlichen Finanzkontrolle, 1998, 131 f.). Diese fragt über die klassische Wirtschaftlichkeitsprüfung hinaus, ob der Einsatz von Finanzmitteln zu einer Optimierung gesellschaftlichen Nutzens beiträgt. Geprüft wird, ob die weitere Steigerung des sozialen Erfolges durch Steigerung des Mitteleinsatzes sinnvoll ist, oder ob der Einsatz der Mittel für eine andere Verwaltungsagenda zu einer optimalen Gemeinwohlverwirklichung beiträgt. Hier tritt der Rechnungshof als weiterer Akteur in die Arena rechtlicher und politischer Optimierung. Diese wohlfahrtstheoretische Variante eines ökonomischen Optimierungsgebotes zielt auf die Verwirklichung der "ratio oeconomica".

${ }^{16}$ Nach BVerfGE 83, 130, 148 darf der Verwaltung keine Beurteilungsermächtigung eingeräumt werden, wenn vorbehaltlos gewährte Grundrechte mit widerstreitenden Gütern von Verfassungsrang zur Konkordanz gebracht werden. Hier wird die einzig richtige, optimale Zuordnung von Freiheit unmittelbar aus der Verfassung abgeleitet.

${ }^{17}$ Klein in: Bitburger Gespräche, Jahrbuch 1995, 81, 94: „Die aus der objektiven Bedeutungsschicht der Grundrechte abzuleitenden Handlungspflichten haben den Charakter von Prinzipien, von Optimierungs- (nicht Maximierungs-)geboten“. - Krit. Böckenförde Zur Lage der Grundrechtsdogmatik nach 40 Jahren Grundgesetz, 1989, 52 ff. m.w.N.

18 Schmidt-Aßmann in: FS Redeker, 1993, 225ff.; Lerche (Fn. 11) 202f. m.w.N.

${ }^{19}$ So Hoffmann-Riem DVBI. 1994, 605, 608f.; Würtenberger/Heckmann/Riggert Polizeirecht in Baden-Württemberg, 3. Aufl. 1997, Rdn. 21. - Zum Untermaßverbot: BVerfGE 88, 203, 254; Isensee, Das Grundrecht als Abwehrrecht und staatliche Schutzpflicht, in: Isensee/Kirchhof (Hrsg.), Handbuch des Staatsrechts, Bd. V, 1992, § 111 Rdn. 165f; Hain DVBl. 1993, $982 \mathrm{ff}$; kritisch Hesse in: FS Mahrenholz, 1994, 541, $550 \mathrm{ff}$.

${ }^{20}$ Hoffmann-Riem in: Schmidt (Hrsg.), Öffentliches Wirtschaftsrecht, Bes. Teil 1, 1995, 563,581 . 
Weise zuordnen. Derartige Thesen führen zu einer problematischen Einschränkung der Ermessens- und Planungsspielräume der Verwaltung. Hierauf ist zurückzukommen.

\section{Spezifisch verwaltungsrechtliche Optimierungsgebote}

Optimierung ist Leitziel verwaltungsrechtlicher Abwägung. Dies gilt

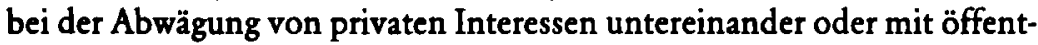
lichen Interessen, etwa bei der Konkretisierung unbestimmter Rechtsbegriffe des Umweltrechts: „Bei der Vorsorge gegen schädliche Umwelteinwirkungen" ( $\$ 5$ Abs. 1 Nr. 2 BImSchG) sind nach dem Standard der „praktischen Vernunft ${ }^{\alpha}$ die angemessenen Maßnahmen gegen vermutete Gefahren zu treffen; damit ist ein verhältnismäßiger Ausgleich zwischen Betreiber- und öffentlichen Interessen gefordert ${ }^{21}$. Solche unbestimmten Rechtsbegriffe zielen auf eine am Verhältnismäßigkeitsprinzip orientierte optimierende Abwägung zwischen privaten und öffentlichen Interes$\operatorname{sen}^{22}$, die damit nicht auf Rechtsprinzipien beschränkt werden kann.

Im Planungsrecht wird seit den 60er Jahren das Handeln der Verwaltung durch den Auftrag zur Abwägung zwischen rechtlichen Planungsleitlinien gesteuert. Die Abwägung hat einen optimierenden Charakter, da die rechtlichen Planungsleitlinien nach dem Verhältnismäßigkeitsprinzip in einer sach-, zeit- und interessenadäquaten Weise in eine rechtsverbindliche Planung umgesetzt werden. Insofern ist das Abwägungsgebot ein allgemeines Optimierungsgebot bei der gesetzlich aufgegebenen Lösung von Konflikten bei der lokalen Nutzung von Boden ${ }^{23}$.

Durch rechtliche Optimierungsgebote verlangt der Gesetzgeber die vorrangige Realisierung ${ }^{24}$ eines Rechtsprinzips, etwa die Beeinträchtigung der natürlichen Funktionen des Bodens so weit wie möglich zu ver-

21 Jarass Bundesimmissionsschutzgesetz, 2. Aufl. 1993, $\$ 5$ Rdn. 53 ff. m.w.N.; Ossenbubl NVwZ 1986, 167; BVerfGE 49, 89, 143 f.; BVerwGE 69, 37, 45.

22 Bleckmann Ermessensfehlerlehre, 1997, 9 ff.; Hoffmann-Riem AöR 119 (1994) 590, 599; Stück ARSP 84 (1998) 405, 413 (abwägungsbezogene Rechtsbegriffe); zur „bestmöglichen Gefahrenabwehr und Risikovorsorge“ aus $\S 1$ Nr. 2 i.V.m. $\S 7$ Abs. 2 AtG: BVerfGE 49, 89,$143 ; 53,30,58 f$.

${ }^{23}$ BVerwGE 56, 110, 116; 57, 297, 300; 61, 307, 311; Hoppe DVB1. 1994, 1033 f. - Zu den durch Abwägung nicht überwindbaren Planungsvorgaben: Brohm Offentliches Baurecht, 1997, § 13 Rdn. 6; BVerwGE 71, 163, 165; BVerwG DVB1. 1990, 1185; eine absolute Vorrangbestimmung ist z.B. $\$ 1$ Abs. 3 S. 1 FStrG: Kreuzungsfreiheit von Autobahnen; vgl. weiter Hoppe UPR 1995, $201 \mathrm{ff}$.

24 BVerwGE 71, 163, 165; 90, 329, 331; WablNVwZ 1990, 426, 437f.; Brobm (Fn. 23) § 13 Rdn. 6 ff.; Hoppe DVBI. 1992, 853 ff.; Steinberg Fachplanung, 2. Aufl. 1993, 199; SchulzeFielitz GK-BImSchG, $\S 50$ Rdn. $27 \mathrm{ff}$., 47 (Vorranggebot); krit. Bartlsperger DVB1. 1996, 1, 2f.; ders. in: Erbguth (Fn. 1) 114. 
meiden ${ }^{25}$. Solche normativen Gewichtungsprivilegien ${ }^{26}$ erfordern eine optimierende Abwägung im Sinne des jeweiligen Rechtsprinzips ${ }^{27}$ und sind in erster Linie Maximierungsgebote ${ }^{28}$ : Beim Ausgleich $\mathrm{zwischen} \mathrm{ver-}$ schiedenen Prinzipien soll das zu optimierende Prinzip möglichst vollständig realisiert werden ${ }^{29}$.

Eine ganz andere, nämlich verfahrensorientierte Variante des Optimierungsgebotes gelangt künftig im Umweltschutz- und Wirtschaftsverwaltungsrecht bei Kontrollgenehmigungen zur Anwendung. Vor allem die immissionsschutzrechtlichen Genehmigungen müssen nach Umsetzung der Richtlinie des Rates über die integrierte Vermeidung und Verminderung der Umweltverschmutzung ${ }^{30}$ den Anforderungen eines medienübergreifenden Umweltschutzes Rechnung tragen, was zu einer im Ausmaß umstrittenen finalen Programmierung und zu Optimierungsentscheidungen zwingt ${ }^{31}$. So wird als allgemeine Optimierungsklausel für eine Anla-

${ }_{25} \S 1$ S. 3 Gesetz zum Schutz des Bodens vom 17. 3. 1998, BGBI. S. 502; § 1 Abs. 5 S. 3 BauGB: Zugriff auf landwirtschaftliche Flächen nur im notwendigen Umfang“.

${ }^{26}$ Zum Streit um die Terminologie: Bartlsperger DVB1. 1996, 1, 3.

${ }^{27}$ Dreier Die normative Steuerung der planerischen Abwägung, 1995, $215 \mathrm{ff}$.; SchulzeFielitz GK-BImSchG, $\S 50 \mathrm{Rdn}$. 33; zu $\S 50 \mathrm{BImSchG}$ als Optimierungsgebot: Jarass (Fn. 21) §50 Rdn. 1; Scbulze-Fielitz GK-BImSchG, §50 Rdn. 31 f.; krit. Bartlsperger DVB1. 1996, 1, 8; zur Festsetzung von Vorbehaltsgebieten nach $\S 7$ Abs. 4 S. 1 Nr. 2 BROG, in denen bestimmten raumbedeutsamen Bodennutzungen bei der Abwägung ein besonderes Gewicht beigemessen werden soll: Erbgutb DVB1. 1998, 209, 212; zu $§ 1$ Abs. 1 FStrG als Optimierungsgebot: Hoppe DVBI. 1992, 853, 855.

${ }^{28}$ Ein solches Optimierungs- bzw. Maximierungsgebot kann eine unterschiedliche normative Verbindlichkeit aufweisen: Zum einen kann geregelt werden, daß einem Rechtsgrundsatz besonders Rechnung zu tragen ist; dies kann dahin gesteigert werden, daß einem Rechtsgrundsatz möglichst weitgehend Beachtung gezollt werden soll.

${ }^{29}$ Es besteht u.a. im Recht der Bauleitplanung die Tendenz, die planungsrechtlichen Optimierungsgebote zu kumulieren (Brobm [Fn. 23] § $13 \mathrm{Rdn}$. 12: $\$ 50 \mathrm{BImSchG,} \S 1$ BodSchG, $\S$ la Abs. 1 BauGB für das Recht der Bauleitplanung). Dann stellt sich bei der Abwägung die Aufgabe, die Optimierungs- bzw. Maximierungsgebote ihrerseits wieder zu optimieren und ihren Rang gegenüber den allgemeinen Planungsgrundsätzen zu bestimmen. Bei einer Kumulation von Optimierungs- bzw. Maximierungsgeboten gewinnt die Verwaltung ein Stück Entscheidungsfreiheit zurück, da sich diese Gebote gegenseitig relativieren. Ebenso wie bei einer Häufung von Staatszielen in der Verfassung wird die normative Kraft rechtlicher Optimierungsgebote umso geringer, je mehr kollidierende Optimierungsgebote geregelt werden (Wahl NVwZ 1990, 426, 438).

${ }^{30}$ Richtlinie 96/61/EG des Rates; hierzu Dolde NVwZ 1997, $313 \mathrm{ff}$.; Steinberg/Koepfer DVBl. 1997, 973 ff.; Scbulz Medienübergreifendes Industrieanlagenzulassungsrecht nach europäischem und deutschem Recht, 1997; Breuer NVwZ 1997, 837.

${ }^{31}$ Masing DVBI. 1998, 549, 553 ff.; Volkmann VerwArch 89 (1998) 363, 390 ff.; Kommissionsentwurf eines UGB, hrsg. vom Bundesministerium für Umwelt, Naturschutz und Reaktorsicherheit, 1997; hierzu Kloepfer DVBI. 1997, 1081 ff.; Schrader NuR 1998, 285, 287 
gengenehmigung vorgeschlagen, „daß unter Berücksichtigung aller Belastungspfade und der Wechselwirkungen zwischen den Umweltgütern die Maßnahmen getroffen werden, die die Umwelt in ihrer Gesamtheit möglichst wenig belasten ${ }^{\alpha 32}$. Hier tritt in letzter Konsequenz an die Stelle klarex normativer Vorgaben, etwa von festen Grenzwerten, der Auftrag zu „best practice-Lösungen ${ }^{433}$, - statt der juristischen Deduktion der einzig richtigen Umweltrechtsauslegung also der offene Diskurs einer für den Schutz der Umwelt optimalen Entscheidung.

Die verwaltungsrechtlichen Optimierungsgebote haben eine unterschiedliche Kraft normativer Steuerung: Auf dem einen Ende der Skala stehen die unbestimmten Rechtsbegriffe mit dem Auftrag zu optimierender Abwägung, die nach nicht unbestrittener Auffassung voller gerichtlicher Kontrolle unterliegt. Präzise gefaßten rechtlichen Optimierungsgeboten kommt ebenfalls eine beachtliche normative Kraft zu; ihre Fixierung der Zielsetzung der Verwaltungsentscheidung nähert sich dem Modus der vollzugsrechtlichen Steuerung. Die normative Kraft von Optimierungsgeboten ist relativ gering, wenn auf dem anderen Ende der Skala lediglich die optimierende Abwägung zwischen gleichgewichtigen, aber gegenläufigen Prinzipien oder z.B. nur die beste umweltschützende Praxis vorgegeben ist.

\section{Die historische Entwicklung des Optimierungsdenkens}

\section{Traditionslinien des Optimierungsdenkens}

Rechtliche Optimierungsgebote sind bestimmende Faktoren der deutschen Verwaltungsrechtsentwicklung. Sicherlich mag man über die groBen Linien der Tradierung des Rechts trefflich streiten, sicherlich hat jede Generation einen unterschiedlichen Blick auf die ihr vorausliegenden geschichtsmächtigen Traditionen. Dennoch sei in thesenhafter Zuspitzung behauptet: Der für Deutschland charakteristische Weg zum Rechtsstaat ist ein wesentlicher Grund für die unterschiedlichen Konzepte von Verwaltungsrecht, von Verwaltungsverfahren und von gerichtlicher Kontrolle im Vergleich zu Frankreich ${ }^{34}$ oder England. Für eine Angleichung

(Suche nach dem Optimum einer möglichst geringen Umweltbelastung); zurückhaltender Schmidt-Prewß DVB1. 1998, 857, 862 f.; Di Fabio NVwZ 1998, 329 ff.; Steinberg/Koepfer DVB1. 1997, 973, 981.

$32 § 83$ Abs. 2 S. 1 UGBE, der auch als Integrationsklausel bezeichnet wird (Kloepfer DVB1. 1997, 1089) ermächtigt die Behörde, die umweltschonendste Maßnahme zu ergreifen (UGBE (Fn. 31) 627).

${ }^{33} \mathrm{Zu}$ dieser Entwicklung: Hill ZG 1995, 82, 84; Breuer in: UTR 45 (1998) 161, $166 \mathrm{f}$.

34 Zum Gesetz als Instrument der Demokratie und zur demzufolge traditionell geringen 
an die Verwaltungskultur und an den allgemeinen Rechtsschutzstandard in der Europäischen Union ist eine rechtskulturelle Vergewisserung der Entwicklung rechtlicher Optimierung und ihrer verwaltungsgerichtlichen Kontrolle angezeigt. Nur wer seine Traditionen kennt, ist in der Lage, die positiven Leistungen des Rechts zu würdigen, aber auch die Ketten einer überkommenen Dogmatik und Rechtskultur wahrzunehmen und diese neu zu schmieden.

Im Staats- und Verwaltungsrecht spielt seit dem ausgehenden 18. Jahrhundert der dem Verhältnismäßigkeitsgrundsatz eigene Optimierungsgedanke eine besondere Rolle. So formuliert Svarez als Grundsatz polizeilicher Gefahrenabwehr: „Der Schaden, welcher durch die Einschränkung der Freiheit der einzelnen abgewendet werden soll, muß bei weitem erheblicher sein als der Nachteil, welcher den einzelnen oder auch dem Ganzen aus dieser Einschränkung entspringt ${ }^{{ }^{3} 35}$, eine klassische Formulierung zugunsten einer staatsfreien Sphäre, die in der Grundrechtsdiskussion des letzten Drittels des 18. Jahrhunderts vorbereitet worden ${ }^{36}$ war.

Das geistige Fundament des Prinzips rechtlicher Optimierung haben Kant und die Philosophie des Idealismus gelegt. Die Kantische Bestimmung des Rechts, daß die Freiheit des einen mit der Freiheit des anderen so abzugrenzen sei, daß beide zusammen bestehen können ${ }^{37}$, daß „Freiheit unter äußeren Gesetzen im größtmöglichen Grad ... angetroffen wird ${ }^{\alpha 38}$, wirkt heute in der Formel von der praktischen Konkordanz oder von der verhältnismäßigen Zuordnung von Freiheit fort.

Die Staatsphilosophie Kants und vernunftrechtliche Traditionen finden u.a. in den Hand- und Lehrbüchern zum Polizeirecht zu Beginn des 19. Jahrhunderts ihren dogmatischen Niederschlag ${ }^{39}$. Sie gewinnen zu-

Bedeutung der Gerichtsbarkeit: Grewe in: Jurt/Krumeich/Würtenberger (Hrsg.), Der Wandel von Rechtsbewußtsein und Recht in Frankreich und Deutschland, 1998, 115ff., 119. Hierzu im Gegensatz steht die deutsche Konzeption des Rechtsstaates, daß der Staat zwar Herr über das Recht, zugleich aber selbst dem Recht unterworfen ist: Zacher in: FS Stern, 1997, 393, 396f.

${ }^{35}$ Conrad/Kleinheyer (Hrsg.), Vorträge über Recht und Staat von C. G. Svarez 1960, 40; Stem in: FS Lerche, 1993, $165 \mathrm{ff}$.

36 Würtenberger in: Gose/Würtenberger (Hrsg.), Zur Ideen- und Rezeptionsgeschichte des Preußischen Allgemeinen Landrechts, 1999, 73 ff. m.w.N.

${ }^{37}$ Kant Metaphysik der Sitten I, 2. Einl., \$ C; ebenso Svarez (Fn. 35) 40; hierzu Zippelius Geschichte der Staatsideen, 9. Aufl. 1994, Kap. 16 c.

${ }^{38}$ Kant Idee zu einer allgemeinen Geschichte in weltbürgerlicher Absicht (1784), „Fünfter Satz".

${ }^{39}$ Von Berg Handbuch des teutschen Policeyrechts, 2. Aufl. 1802, 89f.; Krüger in: Blühdorn/Ritter (Hrsg.), Philosophie und Rechtswissenschaft, 1969, 49 ff.; Stolleis Geschichte des öffentlichen Rechts in Deutschland, 2. Bd., 1992, 159ff., 165; zum Zusammenhang 
nächst Einfluß auf die Lehre und später dann auch auf die Rechtsprechung ${ }^{40}$. Das Naturrecht des ausgehenden 18. Jahrhunderts in seiner vernunftrechtlichen Variante mit der These, die Vernunft sei die letzte Quelle aller Rechtsprinzipien ${ }^{41}$, ebenso wie die Philosophie Kants gehören zur geistigen Grundlage für die Entwicklung öffentlich-rechtlicher Argumentationsweisen, die mit ihrem Postulat rechtsstaatlicher Vernünftigkeit auch heute präsent sind.

Ein Rechtsstaat, der, in Distanz zum demokratischen Belieben, die vernunftgeleitete Realisierung einer optimalen Ordnung der Freiheit zum Ziel hat, kompensiert mangelnde Demokratie ${ }^{42}$. Dies war Grundlage des deutschen Weges zum Verfassungsstaat, der länger als andere westliche Nationen zu Kompromissen bei der demokratischen Selbstbestimmung bereit war und daher das Recht auf rechtsstaatliche Richtigkeit zu bauen versuchte ${ }^{43}$.

Auf dieser Linie liegt, daß die Idee der rechtlichen Richtigkeit durch Verwaltungsverfahren in Deutschland lange Zeit nicht entfaltet wurde. Über die rechtsstaatliche Richtigkeit zu wachen, ist Aufgabe der (Verwaltungs-)Gerichtsbarkeit, die in Deutschland seit jeher eine besonders hohe Akzeptanz genießt. Diese hat frühe historische Wurzeln im ausgehenden 18. Jahrhundert, als vor allem das Reichskammergericht zu einer vorsichtigen Rechtsreform im Geiste aufgeklärter Staatsphilosophie in der Lage war ${ }^{44}$. Freiheitsschutz durch Gerichtsbarkeit ${ }^{45}$ blieb zentrales und erfolgreich durchgesetztes Anliegen im 19. Jahrhundert ${ }^{46}$.

zwischen den Naturrechtslehren und der rechtsstaatlichen Bindung der Polizeigewalt: Mayer Deutsches Verwaltungsrecht, 1. Bd., 3. Aufl. 1923, 209.

40 Vor allem des PrOVG; Nachw. bei Remmert (Fn. 9) $140 \mathrm{ff} ., 145 \mathrm{ff} ., 154 \mathrm{ff}$.

41 Nachw. bei Stolleis (Fn. 39) $167 \mathrm{ff}$; zu Mayers Glauben an „die Macht allgemeiner Rechtsideen und seinen geistigen Wurzeln in der Philosophie des Idealismus: Stolleis S. 404 m.w.N.; vgl. weiter Rupp in: FS Bachof, 1984, 151, 163.

42 Zur Kompensation mangelnder Demokratie durch Ausbau der Justizverfassung in Deutschland: Schulze-Fielitz JZ 1993, 772, 778.

43 Bezeichnend etwa Kleins Trost, wer „in einer Monarchie lebt, worin die bürgerliche Freiheit gehandhabt wird, ... kein Verlangen tragen wird, ein Republikaner zu werden " (Freyheit und Eigentum, 1790, 164); zu dieser für Deutschland typischen Differenzierung zwischen bürgerlicher und politischer Freiheit: Würtenberger in: Aufklärung 3 (1988) H. 2, 53, $68 \mathrm{ff}$ - Vgl. weiterhin Fleiners Bemerkung, daß der Gesetzgeber zur Neuorientierung des Verwaltungsrechts nichts beitrage, sondern der Fortschritt ,vom Spruch des Richters und der stillen Arbeit der Wissenschaft ${ }^{\alpha}$ ausgehe, die das eine Ziel verfolgen, jedem Bürger "gegen den Herrscher Staat ... sein Recht ${ }^{\alpha}$ zu geben (Über die Umbildung zivilrechtlicher Institute durch das öffentliche Recht, 1906, 23 f.). Auch bei Gneist stand nicht „Parlamentarisierung ${ }^{\alpha}$, sondern "Ausbau des Rechtsstaats ${ }^{\alpha}$ im Vordergrund (Stolleis Fn. 39, 388).

44 Würtenberger in: FS Benda, 1995, 443, $450 \mathrm{ff}$.; Neugebauer-Wölck Reichsjustiz und 
Die Rechtsschutzgarantie des Art. 19 Abs. 4 GG und das Konzept des materiellen Rechtsstaates beförderten den richterrechtlichen Zugriff auf rechtliche Optimierung. Der auf Art. 19 Abs. 4 GG gestützte funktionelle Machtzuwachs der Gerichtsbarkeit war auch eine Antwort auf das Unrechtsregime des Dritten Reiches. Die für Deutschland typische Illu$\operatorname{sion}^{47}$, die einzig rechtlich richtige Entscheidung sei für jeden Einzelfall durch richtiges Anwenden der rechtlichen Vorgaben zu finden, bestimmt die umfassende verwaltungsgerichtliche Kontrolle der unbestimmten Rechtsbegriffe seit den 50er Jahren ${ }^{48}$, die zunehmende Kontrolle des Ermessens durch Verhältnismäßigkeit und Gleichheitssatz ${ }^{49}$, die richterrechtlich geschöpfte Kontrolle von Planungsentscheidungen ${ }^{50}$ seit Ende der 60 er Jahre und nicht zuletzt die vielfach kritisierten verfassungsgerichtlichen Vorgaben ${ }^{51}$ für die verwaltungsprozessuale Kontrolldichte ${ }^{52}$. Diese Entwicklung in Rechtsprechung und Rechtsdogmatik geht in allzu einseitiger Zuspitzung davon aus, die Verfassung sei umfassender Hort

Aufklärung, 1993. - So konnte von Berg Über Teutschlands Verfassung und die Erhaitung der öffentlichen Ruhe in Teutschland, 1795, 61 feststellen: Bei den Reichsgerichten „findet der teutsche Bürger Hilfe gegen allen Despotismus, gegen gesetzwidrige Urteile, gegen Verweigerung oder Verzögerung der Justiz, gegen ungerechte Gesetze, gegen verfassungswidrige Eingriffe in seine Freiheiten, gegen willkürliche Auflagen, gegen jeden Mißbrauch der Regierungsrechte ${ }^{\alpha}$.

${ }^{45} \mathrm{Zu}$ erinnern ist an die Kreuzberg-Entscheidung (PrOVGE 9, 353; Kroeschell VBIBW 1993, 268), die mit einer contra-legem-Interpretation des $\S 10$ Teil Il Titel 17 PrALR die Grundlage für ein rechtsstaatliches Polizeirecht in Preußen legte.

${ }^{46}$ Symptomatisch ist, wie bei Einführung der Verwaltungsgerichtsbarkeit in bewußter Antithese zum französischen System die Definitionsmacht über die verwaltungsrechtlichen Begriffe den Verwaltungsgerichten und nicht der Verwaltung zugewiesen wurde; vgl. Habn Rudolf von Gneist 1816 - 1895, 1995, $184 \mathrm{ff}$.

47 Diese liegt auch dem Prinzipiendenken Dworkins zugrunde: Alexy Recht, Vernunft, Diskurs, 1995, 212.

${ }^{48}$ Zur Entwicklung seit der Weimarer Zeit vgl. Rüfner in: Jeserich/Pohl/von Unruh (Hrsg.), Deutsche Verwaltungsgeschichte, Bd. 4, 1985, 639, 642f.; Schoen VerwArch 27 (1919) 85, 112; Bachof JZ 1955, 97 ff.; Ule in: GS Jellinek, 1955, $309 \mathrm{ff}$ - Zum gegenwärtigen Stand: Schulze-Fielitz JZ 1993, 772; BVerwGE 94, 307, 309.

${ }^{49}$ Zur Entwicklung: Bübler Die subjektiven öffentlichen Rechte und ihr Schutz in der deutschen Verwaltungsrechtsprechung, 1914, $162 \mathrm{ff}$; Jellinek Verwaltungsrecht, 3. Aufl. 1928, 36 ff.; Scheuner VerwArch 33 (1928) 68 ff.; Bullinger JZ 1984, 1001 ff. m.w.N. - Zur Kritik: Bettermann Der totale Rechtsstaat, 1986, 36 mit der Mahnung, man müsse „lernen, rechtsfreie und gerichtsfreie Räume zu ertragen".

so Seit BVerwGE 34, 301, 304 ff. aus dem Jahr 1969. - Zu den Einflüssen von Hoppe auf die Abwägungslehre im Planungsbereich: Rengeling in: Erbguth (Fn. 1) $4 \mathrm{ff}$.

${ }^{51}$ Zur Kritik: Sendler DVBI. 1994, $1089 \mathrm{ff}$.

52 Schwarze Europäisches Verwaltungsrecht, Bd. I, 1988, $246 \mathrm{ff}$.; Starck in: Bullinger (Hrsg.), Verwaltungsermessen im modernen Staat, 1986, 15, 40 ff. 
des richtigen Rechts, und führt zu einer verfassungsrechtlichen Aufladung des einfachen Rechts, wie sie anderen Rechtsordnungen unbekannt ist. Die verfassungsorientierte Auslegung des Rechts, - in Abwandlung der französischen "loi-écran ${ }^{{ }_{53}}$ läßt sich von einer "constitution-écran" sprechen -, tendiert nach Ansicht ausländischer Beobachter zu einem Verfassungsimperialismus ${ }^{54}$.

\section{Von ordnungsrechtlichen Rabmensetzungen zu Optimierungsgeboten als Weg $z u$ einer demokratischen und am Umweltschutz orientierten Verwaltung}

In einem nicht weiter zu vertiefenden entwicklungsgeschichtlichen $\mathrm{Zu}$ griff läßt sich die Entwicklung von einer ordnungsrechtlichen Rahmensetzung zu rechtlichen Abwägungs- und Optimierungsgeboten als Weg zu einer demokratischen und sodann am Umweltschutz orientierten Verwaltung beschreiben.

\section{Ordnungsrechtliche Rabmensetzungen für das Verwaltungshandeln}

Das Regelungsmodell des liberalen Rechtsstaates sowie des wirtschaftsund sozialpolitischen Interventionsstaates ${ }^{55}$ sieht für das Verwaltungshandeln klare, konditionale rechtliche Rahmensetzungen vor, die Gleichmaß garantieren und Rechtsschutz ermöglichen ${ }^{56}$. Die gesetzlichen Regeln betrafen vor allem die eingreifende und zuteilende Verwaltung im Bereich des Steuerwesens und der Sozialverwaltung sowie die gefahrenabwehrende Steuerung durch Gebote, Verbote oder Genehmigungsvorbehalte ${ }^{57}$. Das Wirtschaftsverwaltungs- und das Umweltrecht sind weitgehend von diesem traditionellen Steuerungsmodell beherrscht. Dessen unbestimmte Rechtsbegriffe sind durch eine Vielzahl von normkonkretisierenden Verwaltungsvorschriften und von Rechtsverordnungen normativ präzisiert worden. Die derart von der Verwaltungsspitze gemeinsam mit den „beteiligten Kreisen " geschaffenen normativen Umwelt- und Technikstandards ermöglichen Vollzugssicherheit, Rechtsklarheit und eine umfassende gerichtliche Kontrolle.

53 Vedel/Delvolvé Droit administratif, 11. Aufl. 1990, 452.

54 Grewe/Fabri Droits constitutionnels européens, 1995, 186; vgl. Lerche (Fn. 11) 202.

"Zur Entwicklung zum Interventionsstaat: Stolleis in: Jeserich/Pohl/von Unruh (Hrsg.), Deutsche Verwaltungsgeschichte, Bd. 4, 1985, 77, 79.

${ }^{56}$ Vgl. Stolleis (Fn. 39) 406 m.w.N.

${ }^{77}$ Hierzu ausführl. Badura Verwaltungsrecht im liberalen und sozialen Rechtsstaat, 1966; Di Fabio Risikoentscheidungen im Rechtsstaat, 1994, 11 ff.; Gröschner Das Überwachungsrechtsverhältnis, 1992, 3 ff., $46 \mathrm{ff}$. 


\section{Demokratisierung der Verwaltung durch rechtliche Rabmensetzungen und Zielsteuerung}

Im demokratischen Staat ist die konditionale Steuerung der Verwaltung nicht das einzige Steuerungsmodell ${ }^{58}$. Der Gesetzgeber entscheidet, ob er durch rechtliche Rahmensetzungen die Steuerung der Verwaltung eng führt oder ihr Bewegungsfreiheit beläßt. Das sehr vielfältige Steuerungsinstrumentarium reicht von strikter Bindung über Zuerkennung rechtlich gebundener Gestaltungsfreiheit bis zur Ermessensbindung und Einräumung administrativer Gestaltungsfreiheit. Rahmensetzende Gesetze können der Verwaltung etwa Infrastrukturleistungen mit klaren Leistungsstandards aufgeben, ihr es aber auch überlassen, wie diese Infrastrukturaufgaben erfüllt werden ${ }^{59}$. Die normative Dichte rechtlicher Rahmensetzung ist nur zum Teil durch die Lehre vom Gesetzesvorbehalt als verfassungsrechtlichem Programm vorgegeben ${ }^{60}$. In der politischen Praxis dürfte auch ein gewisses Vertrauen oder Mißtrauen des Gesetzgebers gegenüber seiner Verwaltung für die Art und den Umfang der Regelungen mitbestimmend sein.

Im Planungsbereich versagt das Modell konditionaler Steuerung. Soll hier das Wesentliche durch das Verwaltungstecht ${ }^{61}$ geregelt werden, muß neben die konditionale Programmierung im grundrechtsrelevanten Bereich auch eine gesetzliche Zielsteuerung treten. Die Zielsteuerung der Verwaltung durch Rechtsprinzipien, ihre finale Programmierung ${ }^{62}$, ent-

58 Badura in: FS für Huber, 1981, 15 ff.; Berkemann in: FS für Schlichter, 1995, 27, 41 f; Dreier Hierarchische Verwaltung im demokratischen Staat, 1991, 121 ff.; Lange VerwArch 82 (1991) 1 ff.; vgl. weiter Schuppert in: Hoffmann-Riem/Schmidt-Aßmann/Schuppert (Hrsg.), Reform des Allgemeinen Verwaltungsrechts, 1993, $65 \mathrm{ff}$. m.w.N.

59 Verwiesen sei auf die weisungsfreien Pflichtaufgaben im kommunalen Bereich.

Nicht weiter behandelt werden die Prozesse der Deregulierung, die die Verwaltungsrechtsordnung zu einer Rahmenordnung werden lassen. Hierzu zählen etwa die Regeln über die Überwachung der Infrastrukturverantwortung, die Privatisierung der Umweltkontrolle u.a.m. Hier geht es um den Abbau von Staatsaufgaben oder um die Rücknahme staatlicher Kontrolle, die mit rechtlichen Optimienungsgeboten wenig zu tun haben; vgl. Hendler in: Voigt (Hrsg.), Gegentendenzen zur Verrechtlichung, 1983, $59 \mathrm{ff}$.

${ }^{60}$ Zur Wesentlichkeitstheorie vgl. Ossenbübl in: Götz/Klein/Starck (Hrsg.), Die öffentliche Verwaltung zwischen Gesetzgebung und richterlicher Kontrolle, 1985, 9, $24 \mathrm{ff}$; Papier ebd. S. $36 \mathrm{ff}$, jew. m.w.N.

${ }^{61}$ Der hierdurch bedingten Normenflut sind vielfältige Würdigungen (Eichenberger VVDStRL 40 (1982) 7, 13 ff., 19 ff.; Heldrich in: FS für Zweigert, 1981, $811 \mathrm{ff.;}$ von Beyme (Fn. 7) $69 \mathrm{ff}$.) zuteil geworden, so daß diese Thematik nicht nochmals aufzugreifen ist.

${ }_{62}$ Zur finalen Programmierung: Wabl Rechtsfragen der Landesplanung und Landesentwicklung, Bd. I, 1978, $35 \mathrm{ff}$; ders. in: Hoffmann-Riem/Schmidt-Aßmann/Schuppert (Hrsg.), Reform des Allgemeinen Verwaltungsrechts, 1993, 177, $196 \mathrm{ff}$.; Wüttenberger Staatsrechtliche Probleme politischer Planung, 1979, 42f.; Lange VerwArch 82 (1991) 1, 6f.; krit. Rubel Planungsermessen, 1982, $48 \mathrm{ff}$. 
spricht in zweierlei Sicht dem Steuerungsmodell des demokratischen und föderativen Rechtsstaates: Zum einen wird der Verwaltung ein demokratisch legitimiertes Ziel- und Handlungsprogramm vorgegeben; das Handeln der Verwaltung wird durch diese Wegleitung demokratisiert. Eine derartige Zielorientierung verhindert ein verfassungsrechtlich bedenkliches freies Gestaltungsermessen der Verwaltung bei grundrechtseingreifenden Planungen oder bei Genehmigungen. Zum anderen verwirklicht die prinzipienrechtliche Steuerung demokratische Dezentralisation ${ }^{63}$ : Die Entscheidungen der Verwaltung haben sich an den parlamentsbeschlossenen Zielen zu orientieren, ihre realitätsadäquate Umsetzung geschieht unter Bürger- und Öffentlichkeitsbeteiligung vor Ort ${ }^{64}$. Die rechtlich strukturierte Gemeinwohlverwirklichung erfolgt in einem funktionsadäquaten Zusammenspiel zwischen demokratisch legitimierter Zielbestimmung und exekutivischer ebenso wie lokal zu legitimierender Verantwortung für die Sachgerechtigkeit der Abwägung.

\section{Rechtliche Optimierungsgebote als Mittel zur Verwirklichung des Umweltschutzes}

Derzeit stammen die meisten rechtlichen Optimierungsgebote aus dem Bereich des Umweltschutzes ${ }^{65}$. Hier fehlen dem Gesetzgeber das hinreichende Fachwissen und die erforderliche Problemverarbeitungskapazität, so daß er sich mit Richtungsentscheidungen begnügen muß ${ }^{66}$. Die Einschränkung der Abwägungsabhängigkeit der Umweltbelange durch Optimierungsgebote liegt auf der Linie einer Entwicklung zur Ökologisierung der Verfassungs- und Rechtsordnung ${ }^{67}$. Die Rationalität des ökologischen Verfassungsstaates besteht darin, die Umweltschutzbelange in Abwägung mit gegenläufigen Prinzipien und Interessen zu optimaler Realisierung gelangen zu lassen.

${ }^{63} \mathrm{Zu}$ den Vorteilen und Gefahren demokratischer Dezentralisation: Zippelius Allgemeine Staatslehre, 12. Aufl. 1994, § 23 III; Mannz/Zippelius Deutsches Staatsrecht, 30. Aufl. 1998, § 11 III 5; § 16 III.

64 Würtenberger Die Akzeptanz von Verwaltungsentscheidungen, 1996, $26 \mathrm{ff}$., $56 \mathrm{ff}$.

${ }^{65}$ Bartlsperger DVBI. 1996, 1, 10; Leisner (Fn. 1) 134. - Optimierungsgebote wenden sich auch an Betreiber und Unternehmer; zu $§ 15$ Abs. 1 StrahlenschutzVO vgl. Bischof NJW 1991, 2323, 2326.

66 Mußgnug in: Hill (Hrsg.), Zustand und Perspektiven der Gesetzgebung, 1989, 23, 27; Brobm NVwZ 1988, $794 \mathrm{ff}$.; anders aber Murswiek in: FS für Kriele, 1997, 651, $663 \mathrm{ff}$., der von einer Art Rotationsgesetzgebung die Ubernahme parlamentarischer Verantwortung fuir die Risiken der Technik oder für konkrete Umweltstandards erhofft.

${ }^{67}$ Hierzu Berg in: FS für Stern, 1997, 421 ff.; Kloepfer (Hrsg.), Umweltstaat, 1989; Steinberg in: Forschungsgesellschaft für deutsches Verfassungsrecht (Hrsg.), Menschen, Technologie, Umwelt, 1998, 159, 171; Wiegand DVB1. 1993, 533. 
Die aus den Grundrechten hergeleitete umweltrechtliche Optimierungspflicht führt zu einer erheblichen Dynamisierung des Rechts auf allen Stufen der Rechtsordnung. Rechtssetzung und Rechtskonkretisierung schaffen keinen festgefügten Zustand des Rechts, sondern sind immer auf ihre Verbesserungswürdigkeit zu befragen. Auf diesem Trend zur Optimierung liegt, daß dem Gesetzgeber Evaluations- und Nachbesserungspflichten ${ }^{68}$ auferlegt werden oder die Verwaltung im Umweltrecht zur begleitenden Kontrolle oder zum Nachzulassungsmonitoring ${ }^{69}$ verpflichtet wird.

\section{Die entscheidungstheoretische Problematik von Optimierungs- geboten}

$\mathrm{Ob}$ und inwieweit eine optimierende Abwägung und rechtliche Optimierungsgebote Gestaltungsspielräume bei der Auslegung von Verfassungs- und Verwaltungsrecht belassen, bemißt sich nach ihrer Kraft zu normativer Steuerung ${ }^{70}$. Die Beurteilung der entscheidungstheoretischen Leistungsfähigkeit von Optimierungsgeboten ist Ausgangspunkt für die funktionellrechtliche Verortung der Verwaltung im System der Staatsfunktionen.

\section{Unsicherbeit über die Wirkungszusammenbänge}

Planungsleitlinien und rechtliche Optimierungsgebote sind offene Normen, die das Ziel in unsicherer Entscheidungssituation weisen: Ein Widerstreit rechtlich geschützter Interessen ist aufzulösen, komplexe und vernetzte Wirkungszusammenhänge sind zu erkennen und zu steuern, Risiko- und Ungewißheitsfaktoren sind zu bewerten. Optimierende Steuerung im Bereich dynamisch miteinander vernetzter Wirkungsketten gelingt nur, wenn ihre jeweiligen Effekte erforscht und bekannt sind, was aber angesichts des Komplexitätsdilemmas ${ }^{71}$ nur sehr bedingt mög-

\footnotetext{
68 Badura in: FS für Eichenberger, 1990, 481 ff.; Heckmann Geltungskraft und Geltungsverlust von Rechtsnormen, 1997, 82 ff.; Steinberg Der Staat 26 (1987) 161 ff.; BVerfGE 49, 89, 130; 88, 203, 310f.; SächsVerfGH JZ 1996, 957, 965.

69 Gündermann NuR 1998, 351, 353.

${ }^{70}$ BVerfGE 88, 40, $56 \mathrm{ff} ., 61$; Schmidt-Aßmann in: Schoch/Schmidt-Aßmann/Pietzner, VwGO, Einl. Rdn. 182; auch das klassische, konditional programmierte Verwaltungsrecht eröffnet der Exekutive einen eigenen Anteil bei der Rechtsverwirklichung; hierzu Dreier (Fn. 58) $165 \mathrm{ff}$. sowie allgem. Esser Vorverständnis und Methodenwahl in der Rechtsfindung, 1972, 74 ff.; Herzog in: Maunz/Dürig, Art. 20 GG Abschn. VI, Rdn. 42.

${ }^{71}$ Zum Komplexitätsdilemma: Schmidt-Aßmann (Fn. 7) 109 m.w.N.; zur zweifelhaften Rationalität von Risikoentscheidungen: Di Fabio (Fn. 57) $61 \mathrm{ff}$.
} 
lich ist. Gerade im Bereich des neuen Modells des integrierten, medienübergreifenden Umweltschutzes erfolgt Optimierung auf unsicherer wissenschaftlich-technischer Grundlage ${ }^{72}$. Eine optimierende Entscheidung kann aber nur so gut sein wie die Richtigkeit der Fakten, Wirkungszusammenhänge und Prognosen, die ihr zugrunde liegen.

Für die Verwaltungspraxis hat dies zur Folge: Wegen der Unsicherheit über die Wirkungszusammenhänge und Prognosen bedarf es sachverständiger Beratung und muß erforderlichenfalls ein Diskurs unterschiedlicher Richtungen sachverständiger Analyse organisiert werden. Dieser Bereich genuin exekutiver Tätigkeit, meist viel zu verengend als Prognosespielraum bezeichnet, entzieht sich gesetzlicher Feinsteuerung ${ }^{73}$. Die Verwaltung muß mit Zukunftsabschätzungen und Szenarien arbeiten, die alle vertretbaren wissenschaftlichen Erkenntnisse in Erwägung ziehen ${ }^{74}$.

\section{Schwierigkeiten der rechtlichen Bewertung}

Neben dieses wissenschaftlich-technische tritt ein rechtliches Bewertungsproblem: Die Optimierung von Rechtsprinzipien durch Abwägung macht eine Bewertung unerläßlich: Welchem Prinzip gebührt der Vorrang? Mit welchem Gewicht sind Prinzipien in die Abwägung einzustellen? Für derartige Bewertungen gibt es nur allgemeine Vorrangregeln ${ }^{75}$. Prinzipien von höherer Gewichtigkeit sind weitergehend als Prinzipien von geringerer Gewichtigkeit zu verwirklichen. Prinzipien, auch von höherer Gewichtigkeit, die nur in ihrem Randbereich betroffen werden, können eher zurücktreten als Prinzipien, die im Kern betroffen sind (Relation von Bedeutung und Betroffenheit).

Das Grundgesetz und die Rechtsordnung geben nur grobe Anhaltspunkte für die Gewichtung. Die Wertungen zwecks Auflösung widerstrei-

${ }^{72} \mathrm{Zu}$ den Schwierigkeiten, den in vielen Vorschriften verlangten „Stand der wissenschaftlichen Erkenntnis“ (z.B. § 15 Abs. 1 Nr. 3b PflSchG; § 16 Abs. 1, 2 GenTG) zu klären: Gündermann NuR 1998, 351 ff. m.w.N.; vgl. weiter Murswiek VVDStRL 48 (1990) 207, 227 (zur Unmöglichkeit umfassender Technikbewältigung durch das Verwaltungsrecht).

${ }^{73}$ Dies rechtfertigt u.a. den administrativen Spielraum bei Prognoseentscheidungen (BVerwGE 64, 238, 242; 79, 208, 213; Nierbaus DVBl. 1977, 19, 23f.), wie er in $§ 43$ UGBE nunmehr vorgeschlagen wird (krit. Breuer Fn. 33, $162 \mathrm{ff}$.). Die „Konzepte normativer Vergewisserung ${ }^{\alpha}$, also die Würdigung eines komplexen Sachverhalts durch den Gesetzgeber (z.B. der Bedarf für das Projekt), bleiben die Ausnahme; vgl. Schmidt-Aßmann DVB1. 1997, 281, 287; krit. Lübbe-Wolff DVBl. 1996, 825, 831; Ipsen VVDStRL 48 (1990) 177, 201 mit der Forderung größerer normativer Dichte, die aber nicht zu leisten ist.

${ }^{74}$ BVerwG NVwZ 1989, 1168 zur Risikoermittlung durch externen Sachverstand.

75 Hubmann (Fn. 1) 20ff.; Dreier (Fn. 27) 76ff.; Sieckmann Rechtstheorie 26 (1995) 45, $66 \mathrm{ff}$.; Alexy (Fn. 47) $258 \mathrm{ff}$.; Leisner (Fn. 1) $135 \mathrm{f}$., $167 \mathrm{ff}$. 
tender Grundrechtspositionen lassen sich verfassungsrechtlich nur sehr beschränkt als einzig richtig begründen ${ }^{76}$, - ein wesentlicher Einwand gegen überzogene verfassungsrechtliche Optimierungsgebote. Selbst der Umweltschutz, in Art. 20a GG zum Staatsziel erhoben, hat nach überwiegender Ansicht keinen relativen Vorrang vor anderen abwägungsrelevanten Prinzipien ${ }^{77}$. Dies läßt sich verallgemeinern: Es gibt kein normativ bestimmbares objektives Gewicht eines Rechtsprinzips, mit dem es im $A b w a ̈ g u n g s p r o z e B$ in die Waagschale gelegt wird ${ }^{78}$.

Auch rechtliche Optimierungsgebote, wenn etwa nach $\S 1$ Abs. $5 \mathrm{~S} .1$ i.V.m. § 1a BauGB der Umweltschutz durch die Bauleitplanung zu optimieren ist ${ }^{79}$, lösen das Bewertungsproblem nicht ${ }^{80}$. Der Gesetzgeber veranlaßt zwar die Verwaltung, einem bestimmten Prinzip bei ihrer Entscheidung den Vorrang einzuräumen. Damit ist aber nicht geklärt, welcher Rang diesem Vorrang bei der Abwägung mit anderen Prinzipien zukommt: Ist ihr Rang fast schon das Verbot, dieses Prinzip unbeachtet zu lassen? Wie gewichtig muß ein konkurrierendes Prinzip sein, um sich gegen ein rechtliches Optimierungsgebot durchsetzen zu können?

\footnotetext{
${ }^{6}$ Hesse in: FS furr Mahrenholz, 1994, 541, 557; Ossenbübl in: Erbguth (Fn. 1) 25, $29 \mathrm{ff}$; Leisner (Fn. 1) $135 \mathrm{f}$., $167 \mathrm{ff}$.

77 Bericht der Gemeinsamen Verfassungskommission, BT-Drucks. 12/6000, 65f.; Jarass in: Jarass/Pieroth, Grundgesetz, 4. Aufl. 1997, Art. 20a GG, Rdn. 4; Scholz in: Maunzf Dürig, Art. 20a GG, Rdn. 41 ff.; Sendler UPR 1995, 41, 42; BVerwG UPR 1989, 154; diff. Murswiek in: Forschungsgesellschaft (Fn. 67) 177, 195 ff. (hohe Direktivkraft des Art. 20a GG beim Schutz lebensnotwendiger Umweltgüter); ders. in: Sachs (Hrsg.), Grundgesetz, 1996, Art. 20a GG, Rdn. 53 (Art. 20a GG als Optimierungsgebot, die natürlichen Lebensgrundlagen so gut zu schützen, wie dies rechtlich und faktisch möglich ist, ohne die Verwirklichung anderer öffentlicher Aufgaben unmöglich zu machen); zum bestmöglichen Umweltschutz als Präferenzregel im supranationalen Bereich: Kabl Umweltprinzip und Gemeinschaftsrecht, 1993, $178 \mathrm{ff}$.

${ }^{78}$ Leisner NJW 1997, 636, 638; Alexy (Fn. 52) 224; sehr bedenklich BVerwG NVwZ 1997, 1212 ff., wonach Belange des Naturschutzes und der Landschaftspflege mit erheblichem Gewicht anzusetzen sind, ohne daß sie aber Optimierungsgebote wären (zust. Schink DVBl. 1998, 609, 612).

79 Vgl. BVerwGE 90, 329, 332.

${ }^{80}$ Berkemann (Fn. 58) 45 f.; Dreier (Fn. 27) 231 ff., 244 ff. (zur erhöhten Aufklärungspflicht bei Optimierungsgeboten); anders aber Hoppe DVBI. 1992, 853, 859, der zu optimierenden Belangen ein objektives Gewicht zuspricht, sodann aber doch für eine situationsorientierte Gewichtung plädiert.
} 


\section{Zroang zur situativen Konkretisierung des Rechts}

Den Planungsleitlinien und Optimierungsgeboten ist eine besondere Situationsgebundenheit und Einzelfallabhängigkeit eigen. Für Planung und Genehmigungen mit planungsrechtlichem Einschlag gibt es keine klaren rechtlichen Vorgaben, sondern nur eine situative und einzelfallbezogene Rechtskonkretisierung. Die konkreten Lebensverhältnisse und die multilateralen Betroffenheiten, wie sie von der Verwaltung wahrgenommen und eingeschätzt werden, steuern in hohem Maß die Entscheidungen der Verwaltung ${ }^{81}$. Warum und in welchem Umfang das eine Prinzip Vorrang vor dem anderen Prinzip zu beanspruchen vermag, ist vom Entscheidenden angesichts der konkreten Situation zu verantworten und unter Offenlegung der ihn zur Entscheidung veranlassenden Argumente zu begründen. Die Sachstruktur determiniert das Normprogramm ${ }^{82}$.

Damit ergibt sich: Die entscheidende Frage, welches Gewicht einzelnen Prinzipien in der konkreten Situation zukommt, entscheidet die Verwaltung mit den am Entscheidungsprozeß Verfahrensbeteiligten ${ }^{83}$. Zu ihrer Präferenzautonomie gehört, sich jenseits klarer rechtlicher Vorgaben von einem autonom abgestimmten Präferenzsystem leiten zu lassen ${ }^{84}$. Diese Präferenzautonomie der Verwaltung und der Verfahrensbeteiligten, die gesetzlichen Zielvorgaben aus der konkreten Situation eigenständig zu gewichten, ist ein wichtiger Grundsatz lokaler Freiheit und Selbstbestimmung. Jenseits der rechtlichen Vorgaben wird autonom entschieden und gehandelt ${ }^{85}$. Präferenzautonomie bedeutet nicht Willkür. Das Gebot der Optimierung von Prinzipien mit dem ihm innewohnenden Begründungszwang trägt zu Transparenz und Rationalität der Entscheidungsfindung bei.

\section{Keine Garantie optimaler Entscheidung}

Letztlich ist Optimierung nur eine regulative Idee, die anzustreben rechtlich aufgegeben wird, deren Erfüllung aber nicht erwiesen werden kann. Das Optimierungsprinzip verweist letztlich nur auf eine gerechte

81 Ähnlich Schulze-Fielitz GK-BImSchG, §50 Rdn. 39, 146; Bartlsperger DVBI. 1996, 1, 7 (zur Abwägungsabhängigkeit von Optimierungsgeboten).

22 Zum Zusammenhang zwischen "Sachstruktur" und "Normprogramm": Brobm DVB1. 1986, 321, 326; zur „unhintergehbaren Konkretisierungsbedürftigkeit“; : Dreier Die Verwaltung 25 (1992) 137, 146 ff.; Scbmidt-Aßmann (Fn. 7) 175.

${ }^{83}$ Zur ${ }_{n}$ Entscheidungsautonomie" ${ }^{4}$ und ${ }_{n}$ Selbststeuerung " der Verwaltung: Burmeister in: Ress (Hrsg.), Entwicklungstendenzen im Verwaltungsverfahrensrecht und in der Verwaltungsgerichtsbarkeit, 1990, 55, 58f.

* Zur Präferenzautonomie: Eidenmüller Effzzienz als Rechtsprinzip, 1995, 326.

8s Ausführl. zur begründungs- und erkenntnistheoretischen Kritik: Enderlein (Fn. 3) $111 \mathrm{ff}$. 
Lösung ${ }^{86}$, die anzustreben sich lohnt, über deren Erreichen es aber keine letzte Vergewisserung gibt. Das Ziel rechtlicher Optimierung überschätzt die menschliche Fähigkeit, die optimale als einzig richtige Entscheidung erkennen zu können ${ }^{87}$. Damit bietet das Optimierungsmodell letztlich nur Scheinrationalität.

\section{E. Verfassungsrechtliche Grenzen von Optimierungsgeboten \\ I. Grenzen der verfassungsrechtlichen Optimierungsprinzipien}

Verfassungsrechtliche Optimierung ist zwar Ziel der Verfassungspolitik; Grenzen einer verfassungsrechtlichen Kontrolle optimierenden $\mathrm{Ab}$ wägens sind aber dadurch gezogen, daß die Verfassung als Rahmenordnung88 eine große Bandbreite rechtlicher Gestaltung zuläßt. Das Anliegen verfassungsgeleiteter Optimierung hat sowohl den Gestaltungsspielraum des demokratisch legitimierten Gesetzgebers als auch die Einschätzungs- und Gestaltungsprärogative der Verwaltung zu achten. Bleibt, um ein Beispiel zu nennen, die dreistufige Verhältnismäßigkeitsprüfung das Rationalität sichernde Prüfungsprogramm, so begegnet eine überzogene verfassungsrechtliche Aufladung des Übermaßverbotes ${ }^{89}$ berechtigten Bedenken ${ }^{90}$. Ebensowenig wie für den Ausgleich zwischen widerstreitenden Grundrechtspositionen gibt es für den Ausgleich zwischen rechtlich geschützten Belangen einen hinreichend rational überprüfbaren normativen Maßstab, der eine Überprüfung der Optimalität und damit der einzig rechtlichen Richtigkeit des Abwägungsergebnisses ermög-

\footnotetext{
${ }_{86}$ Zur Verbindung von Optimierung und Gerechtigkeit: Maunz/Zippelius (Fn. 63) § 7 I $1 \mathrm{~b}$.

${ }^{87}$ Lubmann Zweckbegriff und Systemrationalität, 5. Aufl. 1991, 114 f.; Höfe (Hrsg.), Einführung in die utilitaristische Ethik, 2. Aufl. 1992, 42 (zu den Grenzen des Nutzenkalküls); Lerche (Fn. 11) $205 \mathrm{ff}$; Kutschera Bestandsschutz im öffentlichen Recht, 1990, $125 \mathrm{f}$.

88 Böckenförde VVDStRL 30 (1972) 165; ders. NJW 1976, 2089, 2091; ders. (Fn. 17) 66 ff.; Wabl Der Staat 20 (1981) 485, 507; Starck in: Isensee/Kirchhof (Hrsg.), Handbuch des Staatsrechts, Bd. VII, 1992, § 164 Rdn. 4 ff.; Lerche (Fn. 11) 203 f.; Breuer in: FS für Redeker, 1993, 11, 52; von Danwitz DVBl. 1998, 928, 936.

89 Wie z.B. in der Entscheidung des BVerfG zur "DDR-Spionage“ (E 92, 277, $325 \mathrm{ff}$.); krit. Volk NStZ 1995, 367; Huber Jura 1996, 301, $306 \mathrm{f}$.

${ }^{9}$ Ossenbübl VVDStRL 39 (1981) 189; ders. in: FS für Lerche, 1993, 151, 157; Schmidt NJW 1969, 1137, 1143; Merten in: FS für Schambeck, 1994, 349 ff.; Scbmidt-Aßmann (Fn. 7) 51 (Auszehrung der Zweckmäßigkeitsmaßstäbe durch überzogene VerhältnismäBigkeitskontrolle).
} 
lichen würde91. Lediglich das angemessene Verhältnis von Zweck und Mittel, lediglich Proportionalität und das ,rechte $\mathrm{MaB}^{\alpha}$ sind gefordert, nicht aber daß zwei Rechtsgüter dergestalt zugeordnet sind, daß sie zu optimaler Wirksamkeit gelangen ${ }^{92}$. Auch bei der Verhältnismäßigkeitsprüfung ist die Prärogative der Verwaltung beim Bewerten und Gewichten zu beachten ${ }^{93}$. Bei der an der Verhältnismäßigkeit orientierten optimierenden Abwägung ist es dem Verwaltungsgericht verwehrt, die Bewertung der Verwaltung durch eine eigene zu ersetzen. Die Abwägungsentscheidung der Verwaltung unterliegt nur einer Vertretbarkeitsoder Evidenzkontrolle ${ }^{94}$.

\section{Begrenzung durch die Garantic kommunaler Selbstverwaltung}

Der Steuerung der Verwaltung durch rechtliche Optimierungsgebote sind in einem föderalistischen System Grenzen gezogen. Die föderative, am Subsidiaritätsprinzip orientierte Demokratie zielt auf eine funktionsadäquate Steuerungsteilung ${ }^{95} z$ wischen parlamentarischer Steuerung und lokal geprägter Eigensteuerung der Verwaltung"6. Mit der Zunahme präziser rechtlicher Optimierungsgebote verliert die Verwaltung traditionelle Räume des Wägens und Bewertens und damit Spielräume planerischer Gestaltung97. Vor allem im Selbstverwaltungsbereich engen fremdbestimmte rechtliche Optimierungsgebote den Spielraum zu autonomer lokaler Selbstgestaltung erheblich ein ${ }^{98}$. Dies gilt zumindest dann, wenn die Abwägungsleitlinien und rechtlichen Optimierungsgebote Anlaß einer engführenden verwaltungsgerichtlichen Kontrolle sind, so daß die kommunale Planungshoheit zwischen der Scylla gesetzlicher Feinsteuerung und der Charybdis verwaltungsgerichtlicher Kontrolle untergeht. Kom-

91 Vgl. Hesse (Fn. 76) 557.

92 Stern (Fn. 35) 173 ff.; Grabitz AöR 98 (1973) 568, 576; Jakobs DVBl. 1985, 97,99 (Verhältnismäßigkeit als Erträglichkeitsgrenze).

${ }_{93}$ Zum Beurteilungs- und Ermessensspielraum: Ossenbübl in: FS für Lerche, 1993, 151, 158.

94 Kirchbof in: FS für Lerche, 1993, 133, 144 für den Bereich der staatlichen Leistung, Verteilung und Planung; anders Haverkate Rechtsfragen des Leistungsstaats, 1983, 257 mit der These, der Rückzug des Richters aus diesen Bereichen der Wertung würde die Geschichte des rechtsstaatlichen Verwaltungsrechts als historischen Irrweg erscheinen lassen.

95 Zur ausgewogenen Gewaltenteilung: Maunz/Zippelius (Fn. 63) § 13 III 1, 4a; Brobm DVB1. 1986, 321, 329 f.; BVerfGE 68, 1, 87.

${ }_{96} \mathrm{Zu}$ dieser Eigenständigkeit der Verwaltung: Schmidt-Aßmann in: Hoffmann-Riem/ Schmidt-Aßmann/Schuppert (Hrsg.), Reform des Allgemeinen Verwaltungsrechts, 1993, S. 11, $51 \mathrm{f}$.

${ }^{7}$ Sendler UPR 1995, 41, 45; Smeddinck DÖV 1998, 370, 376.

${ }^{93}$ Hoppe DVBl. 1992, 853, 861. 
munale Selbstverwaltung im Bau- und Planungsrecht wird durch ein Steuerungsmodell ausgehöhlt, das die kommunale Zielsetzungs- und Konfliktlösungsautonomie zurückdrängt ${ }^{99}$. Dies wird dann verfassungsrechtlich bedenklich, wenn bei einer Gesamtbilanz nicht nur punktuell, sondern in zentralen Bereichen kommunaler Selbstgestaltung rechtliche Optimierungsgebote zu beachten sind. Sollen in einem föderativen System dezentrale politische Freiheit und autonome Selbstgestaltung gewahrt bleiben, so muß die Verwaltungsrechtsordnung eine Rahmenordnung bleiben ${ }^{100}$.

\section{Bedenken gegen eine Ausgestaltung der Kontrollerlaubnis als Optimierungs- entscheidung}

Grundrechtlichen und rechtsstaatlichen Bedenken begegnet es, die bisher als Kontrollerlaubnis auf ordnungsrechtlicher Basis geregelte Anlagengenehmigung als Optimierungsentscheidung zu gestalten ${ }^{101}$. Die Doktrin von der konditionalen Programmierung der Genehmigungsvoraussetzungen wurzelt in einer Rechtsstaats- und Grundrechtskonzeption, die Eingriffe in die Unternehmerfreiheit durch präventive Kontrollerlaubnisse allein aufgrund gesetzlicher Ermächtigung, nicht aber aufgrund verwaltungsbehördlichen Ermessens für statthaft erachtet ${ }^{102}$. Die Theorie und Praxis der umweltrechtlichen Genehmigungsverfahren haben sich allerdings schon seit langem von dieser rigoristischen Doktrin entfernt. Es bestehen Einschätzungs- und Beurteilungsspielräume der Verwaltung bei der Konkretisierung des Vorsorgeprinzips ( $\$ 5$ Abs. 1 Ziff. 2 BImSchG) oder bei der Prognose der künftigen Entwicklung ${ }^{103}$.

${ }^{99}$ Erbguth DVBI. 1998, 209, 213 m.Hinw. auf die im Hinblick auf Art. 28 Abs. 2 S. 1 GG gebotene einschränkende Auslegung von $\S 7$ Abs. 4 S. 2 BROG; Di Fabio NVwZ 1998, 329, 333 mit der These, der neue $\S$ la BauGB lasse kaum noch planerische Gestaltungsfreiheit zu. - Demgemäß werden die Einschränkungen des Art. 28 Abs. 2 GG durch die Ziele der Raumordnung und Landesplanung nur durch die kommunale Teilnahme an den Aufstellungsverfahren gerechtfertigt (BVerwGE 90, 329, 335).

${ }^{100}$ Zur Bedeutung von Selbststeuerung und Selbstgestaltung: Schuppert in: Grimm (Fn. 7) 217, 234 ff.; Hufen ebd., S. 273, 284 ff. (zur Zurücknahme der Steuerungsdichte und Steuerungstiefe durch Räume der Selbstregulierung und Selbstverwaltung).

101 Breuer in: Neue Entwicklungen im Umweltrecht, 1996, 255, $259 \mathrm{ff}$.

102 BVerfGE 20, 150, 157f,; 49, 89, 146; Maurer Allgemeines Verwaltungsrecht, 11. Aufl. 1997, § 9 Rdn. 51 ff.; Wabl DVB1. 1982, 51, 52 ff.; Brobm JZ 1995, 369 ff. m.w.N.; anders Bullinger JZ 1984, 1001.

${ }^{103}$ Vgl. die Nachw. bei Fn. 118; auch kann die Verwaltung gemeinsam mit dem Antragsteller auf eine optimale Unternehmergenehmigung hinwirken: Jarass (Fn. 21) $§ 6$ BImSchG Rdn. 19 a.E.; Hoffmann-Riem AöR 119 (1994) 590, 599 ff.; Würtenberger (Fn. 64) 44; Gromitsaris VerwArch 88 (1997) 52, $69 \mathrm{ff}$. 
Gleichwohl ist es ein Perspektivenwechsel, wenn die finale Normstruktur des supranationalen Umweltrechts die deutsche konditionale Normstruktur der Kontrollgenehmigung 104 überlagert ${ }^{105}$. Úber die supranationale Rechtssetzung setzen sich die Verwaltungs- und Rechtskultur Frankreichs und Großbritanniens durch ${ }^{106}$. Die klaren rechtlichen Vorgaben treten zu Lasten von Prognose-, Bewertungs- und Gestaltungsentscheidungen zurück. $\mathrm{Ob}$ im Wettbewerb der Regelungsmodelle das deutsche konditional programmierte oder das europäische, auf optimierende Abwägung angelegte das bessere ist, läßt sich an dieser Stelle nicht vertiefen ${ }^{107}$. Unter dem Effektivitätsaspekt ist entscheidend, ob das integrierte Konzept zu Innovation im Umweltschutz führt und seinen Zielen entsprechend umgesetzt wird. Aus verfassungsrechtlicher Sicht lockert das supranationale Recht überkommene deutsche Standards des Grundrechtsschutzes und der Rechtssicherheit. Es gibt dem Unternehmer mehr rechtsstaatlichen Grundrechtsschutz, wenn die Unternehmergenehmigung an gesetzlichen Genehmigungsvoraussetzungen abzuarbeiten ist, als wenn der Verwaltung Gestaltungsspielräume eröffnet werden. Der Verlust an rechtsstaatlicher Sicherung der Freiheit mag jedoch durch einen Zuwachs an realer Freiheit kompensiert werden. Die Verfahren des integrierten Umweltschutzes können Freiräume zu neuen Produktionsplanungen und zu einem neuen umweltorientierten Management eröffnen.

Über eine Integration des deutschen ordnungsrechtlichen und des europäischen optimierenden Modells des Umweltschutzes muß sicher noch weiter nachgedacht werden ${ }^{108}$. Auch wenn wegen des $\mathrm{Zwanges}$ zu

${ }^{104} \mathrm{Zu}$ „Zwischen- und Mischformen von Planungsgenehmigung und Kontrollerlaubnis ${ }^{\star}$ bei privatnützigen Planfeststellungen im Wasserrecht oder bei Baugenehmigungen: Wabl DVBl. 1982, 51, $57 \mathrm{ff}$. m.Hinw. auf das Bewirtschaftungsermessen im Wasserrecht und auf die Erforderlichkeit raumplanerischer Abwägungen; Badura in: Erichsen (Hrsg.), Allgemeines Verwaltungsrecht, 10. Aufl. 1995, § 39 Rdn. 23; zur atomrechtlichen Anlagengenehmigung als gemischtem System präventiver Kontrolle und planerischer, sicherheits- und umweltpolitischer Lenkung: Breuer Der Staat 20 (1981) 393, $406 \mathrm{ff}$.

105 Breuer(Fn. 101) 262; ders. NVwZ 1997, 833, 835 f; Weinreich NVwZ 1997, 949, 954 ff. Dies gilt auch für $§ 3$ Abs. 2 Nr. 2 des Gesetzes zur Neuregelung des Energiewirtschaftsrechts (v. 24. 4. 1998, BGB1. 1998 I, 730), der die Genehmigung der Energieversorgung von einer angemessenen Berücksichtigung des Ziels einer sicheren, preisgünstigen und umweltverträglichen Energieversorgung abhängig macht.

${ }^{106}$ Allerdings werden die aufgeworfenen Fragestellungen auch in Deutschland seit längerer Zeit diskutiert: Steiger in: Umweltrecht mildem?, Beiträge zur Umweltgestaltung, Heft A 64 (1982) $150 \mathrm{ff}$.

${ }^{107} \mathrm{Zu}$ den Vorteilen einer gebundenen und durchsetzungsfähigen Ordnungsgewalt des Staates: Breuer (Fn. 101) 264; ders. NVwZ 1997, 833, 837.

${ }^{108}$ Skeptisch zu einem „Modellmix" Breuer NVwZ 1997, 833, 837. 
europarechtlicher Harmonisierung und zur Angleichung der Wettbewerbsbedingungen des Wirtschaftsstandortes Deutschlands ein Sonderweg rechtlich und politisch nicht in Frage kommt, so sollte doch Leitidee sein: Soweit als möglich wegen des grundrechtlich gebotenen Prinzips der gebundenen Kontrollerlaubnis konditionale Kontrollverantwortung, soweit aus Gründen der Effektivität des Umweltschutzes oder europarechtlich nötig optimierende Verfahrensgestaltung durch Eröffnung von Entscheidungsspielräumen. Von der Einhaltung einzelner rechtlicher Grenzwerte zur Risikovorsorge läßt sich z.B. absehen, wenn dadurch andere nachteilige Umweltauswirkungen vermindert und so die Gesamtbelastung der Umwelt erheblich verringert wird. Hier würde das Umweltrecht eine klare, vollzugsfähige Rahmenordnung bleiben und die Optimierungsaufgabe innerhalb rechtlich bestimmter Grenzen zu erfüllen sein ${ }^{109}$. Verfassungsrechtlich muß die Kontrollerlaubnis in einer Hinsicht eine rechtlich gebundene Erlaubnis bleiben. Zur Abwehr von konkreten Gefahren durch Emissionen müssen jene Maßnahmen vorgesehen werden, die das Überschreiten der Gefahrenschwelle unterbinden. Abwägung und Optimierung beginnen erst jenseits der sicherheitsrechtlichen Gefahrenabwehr ${ }^{110}$.

\section{Grenzen richterlicher Kontrolle bei optimierendem Abrwägen und rechtlichen Optimierungsgeboten}

Verwaltungsgerichtlich sind optimierende Abwägungen darauf überprüfbar, ob die auf Optimierung zielenden unbestimmten Rechtsbegriffe, die Planungsleitlinien und die rechtlichen Optimierungsregeln von der Verwaltung berücksichtigt und in ihrer rechtlichen Bedeutung erfaßt wurden. Jenseits dieser klassischen Kontrollkompetenz bestimmt sich in einem gewaltenteiligen System die normative Abgrenzung von Entscheidungs- und Kontrollgewalt bei der Konkretisierung unbestimmter Rechtsbegriffe, bei der Abwägung und bei der rechtlichen Optimierung nach der entscheidungstheoretischen Leistungsfähigkeit juristischer Begriffe. Wo „wegen hoher Komplexität oder besonderer Dynamik der geregelten Materie “ die rechtliche Determinierungskraft von unbestimmten Rechtsbegriffen oder rechtlichen Optimierungsgeboten endet, beginnt der Bereich der exekutivischen Eigenverantwortung, der von der Judikative zu respektieren ist ${ }^{111}$.

${ }^{109}$ So im Ansatz Breuer NVwZ 1997, 833, 842 zur Integration des Öko-Audits in das System der Kontrollerlaubnis; Di Fabio NVwZ 1998, 329, 335; Lange VerwArch 82 (1991) 1, $11 \mathrm{ff}$.

110 Classen Die Verwaltung 31 (1998) 307, $321 \mathrm{f}$.; Wabl DVBl. 1982, 51, 56.

111 BVerfGE 84, 34, 50; Schmidt-Aßmann (Fn. 70) Rdn. 188 (Funktionsgrenze der Gerichtsbarkeit); Brenner Der Gestaltungsauftrag der Verwaltung in der Europäischen 
Für diese freilich seit jeher umstrittene Grenzziehung sprechen die vom Grundgesetz vorausgesetzte Eigenständigkeit der Verwaltung ${ }^{112}$, ihre demokratische Legitimation ${ }^{113}$ sowie ihre Legitimation durch Verfahren der partizipatorisch-diskursiven Konfliktlösung. Die Verwaltung verfügt über bessere Erkenntnismöglichkeiten, kann in Abwägungen besser Folgeabschätzungen einfließen lassen und hat eine Prärogative bei der situativen Konkretisierung des Rechts ${ }^{114}$. So ist z.B. für den „Kampf der Sachverständigen" das Verwaltungsverfahren, nicht aber das Gerichtsverfahren der funktionell richtige Standort ${ }^{115}$. Nicht die Judikative, sondern die Verwaltung verfügt , institutionell und auf Dauer typischerweise ... in hinreichendem Maß über die personellen, sachlichen und organisatorischen Mög-

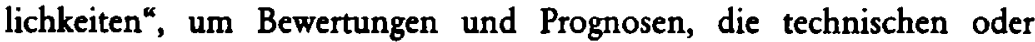
naturwissenschaftlichen Sachverstand voraussetzen, bestmöglich zu erfüllen ${ }^{116}$. Allein die Verwaltung hat die für die effektive Wahrnehmung von Planungsfunktionen adäquate Organstruktur ${ }^{117}$, verfahrensmäßig Kon-

Union, 1996, 196f., 210 (zur faktischen Selbständigkeit der Verwaltung aufgrund von in der Natur der Sache begründeten Steuerungsdefiziten des Gesetzes); Sachverständigenrat "Schlanker Staat“ (Hrsg.), Abschlußbericht, Bd. 1, 1997, 190f.; zur Balance zwischen Verwaltungsverantwortung und Verwaltungsgerichtsbarkeit: Scholz VVDStRL 34 (1976) 145, $160 \mathrm{ff}$; Scbmidt-Aßmann ebd., S. 222, $227 \mathrm{ff}$.; Lecheler Verwaltungslehre, 1988, $46 \mathrm{ff}$.

${ }_{112}$ Zur eigenständigen Verwaltungsrechtsverantwortung der Verwaltung: Zacher VVDStRL 34 (1976) 285; von Danwitz DVBI. 1998, 931 f. m.w.N.; Peters Die Verwaltung als eigenständige Staatsgewalt, 1965; Dreier Die Verwaltung 25 (1992) 137ff.; Lerche in: Frowein (Hrsg.), Die Kontrolldichte bei der gerichtlichen Überprüfung von Handlungen der Verwaltung, 1993, $249 \mathrm{ff}$., $264 \mathrm{ff}$.

${ }^{113}$ Vgl. BVerfGE 49, 89, 125 ff.; 68, 1, 88; Franßen DVB1. 1998, 413, 418; zur Exekutive und Legislative im Handlungsverbund vgl. Dreier (Fn. 58) $200 \mathrm{ff}$.

${ }_{14} \mathrm{Zu}$ dieser funktionellrechtlichen Zuordnung von Staatsfunktionen: Di Fabio in: Blümel/Pitschas (Hrsg.), Verwaltungsverfahren und Verwaltungsprozeß im Wandel der Staatsfunktionen, 1997, 199, 206ff.; Herzog NJW 1992, 2601, 2604; Sendler in: FS für Ule, 1987, 333 ff., 354 ff.; Klein in: Bitburger Gespräche, Jahrbuch 1995, 81, 94.

115 Zur Sachverhaltsfeststellung durch Sachverständige: Schmidt-Aßmann DVBl. 1997, 281, 286; BVerfGE 85, 36, 58; 88, 40, 58 ff.: Die Verwaltungsgerichtsbarkeit muß die von der Verwaltung gegebenen Begründungen von ihrem Erkenntnis- und Verfahrensstand her nachvollziehen; hierzu bedarf das Gericht keiner Sachverständigen, wenn diese bereits im Verwaltungsverfahren gehört wurden und ihre (kontroversen) Ansichten in die Verwaltungsentscheidung eingeflossen sind.

116 So allerdings in einem anderen Zusammenhang: BVerfGE 68, 1, 87; vgl. weiter BVerwGE 72, 300, 317; Brenner (Fn. 100) 212, 402ff. - Gegen eine Reduzierung richterlicher Kontrolldichte: Ipsen VVDStRL 48 (1990) 177, 201 (die Gerichte sollen die Genehmigungsmaßstäbe in eigener Kompetenz entwickeln); Breuer (Fn. 33) $162 \mathrm{ff}$. (gegen die einschränkende gerichtliche Überprüfung von Prognosen und Bewertungen nach § 43 UGBE).

${ }_{17}$ Zur funktionsgerechten Organstruktur: Küster AöR 75 (1949) 397; Ossenbübl in: Isen- 
flikte abzuarbeiten, dezentrale Legitimationsleistungen zu erbringen sowie sach- und raumadäquate Vorsorge zu leisten. Außerdem spricht vieles dafür, bei Begriffen wie "Stand der Technik ${ }^{\alpha}$ in $\S 3$ Abs. 6 BImSchG eine funktionenteilende und normstrukturelle Verwaltungsverantwortung und damit einen administrativen Beurteilungsspielraum zu bejahen ${ }^{118}$.

Die Erwartung, der Richter werde bei der Kontrolle von unbestimmten Rechtsbegriffen die einzig rechtlich richtige Entscheidung finden, ist nur begrenzt erfüllbar ${ }^{119}$. Wenn die Verwaltungsgerichtsbarkeit in die Konkretisierung unbestimmter Rechtsbegriffe durch eigene Prognosen oder Bewertungen des technischen oder naturwissenschaftlichen Erkenntnisstandes oder in die Bewertung von Optimierungsgeboten eingreift, so übt sie materiell verwaltende Tätigkeit, also gerichtliche Mitverwaltung ${ }^{120}$, aus.

Außerdem ist es bedenklich, wenn die abwägungsrelevanten Prinzipien und die rechtlichen Optimierungsgebote entsprechend ihrer objektiven Gewichtigkeit ${ }^{121}$ oder nach ihrer vom Gesetzgeber verliehenen Gewichtigkeit ${ }^{122}$ in die Abwägung eingestellt werden sollen und ihr Ausgleich nach Maßgabe des Verhältnismäßigkeitsgrundsatzes zu erfolgen hat ${ }^{123}$. Ihre Gewichtigkeit kann eben nicht objektiv sein, da diese nur auf Grund eines Bewertungsvorgangs bestimmt werden kann ${ }^{124}$. Dies mag der Grund dafür sein, daß man $z$ war der Idee nach von einer feststellbaren objektiven Gewichtigkeit abwägungserheblicher Belange ausgeht, die Rechtswidrigkeit einer Abwägung aber nur annimmt, wenn der Ausgleich

see/Kirchhof (Hrsg.), Handbuch des Staatsrechts, Bd. III, 1988, §62 Rdn. 48f.; von Danwitz Der Staat 35 (1996) 329, 346.

${ }^{118}$ Anders BVerwGE 55, 250, 253 für die immissionsschutzrechtlichen unbestimmten Rechtsbegriffe; zweifelnd Schmidt-Aßmann in: Schwarze/Schmidt-Aßmann (Hrsg.), Das Ausmaß der gerichtlichen Kontrolle im Wirtschaftsverwaltungs- und Umweltrecht, 1992, 9, 50; Klocpfer Umweltrecht, 2. Aufl. 1998, \$14 Rdn. 46 m.w.N.

119 Vgl. Hofmann Das Recht des Rechts, das Recht der Herrschaft und die Einheit der Verfassung, 1998, 28 mit Kritik an Dworkin; krit. Franßen DVBI. 1998, 413, 419; anders aber Haverkate (Fn. 94) 285, der von der gerichtlichen Entscheidung sehr optimistisch erhofft, sie würde auf „besseren Gründen“ beruhen, sowie Breuer (Fn. 33) 171.

${ }^{120}$ Daher regelt $\S 43$ UGBE eine beschränkte verwaltungsgerichtliche Überprüfung von Prognosen und Bewertungen: UGBE (Fn. 31) $525 \mathrm{ff} ., 532$.

${ }_{121}$ Vgl. Brobm (Fn. 23) § 13 Rdn. 19; Hoppe DVBI. 1994, 1033, 1039 (objektives Gewicht nach rechtlichen Vorgaben und tatsächlichen Gegebenheiten); Stüer NWVBI. 1998, 169, 173 m.w.N.; Storost NVwZ 1998, 797, 800f.; BVerwGE 75, 214, 254 (Bewertung der objektiven Gewichtigkeit durch das Gericht und nur angemessene Berücksichtigung der Vorstellung der Planfeststellungsbehörde); VGH Mannheim VBIBW 1998, 307, 308.

${ }_{122}$ So Finkelnburg/Ortloff Öffentliches Baurecht, Bd. I, 5. Aufl. 1998, 37.

123 So Hoppe DVBl. 1994, 1033, 1039.

${ }_{14} \mathrm{Vgl}$. Sendler UPR 1995, 41: Das Verwaltungsgericht bestimmt den Faktor, mit dem ein Belang in die Abwägung eingestellt wird; krit. Dreier (Fn. 27) 62f.; Steinberg (Fn. 23) $192 \mathrm{f}$. 
einzelner Belange zu ihrer objektiven Gewichtigkeit außer Verhältnis steht $^{125}$. Selbst diese gelockerte Proportionalitätsprüfung täuscht mit der objektiven Gewichtigkeit einen rechtlichen Kontrollrahmen vor, der entscheidungstheoretisch nicht eingelöst werden kann.

Damit gilt für die Kontrolle von Abwägungsentscheidungen durch die Verwaltungsgerichte ${ }^{126}$ : Mit welcher Gewichtigkeit (grund-)rechtlich geschützte Belange in die Abwägung eingestellt werden, entscheidet die Verwaltung. Das Beziehungsgeflecht des normativen Gewichts (grund-)rechtlich geschützter Interessen, das Ausmaß der Betroffenheit des Grundrechtsträgers, das allgemeine und das lokale Gewicht öffentlicher Interessen führen in eine komplexe Entscheidungssituation, in der nur eine offensichtlich verfehlte, also willkürliche Gewichtung bei der Abwägung oder bei der Optimierung justitiabel ist ${ }^{127}$. Wegen dieses Vorrangs der Verwaltungsverantwortung vor verwaltungsgerichtlicher Kontrolle haben $\S 75$ Abs. 1a S. 1 VwVfG und § 214 Abs. 3 S. 2 BauGB eine andere Bedeutung, als gemeinhin angenommen wird. Wenn Mängel in der Abwägung nur dann erheblich sind, wenn sie offensichtlich sind und auf das Abwägungsergebnis von Einfluß waren, so ist dies keine rechtsstaatlich bedenkliche und daher restriktiv zu interpretierende Verkürzung des Abwägungsgebots228. Diese Regelung entspricht vielmehr der entscheidungstheoretisch und funktionellrechtlich richtigen und in anderen Rechtsordnungen geläufigen Abgrenzung von Verwaltung und Verwaltungsgerichtsbarkeit ${ }^{129}$.

${ }^{125}$ Brohm (Fn. 23) § 13 Rdn. 19; Schmidt-Aßmann (Fn. 7) 193 (objektive Gewichtigkeit als ,ein Evidenzkriterium ").

${ }^{126}$ Selbstverständlich wird nach wie vor überprüft, ob der Plan zur Verwirklichung der plangesetzlichen Bestimmung geeignet und im Hinblick auf das Gebot des geringsten Eingriffs auch erforderlich ist; vgl. Bartlsperger in: Erbguth (Fn. 1) 98f.; Redeker NVwZ 1996, $126,128$.

${ }^{127} \mathrm{Zu}$ einer solchen Willkürkontrolle durch den EuGH: Pache DVBI. 1998, 380, 386; Herdegen/Richter in: Frowein (Hrsg.), Die Kontrolldichte bei der gerichtlichen Überprüfung von Handlungen der Verwaltung, 1993, 209, 246f. - Zur Diskussion einer Vertretbarkeitsprüfung und von Beurteilungsspielräumen der Verwaltung: Brobm DVBl. 1986, 321, 330f.; Burmeister (Fn. 83) 61 (zum Vorrang der Verwaltungsverantwortung).

128 Sendler in: FS für Schlichter, 1995, 55, 69 f.; ders. in: Kormann (Hrsg.), Aktuelle Fragen der Planfeststellung, 1994, 9, $25 \mathrm{ff}$.; für eine intensive gerichtliche Abwägungskontrolle aber die verwaltungsgerichtliche Praxis: Storost NVwZ 1998, 797, $801 \mathrm{f}$.; Bonk in: Stelkens/Bonk/Sachs, VwVfG, 5. Aufl. 1998, § 75 VwVfG Rdn. 39 (strikte verfassungskonforme Auslegung und Anwendung).

129 Zum vergleichbaren Kriterium des „erreur manifeste d'appreciation“ oder des "clear error in judgement" vgl. Nolte in: Frowein (Fn. 127) 278, 288. 


\section{F. Optimierung durch Verwaltungsverfahren}

\section{Zur Neuorientierung des Verwaltungsverfahrens}

Die beschränkte rechtliche Steuerungskraft der Abwägungs- und rechtlichen Optimierungsgebote verlagert die Aufgabe der optimierenden Rechtskonkretisierung in das Verwaltungsverfahren. Hier geht es um prozedurale Optimierung, um Optimierung durch Verfahrensgestaltung. Im Planungsverfahren und künftig verstärkt in Genehmigungsverfahren mit Abwägungsvorbehalten hat die Verwaltung einen beträchtlichen rechtlichen Gestaltungsspielraum und erhält eine besondere Verfahrensverantwortung ${ }^{130}$. Je weniger es um Gesetzesvollzug geht und je mehr multipolare Konfliktlagen unter Beachtung vielfältiger rechtlicher Zielsetzungen rechtsgestaltend zu lösen sind, desto eher ist ein Verfahrensmanagement angebracht, das auf eine optimierende Verwaltungsentscheidung zielt, die zudem Akzeptanz aller Verfahrensbeteiligten findet. Für diese nicht mehr nur der Rechtsfindung dienende ${ }^{131}$, sondern integrierende und konfliktlösende rechtsschöpfende Funktion des Verwaltungsverfahrens streitet, daß die Rechtsordnung keine klaren Entscheidungsmaßstäbe zu geben vermag und der gebotene Grundrechtsschutz nur durch die Gestaltung des Verwaltungsverfahrens gewährleistet werden kann ${ }^{132}$. Dies fordert, dem Bürger bei der Suche nach der optimalen Entscheidung eine aktive Verfahrensstellung zuzubilligen ${ }^{133}$.

Diese Neuorientierung vom traditionellen inquisitorischen zum adversatorischen Verwaltungsverfahren ${ }^{134}$ liegt auf der Linie der allgemeinen Verfahrensdiskussion, die den überkommenen Rechtsschutzverfahren prozeduralkommunikative Verfahren der Rechtsfindung ${ }^{135}$ zur Seite stellt. Für das Ver-

\footnotetext{
${ }^{130}$ Schmidt-Aßmann (Fn. 7) 178; grundlegend zu den Funktionen des Verwaltungsverfahrens: Wabl VVDStRL 41 (1983) $153 \mathrm{ff}$.

${ }_{131}$ Zur Kritik an der dienenden Rolle des Verwaltungsverfahrensrechts in der deutschen Konzeption: Schoch in: Schmidt-Aßmann/Hoffmann-Riem (Hrsg.), Strukturen des europäischen Verwaltungsrechts, i. E., Fn. 11 m.w.N.

132 BVerfGE 53, 30; 56, 216, 238 ff.; Blümel in: ders. (Hrsg.), Frühzeitige Bürgerbeteiligung bei Planungen, 1982, 23 ff.; Held Der Grundrechtsbezug des Verwaltungsverfahrens, 1984, $68 \mathrm{ff}$., 80ff.; Hufen Fehler im Verwaltungsverfahren, 3. Aufl., 1998, Rdn. $8 \mathrm{ff}$., $586 \mathrm{ff}$.

${ }_{133}$ Hierzu Hoffmann-Riem DVBl. 1994, 1381 f.; ders. AöR 119 (1994) 590, 599 m.Nachw.; Schmidt-Aßmann (Fn. 7) $95 \mathrm{f}$.

${ }_{134}$ Zum Übergang von einer etatistisch orientierten Verwaltungskultur mit ihrem inquisitorischen Verfahren zu einer Kultur der offenen Verwaltung mit einem adversatorischen Verfahren vgl. Scharpf Die politischen Kosten des Rechtsstaats, 1970; Würtenberger (Fn. 64) 24 ff.; Hill in: Steger (Hrsg.), Lean Administration, 1994, 49, 57; ders. JZ 1993, 330; ders. in: Blümel/Pitschas (Hrsg.), Reform des Verwaltungsverfahrensrechts, 1994, 339 ff.; ders. DÖV 1994, 279, 285 f. (zur Gestaltung kommunikativen Rechts).

135 Wagner JZ 1998, 836 m.w.N.
} 
waltungsverfahren hat dies zweierlei zur Folge: In die Verwaltungsverfahren können zunächst Konflikte von Prinzipien bzw. Interessen ebenso von den Behörden wie von den Antragstellern und verfahrensbeteiligten Bürgern eingebracht werden (sog. Konfliktoffenheit des Verwaltungsverfahrens). Sodann ist nach einem optimalen Ausgleich zwischen konfligierenden Prinzipien und Interessen zu suchen. Gefordert ist eine verfahrensrechtliche Rahmensetzung, die Verfahrensgerechtigkeit garantiert ${ }^{136}$. Die Verwaltung muß ein ausführliches Rechts- und Sachgespräch ermöglichen, externen technischen oder naturwissenschaftlichen Sachverstand in das Verfahren einbeziehen ${ }^{137}$, den Diskurs der Experten ${ }^{138}$ der Verfahrensbeteiligten leiten, inadäquaten Pressionen entgegentreten und im Erörterungstermin Gelegenheit zu einem offenen Diskurs geben. All dies setzt ein Verfahrensmanagement voraus ${ }^{139}$, das sich an einer akzeptanzfähigen Optimierung innerhalb des rechtlichen Gestaltungsspielraums orientiert ${ }^{140}$.

Ob sich eine optimierende Entscheidung verfahrensmäßig finden läßt, hängt in hohem Maß von der behördlichen Verfahrensgestaltung ab. Gefragt ist ein Verfahrensmanager, dem von den Beteiligten Objektivität zugetraut wird und der über die rechtlichen Vorgaben hinaus für eine transparente und nachvollziehbare Entscheidungsfindung sorgt. Diese Fähigkeiten zur ausgleichenden Konfliktschlichtung tragen mehr zur Optimalität der Entscheidung bei als normative Vorgaben, die wenig Flexibilität ermöglichen ${ }^{141}$. Ist Optimierung der Verwaltungsentscheidung weitgehend von erfolgreicher Verfahrensmittlung abhängig, so sollte man wie im angelsächsischen Bereich auch in der deutschen Ausbildung auf die Vermittlung der entsprechenden Fähigkeiten mehr Wert legen.

136 Vgl. die Vorschläge bei Würtenberger (Fn. 64) $124 \mathrm{ff}$; Schmidt-Aßmann DVB1. 1997, 281, 289; Hoffmann-Riem AöR 119 (1994) 590, $600 \mathrm{f}$.

${ }_{137}$ Zur prozeduralen, von Art. 19 Abs. 4 GG gebotenen Einbeziehung des erforderlichen Sachverstands in das Verwaltungsverfahren, soll die gerichtliche Kontrolle eingeschränkt werden: Breuer (Fn. 33) $200 \mathrm{ff}$.

${ }_{138}$ Zur Kooperation der Verwaltung mit den Experten: Di Fabio (Fn. 57) 452f.

139 Würtenberger (Fn. 64) 120ff.; allzu skeptisch Breuer (Fn. 33) 180 mit der These, es gebe keine Gewähr dafür, daß die Vollzugsbehörden bei Einzelfallentscheidungen den externen naturwissenschaftlichen oder technischen Sachverstand heranziehen.

${ }^{140}$ Die Öffentlichkeitsbeteiligung, der im europäischen Verfahrensrecht eine eigenständige Rolle zukommt, ist ein zentraler Eckpunkt der Konfliktoffenheit und der auf Akzeptanz zielenden Optimierungsverfahren. Insofem ist bedenklich, daß das Verwaltungsverfahrensrecht die Öffentlichkeit des Erörterungstermins ( $\$ 73$ Abs. 6 S. 6 i.V.m. $§ 68$ VwVfG) oder die Öffentlichkeit des Scoping-Termins ausschließt (Würtenberger [Fn. 64] 116ff., $121 \mathrm{ff}$.).

${ }^{141}$ In der Praxis sind in Einwendungsverfahren wiederholt Emissionsbegrenzungen durchgesetzt worden, die aufgrund neuer Technologien möglich waren und unterhalb der normativen Standards lagen. 
Für eine akzeptanzfähige Optimierung streiten die diskursethischen Begründungen des Demokratieprinzips und die neueren Strömungen der Wahrheitstheorie ${ }^{142}$. Die relative Richtigkeit von rechtlichen Entscheidungen - wie der Wahrheitsgehalt von Aussagen - liegt in einem diskursiven Verfahren begründet. Die diskursive Begründung von Verwaltungsentscheidungen sollen alle betroffenen Behörden und Bürger aufgrund ihrer Teilnahme am Diskurs für richtig oder zumindest für vertretbar halten können. Eine solche diskursive Begründung ist naheliegend, wenn es Prinzipien und Interessen zu gewichten und gegeneinander abzuwägen gilt. Dies kann nur im Hinblick auf die Interessen der Verfahrensbeteiligten und die jeweiligen örtlichen und zeitlichen Verhältnisse erfolgen. Wenn man den Verfahrensbeteiligten Spielräume bei der Gewichtung der Prinzipien und Interessen sowie bei der Abwägung einräumt, respektiert man deren Autonomie. Damit führt eine akzeptanzfähige Optimierung bei der Lösung von Prinzipien- und Interessenkollisionen auch zur Optimierung lokaler Autonomie ${ }^{143}$. Derartige Optimierungsleistungen sollten Leitlinien von Verwaltungsverfahren sein, die einer freiheitlichen und demokratischen Gesellschaft angemessen sind ${ }^{144}$.

\section{Zur Rücknahme rechtlicher Optimierungsgebote und des Rechtsschutzes}

Geschieht eine Optimierung in einem rechtlich geordneten Verfahren, so kann man fragwürdige rechtliche Optimierungsgebote zurücknehmen. Auf so selbstverständliche Gebote, daß landwirtschaftliche Flächen nur im notwendigen Umfang für andere Nutzungsarten in Anspruch genommen werden dürfen ( $\$ 1$ Abs. 5 S. 3 BauGB) oder daß mit Grund und Boden sparsam und schonend umzugehen ist ( $(1$ a Abs. 1 BauGB), kann verzichtet werden. Derartige Optimierungsgebote geraten zudem rasch mit dem Optimierungsgebot des $§ 50 \mathrm{BImSchG}$, nämlich der Trennung unverträglicher Nutzungen, in Konflikt, so daß die gebotene Abwägung zwischen Optimierungsgeboten zwar den Entscheidungsprozeß komplizierter macht, zur Steuerung der Planung aber wenig beiträgt. Es ist ausreichend, daß der Gesetzgeber durch Planungsleitlinien steuernd dem Verwaltungshandeln repräsentativ-demokratische Legitimität vermittelt und lokal eine an Par-

142 Müller in: FS für Schindler, 1989, 617ff.; Dürr Diskursives Recht, 1994; Watzlawick (Hrsg.), Die erfundene Wirklichkeit, 1985; Alexy in: Rechtstheorie, Beiheft 14 (1994) $143 \mathrm{ff}$.; ders. Theorie (Fn. 3) $17 \mathrm{ff}$., $134 \mathrm{ff} ., 233 \mathrm{ff}$.

143 Würtenberger (Fn. 64) 152f.; zum Ausbau kooperativer gesellschaftlicher Selbstregulierung Hoffmann-Riem AöR 119 (1994) 590, 607 ff. m.Nachw.

144 BVerfGE 90, 1, 20f.: „Die freie Diskussion ist das eigentliche Fundament der freiheitlichen und demokratischen Gesellschaft*, ein Grundsatz, der, soll er nicht folgenlos bleiben, auch die Gestaltung des Verwaltungsverfahrens bestimmen muß. 
tizipation orientierte Selbststeuerung erfolgt ${ }^{145}$. Im Idealfall werden die Verwaltungsentscheidungen durch Elemente der repräsentativen und partizipativen Demokratie legitimiert ${ }^{146}$, also durch eine optimierende Verantwortungsteilung zwischen Staat und gesellschaftlichen Akteuren. Während die Verwaltung die Verfahrensorganisation, die Beachtung übergreifender öffentlicher Interessen und die Wahrung des rechtlichen Rahmens der Entscheidung zur Aufgabe hat, fält die optimierende Entscheidung auch in die rechtliche Verantwortung jener Subjekte, die die ökonomischen, ökologischen und anderen Folgen zu tragen haben ${ }^{147}$.

Diese Integration von staatlicher Verantwortung für das Gemeinwohl und gesellschaftlicher Selbststeuerung erfordert Veränderungen in der Verwaltungskultur. Die traditionelle rechtsstaatliche Verwaltung, mit ihrer Distanz zu den Betroffenen als Credo, verändert sich zu einer demokratischen Verwaltung, die den Bürger als Subjekt ernst nimmt. Solche Annäherungen an die angelsächsische Verfahrenskultur bleiben für die Rechtsschutzkonzeption nicht folgenlos. Der funktionale Zusammenhang zwischen Verwaltungs- und Gerichtsverfahren gewinnt eine neue Akzentsetzung 148: Die Verfahrenskontrolle tritt in den Vordergrund, die Inhaltskontrolle wird sekundär.

Von der Gestaltung des Abwägungs- und Optimierungsdiskurses ist die Erforderlichkeit verwaltungsprozessualen Rechtsschutzes weitgehend abhängig. Wurde die Planungsentscheidung oder Anlagengenehmigung unter Beachtung des skizzierten Verfahrensrahmens mit dem Antragsteller, den Betroffenen und den Trägern öffentlicher Belange entwickelt, genügt die Entscheidung dem Ideal der diskursiven Richtigkeit. Der verwal-

${ }^{145}$ Diese Trennung des policy making von dem service delivery entspricht im übrigen den neuen Managementkonzeptionen für den öffentlichen Sektor: Domkozoski/Precht Public Management, 1995, 141 f. m.w.N.

${ }^{146} \mathrm{Zu}$ einem derartigen Zusammenspiel von Steuerung und Selbststeuerung: Lange VerwArch 82 (1991) 1, 11 (die Entscheidung über das Maß staatlicher Steuerung und gesellschaftlicher Selbststeuerung trifft der Gesetzgeber); zurückhaltend Dreier (Fn. 58) 275: Furcht vor einer Entgegensetzung von Partikular- und Popularwillen, vor einer Zerfaserung des demokratischen Gesamtzusammenhangs und vor einer Gefährdung der gesamtgesellschaftlichen Integration.

147 Ähnlich Volkmann VerwArch 89 (1998) 363, 387; Schrader NuR 1998, 285, 290, der gemeinsam mit den Verfahrensbeteiligten und den am Umweltschutz beteiligten Gruppen ,unterschiedliche Wertvorstellungen, Wahrnehmungen und Interessen in einem rationalen Verfahren zum Ausgleich ${ }^{\alpha}$ bringen möchte; Weinreicb NVwZ 1997, 949, 956: „Integration der Vorhabenzulassung in ein gestuftes System der gesellschaftlichen Selbststeuerung".

148 Hierzu Schmidl-Aßmann DVBI. 1997, 281, 287; ders. (Fn. 7) 197: Je stärker „die eigenständige, rechtssichernde Aufgabe des Verfahrensrechts" betont wird, desto eher lassen sich „administrative Letztentscheidungsbefugnisse ${ }^{\alpha}$ bejahen. 
tungsgerichtliche Schutz eines sachgerechten Optimierungsverfahrens dadurch, daß die nach wie vor umstrittenen Punkte im Diskurs mit den Verfahrensbeteiligten am Maßstab einer Plausibilitäts- und Willkürkontrolle $^{149}$ nachgearbeitet werden, erübrigt eine verwaltungsgerichtliche Überprüfung der Entscheidungsrichtigkeit. Vom Gesetzgeber der 6. VwGONovelle und des Genehmigungsbeschleunigungsgesetzes ist dies freilich nicht begriffen worden. Statt das Augenmerk auf eine Verfahrensordnung zu richten, die einen Rahmen für die diskursive Konkretisierung der rechtlichen Planungs- und Gestaltungsspielräume der Verwaltung setzt, wird durch großzügige Heilungsvorschriften die Verfahrensverantwortung der Verwaltung degradiert ${ }^{150}$.

\section{G. Schlußbemerkung}

Ist das Thema als Frage gestellt, erwartet man am Schluß eine Antwort des Referenten. Diese muß er aus verschiedenen Gründen schuldig bleiben: Die Frage nach rechtlichen Optimierungsgeboten oder Rahmensetzungen und damit nach einer optimierenden Zuordnung beider Steuerungsmodi fordert ihrerseits Fragen heraus, über deren Beantwortung man trefflich streiten mag: Wo endet die Effektivität gesetzlicher Steuerung? In welchem Maße garantiert das Verwaltungsverfahren eine Annäherung an optimale Entscheidungen? Welche Maßstäbe der Verfahrensgerechtigkeit und der rechtlichen Richtigkeit sind gerichtlicher Kontrolle zugänglich? Im Prinzip ist demokratisch zu entscheiden, in welchen Bereichen die Verwaltung durch klare rechtliche Rahmensetzungen, durch optimierendes Abwägen und rechtliche Optimierungsgebote oder lediglich durch allgemein gehaltene rechtliche Verfahrensvorgaben gesteuert wird. Neubestimmungen einer optimierenden Funktionenteilung erfolgen in einem multipolaren Spannungsfeld. Dieses umfaßt die überkommene Rechtskultur und Dogmatik, rechtliche Reform nicht nur durch den Gesetzgeber, sondern auch durch das Richterrecht, und nicht zuletzt durch europarechtliche Einflüsse.

\footnotetext{
149 Zum ${ }_{n}$ Nacharbeiten“ als Leitvorstellung: BVerfGE 85, 26, 58 (zur bloßen Nachvollziehung gegebener Begründungen); Gerbardt in: Schoch/Schmidt-Aßmann/Pietzner, Vor $\S 113$ VwGO Rdn. 20 (zum diskursorientierten Modell des Verwaltungsprozesses, das dem diskursorientierten Verwaltungsverfahren entspricht); Schmidt-Aßmann DVB1. 1997, 281, 288; Schoch (Fn. 131) D II, 2 c; zur Einschränkung der gerichtlichen Prüfungsdichte von Prognosen nach § 43 UGB Schrader NuR 1998, 285, 289; ähnlich Breuer (Fn. 33) 212f.

${ }^{150}$ Krit. zur Abwertung des Verwaltungsverfahrens Schenke NJW 1997, 81, 86ff.; Redeker NVwZ 1996, 521, 522 ff.; Schocb (Fn. 132) B II, 2.
} 
Leitsätze des 1. Berichterstatters über:

\section{Rechtliche Optimierungsgebote oder Rahmensetzungen für das Verwaltungshandeln?}

\section{A. Fragestellung}

1. Neben die Rechtsfindung durch Subsumtion tritt die Rechtskonkretisierung durch Abrwägung. Die prinzipienrechtliche Abreägung sucht Rechtsprinzipien entsprechend ibrem Geltungsanspruch und ihrer Wertigkeit nach den jeweiligen tatsächlichen und rechtlichen Möglichkeiten in einem möglichst boben, optimalen Maß zu verwirklichen.

2. Die Entscheidung für rechtliche Optimierungsgebote oder Rabmensetzungen bängt davon ab, zu welchen Steuerungsleistungen das Recht im Bereich des abwägenden und optimierenden Verwaltungshandelns faktisch in der Lage ist sowie normativ im demokratischen und foderativen Rechtsstaat sein mu $\beta$ und sein darf. Soweit optimierende Entscheidungen im Verwaltungsverfahren rechtsgestaltend zu erarbeiten sind, gelangt das Spannungsfeld von gesetzlicber Steuerung und Selbststeuerung der Gesellschaft in den Blick.

B. Gegenwärtige Erscheinungsformen rechtlicher Optimierungsgebote

I. Optimierung der Freibeit als Prinzip der Verfassungsauslegung?

3. Optimierung liegt, in ibrer Reichweite umstritten, der Verfassungsauslegung zugrunde. So zielen etroa der Verbältnismäßigkeitsgrundsatz und der Grundsatz praktischer Konkordanz auf eine optimale Realisierung grundrechtlicher Freibeit.

4. Das Verwaltungsrecht stebt unter dem Gebot einer bisweilen übersteigerten verfassungsorientierten Optimierung.

II. Spezifisch verwaltungsrechtliche Optimierungsgebote

5. Unbestimmte Rechtsbegriffe zielen vielfach auf eine am Verhältnismäßigkeitsprinzip orientierte, optimierende Abwägung zwischen privaten und öfentlichen Interessen.

6. Das planungsrechtliche Abwägungsgebot ist funktionellrechtlich ein allgemeines Optimierungsgebot bei der Lösung von Konflikten. Durch rechtliche $O_{p}$ - 
timierungsgebote verlangt der Gesetzgeber die vorrangige Realisierung eines Rechtsprinzips. Solche rechtlichen Optimierungsgebote lassen sich auch als Maximierungsgebote qualifizieren.

7. Verfabrensrechtliche Optimierungsgebote zielen auf bestmögliche Ergebnisse, obne allerdings, wie bei der "best practice im Umweltrecht, klare rechlliche Vorgaben zu normieren.

\section{Die historische Entwicklung des Optimierungsdenkens}

\section{Traditionslinien des Optimierungsdenkens}

8. Rechtliche Optimierungsgebote als Prinzipien der Verfassungsauslegung und der verwaltungsrechtlichen Steuerung wurzeln in der deutschen Entwicklung zum Rechtsstaat. Die vernunftrechtlichen Traditionen im Naturrecht des ausgebenden 18. Jabrbunderts und die Rechts- und Staatspbilosophie Kants übten einen starken Einfluß auf die geistigen Grundlagen der Entwicklung der Verwaltungsrechtsordnung im 19. Jabrbundert aus.

9. Die Rechtsscbutzgarantie des Art. 19 Abs. 4 GG und das Konzept des materiellen Rechtsstaates beförderten den richterrechtlichen Zugriff auf rechtliche $O_{p}$ timierung. Hierfür stehen u. a. das Bemüben, die einzig rechtlich richtige Entscheidung für jeden Einzelfall durch richtiges Anwenden der recbtlichen Vorgaben zu finden, sowie eine verfassungsrechtliche Aufladung des einfachen Rechts, wie sie anderen Recbtsordnungen unbekannt ist.

II. Von ordnungsrechtlicben Rabmensetzungen zu Optimierungsgeboten als Weg $z u$ einer demokratischen und am Umweltschutz orientierten Verwaltung

\section{Ordnungsrechtliche Rabmensetzungen für das Verwaltungshandeln}

10. Das Regelungsmodell des liberalen Rechtstaates sowie des wirtschafts- und sozialpolitiscben Interventionsstaates siebt für das Verwaltungshandeln klare, konditionale rechtliche Rabmensetzungen vor.

\section{Demokratisierung der Verwaltung durch rechtliche Rabmensetzungen und Zielsteuerung}

11. Durch die finale Programmierung wird die Verwoaltung zum einen auf ein demokratisch legitimiertes Ziel- und Handlungsprogramm verpflichtet, zum anderen aber auch der Gedanke der demokratischen Dezentralisation verwirklicht. Die rechtlich strukturierte Gemeinwoblverwirklichung erfolgt in einem funktionsadäquaten Zusammenspiel zwischen demokratisch legitimierter Zielbestimmung und exekutivischer ebenso wie lokal zu legitimierender Verantwortung für die Sachgerechtigkeit der Abwägung. 
3. Rechtliche Optimierungsgebote als Mittel zur Verwirklichung des Umweltschutzes

12. Die rechtlichen Optimierungsgebote aus dem Bereich des Umweltschutzes schränken die Abrodgungsabbängigkeit der Umweltbelange ein und liegen auf der Linie einer Entwicklung zur Ökologisierung der Verfassungs- und Rechtsordnung.

D. Die entscheidungstheoretische Problematik von Optimierungsgeboten

\section{Unsicherheit über die Wirkungszusammenhänge}

13. Optimierende Steuerung im Bereich dynamisch miteinander vernetzter Wirkungsketten gelingt nur, weenn die jeweiligen Effekte erkannt und erforscht sind, was wegen des Komplexitätsdilemmas nur sehr bedingt möglich ist. Wegen der Unsicherheit über Wirkungszusammenhänge und zukünftige Entwicklungen bedarf es sachverständiger Beratung der Verwaltung und vielfach eines Diskurses zwischen unterschiedlichen Richtungen wissenschaftlich-technischer Forschung. In Zukunftsabschätzungen und Zukunftsszenarien sind alle vertretbaren wissenschaftlichen Erkenntnisse in Erwägung zu ziehen.

\section{Schwierigkeiten der rechtlichen Bewertung}

14. Das Grundgesetz und die Rechtsordnung geben nur grobe Anhaltspunkte für die Bewertung und Gewichtung der abzuwägenden Rechtsprinzipien. Ein normativ bestimmbares objektives Gewicht eines Rechtsprinzips, mit dem es im $A b$ wägungsprozeß in die Waagschale gelegt wird, gibt es nicht. Auch das Gewicht rechtlicher Optimierungsgebote läßt sich erst im Abrwägungsprozeß konkret bestimmen.

\section{Zwang zur situativen Konkretisierung des Rechts}

15. Die konkreten Lebensverbaltnisse und die multilateralen Betroffenheiten, wie sie von der Verwaltung wabrgenommen und eingeschätzt werden, steuern in hohem Maß den Entscheidungsprozeß der Verwaltung. Diese bestimmt unter Berücksichtigung. der Prafferenzautonomie der am Entscheidungsprozeß Verfabrensbeteiligten das Gewicht der in den Abröggungsprozeß einzustellenden Rechtsprinzipien und Belange.

\section{Keine Garantie optimaler Entscheidung}

16. Optimierung ist entscheidungstheoretisch lediglich eine regulative, letztlich an der Gerechtigkeit orientierte Idee, deren Erfüllung aber nur sebr beschränkt rechtlich erwiesen werden kann. Das Ziel rechtlicher Optimierung überschätzt die menschliche Fäbigkeit, die optimale als einzig richtige Entscheidung erkennen zu können. 


\section{E. Verfassungsrecbtliche Grenzen von Optimierungsgeboten}

\section{Grenzen der verfassungsrechtlichen Optimierungsprinzipien}

17. Grenzen einer verfassungsrechtlich gebotenen Optimierung sind dadurch gezogen, daß die Verfassung als Rabmenordnung eine große Bandbreite rechtlicher Gestaltung zuläßt. Daber ist z. B. bei der Verbältnismäßigkeitsprüfung lediglich das angemessene Verbältnis von Zweck und Mittel, also Proportionalität, der normative Maßstab. Dies verwebrt es der Verfassungs- und Verwaltungsgerichtsbarkeit, die optimierende Abwägung der Verwaltung durch eine eigene zu ersetzen.

II. Begrenzung durch die Garantie kommunaler Selbstverwaltung

18. Die gewaltenteilende föderative Demokratie zielt auf eine funktionsadäquate Steuerungsteilung zwischen zentraler parlamentarischer Steuerung und lokal geprägter Eigensteuerung. Die kommunale Selbstverwaltung kann durch rechtliche Optimierungsgebote ausgeböhlt werden, die die kommunale Zielsetzungs- und Konfliktlösungsautonomie verengen und einer intensiven verwaltungsgerichtlichen Kontrolle unterwerfen.

III. Bedenken gegen eine Ausgestaltung der Kontrollerlaubnis als Optimierungsentscheidung

19. Es ist ein Perspektivenwechsel, wenn die finale Normstruktur des supranationalen Umweltrechts die deutsche konditionale Normstruktur der Kontrollgenebmigung überlagert. Leitidee einer Integration beider Regelungsmodelle sollte sein: Soweit möglich wegen des grundrechtlich gebotenen Prinzips der gebundenen Kontrollerlaubnis konditionale Kontrollverantwortung, soweit aus Gründen der Effektivität des Umweltschutzes oder europarechtlich nötig optimierende Verfabrensgestaltung durch Eröffnung von Entscheidungsspielräumen. Dabei beginnen Abwägung und Optimierung erst jenseits der sicherbeitsrechtlichen Gefabrenabwebr, die auch weiterbin konditional zu programmieren ist.

\section{Grenzen richterrechtlicher Kontrolle bei optimierendem Abwägen und rechtlichen Optimierungsgeboten}

20. Wo wegen hober Komplexität oder besonderer Dynamik der geregelten Materie die Determinierung durch das Recht endet, beginnt die exekutivische Eigenverantwortung. Die Verwaltung hat die adäquate Organstruktur, verfabrensmäßig Konflikte abzuarbeiten, dezentrale Legitimationsleistungen zu erbringen sowie sach- und raumadäquate Entscheidungen zu treffen. Für Bereiche der exekutivischen Eigenverantwortung, die von der Judikative zu respektieren sind, sprechen die vom Grundgesetz vorausgesetzte Eigenständigkeit der Verwaltung, ibre demokratische Legitimation sowie ibre Legitimation durch Verfabren der diskursiven Konfliktlösung. 
21. Es ist bedenklich, wenn die abwögungsrelevanten Prinzipien und die rechtlichen Optimierungsgebote entsprechend ibrer objektiven Gewicbtigkeit in die Abwägung eingestellt werden und ibr Ausgleich nach dem Maßstab des Verhältnismäßigkeitsgrundsatzes erfolgt. Bereits durch diese Begrifflichkeit wird ein rechtlicher Kontrollrabmen vorgetäuscht, der entscheidungstheoretisch nicht einzulösen ist.

22. Wenn nur offensichtliche Abwägungsmängel zur gerichtlichen Aufbebung führen, so ist dies keine bedenkliche Verkürzung des rechtsstaatlichen Abrwägungsgebots, sondern entspricht der entscheidungstheoretisch und funktionell richtigen sowvie in anderen Rechtsordnungen geläufigen Abgrenzung von Verwaltung und Verwaltungsgerichtsbarkeit.

\section{F. Optimierung durch Verwaltungsverfabren}

\section{Zur Neuorientierung des Verwaltungsverfabrens}

23. Die beschränkte rechtliche Steuerungskraft der Abwägungs- und rechtlichen Optimierungsgebote verlagert die Aufgabe der Rechtskonkretisierung in das Verwaltungsveffabren. Je weniger es um Gesetzesvollzug geht und je mebr multipolare Konfliktlagen unter Beachtung vielfältiger rechtlicher Zielsetzungen rechtsgestaltend zu lösen sind, desto eher ist ein Verfabrensrabmen angebracht, der auf eine optimierende Verwaltungsentscheidung zielt.

24. Für das Verwaltungsverfabren ist eine verfahrensrechtliche Rabmensetzung erforderlich, die Konfliktoffenheit und die Möglichkeit der Konfliktlösung in Verfabrensgerechtigkeit garantiert. Die Verwaltung muß ein ausfübrliches Rechtsund Sachgespräch ermöglichen, externen wissenschaftlich-technischen Sachverstand in das Verfabren einbringen (lassen), den Diskurs der Experten der jeweiligen Verfabrensbeteiligten leiten, inadäquaten Pressionen entgegentreten und im Erörterungstermin Gelegenheit zu einem offenen Diskurs geben.

25. Für eine akzeptanzfäbige Optimierung durch Verfabren streiten die diskursethische Begründung des Demokratieprinzips und die neueren Strömungen der Wabrheitstheorie. Vor allem sind diskursive Begründungen nabeliegend, wenn es Prinzipien und Interessen zu gewichten und gegeneinander abzuwägen gilt. Räumt man den Verfabrensbeteiligten Spielräume bei der Gewicbtung der Prinzipien und Interessen ein, trägt man zugleich zur Optimierung lokaler Autonomie bei.

\section{Zur Rücknabme recbtlicher Optimierungsgebote und des Rechtsschutzes}

26. Eine Optimierung durch Verfabren erlaubt die Rücknabme rechtlicher $O p$ timierungsgebote und zum Teil auch verwaltungsgerichtlicber Kontrolldichte. Im Idealfall werden Verwaltungsentscheidungen durch Elemente der repräsentativen wie auch der partizipativen Demokratie legitimiert, d.h. durch eine Verantwortungsteilung zwischen Staat und gesellschaftlichem Bereich. 
27. Der verwaltungsgerichtliche Schutz eines sachgerechten Optimierungsverfahrens dadurch, daß die nach wie vor umstrittenen Punkte mit den Klägern am Maßstab einer Plausibilitats- und Willkürkontrolle nachgearbeitet werden, erübrigt eine verwaltungsgerichtliche Überprüfung der Entscheidungsrichtigkeit. Dann aber darf die Verfabrensverantwortung der Verwaltung entgegen der gegenwärtigen Tendenz nicht durch großzügige gesetzliche Heilungsvorschriften degradiert werden. Bei der Gestaltung des Verwaltungsverfabrensrechts verdient die diskursive Konkretisierung der rechtlichen Abwägungs- und Gestaltungsspielräume der Verwaltung besondere Beachtung.

\section{G. Schlußbemerkung}

28. Neubestimmungen einer optimierenden Funktionenteilung von Gesetzgebung, Verwaltung und Rechtsprechung stehen in einem multipolaren Spannungsfeld. Dieses umfaßt die überkommene Rechtskultur und Dogmatik, rechtliche Reform nicht nur durch den Gesetzgeber, sondern auch durch das Richterrecht, und nicht zuletzt auch durch europarechtliche Einflüsse. 


\section{Zweiter Beratungsgegenstand: \\ Rechtliche Optimierungsgebote oder Rahmensetzungen für das Verwaltungshandeln?}

2. Bericht von Prof. Dr. Herbert Haller, Wien

\footnotetext{
- Anmerkung der Redaktion: Leider konnte dieser Bericht nicht in dem Tagungsband erscheinen, da der 2 . Berichterstatter sich außerstande erklärt hat, die schriftliche Fassung seines Referats für die Drucklegung fertigzustellen.
} 
Leitsätze des 2. Berichterstatters über:

\section{Rechtliche Optimierungsgebote oder Rahmensetzungen für das Verwaltungshandeln?}

\section{A. Themenstellung}

1. Der Gesetzgeber gebietet immer Optimierung und setzt immer Entscheidungsrabmen.

B. Enfahrungen aus der österreichischen Entwicklung

I. Text - Umfeld - Interpretation

2. Beweisaufnabme und Norminterpretation unterliegen verschiedensten Einflüssen, die sich zum Teil kaum rechtlich fassen lassen. Das System der Höchstgerichtsbarkeit bat jedenfalls erbeblichen Anteil am Ergebnis.

II. Problemfelder

3. Die Problemfelder der Determinierungsdebatte wie Privatwirtschaftsverwaltung, besondere Gewaltverbältnisse und Ermessen sind zum Teil „befriedet ${ }^{\alpha}$.

III. Gelockerte Legalität

4. Ein nach Sachbereichen differenzierendes Legalitätsprinzip hat sich durchgesetzt. Vorbersebbarkeit der Entscheidung wird in unterschiedlichem Maß durch Verfabren und dessen Kontrolle ergänzt und ersetzt.

\section{Möglicbkeiten der Veränderung}

I. Die Ausgangsposition

5. Die Debatte zum Legalitätsprinzip ergibt immer noch Warnungen vor einem „Ersticken des Rechtsstaates“. Die angegebenen Gründe für die Gefabr sind nur zum Teil die wabren Gründe der Probleme.

II. Verzicht auf Regelungen

6. Die Reduzierung der Rechtsmasse durch Verzicht auf Regelungen kann nur selten die Lösung sein und ist ein schwer durchsetzbarer Kraftakt. 


\section{Einfachere Regelungen}

7. Vereinfachung von Regeln ist ein wesentlicher Beitrag zur Entlastung und kann die Manövrierfähigkeit der Verwaltung sowie der nachprüfenden Gerichtsbarkeit des offentlichen Rechts wiederberstellen.

\section{Verbesserung von Optimierungsgeboten}

8. Die Verbesserung von Optimierungsgeboten ist vielfach unverzichtbar, wenn man die Vorbersebbarkeit von Einzelentscheidungen beibebalten will.

D. Verlagerung von Entscheidungsgewalt in die Verwaltung

1. Hindernisse

9. Mißstrauen gegen dic Verwaltung im Verband mit Argumenten, wie Verlust der Gleichbehandlung und Kostensteigerung, stehen gegen sachgerechte Anpassung. II. Ausgestaltungsmöglichkeiten

10. Die verschiedenen Ausgestaltungen eines Verwaltungsvollzuges im größeren Rabmen bringen Erprobungsphasen und Vielfalt sowie eine demokratie-politisch vertretbare Nutzung des beweglichen Instruments Verordnung.

\section{E. Einfluß europäischer Rechtsetzung \\ I. Gebote der Rechtsstaatlichkeit}

11. Zur europäischen Rechtsstaatlichkeit gehört eine abgestufte Legalität, die freilich nur geringe Mindeststandards erreicht. Die Verwaltung bat mit der Orientierung am EU-Recht eine zweite Rechtskultur zu bestehen.

II. Kontrolle durch den EuGH

12. Die Rechtskontrolle durch den EuGH orientiert sich an unterschiedlich determinierenden Normenbeständen. Sie ist ungeachtet dessen fallbezogener und interpretativ großzügig - Verfassungsrecht durch Richterspruch. Sie entwickelt sich $z u$ einer an Formeln orientierten Grobkontrolle im Inbaltlichen mit verstärkter Nachschau in Verfabrensfragen.

\section{F. Ausblick}

13. In einigen Bereichen wird es gelingen, den spürbaren Kostendruck zur Verbesserung des Rechtsstaats zu nutzen. Eine Konvergenz zwischen staatlicher und europarechtlicher Determinierung - sachadäquate Differenzierung mit Wertungswidersprüchen, die aus politischem Willen und Zeitgebundenbeit der Regelung resultieren - wird sich einstellen. 
Zweiter Beratungsgegenstand:

\section{Rechtliche Optimierungsgebote oder Rahmensetzungen für das Verwaltungshandeln?}

3. Bericht von Prof. Dr. Eibe Riedel, Mannheim

\section{Gliederung}

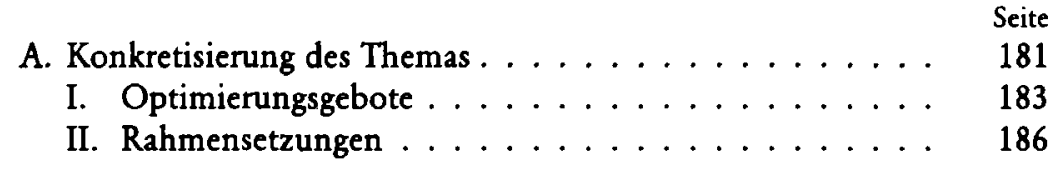

B. Optimierungsgebote und Rahmensetzungen im französischen Recht

I. Stellung der Judikative in Frankreich . . . . . . . . . 187

II. Grundlagen gerichtlicher Kontrolle . . . . . . . . . . 189

III. Die Bindung der Verwaltung an legislative Abwägungsdirektiven . . . . . . . . . . . . . . 194

C. Optimierungsgebote und Rahmensetzungen im englischen Recht . . . . . . . . . . . . . . . . 196

I. Stellung der Judikative im englischen Recht . . . . . . 197

II. Grundlagen der gerichtlichen Kontrolle . . . . . . . . 199

1. Ermessen . . . . . . . . . . . . . . . . . . 199

2. Ultra vires-Kontrolle . . . . . . . . . . . . . 201

III. Ausschluß richterlicher Kontrolle durch Gesetze

(Ouster Clauses) . . . . . . . . . . . . . . . . 205

IV. Selbstbindung der Exekutive durch Tribunals und Inquiries 206

D. Schlußbetrachtung . . . . . . . . . . . . . . . . 209 


\section{A. Konkretisierung des Themas}

Der Auftrag des Vorstands an mich, im Anschluß an die Berichte zur deutschen und europarechtlichen Situation den Beratungsgegenstand in rechtsvergleichender Perspektive vorzustellen, erweist sich als reizvoll, aber auch als schwierig: die wichtigen Ausführungen zum deutschen und europäischen Recht sind bereits kompetent gemacht worden und meiner Darstellung verbleibt somit nur der Versuch einer Arrondierung durch Rechtsvergleich. Ich hoffe aber, daß ein Blick auf das französische und englische Recht dennoch nützlich ist, um zu erfahren, ob und in welcher Weise der Optimierungsgedanke in diesen benachbarten Rechtsordnungen eine Rolle spielt. Anliegen eines solchen Vergleiches ist aber auch, festzustellen, ob die Rechtsintegration in der Europäischen Gemeinschaft zugleich eine stärkere Harmonisierung der Verwaltungsverfahren und des Verwaltungsrechts der Mitgliedstaaten gebietet oder ob - ganz im Sinne des Subsidiaritätsgedankens - nicht vielmehr die Bewahrung der Eigenständigkeit der Verwaltungsrechtsordnungen als spezifischen Kulturleistungen der einzelnen Rechtsordnungen zu respektieren ist. Denn ehe einer weiterreichenden Harmonisierung des Verwaltungsverfahrens und des materiellen Verwaltungsrechts das Wort geredet wird, bedürfte es des sorgfältigen Nachweises gemeinsamer Rechtsauffassungen und -traditionen als Grundlage denkbarer gemeineuropäischer Verwaltungsstandards neben gemeineuropäischen Verfassungsprinzipien.

Um das wichtigste Ergebnis meiner Untersuchung vorwegzunehmen: trotz redlicher Suche konnte ich weder im französischen noch im englischen Recht Optimierungsgebote finden, die, wie etwa im Schrifttum zum deutschen Bauplanungsrecht ${ }^{1}$ erörtert, nach Art der gewichteten Abwägungsdirektiven das Abwägungsergebnis weitgehend steuern und letztlich sogar vorgeben können. Überhaupt stellt sich die Frage einer Abgrenzung oder Alternativität von Optimierungsgeboten oder Rahmensetzungen für das Verwaltungshandeln in England und Frankreich so nicht. Es ist eine sehr deutsche Diskussion, und dies allein ist Grund genug, ihre Grundlagen vor dem Hintergrund der Situation in unseren Nachbarländern kritisch zu beleuchten. Hinter der allgemeinen Frage-

1 Zum ganzen vgl. Hoppe Die Bedeutung von Optimierungsgeboten im Planungsrecht, DVBI. 1992, 853 (854); Battis Offentliches Baurecht und Raumordnungsrecht, 3. Aufl., 1992, 111; Bartlsperger Planungsrechtliche Optimierungsgebote, DVB1. 1996, 1 ff.; Kübling Fachplanungsrecht, 1988, $101 \mathrm{f}$; Sendler Die Bedeutung des Abwägungsgebots in $\S 1$ Abs. 6 BauGB für die Berücksichtigung der Belange des Umweltschutzes in der Bauleitplanung, UPR 1995, 41 ff.; Steinberg Neue Entwicklungen in der Dogmatik des Planfeststellungsrechts, DVBI. 1992, $1501 \mathrm{ff}$. 
stellung nach Optimierungsgeboten oder Rahmensetzungen für das Verwaltungshandeln verbergen sich die schon reichlich bearbeiteten Themen der unbestimmten Rechtsbegriffe ${ }^{2}$ und damit verbundener Beurteilungsspielräume $e^{3}$, der Ermessenseinräumung ${ }^{4}$ in ihren verschiedenen $\mathrm{Va}_{\mathrm{a}}$ riationen, aber auch im Rahmen der Gewaltenteilung die Frage nach der Bindung der Exekutive durch Legislative und Judikative sowie damit einhergehend nach der Kontrolldichte richterlicher Überprüfung von Verwaltungsentscheidungen ${ }^{5}$ mit den allfälligen Verweisen auf das gouvernement des juges, die allgemeine Normenflut und die Verrechtlichung der Politik. Die hinter allen diesen Themen stehende Grundfrage lautet: wer im gewaltenteiligen Rechtsstaat soll das letzte Wort haben dürfen: das Parlament, die Exekutive oder die Richterschaft? Aus dieser Perspektive lassen sich trotz des Fehlens einer spezifischen Optimierungsdebatte in Frankreich und England m.E. sinnvolle Vergleiche herstellen.

Vorab sind jedoch die Begriffe Optimierungsgebote und Rahmensetzungen in der deutschen Terminologie kurz zu erläutern, ehe nach entsprechenden Rechtsfiguren im französischen und englischen Recht gesucht wird.

\footnotetext{
2 Statt aller Maurer Allgemeines Verwaltungsrecht, 11. Aufl., 1997, 129; Sachs in: Stelkens/Bonk/Sachs Verwaltungsverfahrensgesetz, 5. Aufl., 1988, $\$ 40 \mathrm{Rdn}$. $32 \mathrm{ff}$. mit umfangreichen Nachweisen zum Streitstand.

${ }^{3}$ Vgl. statt vieler Wolff/Bacbof/Stober Verwaltungsrecht I, 10. Aufl., 1994, 368 ff.; Peine Allgemeines Verwaltungsrecht, 3. Aufl., 1997, Rdn. 75f.; Maurer (Fn. 2) 135 f.; differenziert Herdegen Beurteilungsspielraum und Ermessen im strukturellen Vergleich, JZ 1991, 747 f., m.w.N.

4 Maurer (Fn. 2) 127f.; Peine (Fn. 3) Rdn. 76 ff.; Alexy Ermessensfehler, JZ 1986, 701 ff.; krit. zur Unterscheidung zwischen Ermessen und unbestimmten Rechtsbegriffen Rupp Grundlagen der heutigen Verwaltungsrechtslehre, 2. Aufl., 1991, $177 \mathrm{ff}$., $213 \mathrm{ff}$.; ders. „Ermessen“, „unbestimmter Rechtsbegriff“ und kein Ende, FS Zeidler, 1987, 455, 466f., m.w.N.; Bullinger Das Ermessen der öffentlichen Verwaltung, 1984, $1001 \mathrm{ff}$; Siarck Verwaltungsermessen im modernen Staat - Rechtsvergleichender Generalbericht, in: Bullinger (Hrsg.), Verwaltungsermessen im modernen Staat, 1986, $15 \mathrm{ff}$.

s Vgl. statt vieler nur Maurer (Fn. 2) 136; Schmidi-Aßmann in: Mainz/Dürig/Herzog Art. 19 Abs. 4, Rdn. 183; Schenke in: Bonner Kommentar, Art. 19 Abs. 4, Rdn. 327; Schulze-Fielitz in: Dreier GG, 1996, Art. 19 Abs. 4, Rdn. 87 ff.; ders. Neue Kriterien für die verwaltungsgerichtliche Kontrolldichte bei der Anwendung unbestimmter Rechtsbegriffe, JZ 1993, 772; Jarass in: Jarass/Pieroth GG, Art. 19, Rdn. 42 f.; Krüger in: Sachs GG, 1996, Art. 19, Rdn. 140f.; Kutscheidt Verfahrensbeschleunigung und richterliche Kontrolldichte, NWVBl. 1995, 121 f.; für den Bereich des Planungsrechts Sendler (Fn. 1) 41; Bartlsperger (Fn. 1) 10; zur europäischen Dimension Schwarze Das Verwaltungsrecht unter europäischem Einfluß, 1996, $197 \mathrm{ff}$.
} 


\section{Optimierungsgebote}

1. Der Optimierungsgedanke wird in der rechtstheoretischen Diskussion vor allem im Verfassungsrecht bei der Unterscheidung von Rechtsregeln und Prinzipien verwendet. Nach Robert Alexy sind Rechtsregeln definitive deontologische Pflichtsätze relativ geringen Abstraktionsgrades mit Konditionalprogramm, die eine bestimmte Rechtsfolge gebieten. Sie können stets erfüllt oder nicht erfüllt werden. Ein Beispiel für eine solche Regel ist etwa $\S 5$ Abs. 1 der StVO, demzufolge links zu überholen ist? Prinzipien stellen demgegenüber Optimierungsgebote dar, die dadurch gekennzeichnet sind, daß sie in unterschiedlichen Graden erfüllt werden können und „daß das Maß ihrer Erfüllung nicht nur von tatsächlichen, sondern auch von den rechtlichen Möglichkeiten abhängt ${ }^{\alpha}{ }^{8}$. Prinzipien des Verfassungsrechts zeichnen sich nach dieser Unterscheidung vor allem dadurch aus, daß sie in Konkurrenz zu gegenläufigen Prinzipien treten können - etwa Grundrechten als Verfassungsprinzipien - und dann eine Abwägung im Sinne von Gewichtungen verlangen. Diese Gewichtung wird in Form einer Güterabwägung durchgefuihrt, aufgrund derer im konkreten Anwendungsfall auch bei abstrakt gleichrangigen Belangen ein Prinzip hinter das andere zurücktritt'. Der Optimierungsgedanke gebietet folglich, jedes Prinzip prima facie in tatsächlicher wie rechtlicher Hinsicht in möglichst großem Umfang zu realisieren. Im Falle der Kollision mit gegenläufigen Prinzipien entpuppt sich eines dann in der konkreten Anwendung als Vorrangregel, die aber erst in einem Prozeß $B$ der wertenden Abwägung gefunden wird. Nach gründlicher Analyse der möglichen Einwände gegen diese Kategorisierung gelangt Alexy zu der Auffassung, daß ,eine Ordnung der Werte oder Prinzipien, die das grundrechtliche Entscheiden in allen Fällen intersubjektiv zwingend festlegt, nicht möglich ist ${ }^{\text {"10 }}$. Immerhin sei aber durch die Rechtsprechung des Bundesverfassungsgerichts ein Netzwerk konkreter Präferenzentscheidungen entstanden ${ }^{11}$, bei denen die Abwägung im Wege rationaler juristischer Argumentation effolge ${ }^{12}$. Damit wird eine inhaltliche Festlegung auf bestimmte Prinzipien nicht begründet, aber die verfahrens- und argumentationsmäßige Kanalisierung von Präferenzentscheidungen eröffnet. In dieser letztlich prozeduralen Theorie wird

\footnotetext{
6 Alexy Theorie der Grundrechte, 1985, $71 \mathrm{ff}$., insbes. $75 \mathrm{ff}$.

7 Alexy (Fn. 6) 76.

${ }^{8}$ Alexy (Fn. 6) 76.

${ }^{9}$ Alexy (Fn. 6) $79 \mathrm{f}$.

10 Alexy (Fn. 6) 142.

11 Alexy (Fn. 6) 143.

12 Alexy (Fn. 6) 152.
} 
über die inhaltliche Fixierung bestimmter zu optimierender Werte jenseits hochabstrakter Staatsstrukturprinzipien wenig gesagt, jedoch der Weg zur Ermittlung solcher Prinzipieninhalte gewiesen. Der Inhalt bestimmt sich nach konkreten Fallentscheidungen über zu präferierende Prinzipien, mithin durch Wertentscheidungen des Normanwenders, speziell des Bundesverfassungsgerichts.

Zweierlei bleibt für unser Thema festzuhalten: erstens bedeutet Optimierung hier Einräumung relativen Vorrangs bei Prinzipien, die im Gegensatz zu Rechtsregeln häufig wesentlich abstrakter formuliert sind und zweitens eröffnen sich trotz der Optimierungsaufgabe für jedes einzelne Prinzip grundsätzlich Abwägungsspielräume, sobald es auf andere Prinzipien stößt. Die Abwägung im konkreten Einzelfall bildet damit den Angelpunkt der Entscheidung. Dem Rechtsanwender - nach Art. 1 III GG jeder Inhaber staatlicher Gewalt - wird somit die Prinzipienoptimierung als Abwägungsleistung abverlangt.

2. Auf der Ebene unterhalb des Verfassungsrechts werden unter Optimierungsgeboten im juristischen Sinne Abwägungsdirektiven für die Verwaltung verstanden, die grundsätzlich durch die Legislative vorgegeben werden und vor allem im Planungsrecht von Bedeutung sind ${ }^{13}$. Nach herrschender Meinung sind Optimierungsgebote etwa das aus $\S 1$ I 1 FStrG abgeleitete Gebot eines möglichst störungsfreien Verkehrsflusses ${ }^{14}$; die Vermeidung von schädlichen Umwelteinwirkungen auf schutzbedürftige Gebiete nach $\S 50 \mathrm{BImSchG}{ }^{15}$; beim Bau oder der wesentlichen Änderung öffentlicher Straßen die Vermeidung von schädlichen Umwelteinwirkungen durch Verkehrsgeräusche, die nach dem Stand der Technik vermeidbar sind ( $(41 \mathrm{I} \mathrm{BImSchG)})^{16}$, oder auch das Gebot zur Minimierung vermeidbarer, naturschutzrechtlicher Eingriffe gem. $\$ 8$ II und III

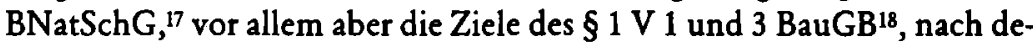
nen Bauleitpläne eine nachhaltige städtebauliche Entwicklung und eine dem Wohl der Allgemeinheit entsprechende sozialgerechte Bodennut-

\footnotetext{
$13 \mathrm{Vgl}$. hierzu die in Fn. 1 genannten Autoren.

14 BVerwGE 71, 163 (165f.).

15 BVerwGE 71, 163 (165).

${ }_{16}$ BVerwG v. 13. 7. $1989-4$ NB 20/89, unveröffentlicht, zit. nach Hoppe (Fn. 1) 853 (855) und Bartlsperger (Fn. 1) 7.

${ }^{17}$ BVerwG NVwZ 1991, 69 (70); BVerwGE 85, 348 (362).

${ }^{18}$ BVerwGE 90, 329 (332). Ausdrücklich kein Optimierungsgebot enthält nach der jüngsten Rspr.-§ 8a Abs. 1 S. 1 BNatSchG, BVerwGE 104, 68 (72, 74f.). Vgl. zu dieser Frage u.a. Sendler (Fn. 1) 46; Müller Die Eingriffsregelung des $§ 8$ a BNatSchG als elementarer Planungsgrundsatz städtebaulicher Planung, NVwZ 1994, 850; Felder Naturschutzrechtliche Eingriffsregelung im Bauleitplanungsrecht gemäß $\S 8$ a Abs. 1 S. 1 BNatSchG, NuR 1994, 53 ff.
} 
zung gewährleisten und dazu beitragen sollen, eine menschenwürdige Umwelt zu sichern, die natürlichen Lebensgrundlagen zu schützen und zu entwickeln (Satz 1), und nach denen landwirtschaftliche, als Wald oder für Wohnzwecke genutzte Flächen nur im notwendigen Umfang für andere Nutzungen in Anspruch genommen werden sollen (Satz 3).

Diese Auflistung exlangt Anspruch auf Gültigkeit nur auf der Grundlage der herrschenden Meinung. Gelegentlich wird in einem weiten, an die Begrifflichkeit Alexys erinnernden Sinne von Optimierungsgeboten allerdings schon dann gesprochen, wenn ein bestimmter Belang überhaupt dem Abwägungsvorgang unterworfen wird, wie z.B. im Falle des $\S 1$ V 2 BauGB ${ }^{19}$. Nach der ganz herrschenden, auch von der Rechtsprechung geteilten Ansicht hingegen ist von Optimierungsgeboten erst dann zu sprechen, wenn einem bestimmten Belang durch gesetzliche Vorschrift ein besonderer, hervorgehobener relativer Rang zuerkannt wird ${ }^{20}$. Die Beeinträchtigung eines solchen Belanges bedarf dabei besonders gewichtiger, sachlicher Rechtfertigung. Die Argumentationslast ist zu seinen Gunsten verschoben. Der Punkt, an dem die Planung nicht mehr abgewogen erscheint, wird eher erreicht. Den engsten Begriff vertritt schließlich Hoppe $e^{21}$. Optimierungsgebote seien ein plus und ein aliud gegenüber relativen Vorrangregeln, ihre Steuerungskraft stärker und zugleich anders: Anstelle eines proportionalen Ausgleichsverfahrens stehe nurmehr ein Optimierungsverfahren, das einen bestimmten Belang bevorzuge. Damit überwinden Optimierungsgebote die übliche Abwägung im Planungsrecht. Die durch das Optimierungsgebot favorisierten Belange müßten möglichst vollständig realisiert werden - auch gegenüber gewichtigen anderen Belangen. Das geschehe durch Maximierung der zu optimierenden und Minimierung der entgegenstehenden Belange. Einer Gewichtungsphase des zu optimierenden Belanges folge eine Ausgleichsphase, bei der dann nicht nur das Optimum zu realisieren, sondern konfligierende Belange ohne Rücksicht auf die Proportionalität zurückzustellen seien. Die Ausgleichsentscheidung ziele also nicht mehr auf Verhältnismäßigkeit, sondern auf Optimierung und Minimierung. $\mathrm{Zu}$ gleich werde so die planerische Gestaltungsfreiheit eingeschränkt und die gerichtliche Kontrolldichte erhöht. Erst wenn sich zwei zu optimierende Belange gegenüberstünden, sei ein Ausgleich mittels des VerhältnismäBigkeitsgrundsatzes wieder möglich. Wegen dieser starken Bindung warnt

19 Battis (Fn. 1) 111.

${ }^{20}$ Erbguth/Schink UVPG-Kommentar, 1992, § 12 UVPG, Rdn. 64; Funke Die Lenkbarkeit von Abwägungsvorgang und Abwägungsergebnis zugunsten des Umweltschutzes, DVBI. 1987, 511/516 ff.; Hoppe (Fn. 1) 855, Fn. 27 m.w.Hinw.

${ }^{21}$ Hoppe (Fn. 1) $859 \mathrm{f}$. 
Hoppe allerdings vor einer allzu großzügigen Auslegung von Vorschriften als Optimierungsgebote, da sie als materielle Rechtsbegriffe durch die Gerichte voll überprüfbar seien ${ }^{22}$.

Optimierungsgebote im Rahmen der planerischen Gestaltungsfreiheit weisen im Ergebnis Ähnlichkeiten mit Soll-Vorschriften im Rahmen des sonstigen Verwaltungsermessens auf. In beiden Fällen ist eine verstärkte Bindung der Verwaltung gewollt, die jedoch - wenn nicht die Meinung Hoppes zugrundegelegt wird - bei Soll-Vorschriften mit ihrer Regelfallbindung stärker ausfällt als bei Optimierungsgeboten, die nur möglichst weitgehende Beachtung fordern. In jedem Fall bewirken Optimierungsgebote eine sehr starke Bindung der Gestaltungsfreiheit der Verwaltung, die eine Ausdehnung dieser im Planungsrecht entwickelten Rechtskategorie in andere Rechtsbereiche jedenfalls nicht nahelegt. Auf eine genauere Begriffsanalyse kann ich verzichten und verweise insoweit auf die Ausführungen von Herrn Würtenberger.

\section{Rabmensetzungen}

In seiner weiteren Bedeutung kennzeichnet der rechtlich nicht speziell besetzte Begriff „Rahmensetzung" demgegenüber jegliches legislative Handeln: Der Gesetzgeber fixiert einen normativen Rahmen, innerhalb dessen Akteure in gewissen Grenzen rechtlich frei sind und keiner gerichtlichen Überprüfung unterliegen. Beispiele für spezielle Formen der Rahmensetzung lassen sich in unterschiedlichsten Formen finden, etwa als Rahmengesetzgebung des Bundes nach Art. 75 GG. Der Bund erläßt hier ausfüllungsbedürftige und ausfüllungsfähige Gesetze, die nur ausnahmsweise detaillierte Regelungen enthalten dürfen. Den Ländern wird dadurch ein Rahmen für eigenes legislatives Handeln vorgegeben. Bei Überschreitung des Rahmens sind die ausfüllenden Gesetze mangels Kompetenz oder wegen Verletzung des Art. 31 GG nichtig ${ }^{23}$. Eine andere Art von Rahmensetzung stellen EG-Richtlinien dar, die das Verhältnis der gemeinschaftsrechtlichen zur innerstaatlichen Rechtsetzung betreffen. EG-Richtlinien weisen allerdings im Unterschied zu Rahmengesetzen nach Art. 75 GG häufig sehr detaillierte Regelungen auf und belassen dem nationalen Gesetzgeber bei ihrer Umsetzung wenig Freiraum. Hinsichtlich ihres materiellen Gehalts rücken sie damit in die Nähe von EGVerordnungen ${ }^{24}$. Ihr Rahmencharakter wird weiterhin dadurch ge-

${ }^{22}$ Hoppe (Fn. 1) 861; ähnlich ders. „Verwirrung“ und „Entwirrung“ beim Abwägungsgebot (§ 1 Abs. 6 BauGB), UPR 1995, $201 \mathrm{f}$.

${ }^{23}$ Vgl. etwa Degenhart in: Sachs GG, 1996, Art. 75 Rdn. $1 \mathrm{ff}$, $39 \mathrm{ff}$.

${ }^{24}$ Statt vieler Streinz Europarecht, 3. Aufl., 1996, Rdn. 384 ff. 
schwächt, daß sie nach Ablauf der vorgesehenen Umsetzungsfrist unmittelbare Wirkung entfalten können ${ }^{25}$.

Allgemeiner gesprochen bezeichnet der Begriff "Rahmen" rechtliche Vorgaben, innerhalb derer sich staatliche Institutionen bei der Setzung von Rechtsakten frei und ohne Kontrolle durch andere Instanzen bewegen können. „Rahmen" bestehen folglich nicht nur für die parlamentarische Gesetzgebung, sondern auch für die Rechtsetzung der Exekutive und für einzelne Entscheidungen der Verwaltung ${ }^{26}$.

Will der Gesetzgeber Normsetzungsbefugnisse delegieren, kann er dies dadurch bewirken, daß er dem Verordnungsgeber einen Rahmen absteckt, innerhalb dessen dieser frei ist, die im Rahmen enthaltenen Zwecksetzungen zu verwirklichen, solange Art. 80 I 2 GG gewahrt bleibt ${ }^{27}$. Im Grunde genommen kann aber auch jede Regelung, die der Verwaltung ein Ermessen einräumt, als Rahmenregelung verstanden werden. Bedeutsam wird die Verwendung des Begriffes „Rahmen “ dann bei der konkreten Ausübung von Ermessen. Im Unterschied zu „Optimierung ${ }^{\alpha}$ legt „Rahmensetzung ${ }^{\star}$ größere Gestaltungsfreiheit für die Ermessen ausübende Verwaltung nahe und verringert somit tendenziell die gerichtliche Kontrolldichte.

Vor diesem Hintergrund möchte ich nunmehr Optimierungsgebote und Rahmensetzungen im französischen und englischen Recht untersuchen, obgleich diese Kategorisierung - wie eingangs gesagt - dort so nicht getroffen wird.

\section{B. Optimierungsgebote und Rahmensetzungen im französischen Recht}

\section{Stellung der Judikative in Frankreich}

In Frankreich gibt es keine umfassende Kodifikation des allgemeinen Verwaltungsrechts. Der Code Administratif ist lediglich eine redaktionelle Zusammenstellung einzelner Gesetze und Verordnungen. Inhaltlich ent-

\footnotetext{
${ }^{25}$ Streinz (Fn. 24) Rdn. 394 ff.

${ }^{26}$ Rechtsetzungsakte der Exekutive unterliegen bereits insofern der Rahmensetzung, als etwa Planungsentscheidungen, die sich stets innerhalb des durch das Gebot gerechter $\mathrm{Ab}$ wägung gesetzten Rahmens bewegen müssen, nicht nur als Verwaltungsakte in Form von Planfeststellungsbeschlüssen ergehen, sondern auch in Form von Rechtsnormen, wie etwa Bebauungspläne als Satzungen ( 10 I BauGB) oder sogar, wie im Falle Hamburgs, als Landesgesetze (vgl. §246 II 1 BauGB).

${ }^{27}$ Zur Delegation an den Verordnungsgeber vgl. Kischel Delegation of legislative power to agencies: a comparative analysis of United States and German Law, Administrative Law Review 46 (1994) 213 (228ff.).
} 
halten die Gesetze häufig nur organisatorische Regelungen, selten materiellrechtliche Vorgaben für das Verwaltungshandeln ${ }^{28}$. Das allgemeine Verwaltungsrecht in Frankreich ist somit weitgehend Richterrecht. Entscheidungen der obersten Gerichte werden dementsprechend als eigene Rechtsquelle angesehen. Die Grundsatzurteile des Conseil d'Etat bilden hierbei wesentliche Versatzstücke, zumal der Conseil d'Etat nur höchst selten von seinen Urteilen abweicht und die Verwaltung sich an seine Rechtsprechung in gleichem Maße wie durch Gesetze gebunden fühlt. Trotz der besonderen Bedeutung judikativer Maßstäbe für exekutives Handeln ist die gerichtliche Kontrolldichte verglichen mit der deutschen Rechtslage gering. Seit den Zeiten des Ancien Régime hat sich in der französischen Bevölkerung - ganz anders als in Deutschland - ein solides Mißtrauen gegenüber der Gerichtsbarkeit gehalten, wodurch eine starke Stellung der Exekutive im französischen System der Gewaltentrennung begünstigt wurde ${ }^{29}$. Im deutschen Recht stehen die individuellen Grundrechte im Vordergrund: dies ist in Frankreich nicht in solchem Ausmaß der Fall. Andererseits genügt in Frankreich für die Klagebefugnis ein intérêt pour agir, während in Deutschland eine mögliche Verletzung subjektiver Rechte des Klägers vorliegen muß $\beta^{30}$. Bei alledem wird in Frankreich der Sicherung der Funktionsfähigkeit und Leistungsfähigkeit der Verwaltung eine herausragende Bedeutung beigemessen. Dahinter steht auch die Furcht vor einem gouvernement des juges, vor einem „Richterstaat $^{\alpha}{ }^{\alpha 1}$. Die Unterschiede im deutschen und französischen Verwaltungsrecht erklären sich somit aus der unterschiedlichen Geschichte, Tradition und Mentalität, worauf schon Herr Würtenberger hingewiesen hat. Der Conseil d'Etat sieht sich selbst mehr als Partner denn als Gegenspieler der Verwaltung und übt sich meist in "contrôle restreint ${ }^{\text {, }}$, richterlicher Zurückhaltung. Diese Rolle richterlicher Zurückhaltung wird ihm auch dadurch erleichtert, daß er neben der nachträglichen Rechtsprechung vorab Rechtsgutachten für die Regierung erstellen kann, von denen er in einem späteren Gerichtsverfahren verständlicherweise kaum abweichen wird ${ }^{32}$.

\footnotetext{
${ }^{28}$ Zum folgenden vgl. Vedel/Delvolvé Droit administratif, Bd. 2, 12. Aufl., 1992, $19 \mathrm{ff}$; Chapus Droit administratif général, Bd. 1, 11. Aufl., 1997, 667 ff., 713 ff.; Braibant/Stim Le droit administratif français, 4. Aufl., 1997, 443 ff.; Grote Ermessenslehre und Ermessenspraxis in Frankreich, NVwZ 1986, $269 \mathrm{ff}$.

${ }^{29}$ Schwarze Europäisches Verwaltungsrecht, Bd. I, 1988, 109.

30 Schwarze (Fn. 29) 109; Classen Die Europäisierung der Verwaltungsgerichtsbarkeit, 1996, 57 ff.; s. a. Woebrling Die französische Verwaltungsgerichtsbarkeit im Vergleich mit der deutschen, NVwZ 1985, $21 \mathrm{ff} ., 24$.

31 Woebrling (Fn. 30) 22; Grote (Fn. 28) $269 \mathrm{f}$.

32 Von Danwitz Rechtliche Optimierungsgebote oder Rahmensetzungen für das Verwaltungshandeln, DVBI. 1998, 928 ff., 933; vgl. auch Fleck/Müller/Perret Der Conseil
} 
Aufgrund der geringen Bedeutung der ohnehin nur punktuellen Verwaltungsgesetze und der starken Zurückhaltung des Conseil d'Etat in der Ausübung seiner gerichtlichen Kontrolle läßt sich bereits vorab vermuten, daß das Verwaltungshandeln im französischen System der Gewaltentrennung durch gesetzlich vorgegebene oder richterrechtlich bestimmte Optimierungsgebote oder Abwägungsdirektiven nicht sehr eingeschränkt wird. Für das Thema dieses Berichts bedeutet dies, daß sich das französische Verhältnis der Exekutive zu Legislative oder Judikative über den Begriff des Handlungsspielraums innerhalb weit gezogener rechtlicher Rahmenregelungen erheblich besser begreifen und erfassen läßt.

\section{Grundlagen der gerichtlichen Kontrolle}

Da sich das französische Verwaltungsrecht vor allem über das Richterrecht und das streitige Gerichtsverfahren entwickelt hat, erfährt es eine im Vergleich zum deutschen Recht sehr prozessuale Prägung: Das Verwaltungsrecht richtet sich an den möglichen Verwaltungsfehlern, den Klagegründen (cas d'ouverture) sowie den einschlägigen prozessualen Klagearten aus ${ }^{33}$. Schon hieraus ergibt sich, daß im Mittelpunkt weniger die Vorgaben für das materielle Verwaltungshandeln (als materielle Abwägungsdirektiven) stehen, sondern vielmehr die (vom Prozeßrecht formulierte) Frage, wann die Verwaltung den ihr gesetzten äußeren rechtlichen Rahmen etwa aufgrund von Form- und Verfahrensfehlern (vice de forme) oder Gesetzesverletzungen (violation de la lot) überschritten hat ${ }^{34}$.

Das französische Recht unterscheidet drei Arten der gerichtlichen Verwaltungskontrolle: Normalkontrolle (contrốle normal, plein contrôle); Minimalkontrolle (contrôle minimum, contróle restreint); Maximalkontrolle (contróle maximum, théorie du bilan).

d'Etat, o.J., 10; i.d.S. vgl. generell Mestre Le Conseil d'Etat - Protecteur des Prérogatives de l'Adminstration, 1974; Favoreu Le Conseil d'Etat - Défenseur de l'Exécutif, in: Mélanges en hommage à Jean Boulois, 1991, 237 ff.; ferner Müller Der Conseil d'Etat, AöR 117 (1992) $338 \mathrm{ff}$., $354 \mathrm{ff}$.

33 Vgl. zum ganzen Schlette Die verwaltungsgerichtliche Kontrolle von Ermessensakten in Frankreich, 1991, 73 ff., 180 ff., 192; s.a. Woebrling Die deutsche und französische Verwaltungsgerichtsbarkeit an der Schwelle zum 21. Jahrhundert, NVwZ 1998, $462 \mathrm{ff}$.

${ }^{34} \mathrm{Vgl}$. statt vieler Varadinek Ermessen und gerichtliche Nachprüfbarkeit im französischen und deutschen Verwaltungsrecht und im Recht der Europäischen Gemeinschaft, 1993, 44 f.; zur Ermessensproblematik, die hier nicht vertieft werden kann, vgl. statt vieler Schroarze (Fn. 29) 248; Starck (Fn. 4) 15 ff.; Bleckmann Ermessensfehlerlehre, 1997, $97 \mathrm{ff} ., 171 \mathrm{ff}$; Gaudemet Pouvoir discrétionnaire de l'administration modeme, in: Bullinger Verwaltungsermessen im modernen Staat, 1986, $113 \mathrm{ff}$. 
Damit sind unterschiedliche Kontrolldichten vorgezeichnet, deren genaue Abgrenzung umstritten bleibt. Im Bereich der Normalkontrolle findet grundsätzlich eine volle Überprüfung der Verwaltungsentscheidung statt ${ }^{35}$. Dabei müssen jedoch zwei bedeutende Einschränkungen dieser "vollen Überprüfbarkeit" herausgestellt werden, die die Ähnlichkeiten zum deutschen Verwaltungs- und Verwaltungsprozeßrecht stark minimieren:

Im Bereich des materiellen Rechts üben die Gerichte eine gewisse Zurückhaltung und legen den Schwerpunkt ihrer Kontrolle auf die Einhaltung des formellen Rechts, also einschlägiger Anhörungs-, Beteiligungsund Verfahrensrechte. Zudem wird in den häufigen Fällen des Ermessens, das im französischen Recht auch unbestimmte Rechtsbegriffe umfaßt, nur die sogenannte Minimalkontrolle durchgefuihrt, bei der die Subsumtion des Sachverhalts unter den Tatbestand nur bei offensichtlichen Bewertungsfehlern der Verwaltung (erreurs manifestes d'appréciation des faits) ${ }^{36}$ gerichtlich zu beanstanden ist. Dasselbe gilt in einer Reihe hier nicht näher darstellbarer Ausnahmen. Dazu zählen etwa Verwaltungsentscheidungen, die technische Detailkenntnisse voraussetzen, v.a. im Bau- und Umweltrecht, bei Flächennutzungs- und Bebauungsplänen sowie der Baugenehmigung ${ }^{37}$. Ebenso zählen dazu Verwaltungsentscheidungen, bei denen der spezifisch politische Inhalt eine geringere gerichtliche Kontrolle erforderlich macht, etwa im Ausländer- und Ordnungsrecht ${ }^{38}$. Im einzelnen bleibt ein erheblicher Einschätzungsspielraum des Richters dahingehend, welcher Kontrollmaßstab zur Anwendung gelangt. Die Übergänge zwischen den verschiedenen Kontrollmaßstäben sind fließend ${ }^{39}$. Obgleich die Minimalkontrolle nur als Ausnahme zur Normalkontrolle konzipiert wurde, stellt sie in der gerichtlichen Praxis die häufigste Form der Kontrolle dar.

Vor allem bei der Minimalkontrolle wird der exekutive Gestaltungsspielraum einer nur den Rahmen absteckenden Verwaltungsbindung im Sinne einer Rahmensetzung deutlich. Im Rahmen der erreurs manifestes kann die Verwaltung frei handeln und bleibt in ihrer Ermessensausübung unkontrolliert ${ }^{40}$.

${ }^{35}$ Lerche Landesbericht Frankreich, in: Frowein (Hrsg.), Die Kontrolldichte bei der gerichtlichen Überprüfung von Handlungen der Verwaltung, 1993, $1 \mathrm{ff} ., 11$; Varadinek (Fn. 34) 50; Peiser Contentieux administratifs, 9. Aufl., 1995, 149ff.; Debbasch/Ricci Contentieux administratif, 5. Aufl., 1990, 586 ff.

${ }^{36}$ Lerche (Fn. 35) 9; Varadinek (Fn. 34) 70; Schlette (Fn. 33) 270.

${ }^{37}$ Schlette (Fn. 33) $253 \mathrm{ff}$; $256 \mathrm{f}$., 271.

${ }^{38}$ Lerche (Fn. 35) 11; Schlette (Fn. 33) 257 ff.; aber auch im Wirtschaftsverwaltungsrecht, Beamtenrecht und im Prüfungsrecht, vgl. dazu ausführl. Varadinek (Fn. 34) 55.

39 Grabenwarter Verfahrensgarantien in der Verwaltungsgerichtsbarkeit, 1997, 179.

40 Lerche (Fn. 35) 9, 11. 
Die dem deutschen Recht ähnlichste Kontrolle bildet die Maximalkontrolle (contróle maximum). Im Rahmen einer sogenannten Bilanzierung (theorie du bilan) wägt der Conseil d'Etat den Nutzen eines geplanten Vorhabens für die Allgemeinheit gegen die damit verbundenen Nachteile für unmittelbar Betroffene und die Allgemeinheit sorgfältig ab. Elemente des Verhältnismäßigkeitsgrundsatzes (principe de proportionnalite) können daneben als Gesichtspunkte im Rahmen einer Argumentation mit dem allgemeinen Gerechtigkeitsprinzip berücksichtigt werden ${ }^{41}$. Voraussetzung für die Maximalkontrolle ist, daß Grundrechte (libertés publiques) besonders betroffen sind. Die Anwendung der théorie du bilan, ursprünglich zum Schutz gegen Grundrechtseingriffe der Gemeindepolizei entwickelt, wurde in den letzten Jahren von der Verwaltungsgerichtsbarkeit vor allem bei Enteignungen kontinuierlich ausgedehnt ${ }^{42}$. In der Literatur werden regelmäßig die folgenden Fallgruppen als Kandidaten für eine Maximalkontrolle genannt:

- Maßnahmen des Polizei- und Versammlungsrechts ${ }^{43}$,

- Enteignungen/Eigentumsbeschränkungen zugunsten öffentlicher Bauvorhaben,

- Verwaltungsentscheidungen, die bewußt von einem Bebauungsplan abweichen ${ }^{44}$,

- das Disziplinarrecht der Beamten ${ }^{45}$ und

- die Entlassung geschützter Arbeitnehmer ${ }^{46}$.

Beispielhaft möchte ich drei Entscheidungen herausgreifen, die verdeutlichen, unter welchen Voraussetzungen der Conseil d'Etat anstelle seiner regelmäßigen Rahmen- oder Minimalkontrolle die von der Verwaltung vorgenommene Abwägung einer intensiven rechtlichen Prüfung unterzicht:

41 Schroarze (Fn. 29) 666f.; Varadinek (Fn. 34) 85; Schlette (Fn. 33) 300 ff.; zur theorie du bilan coûts-avantages s. a. Scbrwarze Grundlinien und neuere Entwicklungen des Verwaltungsrechtsschutzes in Frankreich und Deutschland, NVwZ 1996, $22 \mathrm{ff.}, 25$.

42 Lerche (Fn. 35) 13; Grabenwarter (Fn. 39) 183; Varadinek (Fn. 34) 77; maximaler gerichtlicher Kontrolle unterliegt hier die für eine Enteignung erforderliche Gemeinnützigkeitserklärung (déclaration d'utilité publique), st.Rspr. seit C.E. 28. 5. 1971, Ville NouvelleEst, Rec. 409.

${ }^{43}$ St.Rspr. seit C.E. 19. 5. 1933, Benjamin, Rec. 541; Lerche (Fn. 35) 18.

${ }_{41}$ C.E. 18. 7. 1973, Ville de Limoges, Rec. 530; Lerche (Fn. 35) $14 \mathrm{f}$.

45 Grabenroarter (Fn. 39) 183.

${ }^{46}$ C.E. 5. 5. 1976, S.A.F.E.R. d'Auvergene c/Bemette, Droit social 1976, 345; alle Beispiele bei Long/Weil/Braibant Les grands arrêts de la jurisprudence administrative, 10. Aufl., 1993, 659. 
In der Rechtssache Benjamin (1933) ${ }^{47}$ hatte der Bürgermeister von Nevers eine geplante öffentliche Vortragsveranstaltung wegen befürchteter gewalttätiger Ausschreitungen untersagt. Der Conseil d'Etat hielt die Verbotsverfügung für rechtswidrig, weil die öffentliche Ordnung (ordre public) auch mit milderen Mitteln als mit einem Veranstaltungsverbot hätte aufrechterhalten werden können. Mit dieser Entscheidung erkannte der Conseil d'Etat den Grundsatz der Verhältnismäßigkeit bei libertés publiques an.

Die zweite und für das französische Planungs- bzw. Enteignungsrecht noch immer grundlegende Entscheidung, ist die Rechtssache Ville nouvelle Est (1971) ${ }^{48}$. In einem Vorort von Lille sollten eine neue Universitätsstadt entstehen und bestehende Siedlungen dafür abgerissen werden. Der Conseil d'Etat überprüfte die Gemeinnützigkeitserklärung der vorgesehenen Enteignungen (déclaration d'utilité publique). Nach der Bilanztheorie sprach sich der Conseil d'Etat nach Abwägung aller Vor- und Nachteile für das neue Universitätsprojekt aus, so daß die Klage letztlich abgewiesen wurde. In die Abwägung der Vor- und Nachteile des Projekts wurden Eingriffe in das Privateigentum, finanzielle Aufwendungen des Staates und die „sozialen Kosten “ wie beispielsweise Umweltverschmutzung und Eingriffe in das natürliche und kulturelle Erbe des Landes eingestellt. Obwohl eine Abwägung vorgenommen wurde, kam den Grundrechtsargumenten ein höherer Rang im Sinne eines Optimierungsgebotes letztlich nicht zu. Die Klage der Betroffenen wurde abgewiesen.

Ein Jahr später hatte der Conseil d'Etat in der Rechtssache Societté civile Sainte-Marie de l'Assomption, (1972)49 Gelegenheit, seine Rechtsprechung fortzuentwickeln. In dem Fall ging es um den Bau einer Umgehungsstraße in Nizza. Ein Anschlußstück sollte über das Grundstück einer psychiatrischen Klinik führen, die dadurch aller ihrer Grünflächen beraubt worden wäre. Der Conseil D'Etat räumte den Belangen der Klinik letztlich Vorrang ein. Im Unterschied zu Ville nouvelle Est war hier nicht ein öffentliches Interesse gegen ein Privatinteresse abzuwägen, vielmehr war zwischen zwei öffentlichen Belangen zu entscheiden, nämlich den Interessen des Gesundheitswesens und denen der Verkehrsplanung und Förderung der Infrastruktur (santé publique / circulation). In der französischen Literatur stießen diese und weitere vergleichbare Entscheidungen ${ }^{50}$

47 C.E. 19. 5. 1933, vgl. Scbwarze (Fn. 29) 664; Long/Weil/Braibant (Fn. 46) 214 ff.; Scblette (Fn. 33) $219 \mathrm{f}$.

${ }^{48}$ C.E. 28. 5. 1971, D. 1972, 194; Varadinek (Fn. 34) 78f.; Long/Weil/Braibant (Fn. 46) $648 \mathrm{ff}$.

49 C.E. 20. 10. 1972, Rec. 657; Long/Weil/Braibant (Fn. 46) 655; Varadinek (Fn. 34) 79.

${ }^{50}$ Grassin, C.E. 26. 10. 1973, Rec. 598; Varadinek (Fn. 34) 79f.; Schroarze (Fn. 29) 666; 
auf Kritik, weil es nicht Aufgabe des Gerichts sondern der Verwaltung sei, zwischen zwei jeweils schützenswerten öffentlichen Belangen eine Hierarchie aufzustellen.

Im Vergleich mit dem deutschen Recht finden sich bei der Maximalkontrolle starke Ähnlichkeiten hinsichtlich der allgemeinen Kontrolldichte und auch der allgemeinen Abwägungsgebote: öffentliche und private Belange werden eingehend gerichtlich geprüft. Gleichwohl gibt es nur wenige konkrete Entscheidungen, die mit Hilfe der théorie du bilan durch die Gerichte aufgehoben worden sind ${ }^{51}$. Dabei ist die Tendenz festzustellen, daß die erfolgreichen Anwendungsfälle für diese Theorie allenfalls Verwaltungsentscheidungen mit lokalem Bezug waren, nicht jedoch solche von regionaler oder gar nationaler Bedeutung 52 . Überhaupt soll die théorie $d u$ bilan weniger eine echte materiellrechtliche Kontrolle durch die Rechtsprechung als vielmehr überhaupt die Vornahme einer Abwägung im Vorfeld der zu treffenden Verwaltungsentscheidung sicherstellen ${ }^{53}$. Zwar werden Verwaltungsentscheidungen im Rahmen der Maximalkontrolle uneingeschränkt nachvollzogen, de facto aber nur höchst selten aufgehoben.

Legt man nun an diese dogmatischen Unterscheidungen des französischen Rechts die Elle der Optimierungsgebote oder Rahmensetzungen an, könnte man behaupten, daß die Minimalkontrolle einer Rahmensetzung ähnelt, die Maximalkontrolle hingegen schlichten Abwägungsgeboten - und damit Optimierungsgeboten im weitesten Sinne - nahekommt $^{54}$. Dabei stellt die Minimalkontrolle (also eine gerichtliche

Ville de Limoges, C.E. 18. 7. 1973, Rec. 530; Schlette (Fn. 33) 312. Mit dem Gesetz Nr. 76-1285 v. 31. 12. 1976 wurde die Dispenserteilung legislativ allerdings erheblich eingeschränkt, so daß die Ville de Limoges-Rspr. weitgehend zum Erliegen kam; so Scblette (Fn. 33) 313 m.w.N.

${ }^{51}$ Helin Le contrôle juridictionnel des décisions administratives dans les domaines de l'économie, de la planification et de l'énergie nucléaire en France, in: Schroarze/SchmidtAßmann Das Ausmaß der gerichtlichen Kontrolle im Wirtschaftsverwaltungs- und Umweltrecht, 1992, $63 \mathrm{ff}, 86$.

${ }^{52}$ Long/Weil/Braibant (Fn. 46) 658.

${ }^{53}$ Helin (Fn. 51) 105.

${ }^{34}$ Ein Blick in die neueren französischen Gesetze zeigt, daß lediglich klassische Abwägungs- oder Berücksichtigungsgebote normiert werden. Dabei wird aber keine optimale Geltung der Belange gefordert, sondern nur eine Berücksichtigung, bzw. Einstellung in den Abwägungsvorgang. Typische Formulierungen des Gesetzgebers sind dafür ,prendre en compte ", „enir compte ${ }^{\alpha}$, pprendre en considération ${ }^{\alpha}$, vgl. etwa Art. L 110, L 122-1, L 122-1-1; 123-1, Code de l'urbanisme. Deutsche Optimierungsgebote i.e.S. sind dagegen durch Formulierungen wie „im notwendigen Umfang", „besonders Rechnung tragen“, „soweit wie möglich vermeiden“, etc. gekennzeichnet. Ein Optimierungsgebot könnte lediglich in der Formulierung des Art. L 200-1 Code rural, s. 59, 60 im Code de l'Environnement, 
Rahmenkontrolle) den Regelfall dar. Die Bedeutung von Optimierungsgeboten und Rahmensetzungen im französischen Recht erschließt sich in der Untersuchung der Rechtsprechung in jedem Einzelfall. Die Bestimmung der Kontrollstufe (contrôle minimum - normal - maximum) für den jeweiligen Fall wird nicht von der Gesetzgebung vorgegeben, sondern von den Gerichten weitgehend autonom festgelegt. Es ist somit schwerpunktmäßig die Rechtsprechung, die nach französischer Tradition entscheidet, welchen rechtlichen Bindungen die Verwaltung unterliegt.

\section{Die Bindung der Verwaltung an legislative Abrwägungsdirektiven}

In einzelnen Rechtsgebieten bestehen allerdings Ausnahmen, bei denen Abwägungsdirektiven in Gesetzen und Dekreten nachweisbar sind ${ }^{55}$. So wird etwa im Umweltrecht der Gedanke des Umweltschutzes zum Gegenstand des „öffentlichen Interesses“ (d'intérêt général) erhoben und kommt somit auch in anderen Rechtsgebieten als zusätzlicher Abwägungsgesichtspunkt zum Zuge:

"La protection des espaces naturels et des paysages, la préservation des espèces animales et végétales, le maintien des équilibres biologiques auxquels ils participent et la protection des ressources naturelles contre toutes les causes de dégradation qui les menacent sont d'intérêt général ${ }^{56}$. Dies trifft etwa auf die Anwendung des Gesetzes über die Bewahrung historischer Bauwerke, auf das Landschaftsschutzgesetz und auf das Architekturgesetz $\mathrm{zu}^{57}$.

Im französischen Verwaltungsverfahren steht das Kernanliegen der Erhaltung der Funktionsfähigkeit der Verwaltung an vorderster Stelle. Demgegenüber tritt der materielle Schutz des Einzelnen, so wie wir ihn in Deutschland gewohnt sind, stark zurück. In der Praxis führt dies dazu, $\mathrm{da} ß$ das französische Verwaltungsverfahrensrecht $z$ war bezüglich der $\mathrm{Be}$ teiligung möglicher Interessenten sehr großzügig verfährt, aber nur selten materiellen gerichtlichen Schutz gegen die Verwaltungsmaßnahmen bereitstellt ${ }^{58}$. Anstelle von Optimierungsgeboten und Abwägungsdirektiven zur materiellen Kontrolle planerischer Verwaltungsentscheidungen verla-

Loi no. 76-629, v. 10. 7. 1976 gesehen werden. Obgleich der Wortlaut dies nahezulegen scheint, entspricht dies jedoch nicht den deutschen Optimierungsgeboten, da es gerade an der für deutsche Optimierungsgebote charakteristischen vollen gerichtlichen Kontrolle fehlt; vgl. Fn. 2, 3 zu Art. L 200-1 Code rural; s. a. Auby/Périnet-Marquet Droit de l'urbanisme et de la construction, 5. Aufl., 1998, 20ff., 59 ff.; Morand-Deviller Droit de l'urbanisme, 4. Aufl., 1998, $38 \mathrm{ff}$., $47 \mathrm{ff}$., $57 \mathrm{ff}$.

${ }^{55}$ Grabenwarter (Fn. 39) 182.

${ }^{56}$ Art. 1 des Gesetzes Nr. 76-629 v. 10. 7. 1976.

${ }^{57}$ Lerche (Fn. 35) 20.

58 Woebrling Umweltschutz und Umweltrecht in Frankreich, DVB1. 1992, 887. 
gert der Gesetzgeber formelle präventive Verfahrensgarantien in das Vorfeld der Entscheidung. Hat die Verwaltung eine formell korrekte KostenNutzen-Analyse durchgeführt, wird die materielle Planungsentscheidung nur sehr selten aufgehoben. Der Richter beschränkt seine Kontrolle in diesen Fällen auf die Existenz und Vollständigkeit des vorbereiteten Verwaltungsverfahrens ${ }^{59}$.

Das wichtigste Verfahren im Umwelt- und Planungsrecht ist die „öffentliche Untersuchung " (enquête publique), vergleichbar in etwa dem deutschen Planfeststellungsverfahren ${ }^{60}$. Bei der allerdings nur seltenen öffentlichen Anhörung, vor der jedermann die relevanten Akten einsehen kann und auch schriftliche oder mündliche Einwendungen erhoben werden dürfen, verfaßt ein unabhängiger, vom Präsidenten des Verwaltungsgerichtes eingesetzter commissaire enquêteur am Ende der Anhörung einen Bericht und einen Entscheidungsvorschlag. Im Verfahren braucht zwar keine persönliche Betroffenheit nachgewiesen zu werden, doch zielt das französische Verwaltungsverfahren darauf ab, die zweckmäßigste Entscheidung zu treffen, nicht primär die betroffenen Bürger zu schützen.

Bei technischen Großprojekten ${ }^{61}$ muß eine enquête publique durchgeführt werden, bei der für die Planungsphase mindestens folgende Analyseschritte einzuhalten sind:

(1) eine Bau- und Instandhaltungskostenanalyse,

(2) eine finanzielle Rentabilitätsberechnung,

(3) eine Begründung, weshalb das Projekt in Angriff genommen wurde, sowie schließlich

(4) eine Analyse der Projektvereinbarkeit mit den anwendbaren Flächennutzungsplänen.

Bei Kernkraftwerken und anderen besonders klassifizierten Anlagen kommt darüber hinaus den Verfahrensgarantien der Umweltverträglichkeitsprüfungen große Bedeutung zu ${ }^{62}$. Die UVP muß danach mindestens die Untersuchung des Ursprungszustandes, sodann die Einwirkung auf

${ }^{59}$ Helin (Fn. 51) 87; s. a. Fromont Le pouvoir discrétionnaire et le juge adminstratif français, in: FS Hermann Jahrreiß, 1974, $67 \mathrm{ff}$.

${ }^{60}$ Zum ganzen Halin et al. Les nouvelles procédures des enquêtes publiques, 1986; Braibant/Stim (Fn. 28) 441; Woebrling (Fn. 58) 887, m.w.Hinw.

61 Woebrling (Fn. 58) 887.

62 Woebrling (Fn. 58) 887; Ladeur Die Umsetzung der EG-RL zur Umweltverträglichkeitsprüfung in nationales Recht und ihre Koordination mit dem allgemeinen Verwaltungsrecht - Das Beispiel Frankreichs und Deutschlands, UPR 1996, $419 \mathrm{ff}$; Lerche (Fn. 35) $21 \mathrm{ff}$. 
die Umwelt enthalten, ferner die Gründe, weshalb das konkrete Vorhaben geplant und wie die Wahl zwischen verschiedenen Varianten durchgeführt worden ist. Auch ist zu Maßnahmen Stellung zu beziehen, durch welche schädliche Auswirkungen auf die Umwelt abgemildert werden. Wiederum kann jedermann diese Unterlagen einsehen und bei der öffentlichen Anhörung kommentieren. Wesentliche Verfahrensfehler bei der UVP (vice de forme) führen zur gerichtlichen Aufhebung des Genehmigungsbescheids ${ }^{63}$. Von der UVP wird inhaltlich verlangt, daß sie vollständig und seriös ist, gleichwohl unterliegt sie inhaltlich lediglich dem Maßstab der Minimalkontrolle. Bei der Durchführung der UVP und der Gestaltung des Verwaltungsverfahrens für klassifizierte Anlagen, etwa Kernkraftwerken, bedient sich der zuständige Minister behördeneigener Inspektoren, die in einem Anhörungsverfahren die Entscheidung des Präfekten oder des zuständigen Ministers vorbereiten. Die Inspektoren haben aber nur die Aufgabe, Fakten zu ermitteln und die behördliche Entscheidung vorzubereiten. Die eigentliche Abwägung etwa sozialer, wirtschaftlicher, finanzieller und politischer Interessen gegenüber Umweltbelangen trifft der Präfekt ${ }^{64}$.

Zusammenfassend kann festgehalten werden, daß in der neueren Gesetzgebung Frankreichs eine verstärkte Verfahrensbeteiligung vorgesehen ist. Die gerichtliche Kontrolle beschränkt sich aber nur auf den Nachweis der Vollständigkeit des vorbereitenden Verwaltungsverfahrens ${ }^{65}$. Der Gesetzgeber legt der Verwaltung nur wenige materielle Beschränkungen auf, und die Gerichte legen ihrerseits den Schwerpunkt der Kontrolle auf die Einhaltung formeller Verfahrensschritte. Nur bei eindeutigen Abwägungsfehlern (erreurs manifestes) in besonders grundrechtssensiblen Bereichen greift eine Evidenzkontrolle am Maßstab der Verhältnismäßigkeit ${ }^{66}$.

\section{Optimierungsgebote und Rahmensetzungen im englischen Recht}

Wenden wir uns nun dem englischen Recht $\mathrm{zu}$. Wie eingangs betont, wird dort keine Optimierungsdebatte geführt. Wenn überhaupt, lassen sich verschiedene Versionen der Rahmensetzung im Verhältnis der Legislative zur Exekutive und speziell zur Kommunalverwaltung ausmachen. Daneben wird eine lebhafte Debatte zur prozeduralen Selbstbindung des

\footnotetext{
${ }^{63}$ Ladeur (Fn. 62) 423; Lerche (Fn. 35) 21.

64 Woehrling (Fn. 58) 891.

${ }^{65}$ Helin (Fn. 51) 87.

66 Von Danwitz (Fn. 32) 940; Lagasse L'erreur manifeste d'appréciation, 1986, 192ff., $450 \mathrm{ff}$.
} 
Parlaments im Bauplanungsrecht geführt. Die Gerichte haben zwar in den letzten Jahrzehnten die Kontrolle der Verwaltung durch eine reiche, zunehmend spezialisierte Judikatur verfeinert, doch beschränkt sich die Kontrolle im wesentlichen auf formelle Verfahrensverstöße. Erst in allerjüngster Zeit sind hier wie in Frankreich unter dem Einfluß des Europarechts und der Europäischen Menschenrechtskonvention Anzeichen für eine beschränkte materiellrechtliche Überprüfung des Verwaltungshandelns zu erkennen.

\section{Stellung der Judikative im englischen Recht}

Zwei grundlegende Verfassungsprinzipien prägen die britische Rechtslage des Verhältnisses von Parlament und Judikative bis zum heutigen Tage: die Souveränität des Parlaments und die Rule of Law67. Zwar hatte das Parlament in der Glorious Revolution 1688/89 im Verbund mit der Common Law-Richterschaft die Willkürherrschaft der Stuarts beseitigt, gesiegt hatte letztlich aber nur das Parlament. Anders als später in Frankreich und in den USA konnte die Richterschaft in England nicht die gleiche Stellung im Gewaltenverschränkungsmodell für sich beanspruchen wie das Parlament68. Hatten sich die Richter zu Beginn des 17. Jahrhunderts unter Lord Chief Justice Coke noch selbstbewußt als Löwen unter dem Thron ,lions under the throne ${ }^{\star}$ bezeichnet, um damit ihre Unabhängigkeit und Wächterfunktion im Falle von Machtmißbrauch durch den Monarchen zu charakterisieren, verloren sie diese privilegierte Stellung im 18. Jahrhundert zunehmend. Überspitzt formuliert läßt sich sagen: an die Stelle des mit absoluter Macht ausgestatteten Königs trat seither die absolute Macht des Parlaments, begrenzt nur durch den ygood sense of the British people und durch die Annahme, daß kein Parlament willkürliche Gesetze erlassen würde ${ }^{69}$. Die folgenden 300 Jahre Verfassungspraxis haben diese optimistische Behauptung weitgehend bestätigt. Statt eines zu erwartenden Machtkampfes zwischen der ersten und dritten Staatsgewalt gab es im Vereinigten Königreich eine Kombination von nachdrücklich geforderter und auch in Anspruch genommener Parlamentssouveränität und richterlicher Selbstbeschränkung, deren Berechtigung und genauer Umfang bis zum heutigen Tage nicht ausdiskutiert ist ${ }^{70}$. Das Verhältnis

\footnotetext{
67 Riedel Kontrolle der Verwaltung im englischen Rechtssystem, 1976, 231 ff., $252 \mathrm{ff}$.

68 Riedel (Fn. 67) $204 \mathrm{ff}$.

69 Riedel (Fn. 67) 196ff., insbes. $204 \mathrm{f}$.

${ }^{70}$ Statt vieler Taswell-Langmead English Constitutional History from the Teutonic Conquest to the Present Time, 11. Aufl., 1960, $418 \mathrm{ff}$., 465 f., $538 \mathrm{ff}$.; s. a. Wade Einfuihrung zu
} 
von Legislative und Judikative wird seit 1689 von einer eindeutigen Suprematie des Parlaments geprägt, die diesem für alle wesentlichen Fragen der Nation das Recht des ersten Zugriffs und der Letztentscheidung vorbehält. Den verbleibenden Spielraum innerhalb dieser Grundorientierung haben die Gerichte in der Folgezeit mit Hilfe der rule of law jedoch sehr kreativ zu nutzen gewußt $\mathrm{t}^{71}$.

Neben der Parlamentssouveränität kommt nämlich der rule of law, der Herrschaft des Rechts, ganz wesentliche Bedeutung zu. Die rule of law verlangt zunächst, daß sich jedes exekutive Handeln - von wenigen Ausnahmen der verbliebenen Prärogativrechte der Krone abgesehen - durch Gesetz legitimieren lassen muß, oder, wie Herr Starck dies zutreffend formuliert hat, „alles staatliche Handeln nur im Rahmen der Souveränität des Parlaments erlaubt ist ${ }^{{ }^{*} 72}$. Strikte gesetzliche Grundlagen werden nach der rule of law für alle Verwaltungsmaßnahmen verlangt, die Rechte, Pflichten oder Freiheiten von Personen betreffen (principle of legality) ${ }^{73}$. Die rule of law bildet somit den Gegenpol zur Parlamentssouveränität, wird aber im britischen Schriftum zunehmend sogar als integrierter Bestandteil dieser Souveränität begriffen ${ }^{74}$. Da eine gerichtliche Prüfung der Gesetze in England nach herrschender Auffassung nicht stattfindet - zu den Einflüssen des EG-Rechts komme ich später -, wirkt die rule of law nicht für die Gesetzgebung, sondern als Maßstab für die Verwaltung, aber auch für alle nachgeordneten Gesetze, statutory instruments und bye-laws. In diesen Bereichen entfaltet die Richterschaft wesentliche Kontrollfunktionen, auf die sich nicht zuletzt ihr großes Ansehen in der Bevölkerung stützt. $\mathrm{Da}$ Parlamentsgesetze der Verwaltung vielfach weite Beurteilungsund Ermessensspielräume zubilligen, kommt der Judikative bei der Kontrolle administrativer Maßnahmen im Rahmen der rule of law eine gewichtige Rolle zu. Wade bezeichnet es deshalb als vornehmste Aufgabe der am Common Law geschulten Richterschaft, zwischen den Zeilen der Gesetze zu lesen und allgemeine Prinzipien zu entwickeln, for keeping executive power within proper guidelines, both as to substance and as to procedure ${ }^{\infty 75}$. Wie wir sehen werden, ist eine materiellrechtliche "substance ${ }^{\alpha}$ Kontrolle aber nur in sehr engen Grenzen möglich.

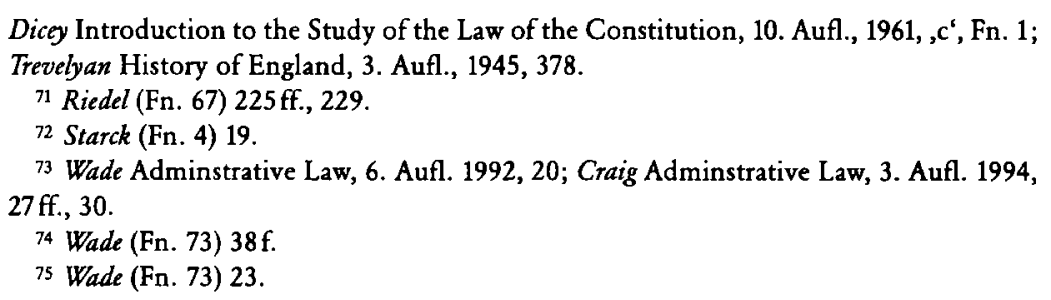


Generell läßt sich sagen, daß die richterliche Kontrolldichte - wie in Frankreich - in dem Maße zunimmt, je weiter von der Zentralregierung entfernt, je nachgeordneter die angegriffene Verwaltungshandlung ist. Die Bereitschaft der Richterschaft zur Legalitätskontrolle wird auch um so größer, je mehr es um die Kontrolle der delegated legislation, der den Parlamentsgesetzen nachgeordneten Rechtsvorschriften und der darauf gestützten Verwaltungsentscheidungen geht. Hintergrund für diesen Befund ist, daß die Bevölkerung der Exekutive und Administration in England grundsätzlich größeres Vertrauen entgegenbringt, als dies in Deutschland der Fall ist. Die als selbstverständlich empfundene Konzeption der Regierung als Treuhand im Sinne John Lockes, des government as trust $^{76}$, markiert nur das Unverständnis gegenüber dem kontinentaleuropäischen Credo „Vertrauen ist gut, Kontrolle ist besser". Daraus abgeleitet wird die treuhänderische Verwaltung auch wie selbstverständlich mit größtmöglicher discretion, Ermessensfreiheit, ausgestattet, begrenzt nur durch die Parlamentsgesetze, Grundprinzipien der rule of law, parlamentarische Verantwortlichkeit des zuständigen Ministers (ministerial responsibility) ${ }^{\pi}$ und eine stets wachsame Öffentlichkeit. Hieraus wird deutlich, weshalb Ermessen in Großbritannien eine wesentlich größere Rolle als etwa in Deutschland einnimmt und weshalb die Richterschaft bei der Ermessenskontrolle wesentlich größere Zurückhaltung an den Tag legt.

\section{Grundlagen der gerichtlichen Kontrolle}

\section{Ermessen}

Ermessen (discretion) als solches wird im englischen Recht nicht gesetzlich definiert. Ausdrücklich Bezug genommen wird auf discretion auch nur in wenigen Vorschriften ${ }^{78}$. Seine nähere Ausgestaltung findet es im richterrechtlich entwickelten common law. Die Literatur bescheidet sich mit knappsten Definitionen. Typisch ist hierfür die Äußerung von DeSmith/Brazier: „Eine Ermessensermächtigung setzt Wahlfreiheit voraus. Die zuständige Behörde kann selbst entscheiden, ob sie handeln will oder nicht, und wenn ja, wie (...). Ermessen impliziert die Befugnis (power), zwischen alternativen Verhaltens- und Vorgehensweisen zu wäh-

${ }^{6}$ Riedel Die Eigentumsgarantie als Problem der allgemeinen Staatslehre und des Verfassungsrechts am Beispiel Großbritanniens, in: Scbroartländer/Willoweit Das Recht des Menschen auf Eigentum, 1983, $129 \mathrm{ff}$.

$n$ Riedel (Fn. 67) Kap. 16, 252 ff.

${ }_{78}$ Zum folgenden Brinktrine Verwaltungsermessen in Deutschland und England, 1998, $181 \mathrm{ff}$. 


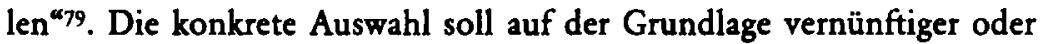
plausibler Erwägungen erfolgen. Eine allein richtige Entscheidung soll es aber objektiv nicht geben können; also Plausibilitäts-, nicht Wahrheitsoder Richtigkeitsanspruch. Dem Entscheider wird damit in engen, meist formalen Grenzen des Rechts die Kompetenz zur letztverbindlichen Festlegung bescheinigt.

Anders als im deutschen Recht - aber wie in Frankreich - erstreckt sich Ermessen auf eine umfassende Abwägung aller entscheidungsrelevanten Gesichtspunkte. Es erfaßt mithin sämtliche Tatsachenfeststellungen, Interpretationsspielräume sowie Subsumtionsprozesse, vereinigt folglich aus deutscher Sichtweise unbestimmte Rechtsbegriffe und Beurteilungsspielräume auf der Tatbestandsseite wie auch die gesamte Ermessensproblematik auf der Rechtsfolgenseite ${ }^{80}$. Zur Lenkung und Steuerung der Ausübung von discretion begrüßen es weite Teile der Literatur, wenn der Gesetzgeber oder die Verwaltung den Gebrauch von Ermessensbefugnissen durch möglichst umfassende und genaue Entscheidungsvorgaben vorstrukturieren ${ }^{81}$. Die Ausübung dieser discretionary power wird zumeist im ermächtigenden Gesetz vorgezeichnet. Die Norm kann sowohl Ziele als auch Zwecke als Orientierungswerte - nicht jedoch Optimierungswerte! -

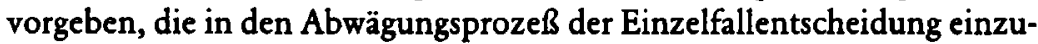
stellen oder nicht einzustellen sind ${ }^{82}$. Daneben gibt es verschiedene Möglichkeiten, unterhalb von $\mathrm{Zwangsmaßnahmen} \mathrm{(coercive} \mathrm{measures)}{ }^{83}$ auf das Entscheidungsverhalten nachgeordneter Behörden, vor allem Kommunalverwaltungen, Einfluß zu nehmen. Als Selbstbindung der Verwaltung durch übergeordnete Behörden reicht die Palette solcher Einflußnahme von extensiven schriftlichen Gesetzeserläuterungen und Entscheidungsanleitungen (guidance, circulars oder codes of practice) ${ }^{84}$ über konkrete, einzelfallbezogene Empfehlungen (recommendations) bis hin zu informalen Techniken wie Besprechungen und Diskussionen. Diese Entscheidungsgrundlagen unterliegen keiner gerichtlichen Kontrolle. Daneben gibt es

\footnotetext{
79 De Smith/Brazier Constitutional and Administrative Law, 7. Aufl., 1994, 83f., 617; Craig (Fn. 72) 272.

${ }^{80}$ Brinktrine (Fn. 78) 191; Beatson/Mattheres Administrative Law, Cases and Materials, 1989, 73; Peiris Jurisdictional Review and Judicial Policy: The Evolving Mosaic, Law Quarterly Review 103 (1987) 66 ff., $100 \mathrm{f}$.

al Vgl. Cane An Introduction to Administrative Law, 2. Aufl., 1992, 133; Craig (Fn. 73) 397.

${ }^{82}$ Brinktrine (Fn. 78) $321 \mathrm{ff.}, 327$.

${ }^{83} \mathrm{Zu}$ solchen stärkeren Einflußmaßnahmen vgl. Bailey Cross on Principles of Local Government Law, 1992, 272.

84 Turpin British Government and the Constitution, 3. Aufl., 1995, 350.
} 
eine Fülle von verwaltungsinternen Ermessenssteuerungen durch policies und administrative rules, mit denen die Ressortpolitik der Verwaltung gelenkt oder der Erlaß ermessensgelenkter Richtlinien gesteuert wird ${ }^{85}$. Sie bedürfen keiner gesetzlichen Grundlage, unterliegen jedoch beschränkter Rechtskontrolle durch die Gerichte. Vor allem müssen sie intra vires ergehen, d.h. sich im Rahmen der geschriebenen oder ungeschriebenen Handlungsermächtigungen der Verwaltung halten ${ }^{86}$.

\section{Ultra vires-Kontrolle}

Die zentrale Kategorie der Legalitätskontrolle der Rechtsprechung bildet dabei die ultra vires-Lehre. Dahinter steht die Frage, wie weit das Ermessen der Verwaltungsbehörden bei der Ausübung ihrer Entscheidungsbefugnisse letztlich reicht ${ }^{87}$. Die klassische Formulierung der ultra vires-Prinzipien von Lord Greene findet sich im Wednesbury-Fall aus dem Jahre $1948^{88}$ und markiert die Grenze, bis zu der Gerichte in ihrer Kontrollfunktion bei öffentlich-rechtlichen Streitigkeiten zu gehen bereit sind. In dem Fall ging es darum, ob die Stadtverwaltung der Stadt Wednesbury eine Filmauffuhrerlizenz mit der Auflage verbinden durfte, Kindern unter 15 Jahren weder mit noch ohne Begleitung Erwachsener $\mathrm{Zu}$ gang zu Filmveranstaltungen zu gestatten. Das Gericht sah hierin keinen Ermessensfehlgebrauch. Wie Lord Irvine of Lairg jüngst ausführte, sind es vier Grundprinzipien, die die Kontrolldichte der Entscheidungen durch die Gerichte letztlich bestimmen:

(1) Das Gericht darf sich nicht als Berufungsinstanz über die Verwaltungsentscheidung begreifen;

(2) es darf seine Meinung nicht an die Stelle der Verwaltungsentscheidung setzen;

(3) es befindet nur über die Rechtmäßigkeit einer Entscheidung, nicht darüber, ob sie inhaltlich richtig ist; und

(4) wird sich nur mit der Art der Entscheidungsfindung, nicht mit der

85 Vgl. hierzu ausführl. Baldwin/Houghton Circular Arguments: The Status and Legitimacy of Administrative Rules, Public Law 1986, $239 \mathrm{ff}$, $241 \mathrm{f}$.

${ }^{86}$ Brinktrine (Fn. 78) 331 f.; Craig (Fn. 73) 392; s. a. Galligan The Nature and Function of Policy within Discretionary Power, Public Law 1976, $332 \mathrm{ff} ., 336$.

87 Riedel (Fn. 67) Kap. 7, $88 \mathrm{ff}$.

${ }^{88}$ Associated Provincial Picture Houses Ltd. v. Wednesbury Corporation, 1947, 2 All ER 680, $683 \mathrm{ff}$, per Lord Greene, M.R. „The court is entitled to investigate the action of the local authority with a view to seeing wether it has taken into account matters which it ought not to take into account, or conversely, has refused to take into account or neglected to take into account matters which it ought to take into account ...". 
materiellen Begründetheit der Verwaltungsentscheidung befassen (substantive merits of the decision) ${ }^{89}$.

Es befaßt sich nur mit der Frage, ob die Behörde ultra vires, $d$.h. außerhalb der ihr eingeräumten Befugnisse entschieden hat. Der Behörde kommt deshalb zunächst ein breites Ermessen hinsichtlich aller Belange zu, die bei der Entscheidungsfindung zu berücksichtigen sind. Begrenzt wird dieses Ermessen allenfalls durch Gesetze, die ausdrücklich die Berücksichtigung oder Nichtberücksichtigung eines bestimmten Belangs vorschreiben. Sobald die Behörde zu berücksichtigende Belange festgelegt hat, unterliegt es ihrem freien Ermessen, welches Gewicht den einzelnen Belangen zukommt. Die Gerichte heben Entscheidungen der Verwaltung nur dann als unreasonable, als sachlich unangemessen auf, wenn ihre Unangemessenheit ein solches Ausmaß erreicht, daß kein vernünftiger Entscheidungsträger sie hätte fällen können („the decision will only be struck down as unreasonable where it is so unreasonable that no reasonable decision-maker could bave made it ${ }^{90}$, etwa die Entlassung einer Lehrerin nur wegen ihrer roten Haare" ${ }^{91}$ Die heutige Position der Richter hob Lord Templeman im Nottinghamshire-Fall (1986) hervor:

"Parliament [is] exercising the supremacy of power conferred on Parliament by the unwritten constitution of the United Kingdom, subject to quinquennial democratic control and to the daily force of public opinion ${ }^{92}$.

Die Kritik am Wednesbury-Test stützt sich im wesentlichen auf drei Entwicklungen aus neuester Zeit: erstens hat die Rechtsprechung die Konturen dieses Tests gleich in zwei Richtungen abzuändern versucht und damit abgeschwächt: einmal erweiternd ausgelegt, soweit sich Kläger auf Menschenrechtsverletzungen beriefen, zum anderen restriktiv interpre-

${ }^{89}$ Lord Irvine of Lairg Judges and Decision-Makers: The Theory and Practice of Wednesbury Review, Public Law 1996, 59 ff., 60.

${ }_{90}$ Lord Irvine of Lairg (Fn. 89) 62.

${ }^{91}$ Die darin liegende erhebliche richterliche Selbstbeschränkung ist weit weg von der Definition der Obersten Richter Coke in Bonbam's Case und Hobart in Day v. Savage zu Beginn des 17. Jahrhunderts, die noch mutig formulierten: , when an act of parliament is against common right and reason, or repugnant, or impossible to be performed, the common law will control it, and adjudge such act to be void ... " oder „even an act of parliament itself made against natural equity ... is void in itself, for iura naturae sunt immutabilia, and they are leges legum", zit. in Lord Irvine of Lairg (Fn. 89) 61 m.w.Hinw.

${ }_{92} R$. v. Secretary of State for Environment, ex parte Nottinghamshire County Council, 1986, I A.C. $240,265$. 
tiert, wenn es um Fragen der nationalen Sicherheit oder Wirtschaftspolitik ging; zweitens hat die Rechtsprechung in einer ganzen Serie von Entscheidungen die Klagegründe erweitert und prüft jetzt materiellrechtlich auch Verstöße gegen natural justice, natürliche Gerechtigkeit, zu der etwa rechtliches Gehör, faimess und Unvoreingenommenheit (impartiality), das Recht auf einen Rechtsbeistand, sowie das Verbot der Befangenheit (rule against bias), zählen ${ }^{93}$. Als drittes und schlagkräftigstes Argument wird von der Literatur der zunehmende Einfluß des Europarechts und der anderen Rechtsordnungen der EG sowie der EMRK vorgebracht ${ }^{94}$. Zwei typische Fälle zu Menschenrechtsfragen mögen dies verdeutlichen: Im Laker Airways-Fall (1977) ${ }^{95}$ hatte der zuständige Minister der zivilen Luftfahrtbehörde eine Verhaltensrichtlinie (guidance) auferlegt. In Anwendung dieser Ermessensbindung der Luftfahrtbehörde wurde Laker Airways zunächst eine Fluglizenz erteilt, die jedoch später nach einem Regierungswechsel widerrufen werden sollte. Der Court of Appeal hob die ministeriell angeleitete Entscheidung der CAA auf und begründete dies damit, daß dem Minister nach dem Luftverkehrsgesetz zwar erhebliches Ermessen in vier Fallkonstellationen zukomme, nämlich in Kriegszeiten, zur Wahrung nationaler Sicherheit, im Bereich der internationalen Beziehungen und zum Schutze der Umwelt. Ein darüber hinausgehendes allgemeines Recht des Widerrufs von Lizenzen könne aus dem Gesetz jedoch nicht hergeleitet werden. Der Minister habe folglich kompetenzwidrig, ultra vires, gehandelt. Auch sei gegen natural justice in Form der Verweigenung rechtlichen Gehörs verstoßen worden.

Betrachtet man die ultra vires-Rechtsprechung etwas näher, so stellt sich heraus, daß die Gerichte bei Verfahrensfehlern oder evidenten Formverstößen generell eher geneigt sind, Entscheidungen der Verwaltung aufzuheben. Anders liegt dies, wenn materiellrechtliche Probleme im Vordergrund stehen.

Im Falle Brind (1991) ${ }^{96}$ hatten sich Journalisten gegen eine Weisung des Innenministers gewandt, mit der dieser, gestützt auf eine Ermächtigung im Fernsehgesetz von 1981, die BBC anwies, Terrorismusverdächtigen keine Gelegenheit zum Auftritt in ihren Sendungen zu geben. Das House of Lords wies die dagegen gerichtete Klage mit der Begründung ab, daß keine „unreasonableness ${ }^{\star}$ im Sinne des Wednesbury-Tests vorliege. Es gäbe

${ }_{93}$ Zum ganzen Riedel (Fn. 67) Kap. 8, $106 \mathrm{ff}$.

${ }^{94}$ Jowell/Lester Beyond Wednesbury: Substantive Principles of Administrative Law, Public Law 1987, $368 \mathrm{ff}$.

95 Laker Airways Ltd. v. Department of Trade, 1977, Q.B. 643 (C.A.); vgl. auch Turpin (Fn. 84) $479 \mathrm{ff}$.

${ }^{96}$ R. v. Secretary for the Home Department, ex parte Brind, 1991, 1 A.C. 697. 
Abwägungsspielraum, den der Minister zulässigerweise genutzt habe. Das Argument des Klägers, das Gericht solle den Grundsatz der Verhältnismäßigkeit anwenden, da der Minister hier einen Vorschlaghammer zum Knacken einer kleinen Nuß gewählt habe, wurde von Lordrichter Slade zwar als ein sehr schönes Bild für den Wednesbury-Test bezeichnet, konkret habe der Minister aber eben keinen Vorschlaghammer benutzt. Weitere Versuche, eine unmittelbare Anwendung der Meinungsfreiheit des Art. 10 EMRK zu erreichen, schlugen feh197.

Dennoch gibt es vereinzelt Fälle, in denen schon heute der Verhältnismäßigkeitsgrundsatz, abgeleitet aus den EMRK-Verpflichtungen, wenigstens in unteren Instanzen direkt angewendet wird ${ }^{98}$. Die Oberrichter halten entgegen verbreiteter Auffassung in der Literatur einstweilen aber noch an der im Brind-Fall bekräftigten restriktiven Anwendung von Verhältnismäßigkeitskriterien fest.

Ganz anders stellt sich die Lage bezüglich der unmittelbaren Auswirkungen des EG-Rechts auf das britische Verwaltungsrecht dar. Dem Gemeinschaftsrecht wird generell Vorrang vor widersprechendem innerstaatlichem Recht eingeräumt. Die Gerichte haben sich insoweit konsequent und nachdrücklich bereitgefunden, entgegen dem Suprematieanspruch des Parlaments Gesetze zu suspendieren"9, ausdrücklich nicht anzuwenden ${ }^{100}$ oder für schlicht rechtswidrig und nichtig zu erklären ${ }^{101}$, wenn sie gegen geltendes Gemeinschaftsrecht verstießen. Seit der Francovich-Entscheidung des EuGH sprechen britische Gerichte sogar Entschädigungsansprüche für Schäden zu, die durch gemeinschaftswidrige Gesetze verursacht wurden ${ }^{102}$. Es kann also keinem Zweifel unterliegen, daß das immer dichter werdende gemeinschaftsrechtliche Netz das Verhältnis der Legislative zur Judikative in England nachhaltig verändern wird. Dabei nimmt das EG-Recht fast die Rolle ein, die sonst eine geschriebene Verfassung vermittelt. Schon gibt es vereinzelt Fälle, in denen kein unmittelbarer Gemeinschaftsrechtsbezug mehr besteht und die Gerichte dennoch unter Verweis auf Factortame (No. 2) entgegen früherer Praxis einstweiligen Rechtsschutz gegen die Krone gewähren ${ }^{103}$ oder die teleolo-

${ }^{77}$ Zum ganzen vgl. Turpin (Fn. 84) $489 \mathrm{f}$.

${ }^{98}$ So etwa in den Fällen R. v. Barnsley M.B.C., ex parte Hook, 1976, 1 W.L.R. 1052; R. v. Higbbury Corner Justices, ex parte Uchendu, The Times, 28. 1. 1994.

"9. $R$. v. Secretary of State for Transport, ex parte Factortame Ltd. (No. 2) 1991, 1 A.C. 60.

100 Marshall v. Southampton and West Area Health Authority (No. 2) 1994, 2 W.L.R. 292.

$101 R$. v. Secretary of State für Employment, ex parte Equal Opportunities Commission, 1995, 1 A.C. 1.

102 Lord Irvine of Lairg (Fn. 89) 75, m.w.Hinw.

${ }^{103}$ M.v. Home Office, 1994, 1. W.L.R. 327. 
gische Gesetzesauslegung des Gemeinschaftsrechts entgegen der klassischen, an der literal interpretation ausgerichteten Auslegungsregel auch auf einen Fall ohne unmittelbaren Gemeinschaftsrechtsbezug anwenden. Lord Irvine bezeichnet dies zu Recht als einen erstaunlichen "Spillover"Effekt, der das britische Verwaltungsrecht künftig revolutionieren könnte ${ }^{104}$. Nach alledem scheint es - wie Jürgen Schwarze dies jüngst formuliert hat - nur eine Frage der Zeit, bis das Verhältnismäßigkeitsprinzip formell Eingang in das britische Verwaltungsrecht findet ${ }^{105}$.

\section{Ausschluß richterlicher Kontrolle durch Gesetze (Ouster Clauses)}

Angesichts des immerwährenden Streits über die Kontrolldichte der richterlichen Entscheidungen im Verhältnis zur Legislative und Exekutive hat der britische Gesetzgeber immer wieder versucht, die Gerichtskontrolle durch gesetzliche Ausschlußklauseln, sog. „ouster clauses“, zu begrenzen. Dabei wurden verschiedenste Formen solcher Klauseln entwickelt, doch sind die Richter stets bemüht, ihre Reichweite einzuschränken. Vollständige Ausschlußklauseln, sog. „Henry VIII-clauses“, mit Formulierungen wie shall not be questioned in any court of law "werden von den Gerichten argwöhnisch beäugt und letztlich selten akzeptiert ${ }^{106}$.

Die mäandernde Kasuistik zu dieser Frage unterscheidet im übrigen hauptsächlich drei Fallgruppen, die entweder unstreitig unüberprüfbares Ermessen gewähren oder dies zumindest nicht gänzlich in Abrede stellen. Es sind dies sog. "subjektive ${ }^{*}$ Sprachwendungen, daneben "objektive Sprachwendungen und schließlich unpräzise oder vage Gesetzesbestimmungen. Nur objektive Sprachwendungen und in geringerem Umfang vage Gesetzesbestimmungen werden als Einfallstore für begrenzte richterliche Kontrolle betrachtet, bei denen erhöhte Anforderungen an Plausibilität und Nachvollziehbarkeit der behördlichen Abwägung gestellt werden ${ }^{107}$.

$104 \mathrm{Vgl}$. Lord Irvine of Lairg (Fn. 89) $75 \mathrm{ff}$.

105 Schwarze Die Europäisierung des Nationalen Verwaltungsrechts, ebd., 789 ff., 793; sowie Jovell/Birkinshawe Britischer Landesbericht in: Schwarze (Hrsg.), Das Verwaltungsrecht unter europäischem Einfluß, 1996, $272 \mathrm{ff}$., $282 \mathrm{ff}$.; Jozeell/Lester Proportionality: Neither Novel nor Dangerous, in Jowell/Oliver New Directions in Judicial Review, 1988, $51 \mathrm{ff} ., 59 \mathrm{ff}$.

${ }_{106}$ Zum ganzen vgl. Craig (Fn. 73) 600; Wade (Fn. 72) 724; Cane (Fn. 80) $186 \mathrm{ff}$.

${ }^{107}$ Bei subjektiven Wendungen lauten die Klauseln if the Minister is satisfied ${ }^{\alpha}$ (s. 68, Education Art 1944) oder , if the Secretary of State deems his deportation to be conducive to the public good" (s. 3 (5) (b) Immigration Act 1971). Solche Klauseln schließen die richterliche Kontrolle des behördlichen Ermessens in tatsächlicher wie rechtlicher Hinsicht aus. Anders liegen die Dinge bei Sprachwendungen, die objektiver gefaßt sind: „as if enacted in 
Ähnlich verfährt die Rechtsprechung mit unterstellten Ermessensspielräumen aufgrund der Verwendung unbestimmter oder vager Rechtsbegriffe ("imprecise, open or vague terms") wie "reasonably necessary" oder "not required". Bei aller Skepsis gegenüber solchen Klauseln heben die Gerichte darauf gestützte Ermessensentscheidungen nur selten auf ${ }^{108}$.

\section{Selbstbindung der Exekutive durcb Tribunals und Inquiries}

1. Da eine spezialisierte Verwaltungsgerichtsbarkeit in England nicht entwickelt wurde, gleichzeitig aber seit dem 1 . Weltkrieg ein immer dichteres Netz von Gesetzen mit großen Ermessensspielräumen für die Verwaltung auf allen Ebenen gespannt wurde und die Entscheidungsprozesse der Verwaltung immer undurchschaubarer wurden, entwickelten sich in der Folge zahlreiche Tribunals anstelle von Verwaltungsgerichten. Die weit über 2000 Tribunals ${ }^{109}$ sind in einer Grauzone zwischen rein verwaltungsinterner und gerichtlicher Kontrolle angesiedelt. Einige ähneln Gerichten in Aufbau, Zusammensetzung und Verfahren fast völlig, andere schließen weitere Kontrolle durch ordentliche Gerichte bewußt aus und überlassen es dem Ressortminister, eine verwaltungsinterne Kontrolle auszuüben. Grundsätzlich unterscheidet man heute zwischen „administrative ${ }^{\alpha}$ und ,domestic tribunals ${ }^{\alpha}$, zwischen Tribunals, die aufgrund eines Gesetzes entstanden und solchen, die freiwillig von Clubs, Verbänden, Gesellschaften, Gewerkschaften aufgrund vertraglicher Vereinbarungen errichtet worden sind ${ }^{110}$. Bei den gesetzlich errichteten Tribunals finden sich vor allem solche, die sich mit Baurecht, Planungsrecht,

this $A c t^{*}$, oder eine ministerielle Bestätigung ${ }_{n}$ shall be conclusive evidence", daß die gesetzlichen Erfordernisse erfüllt seien. Grenzfälle, bei denen "subjektive" und „objektive* Wendungen gekoppelt werden, etwa: "if the Minister has reasonable cause to believe" oder "where the controller bas reasonable grounds to believe", führen dazu, daß die "objektiven" Komponenten "reasonable oder "appear to be necessary“, jedenfalls häufig als Einfallstore für begrenzte richterliche Kontrolle betrachtet werden. Die Richter stellen dann mindestens erhöhte Anforderungen an die Plausibilität und Nachvollziehbarkeit der behördlichen Abwägung; vgl. dazu Brinktrine (Fn. 78) 202 ff.; Craig (Fn. 73) 603.

${ }_{108}$ In der Literatur werden noch zahlreiche weitere Klassifizierungsversuche unternommen, so etwa von Craig (Fn. 73) $600 \mathrm{ff}$. oder von Wade/Forsyth Administrative Law, 7. Aufl., 1994, 456ff. Stichworte dafür sind "finality clauses", "certiorari clauses“, "shall no be questioned clauses". Die jüngste Novellierung des Tribunals and Inquiries Act, 1992, s. 12 (1) hat jedenfalls die Berufungsmöglichkeit in Rechtsfragen trotz solcher ,ouster clauses" offengehalten, vgl. Craig (Fn. 73) 604.

${ }^{109} \mathrm{Vgl}$. statt vieler nur Wade (Fn. 73) $948 \mathrm{ff}$.

110 Zum folgenden ausführl. Riedel (Fn. 67) 120ff.; und Foulkes Administrative Law, 1990, $131 \mathrm{ff}$.; Jones Garner's Administrative Law, 7. Aufl., 1989, $275 \mathrm{ff}$.; DeSmith/Brazier (Fn. 79) Kap. 31; Wiesner Administrative Tribunals in Großbritannien, 1973, $79 \mathrm{ff}$. 
Sozialrecht, Transportrecht, dem materiellen Gesundheitswesen und zahlreichen anderen speziellen Verwaltungsbereichen befassen. Stets geht es darum, Ermessensentscheidungen von Verwaltungsbehörden zu überprüfen. Die Tribunals haben jedoch keine einheitliche Gestalt. Einige Tribunals führen vollständige Zweckmäßigkeitskontrollen wie Verwaltungsbehörden durch, andere überprüfen wie Gerichte formelle Gesetzesverstöße und befassen sich mit den rechtlichen Grenzen der Ermessensausübung. Überragende prozedurale Prinzipien für sämtliche Tribunals sind die Grundsätze der sopenness, fairmess, impartiality ${ }^{\circ}$. Verstöße gegen diese formalen Rechtsgrundsätze führen regelmäßig zur Aufhebung von Ermessensentscheidungen der Verwaltung. Weiterreichende inhaltliche Kontrollen finden sich in unterschiedlichster Form in Spezialgesetzen, die sich einer einheitlichen Kategorisierung versperren.

Gleichwohl können die Ermessen einräumenden Gesetze häufig als Rahmensetzungen verstanden werden. Ihre Ausfüllung erfolgt erst durch den Rechtsanwender. Die Gerichte heben solche Ermessensentscheidungen der Verwaltung, aber auch die Ermessensausübung überprüfenden verwaltungsexternen Tribunalentscheidungen nur sehr selten aus Rechtsgründen auf. Mehr noch als beim allgemeinen Ermessen beschränkt sich die Kontrolle der Gerichte bei Ermessensentscheidungen der Verwaltung, die einer zusätzlichen Überprüfung durch Tribunals unterliegen, auf formale Verfahrensfragen. Eine Inhaltskontrolle wird nur in den engen Grenzen der ultra vires-Doktrin und unter dem Einfluß des EG-Rechts zugelassen, sofern dafür Anhaltspunkte im nationalen Kontext gegeben sind. Viele Streitigkeiten ranken sich um Enteignungsentschädigungen, Mietstreitigkeiten oder um das planerische Ermessen der Behörden bei der Verabschiedung von structure plans, aber auch bei konkreten planning permissions, Bauleitplänen und Stadtsanierungsmaßnahmen (slum clearance). In allen diesen Fällen besteht die Möglichkeit des Widerspruchs beim zuständigen Minister (appeal), gegen dessen Letztentscheidung nur eine sehr begrenzte richterliche Kontrolle möglich ist ${ }^{111}$. Die Rücknahme der Kontrolldichte wird in allen diesen Fällen hingenommen, weil der betroffene Bürger ein judiziäres oder quasi-judiziäres Überprüfungsverfahren der Ermessensentscheidung vor Tribunals zur Verfügung hat, das eine umfassendere Kontrolle durch die ordentlichen Gerichte weniger angezeigt erscheinen läßt. Da aber sowohl die Gerichte als auch die Tribunals ihre Kontrolle im wesentlichen auf Verfahrensfehler beschränken, ist mit

${ }^{111}$ Auf Einzelheiten soll hier nicht eingegangen werden; vgl. Jones (Fn. 110) $275 \mathrm{ff}$.; Ricdel Europäische Verwaltungsverfahrenssysteme im Vergleich - Sachverhaltsermittlung und Rechte der Betroffenen, in: Schwarze/Starck (Hrsg.), Vereinheitlichung des Verwaltungsverfahrensrechts in der EG, Europarecht, Beiheft 1/1995, $59 \mathrm{ff} ., 61 \mathrm{ff}$. 
dem Hinweis, daß im Streitfalle ein Tribunal entscheidet, das zweifellos die meisten Kriterien eines Gerichts erfüllt, für den rechtsuchenden Bürger nicht sehr viel gewonnen. Aus der Sicht der Exekutive bürgt dieses System für schnelle Entscheidungen, niedrige Kosten und die gewünschte inhaltliche Letztentscheidung bei der Exekutive, nicht den Gerichten. Außerdem sind die Tribunals aufgrund ihrer Tätigkeit häufig stilbildend und strukturieren somit die Ausübung des behördlichen Ermessens vor.

2. Ähnlich wie bei Tribunals gibt es auch bei Anhörungsverfahren (inquiries) eine Typenvielfalt ${ }^{112}$. Der typische Verfahrensablauf läßt sich am Beispiel des Planungsverfahrens darstellen. Zunächst muß die Genehmigung bei der zuständigen Kommunalbehörde beantragt werden, im Falle der Kommunalbehörde direkt beim Minister. Der Antragsteller kann bei ablehnendem Bescheid innerhalb einer kurz bemessenen Frist Beschwerde einlegen. Vor der Widerspruchsentscheidung muß der Minister sowohl der Kommunalverwaltung als auch dem Antragsteller rechtliches Gehör einräumen. Hierfür bieten sich drei Möglichkeiten: Der Minister kann entweder schriftliche Einlassungen anfordern, aufgrund derer er seine Entscheidung trifft, er kann aber auch unter Ausschluß der Öffentlichkeit einen Ministerialbeamten beauftragen, die Parteien anzuhören bzw. ein Hearing abzuhalten, und schließlich kann der Minister statt dessen ein öffentliches Anhörungsverfahren (public inquiry) abhalten lassen. Im Unterschied zu vielen Tribunals, die verbindliche Entscheidungen erlassen können, ist es Aufgabe des die Anhörung durchführenden Inspektors, am Schluß einen zusammenfassenden Bericht und Entscheidungsvorschlag für den Minister zu erstellen, der hieran jedoch nicht gebunden ist. Ministerielle Ermessensentscheidungen werden von den Gerichten nur in sehr begrenztem Umfang überprüft. Lediglich Formverstöße, Verweigerung rechtlichen Gehörs oder Verletzung der sonstigen Prinzipien der natural justice ${ }^{113}$ eröffnen gerichtliche Kontrollmöglichkeiten. Bei Anhörungsverfahren sind die Anforderungen an die Klagebefugnis gering ${ }^{114}$. Jedermann, also auch ein Verband, der ein Interesse an dem in Frage stehenden Projekt hat, kann partizipieren. Dies entspricht ganz der französischen Rechtslage. Der großzügigen Verfahrensbeteiligung korrespondiert jedoch eine fast ausschließlich auf Verfahrensverstöße gerichtete Kontrolle. Dies wird von den meisten britischen Kommentatoren aber

112 Riedel (Fn. 67) 136; ausführl. auch Boussard L'enquête publique en Angleterre, 1969, $22 \mathrm{ff}$; Friedmann Kontrolle der Verwaltung in England, Fallstudien zur Beschwerdebehandlung im britischen Unterhaus, $1970,85 \mathrm{ff}$.

${ }_{113}$ Riedel (Fn. 67) Kap. 8, 106 ff., m.w.Hinw.; ders. (Fn. 110) 56 ff.; Craig (Fn. 73) $324 \mathrm{f}$.

${ }^{114}$ Craig (Fn. 73) 142ff.; Riedel (Fn. 111) $55 \mathrm{f}$. 
nicht als Nachteil, sondern als Vorteil empfunden: alle wesentlichen Fragen der Politik, zu denen auch Planungsentscheidungen zählen, sollen politisch verantwortet und mit gesetzlichen Ermessensspielräumen versehen von der Exekutive wahrgenommen werden. Eine zu stark an materiellrechtlichen Erwägungen ausgerichtete Inhaltskontrolle der Gerichte würde jjudicial activism ", ein ygouvernement des juges " produzieren, und die Handlungsfähigkeit der Exekutive und letztlich auch des Parlaments entscheidend schwächen ${ }^{115}$. Inhaltskontrolle, wenn überhaupt, könne nur krasse Fälle von Ermessensfehlgebrauch, unreasonableness im Wednesbury-Test, oder evidente Rechtsverstöße erfassen. Die gegenläufige Tendenz, über einen Spillover-Effekt des Gemeinschaftsrechts in britisches Recht und die allmähliche Anerkennung des Verhältnismäßigkeitsprinzips und des Menschenrechtsschutzes nach der EMRK größeren Rechtsschutz zu erreichen, hat mittlerweile zu einem fundamentalen Umdenken gefürtt ${ }^{116}$. Die Rechtsprechung befleißigt sich demgegenüber aber noch großer Zurückhaltung. Gleichwohl ist der auf den Gleisen des Europarechts und der EMRK abgefahrene Zug wohl nicht mehr aufzuhalten.

\section{Schlußbetrachtung}

Der Vergleich der französischen und englischen Rechtslage mit der deutschen Situation läßt nun einige Schlüsse zu. Weder das französische noch das englische Verwaltungsrecht befassen sich mit Optimierungsgeboten. Nur wenn Optimierung als schlichtes Berücksichtigungsgebot, als Verpflichtung zur Einstellung relevanter Belange in den behördlichen Abwägungsvorgang begriffen wird, finden sich Parallelen zur deutschen Diskussion. Hauptgrund für das Fehlen einer Optimierungsdebatte in den beiden herangezogenen Rechtsordnungen ist die mit dem Optimierungsgedanken zentral verbundene Vorstellung einer formellen und inhaltlichen Vollkontrolle der behördlichen Entscheidungen. Ein solches auf Mißtrauen gegenüber der Exekutive gegründetes Vorverständnis fehlt

115 Lord Irvine of Lairg (Fn. 89) 77, jedoch mit Einschränkungen; dagegen Jowoell/Lester (Fn. 94) insbes. 374 ff.; am Beispiel des Planungsrechts auch Purdue Material Considerations: An Ever Expanding Concept?, Journal of Planning and Environmental Law 1989, 156ff., 161; Carmwath The Reasonable Limits of Local Authority Powers, Public Law 1996, $144 \mathrm{ff}, 258 \mathrm{f}$.

116 Zurückgehend auf den Artikel von Jovecll/Lester (Fn. 94) insbes. $374 \mathrm{ff}$. , der von Sir Robert Camwatb insoweit als ,trail-blazing " gekennzeichnet worden ist, vor allem durch Einbeziehung der Menschenrechtsdimension der EMRK, vgl. Carmoath (Fn. 115) 260f., mit Verweis auf R. v. Coventry City Council, ex parte Phoenix Aviation, 1995, 3 All E.R. 27, 62; sowie West Glamorgan C.C. v. Rafferty, 1987, 1. W.L.R. 457. 
sowohl in England als auch in Frankreich. Ausdruck dieses von den jeweiligen Bevölkerungen getragenen Grundvertrauens ist die für deutsche Verhältnisse kaum verständliche Akzeptanz großer Ermessensspielräume für die Verwaltung. Gerichtliche Kontrolle wird lediglich als notwendiges Legalitätskorrektiv für gravierenden Mißbrauch in Fällen grober Verfahrensfehler oder evidenter materiellrechtlicher Verstöße, „erreurs manifestes" oder "errors of law on the face of the record " begriffen, ansonsten aber vornehmlich als Verfahrenskontrolle, nicht als Inhaltskontrolle gesehen. Ausnahmen hierzu bilden die in jüngster Zeit unter dem Eindruck des Europarechts entwickelten materiellen Grundrechtsgesichtspunkte und der aus dem Gemeinschaftsrecht übernommene Verhältnismäßigkeitsgrundsatz. Wenn dadurch auch eine allmähliche Annäherung an deutsche materiellrechtliche Kontrollparameter bewirkt wird, so werden einstweilen nach noch herrschender Auffassung im französischen und englischen Schrifttum Grundrechtspositionen zwar als Abwägungsgesichtspunkte neben anderen öffentlichen Gemeinwohlbelangen berücksichtigt, anders als in Deutschland bilden sie aber - außer in Fällen direkter Anwendung des EG-Rechts - keine Abwägungstrümpfe, die andere Gemeinwohlbelange im Zweifel auszustechen vermögen. Vielmehr stehen Sie gleichrangig neben diesen. Die Bestimmung des Verhältnisses aller einschlägigen Belange zueinander wird der Exekutive in der konkreten Abwägung überlassen. Die Gerichte in England und Frankreich fordern dabei keine optimierte Geltung bestimmter Belange, sondern allenfalls eine grundsätzliche Berücksichtigung durch Einstellung in den Abwägungsvorgang der Behörde. Die einschlägigen gesetzlichen Vorgaben konzentrieren sich zumeist auf verfahrensrechtliche und organisatorische Regeln und überlassen etwa in Frankreich alles weitere der eher verwaltungsfreundlichen Judikative.

Besonders klar wird diese Grundeinstellung am Beispiel des Conseil d'Etat: Er betont sehr deutlich die objektive Kontrollfunktion, die die Verwaltungsgerichtsbarkeit vermittele. Dem Individuum wird eine eigene Rechtsstellung folglich nur in Konkretisierung der primär objektiv-rechtlichen Rechtswahrungsfunktion der Verwaltungsgerichtsbarkeit gewährt ${ }^{117}$. Der Conseil d'Etat sieht sich also in der Rolle eines protecteur des prérogatives de l'ad-ministration "und als "défenseur de l'executif ${ }^{\text {"11.18. }}$. Entsprechend erfüllen von den fünf Abteilungen des Conseil d'Etat auch vier eine Regierungsberatungsfunktion durch Erstellung von Gutachten zu Gesetz- und Verordnungsentwürfen nach Art. 37-39 der Verfassung. Dabei beschränkt sich

117 Von Danwitz (Fn. 32) 993.

${ }^{118}$ Favoreu (Fn. 32) $237 \mathrm{ff}$. 
ihre Prüfung nicht nur auf die Rechtmäßigkeit, sondern erfaßt ebenso Zweckmäßigkeitsgesichtspunkte ${ }^{119}$. Die enge Vertrautheit mit den Entscheidungsprozessen in den Behörden fördert diese exekutivfreundliche Grundeinstellung des Conseil d'Etat. Dies mag aus deutscher Sicht verfassungsrechtlich bedenklich erscheinen, unterstreicht jedoch die stärker an Gemeinwohlinteressen als an Individualrechtsschutz orientierte Verwaltungsgerichtspraxis in Frankreich und mit wenigen Abstrichen auch in England. Eine Ausnahme bilden in Frankreich Enteignungsfalle. Hier werden bei der Überprüfung der Unbedenklichkeitsbescheinigung seit der grundlegenden, oben dargestellten Entscheidung des Conseil d'Etat im Fall -Ville nouvelle Est ${ }^{\text {๙20 } 20}$ die Vor- und Nachteile vom Gericht gegeneinander abgewogen. Im Ergebnis sind aber nur sehr wenige Unbedenklichkeitsbescheinigungen für rechtswidrig erklärt worden. Auch in diesen Fällen geht es letztlich nicht um Belange, die optimal zur Geltung gebracht werden müßten; vielmehr wird die Verwaltungsentscheidung nur aufgehoben, wenn keine rationalen Gründe seitens der Verwaltung vorgebracht wurden. Dies entspricht weitgehend den Wednesbury-Regeln des englischen Rechts.

Nur auf den ersten Blick grundlegend anders stellt sich die Lage im englischen Recht dar. Wenn im Planungsrecht bei der Überprüfung des Abwägungsvorgangs durch die Gerichte vom Gesetzgeber leicht mißverständlich die Berücksichtigung aller relevanten Umstände, aller Planungsbelange (planning consideration oder die Einhaltung einer good planning policy) verlangt wird, so beschränken sich die Gerichte dennoch auf die Forderung, $\mathrm{da} B$ der Normanwender solche Überlegungen überhaupt anstellt - die Abwägung selber bleibt gerichtlicher Nachprüfung entzogen ${ }^{121}$.

Der Ermessensrahmen ist im übrigen in beiden Rechtsordnungen weiter gesteckt als in Deutschland. Jedenfalls im Grundsatz soll das Letztentscheidungsrecht primär bei der Exekutive und in England allenfalls noch beim Parlament, nicht bei den Gerichten liegen. Eine Trennung des Ermessens von unbestimmten Rechtsbegriffen auf der Tatbestandsseite wird nicht für erforderlich gehalten. Je mehr Fragen des Tatbestandes thematisiert werden, desto größer wird das den Behörden eingeräumte Ermessen bezüglich der Sachverhaltsaufklärung und der Subsumtion. Stets wird die Gefahr der Justizialisierung politisch zu verantwortenden Ermessens beschworen.

So nimmt es nicht wunder, daß auch in Deutschland der Ruf nach einer Rücknahme gerichtlicher Kontrolldichte bei gleichzeitig größerem

${ }^{119}$ Perret Der Conseil d'Etat, o.J. 14f.; Müller (Fn. 32) $338 \mathrm{ff} ., 354 \mathrm{ff}$.

120 Vgl. o. Fn. 42, m.w.Hinw.

121 Riedel (Fn. 111) $62 \mathrm{ff}$. 
Entscheidungsspielraum der Verwaltung und nach einer Konzentration auf Verfahrenssicherungen immer lauter wird. Rüdiger Breuer und viele andere haben dies ausführlich analysiert ${ }^{122}$. Am Beispiel des Umweltrechts geht es im Kern um das Anliegen, daß an die Stelle des zähen, als quälend und unfruchtbar empfundenen Ringens um die juristische Deduktion der einzig richtigen, letztlich von den Gerichten aufzufindenden Umweltrechtsauslegung und -anwendung (...) der offene, breite und unverkrampfte Disput über umfassend ermittelte und abgewogene, nachvollziehbare und angemessene, faktisch und rechtlich vertretbare Lösungen " trete ${ }^{123}$. Dies stehe in Übereinstimmung mit Vorbildern aus anderen Rechtsordnungen wie etwa Frankreich, Großbritannien, aber auch Italien, Österreich, Schweiz, Spanien und den USA. Úberdies haben immer mehr Kommentatoren, wie Ossenbühl, Wabl, Pietzcker, Schulze-Fielitz, Hufen - um nur einige zu nennen -zahlreiche Einwände gegen die wachsende Verrechtlichung erhoben ${ }^{124}$. Der $§ 43$ UGB-KomE mit seiner deutlich beschränkten gerichtlichen Überprüfbarkeit von Prognosen und Bewertungen setzt dieser Tendenz die Krone auf. Der Kampf um die Prärogativen der Exekutive gegenüber zu großer Kontrolldichte durch die Gerichte steht mithin kurz vor dem Sieg, wenigstens im Bereich des Umweltrechts. Da dieses Rechtsgebiet aufgrund seiner Querschnittsfunktionen in zahlreiche weitere Rechtsmaterien hineinwirkt, könnte der neue $\S 43$ UGB-KomE aber, wenn er denn Gesetz würde, in den Worten von Herrn Breuer „über 50 Jahre Verwaltungsrechtsdogmatik den Stab bre-

122 Breucr Tendenzwende des Rechtsschutzes? Betrachtungen zu den $\$ \$ 43 \mathrm{ff}$. UGBKomE, in: Jahrbuch des Umwelt- und Technikrechts, 1998, $161 \mathrm{ff}$.

${ }^{123}$ Breuer (Fn. 122) 166.

$124 \mathrm{Vgl}$. Ossenbübl Die gerichtliche Überprüfung der Beurteilung technischer und wirtschaftlicher Fragen in Genehmigungen des Baus von Kraftwerken, DVBl. 1978, 1ff. 9; ders. Grundrechtsschutz im und durch Verfahrensrecht, in: FS Eichenberger, 1982, $183 \mathrm{ff}$., insbes. $194 \mathrm{f}$; ders. Verwaltungsverfahren zwischen Verwaltungseffizienz und Rechtsschutzauftrag, NVwZ 1982, $465 \mathrm{ff}$., insbes. 472; Wabl Verwaltungsverfahren zwischen Verwaltungseffizienz und Rechtsschutzauftrag, VVDStRL 41 (1983) 153 ff., 159 ff.; Pietzcker Das Verwaltungsverfahren zwischen Verwaltungseffizienz und Rechtsschutzauftrag, ebd., $194 \mathrm{ff}$., insbes. Thesen 9 und 17, $229 \mathrm{ff}$; Wabl Risikobewertung der Exekutive und richterliche Kontrolldichte - Auswirkungen auf das Verwaltungs- und das gerichtliche Verfahren, NVwZ 1991, 409 ff., 414; Scholz Technik und Recht, in: FS zum 125-jährigen Bestehen der juristischen Gesellschaft zu Berlin, 1984, 691 ff., 707; Scbulze-Fielitz (Fn. 5) 772ff., 781; Sendler Skeptisches zum unbestimmten Rechtsbegriff, in FS Ule, 1987, $337 \mathrm{ff}$, inbes. $352 \mathrm{f}$., 358; ders. Die neue Rechtsprechung des Bundesverfassungsgerichts zu den Anforderungen an die verwaltungsgerichtliche Kontrolle, DVBI. 1994, $1089 \mathrm{ff}$.; Fraußen 50 Jahre Verwaltungsgerichtsbarkeit in der Bundesrepublik Deutschland DVB1. 1998, $413 \mathrm{ff}$., $417 \mathrm{ff}$; s. a. Hufen Fehler im Verwaltungsverfahren, 3. Aufl. 1998, 356, m.w.Hinw.; ferner Breuer (Fn. 123) 161 ff., 168 m.w.Hinw. 
chen $^{{ }^{125}}{ }^{2}$. Auf den ersten Blick überzeugen die Argumente der Kritiker: Eine Beschränkung der gerichtlichen Kontrolle auf evidente Fehler erscheint plausibel und funktioniert nach Meinung ausländischer Beobachter hinreichend, um auch in Deutschland praktiziert werden zu können.

Vor einer endgültigen Entscheidung sollten jedoch die Gegenargumente sorgfältig bedacht werden: Als Alternative käme unter anderem in Betracht, daß der Gesetzgeber - wie im Umweltrecht üblich - verstärkt Standardisierungsermessen einräumte, wie dies bei den Umwelt- und Technikstandards, etwa der TA-Luft, TA-Abfall, der Fall ist. Hierbei handelt es sich nach Breuer um eine konditionierte Letztverantwortung der Exekutive für „Gesetzeskonkretisierung“, die ähnlich der Letztverantwortung der Minister in Frankreich und Großbritannien administrative Standardisierungsspielräume schaffe ${ }^{126}$. Da diese Spielräume nicht mit den voll kontrollierbaren Beurteilungsspielräumen verwechselt werden dürfen, ist hier ein Bereich, in dem aufgrund der Technizität und Komplexität der Materie eine Rücknahme der Kontrolldichte noch am ehesten hinnehmbar erscheint. Die gerichtliche Kontrolle beschränkt sich dann darauf, ob die in den Technikstandards niedergelegten Wertungen in Bezug auf die wissenschaftlich-technische Streitfrage ${ }_{n}$ den Anforderungen der Willkürfreiheit, Plausibilität und Vertretbarkeit genügen ${ }^{127}$. Aber selbst wenn man die Anerkennung größerer Entscheidungsprärogativen für die Exekutive als Gebot der gegenseitigen Rücksichtnahme zwischen Staatsgewalten für grundsätzlich berechtigt hält, etwa weil die Voraussetzungen eines umfassenden Mißtrauens gegenüber einer machtbesessenen, Arkanbereiche pflegenden und nur dem Staat, nicht seinen Bürgern verpflichteten Exekutive seit 1949 entfallen sind, läßt sich unter dem Grundgesetz eine völlige volte-face meines Erachtens nicht rechtfertigen.

Dabei sollte zunächst bedacht werden, daß bei stärkerer Verfahrensorientierung anstelle materiell-rechtlicher Überprüfung die Probleme häufig nicht gelöst, sondern nur verlagert werden. Wie Woebrling für Frankreich dargelegt hat ${ }^{128}$, führt der strikte Vorrang verfahrensrechtlicher Fragen nicht selten zu Urteilen, die die wichtigsten Streitpunkte nicht lösen: wenn z.B. eine Genehmigungsversagung wegen eines Verfahrensfehlers aufgehoben wird, ohne daß das Gericht sich zur materiellen Rechtmäßigkeit der Verwaltungsentscheidung geäußert hat, können solche aufgehobenen Entscheidungen sogleich durch neue Genehmigungen ersetzt werden.

\footnotetext{
125 Breuer (Fn. 122) 167.

126 Brewer (Fn. 122) $142 \mathrm{ff}$.

$127 \mathrm{Vgl}$. Breuer (Fn. 122) 177.

128 Woebrling (Fn. 33) 462 ff.; ders. (Fn. 58) $884 \mathrm{ff.}$
} 
Der gewichtigere Einwand gegenüber einer starken Abkehr von der gerichtlichen Vollkontrolle ergibt sich jedoch aus dem Verfassungsrecht: Die grundgesetzlichen Verfassungsvorgaben erfordern eine strikte Beachtung der Rechtsschutzgarantie, der Gewaltenteilung sowie des Vorrangs und Vorbehalts des Gesetzes. Zentrale Bedeutung kommt dabei Art. 19 IV GG $\mathrm{zu}^{129}$. Seine Bedeutung liegt vor allem darin, daß kein Akt der Exekutive, der in Rechte des Bürgers eingreift, richterlicher Nachprüfung entzogen werden kann ${ }^{130}$. Zum Justizgewährleistungsanspruch gehört deshalb die Möglichkeit einer grundsätzlich umfassenden, tatsächlichen und rechtlichen Prüfung des Streitgegenstands ${ }^{131}$ durch ein Gericht ${ }^{132}$. Das Bundesverfassungsgericht hat gleichwohl mehrfach betont, daß unbestimmte Rechtsbegriffe aufgrund hoher Komplexität der geregelten Materie so vage und ihre Konkretisierung im Nachvollzug der Verwaltungsentscheidung so schwierig sein können, daß die gerichtliche Kontrolle an die Funktionsgrenzen der Rechtsprechung stöß ${ }^{133}$. Das Gericht hat letztlich also selber Eigenbereiche der Verwaltungsentscheidungen konzediert.

Der aus Art. 19 IV GG folgende Grundsatz der vollständigen gerichtlichen Überprüfung wird folglich durch das Gewaltenteilungsprinzip und die von ihm geforderten Eigenbereiche der vollziehenden Gewalt eingeschränkt ${ }^{134}$. Bestimmte sich die Kontrolldichte allein nach Art. 19 IV GG, so bliebe von der eigenständigen Bedeutung der gesetzesvollziehenden Verwaltung nicht viel übrig ${ }^{135}$. Daraus folgt aber, daß das Grundgesetz einen radikalen Wechsel weg von materiellrechtlicher hin zu bloßer Verfahrenskontrolle ausschließt.

Anders als in Frankreich und Großbritannien verbietet darüber hinaus der Gesetzesvorbehalt, Entscheidungsspielräume für die Exekutive durch vage, allgemein und abstrakt gehaltene Generalklauseln zu schaffen. Vielmehr muß der Entscheidungsspielraum entsprechend der Regelung gemäß Art. 80 I 2 GG nach Inhalt, Zweck und Ausmaß hinreichend bestimmt $\operatorname{sein}^{136}$. Die britische Lösung, daß bei unbestimmter Gesetzesfor-

${ }^{129}$ Riedel Access to Justice as a Fundamental Right in the German Legal Order, in: Riedel (Hrsg.), German Reports of Public Law, 1998, $55 \mathrm{ff}$.

130 BVerfGE 10, 164 (167).

131 BVerfGE 85, 337 (345).

132 BVerfGE 15, 275 (282).

133 BVerfGE 84, 134 (150f.).

134 So Scbmidt-Assmann Art. 19 IV GG als Teil des Rechtsstaatsprinzips, NVwZ 1983, $1 \mathrm{ff} ., 5$ ff; Schulze-Fielitz in: Dreier GG, Art. 19 Abs. 4, Rdn. 88; Kutscheidt Verfahrensbeschleunigung und richterliche Kontrolldichte, NWVBl. 1995, 121 f.; Kissel Grenzen der rechtsprechenden Gewalt, NJW 1982, 1777, $1781 \mathrm{f}$.

135 So Kübling Fachplanungsrecht, 1988, 68.

136 Vgl. nur Schenke (Fn. 5) Rdn. 304 ff., 334 ff., 341 ff.; Scbulze-Fielitz (Fn. 134) Rdn. 88. 
mulierung ein weiter Ermessensbereich der Exekutive angenommen wird, scheidet unter dem Grundgesetz folglich aus.

Abgesehen von diesen Verfassungsschranken muß bei der Bestimmung des Ausmaßes von Entscheidungsspielräumen stets der in 50 Jahren verfestigte und dominierende Einfluß der Grundrechte beachtet werden. Je stärker nämlich der Grundrechtsbezug ist, desto intensiver wirkt sich auch die Kontrolle durch die Gerichte aus. Grundrechte sind aber bei fast allen Verwaltungsentscheidungen zumindest mitbetroffen. Nach alledem scheidet eine grundsätzliche Verlagerung von materiellrechtlicher hin zu nur verfahrensrechtlicher Kontrolle in Deutschland aus.

Ein gangbarer Weg scheint mir jedoch der Ausbau des Standardisierungsgedankens zu sein, wie ihn Herr Breuer jüngst beschrieben hat. Im übrigen sollte die weitere europarechtliche Integration geduldig abgewartet werden. Der stetige Kontakt mit den Rechtsvorstellungen der Nachbarländer und die zunehmenden grenzüberschreitenden Wirkungen des Verwaltungshandelns gebieten ein behutsames Aufeinanderzugehen der EG-Mitgliedstaaten, dem sich à la longue auch Deutschland nicht entziehen kann. Über das Europarecht läßt sich vermutlich auch das dem deutschen Recht nachgebildete Verhältnismäßigkeitsprinzip auf einen Wesenskern zurückführen: Anstelle eines Kontrollmaßstabes, der die behördliche Abwägungsentscheidung allzu häufig durch eine ,im engeren Sinne verhältnismäßige“, „angemessene“ oder „zumutbare“ Sicht der Gerichte ersetzt, könnte stärker auf die letztlich verfahrensgeleitete $A b w a ̈-$ gungsverpflichtung und Beachtung der Zweck-Mittel-Relation abgestellt werden, wie dies in vielen Entscheidungen des Bundesverfassungsgerichts vorgezeichnet wurde.

Mein Ausflug in das französische und englische Recht hat im Ergebnis keine grundstürzenden Veränderungen für das deutsche Recht nahegelegt. Der Blick in diese Rechtsordnungen hat allerdings gezeigt, daß der Bonus für die Exekutive und Administrative erheblich größer als in Deutschland ist. Dies erhöht dort zweifellos Entscheidungsfreude und Flexibilität des Verwaltungshandelns, freilich häufig um den Preis der Interessen der unmittelbar betroffenen Einzelnen. Insgesamt aber entwikkeln sich die drei Rechtsordnungen aus ihren bei idealtypischer Betrachtung entgegengesetzten Ausgangssituationen aufeinander zu. Dies wird auf künftige Harmonisierungsbestrebungen in der Europäischen Union sicher großen Einfluß haben. Der Subsidiaritätsgedanke zwingt aber bei so stark traditionsgebundenen Materien zu einer sehr sorgfältigen Vorbereitung weiterer Integrationsschritte.

Aus der Analyse der in Frankreich und Großbritannien praktizierten enquêtes publiques und public inquiries mit ihren zahlreichen prozeduralen Abstufungen ließe sich jedoch eine stärkere Hinwendung zu Formen in- 
formellen Verwaltungshandelns, der Mediation, Konfliktmittlung und generell zu größeren Beteiligungsmöglichkeiten für Einzelne und Interessenverbände im Vorfeld der eigentlichen Verwaltungsentscheidungen entwickeln ${ }^{137}$. Dies könnte in Deutschland der Tendenz zu immer stärkerer Inanspruchnahme der Gerichte entgegenwirken. An der prinzipiellen Kontrollmöglichkeit der Gerichte in Deutschland sollte und kann dies aber nichts ändern.

${ }^{137}$ Statt vieler: Würtenberger Die Akzeptanz von Verwaltungsentscheidungen, 1996, $13 \mathrm{ff}$., $98 \mathrm{ff}$.; Hoffmann-Riem Konfliktmittler in Verwaltungsverhandlungen, 1989; SchmidtAßmann Verwaltungsverfahren, in: Isensee/Kirchbof, Handbuch des Staatsrechts III, 1988, $\S 70$, Rdn. 12, 14 ff.; Hoffmann-Riem/Schmidt-Aßmann Konfliktbewältigung durch Verhandlungen, 2 Bde., 1990; Kunig/Rublack Aushandeln statt Entscheiden? Das Verwaltungsverfahrensrecht vor neuen Herausforderungen, Jura 1990, $1 \mathrm{ff}$., jedoch mit Betonung rechtsstaatlicher Grenzen, 7ff.; Schoch Der Verfahrensgedanke im allgemeinen Verwaltungsrecht, Die Verwaltung 25 (1992) 21 ff., insbes. 51 ff.; Maurer (Fn. 2) § 15, Rdn. $14 \mathrm{ff}$. 
Leitsätze des 2. Berichterstatters über:

\section{Rechtliche Optimierungsgebote oder Rahmensetzungen für das Verwaltungshandeln?}

\section{A. Konkretisierung des Themas}

1. Verfassungsrechtlich finden sich Optimierungsgebote in allen Prinzipien, die - im Gegensatz zu Rechtsregeln - in Konkurrenz untereinander erst durch $A b$ wägung im konkreten Einzelfall konkretisiert werden können. Optimierung bedeutet hier Einramung relativen Vorrangs im Rabmen bestebender Abrodgungsspielräume bei der Recbtsanwendung im Einzelfall.

2. Verwaltungsrechtlich wird unter Optimierungsgeboten als Facbbegriff aus dem Bereich des Planungsrechts nur selten die Abwägung zwischen verschiedenen Belangen im allgemeinen verstanden, sondern in aller Regel die gesetzgeberische Herausbebung eines einzelnen Belanges, dem in der Abrodgung gegenüber anderen Belangen vorrangige Bedeutung zukommen soll und dessen Beeintrachtigung besonders gewichtiger sacblicher Rechtfertigung bedarf. Gelegentlich wird dabei so weit gegangen, bei der efforderlichen Maximierung oder Minimierung keine Rücksicht auf das Verbältnismaßßigkeitsprinzip mebr zu nebmen.

3. Rahmensetzung als rechtlich nicht speziell besetzter Begriff bezeichnet die Aufstellung von Vorgaben, innerhalb derer sich staatliche Institutionen bei der Setzung von Rechtsakten frei und obne Kontrolle durch andere Instanzen bewegen können. Rabmen dieser Art können für Gesetzgebung wie Exekutive bestehen.

4. Im Gegensatz zu Optimierungsgeboten legt Rahmensetzung größere Gestaltungsfreibeit und tendenziell geringere Kontrolldichte nabe.

B. Optimierungsgebote und Rahmensetzungen im französischen Recht

I. Stellung der Judikative in Frankreich

5. Bedingt durch traditionelles Mißtrauen gegenüber der Gerichtsbarkeit und Furcht vor einem gouvernement des juges kommt der Exekutive im französischen Verwaltungsrecht eine berausragende Stellung gegenüber den Gerichten zu. Auch der Conseil d'Etat sieht sich nicht als Gegenspieler der Verwaltung und übt meist richterliche Zurückhaltung. 


\section{Grundlagen der gerichtlichen Kontrolle}

6. Der Begriff der discrétion unterscheidet nicht zwoischen unbestimmten Rechtsbegriffen und Ermessen im Sinne der deutschen Dogmatik.

7. Das französische Recht unterscheidet bei der gerichtlichen Kontrolldichte Normal-, Minimal- und Maximalkontrolle. Welcher dieser fließend ineinander übergebenden Kontrollmaßstäbe im Einzelfall zur Anwendung kommt, ist nicht gesetzlich festgelegt, sondern unterliegt der Einschätzung der Gerichte.

8. Die Normalkontrolle fübrt zur grundsätzlich vollen Überprüfung der Verwaltungsentscheidung, jedoch mit Schwerpunkt im Bereich des formellen, nicht des materiellen Rechts.

9. Im Rabmen der Minimalkontrolle wird die Subsumtion nur auf offensichtliche Bewertungsfebler (erreurs manifestes d'appréciation des faits) überprüft. Sie ist die bäufigste Form der Kontrolle und greift vor allem bei Ermessensentscheidungen der Verwaltung, aber auch etwa bei Verwaltungsentscheidungen, die technische Detailkenntnisse voraussetzen oder die einen spezifisch politischen Inbalt aufweisen.

10. Die Maximalkontrolle greift ein, wenn libertés publiques besonders betroffen sind, und findet ein prominentes Anwendungsfeld bei Enteignungen im Bereich des Planungsrechts. Hier wird der Nutzen eines geplanten Vorhabens für die Allgemeinbeit mit den Nacbteilen für die Allgemeinheit und unmittelbar Betroffene abgerwogen. Trotz der scheinbaren Äbnlichkeit mit Optimierungsgeboten in ibrem weitesten Sinn als schlichte Abwägungsgebote dient diese theorie du bilan in der Praxis weniger dazu, eine echte materiellrechtliche Kontrolle durch die Rechtsprecbung sicherzustellen, als vielmebr überbaupt eine Abröagung durch die Verwaltung im Vorfeld der $z u$ treffenden Entscheidung zu gerwährleisten. Entsprechend führt auch die Maximalkontrolle nur böcbst selten zu aufbebenden Entscheidungen.

\section{Die Bindung der Verwaltung an legislative Abwägungsdirektiven}

11. Nur vereinzelt gibt der französische Gesetzgeber Abrwägungsdirektiven vor, wie etwa den Umweltschutz als Gegenstand öffentlichen Interesses im Umweltrecht.

12. Tendenziell tritt im französischen Verwaltungsrecht an die Stelle materieller Optimierungsgebote und Abwügungsdirektiven die Prävention durch formelle Verfabrensgarantien im Vorfeld der Entscheidung, etwa durch die enquête publique im Umwelt- und Planungsrecht.

\section{Optimierungsgebote und Rabmensetzungen im englischen Recht}

13. Eine Optimierungsdebatte wird in England nicht geführt. Es lassen sich allenfalls Variationen der Rabmensetzung im Verbältnis der Legislative zur Exekutive und speziell zur Kommunalverwaltung ausmachen. 
14. Die gerichtliche Kontrolle beschränkt sich im wesentlichen auf formelle Verfahrensverstöße. Unter dem Einfluß des Europarecbts werden Ansätze zu einer bescbränkten Inbaltskontrolle des Verwaltungshandelns erkennbar.

\section{Stellung der Judikative im englischen Recht}

15. Die Souveränität des Parlaments und die „rule of law " bestimmen bis zum beutigen Tage das Verballtnis von Parlament und Exekutive zur Judikative. Die - rule of law " wirkt nicht als Maßstab für die Gesetzeskontrolle, sondern als Maßstab für die Verwaltung sowie für alle nachgeordneten Gesetze.

II. Grundlagen der gerichtlichen Kontrolle

16. Der Begriff Ermessen (discretion) erfaßt - anders als in Deutschland sämtliche Tatsachenfeststellungen, Interpretationsspielräume sovvie Subsumtionsprozesse.

17. Eine Inhaltskontrolle von Verwaltungsentscheidungen wird in erster Linie auf die ultra vires - Lebre und auf Grundsätze der "natürlichen Gerechtigkeit" (natural justice) gestützt. Verwaltungsentscheidungen werden nur aufgeboben, wenn sie sacblich so unangemessen (unreasonable) sind, daß kein vernünftiger Entscheidungsträger sie bätte fällen können.

18. In der mäandernden Kasuistik wird die Kontrolle teils intensiviert, insbesondere bei Menschenrechtsfragen, teils zurückgenommen, etwa bei Fragen der nationalen Sicherbeit oder Wirtschaftspolitik. Daneben verstärkt sich die Kontrolldichte auch unter dem zunebmenden Einfluß des Europarechts.

\section{Ausschluß richterlicher Kontrolle (ouster clauses)}

19. Ein vollständiger gesetzlicher Ausschluß der Gerichtskontrolle wird von den Gerichten selten akzeptiert. Sie verzichten jedoch weitgebend auf eine richterliche Ermessenskontrolle bei subjektiv gefaßten Ausschlußklauseln. Bei objektiver formulierten Klauseln werden bingegen zumindest Plausibilitat und Nachvollziebbarkeit der bebördlichen Abwägung von den Gerichten überprüft.

\section{Selbstbindung der Exekutive durch Tribunals und Inquiries}

20. Bei „tribunals" richtet sich die Kontrollintensität nach der Art ibrer Handlungsbefugnisse. Soweit ibnen Abwägungen unter Zweckmäßigkeitsaspekten gestattet sind, findet keine Ermessenskontrolle statt. Soweit sie eine Legalitätskontrolle vormebmen, unterliegen Verstöße gegen formale Verfabrensgrundsatze wie bei Anbörungsverfabren (public inquiries) einer Gerichtskontrolle. 


\section{Schlußbetrachtung}

21. Hauptgrund für das Feblen einer Optimierungsdebatte im französischen wie englischen Recht ist die fehlende Fixierung auf eine formelle und inhaltiche Vollkontrolle sowie das traditionelle Vertrauen und nicht Mißtrauen gegenüber der Verwaltung. Die grundsätzliche Beschränkung materieller Kontrolle auf grobe oder evidente Fehler und die Konzentration auf die Überprüfung des Verfabrens wird in jüngster Zeit vor allem unter dem Eindruck des Europarechts durch materielle Grundrechtsgesichtspunkte und den Verbältnismäßigkeitsgrundsatz ergänzt, wenn auch nicht grundlegend umgestaltet. Die Gefahr der Justizialisierung politisch $z u$ verantwortenden Ermessens wird auch weiterhin stets beschworen. Bebutsam aber entwickeln sich französisches, englisches und deutsches Recht aufeinander zu.

22. Die Vorstellungen der betrachteten ausländischen Rechtssysteme können nur vorsichtig und unter Beachtung der - insbesondere verfassungsrechtlichen Besonderbeiten in die deutsche Rechtsordnung übertragen werden. Durch eine stärkere Konzentration auf Verfabrenssicherungen werden Probleme oft nicht gelöst, sondern nur verlagert.

23. Eine Rücknabme der Kontrolldichte ist am ebesten in Bereichen boher tatsäcblicher Technizitat und Komplexität binnehmbar, etwoa durch Einräumung eines Standardisierungsermessens an den Gesetzgeber.

24. Verfassungsrechtlich wird eine Beschränkung der Kontrolldichte vor allem durch die Rechtsschutzgarantie des Art. 19 Abs. 4 GG begrenzt, die in einem Spannungsverbältnis zu dem vom Gewaltenteilungsgrundsatz garantierten Eigenbereich der Exekutive steht. Daneben bescbränkt der Vorbehalt des Gesetzes den Einsatz vager Generalklauseln und fordert der für das deutsche öffentliche Recht kennzeichnende Einfluß $\beta$ der Grundrechte eine mit steigendem Grundrechtsbezug zunehmende Intensität der Kontrolle.

25. Wünschenswert für die zukünftige Entwicklung ist nicht eine grundlegende Veränderung der deutschen Konzeption zur Kontrolldichte, sondern - auch unter dem Einfluß $\beta$ der fortschreitenden europäischen Integration - eine bebutsame Anpassung etwa durch verstärkte Konfliktvermeidungsstrategien im Vorfeld der Verwaltungsentscheidungen (informelles Verwaltungshandeln, Mediation, verbesserte Beteiligungsmöglicbkeiten). An der prinzipiellen Kontrollmöglicbkeit der Gerichte ändert dies nichts; sie sind aber bei der Ausübung ibrer Kontrollfunktion im Rabmen der bereits bestehenden Maßstabe aufgerufen, Augenmaß zu beweisen. 


\section{Aussprache und Schlußwoorte}

\section{Rechtliche Optimierungsgebote oder Rahmensetzungen für das Verwaltungshandeln?}

Vorsitzender (Breuer): Verehrte Kolleginnen und Kollegen, ich eröfne die Aussprache zum zweiten Beratungsgegenstand unserer Tagung.

Die Optimierungsgebote und die Rahmensetzungen sind in dem Thema mit einem Fragezeichen versehen worden und bewußt in einen Gegensatz gestellt worden. Es dürfte durch die drei erhellenden Referate von Herrn Würtenberger, Herrn Haller und Herm Riedel klar geworden sein, daß es hierbei zum einen um einen gleichsam archetypischen $\mathrm{Ge}-$ gensatz zwischen verwaltungsrechtlichen Normierungen und Aufträgen an die Verwaltung geht und daß zum anderen die Rechtsvergleichung dabei eine ganz zentrale Rolle spielt. Die Beobachtung war, das darf ich noch einmal an den Anfang stellen, daß die verwaltungsrechtlichen $\mathrm{Ge}$ setze in der jüngsten Zeit immer mehr anspruchsvolle, ehrgeizige, eben optimierende Zielsetzungen vorgeben, und die Frage ist, ob dies in unserem Rechtsstaat durchgehalten werden kann und justitiabel ist. Hierzu haben die Referenten Antworten gegeben, die das Thema aufgenommen haben und zu unterschiedlichen Schlüssen gekommen sind. Ich möchte im ersten Teil dieser Diskussion die Wortmeldungen aufrufen, die sich mit der Frage befassen, ob eigentlich die Gegenüberstellung von positiven Optimierungsgeboten und negativen Rahmensetzungen überzeugend und tragfähig ist oder ob insoweit methodenkritische Grundsatzbemerkungen zu machen sind. Im zweiten Teil soll es dann um rechtsvergleichende Überlegungen und konkretere Bewertungen und schließlich um die Schlußfolgerungen gehen. Es gehört, soviel darf ich vorab sagen, offenbar zu den Besonderheiten des deutschen Verwaltungsrechts, daß der deutsche Idealismus oder auch ein anspruchsvoller vernunftrechtlicher Horizont, wie Herr Würtenberger ihn dargestellt hat, in Rechtsform gegossen werden soll. Der frühere Präsident des Bundesverwaltungsgerichts Fritz Werner hat dies in verschiedenen Vorträgen und $\mathrm{Pu}-$ blikationen sehr deutlich zum Ausdruck gebracht. „Recht und Gericht in unserer Zeit", so lautet der Titel seines Werkes, und wir sollten nach Jahrzehnten dieser Entwicklung in Deutschland kritisch reflektieren, wie weit dieser Weg auf die Dauer tragfähig ist, wie weit wir uns vielleicht Selbstbeschränkungen im Sinne der Rahmensetzungen unterwerfen sollten 
und was die ausländischen Rechtsordnungen wie auch das Europarecht dazu beizutragen haben.

Bullinger: Meine sehr verehrten Damen und Herren Kollegen. Ich habe den Konzeptionen der Referenten, der großen von Herrn Würtenberger und den beiden ergänzenden von Herrn Haller und Herrn Riedel, nichts Gleichwertiges entgegenzusetzen, wage aber eine Frage zu stellen: Wie kann man solche Optimierungs- oder Rahmengesetze überhaupt verwirklichen? Im Jahre 1991 besuchte eine Freiburger Schulklasse eine Behörde in Weimar und fragte die Dame, die ihr zur Verfügung stand: Was machen Sie da? Sie sagte: Ich warte. Ich habe eine Akte zu bearbeiten. Dabei ist ein neues Gesetz anzuwenden, und ich komme damit nicht zurecht. Es heißt darin: „Unter Berücksichtigung von ... kann die Behörde ...". Wie soll ich eine solche Vorschrift anwenden? Wir waren gewohnt, in solchen Fällen in Berlin anzurufen, und die haben das Weitere bestimmt. Ich versuche es die ganze Zeit, aber da meldet sich niemand mehr.

Dieser Vorgang läßt nachdenken. Wie kann man, wenn ein offenes Gesetz erlassen wird, überhaupt erreichen, $\mathrm{da} B$ es ausgefüllt und angewendet wird? Die Frage hat auch Herr Würtenberger gestellt. Wie läßt sich, das ist die erste Frage, eine Verwaltung schaffen und mobilisieren, die eine so schwierige Aufgabe der Vollendung dessen, was der Gesetzgeber offen gelassen hat, zu bewerkstelligen vermag? Welche fachliche Ausbildung, welche Schulung und welchen Enthusiasmus des Einsatzes für das Gemeinwohl braucht eine solche Verwaltung? Mit der bloßen Vollzugsbereitschaft ist es ja nicht getan. Es muß Gestaltungsermessen ausgeübt werden, und dazu bedarf es der Bereitschaft zur Gestaltung. Das zweite, nicht weniger Wichtige scheint mir folgendes zu sein: Für den Normadressaten ist der Partner auf der Seite des Staates herabgestuft. Aus dem mächtigen Gesetzgeber wird eine bloße Behörde. Infolgedessen ist die Frage: Wie bekommt man, etwa im Umweltschutz, im Hochschul- oder Rundfunkwesen die Normadressaten dazu, sich im Rahmen der Ausfüllung offener Normen der Behörde kooperativ zur Verfügung zu stellen? Man kann offene Normen nicht einfach vollziehen wie Gesetze, in denen steht, was der Bürger zu tun und zu unterlassen hat. Infolgedessen braucht man als Begleitfigur offener Normen meines Erachtens die Schaffung von Strukturen, die den Vollzug unter Mitwirkung der Betroffenen ermöglichen. Man muß also unter anderem Anreize (incentives) schaffen. Die bei den Betroffenen vorhandenen Interessen an effektivem Gesetzesvollzug müssen geweckt, neue Interessen geschaffen werden, verbunden mit einer gewissen Bereitschaft, sich für das Gemeinwohl einzusetzen. Wie in England und Frankreich sollten wir jeweils überlegen, 
wie weit eine Öffnung des Gesetzes statt starrer Regelung im Endergebnis einen höheren Beitrag zum Gemeinwohl erbringen kann und wie man Behörden wie Bürger dafür mobilisieren muß. Ich bedanke mich.

Engel: Ich möchte zuerst zu bestimmen versuchen, was der Begriff Optimierung in unserem Zusammenhang meinen könnte. Ich möchte dann zweitens eine der möglichen Deutungen dieses Begriffs herausgreifen und daran deutlich machen, welche Kosten dieses Streben nach Optimierung hat. Schließlich möchte ich drittens fragen, ob diese Kosten nicht zu hoch sind.

Zunächst also: Was kann Optimierung in unserem Zusammenhang bedeuten? Herr Riedel hat sich ja gleichsam die verwaltungsdogmatische Brille aufgesetzt. Optimierungsgebote greifen dann einen bestimmten Belang heraus und geben ihm ein Prae gegenüber anderen Belangen. Ich glaube aber nicht, daß damit unser Thema erschöpft wird. Eine zweite Deutung würde vom Rechtsanwender verlangen, daß er mehrere, vom Gesetz abschließend aufgezählte Belange in ein angemessenes Verhältnis setzt. Bei der dritten Deutung verzichtet der Gesetzgeber auch auf diese Aufzählung und verlangt vom Rechtsanwender ganz allgemein, daß er alle im Einzelfall relevanten Belange gegeneinander abwägt. So liegt es etwa beim integrierten Umweltschutz.

Der Gesetzgeber kann auch noch in einer zweiten Dimension variieren. Im strengsten Fall muß der Rechtsanwender nur zwei vom Gesetz vorher definierte Instrumente mit Blick auf die relevanten Belange vergleichen. Das ist noch einigermaßen gut zu bewältigen. Schon schwieriger wird es, wenn das Gesetz eine Vielzahl von Instrumenten zur Auswahl stellt. Schließlich kann auch hier der Gesetzgeber ganz auf einen Katalog verzichten und verlangen, daß das beste Instrument gewählt wird. Wiederum ist der integrierte Umweltschutz das prominenteste Beispiel. Optimierung heißt hier also, daß jedes nur denkbare Instrument in Beziehung zu jedem nur denkbaren relevanten Belang gesetzt werden muß.

Von dieser - zugegeben extremen, aber eben auch praktischen - Deutung des Begriffs der Optimierung möchte ich im folgenden ausgehen. Die Kosten solch eines Optimierungsgebots lassen sich relativ einfach in den Kategorien des Demokratieprinzips und des Rechtsstaatsprinzips beschreiben. Das Demokratieprinzip muß dann auf das Gebot der sachlichen demokratischen Legitimation des Verwaltungshandelns durch das Gesetz verzichten. Es bleibt natürlich die persönliche demokratische Legitimation. Der Verwaltungsbeamte ist ja in einem demokratischen Verfahren in sein Amt gelangt. Sie wird ergänzt um etwas, das man organisatorische und prozedurale demokratische Legitimation nennen könnte. Aber das bleibt weniger als sachliche Legitimation. 
Der zweite Punkt auf der Verlustliste ist, das hat auch Herr Riedel deutlich hervorgehoben, der Rechtsstaat. Der Rechtsschutz muß dann nämlich von einer materiellen auf eine bloß prozedurale Kontrolle zurückgenommen werden. Denn kontrollieren können die Gerichte die Erfüllung des beschriebenen Optimierungsgebots nicht mehr. Sie könnten die Verwaltungsentscheidung bestenfalls kreativ nachschöpfen. Damit wären aber die Grenzen überschritten, die der dritten Gewalt gezogen sein müssen. Der Rechtsschutz wird dadurch zwar nicht sinnlos. Die Gerichte sinken dann aber zu Instanzen herab, die dem Bürger Tauschmasse für Verhandlungsprozesse mit der Verwaltung zuweisen. Je nachdem, wieviel Verfahrenslast sie der Verwaltung auferlegen, geben sie dem Kläger mehr oder weniger Möglichkeiten, in Verhandlungen mit der Verwaltung etwas herauszuschlagen.

Ich frage nun, ob dieser Preis nicht zu hoch ist. Natürlich kann man diese Frage nicht abstrakt beantworten. Vielmehr hängt vom jeweiligen Gegenstand ab, wie dringlich uns erscheint, daß die Verwaltungsentscheidung so gerecht wie möglich wird. Trotzdem sollte man, glaube ich, eher zur Vorsicht raten als zu mutigem Voranschreiten. Warum das so ist, macht ein Seitenblick auf die Ökonomie deutlich. Dort ist das Optimum ja ein alltäglicher Begriff. Es bezeichnet einen Zustand, der auf keine Weise mehr verbessert werden kann. Mir scheint, daß wir im Verwaltungsrecht genau dahin streben - also zu einer Utopie. Der Wirklichkeit vollständig gerecht werden zu wollen, heißt ihr ungerecht werden zu müssen. Wir sollten deshalb wieder stärker darauf achten, was eine Rechtsordnung sinnvoll noch kann, wenn Rechtsstaat und Demokratie im wesentlichen erhalten bleiben sollen. Wirkungszusammenhänge sind ubiquitär. Die zentral handelnde Rechtsordnung muß sich damit begnügen, Wirkungszusammenhänge herauszufiltern, die solches Gewicht haben, daß ihre Reaktion erforderlich wird. Wenn wir in diesem Sinne Relevanzschwellen definieren, haben wir zugleich den legitimen Bereich der Verwaltungsautonomie bestimmt.

Vorsitzender: Als nächsten Redner darf ich Herrn Fromont bitten, die rechtsvergleichende Perspektive gleichsam authentisch zu eröffnen.

Fromont: Für einen Franzosen ist es gar nicht leicht, in diese Debatte einzuspringen. Erstens ist der Begriff der Optimierung im französischen Verwaltungsrecht gar nicht üblich, wie Herr Riedel schon bemerkt hat. Im Grunde genommen handelt es sich entweder um die Abwägung von Belangen oder um die Vorrangstellung von bestimmten Belangen. Dann kommt die zweite Schwierigkeit hinzu: Nur selten, zum Beispiel im Planungsrecht, setzt das Gesetz klar fest, welche Belange zu beachten sind 
und mit welchem Vorrang. In vielen Fällen sind solche Abwägungsgebote und Vorrangstellungen im Gesetz nur implizit geschrieben. Deshalb kann die Frage der Optimierung, aus der Sicht der französischen Rechtsdogmatik, nur mit großen Schwierigkeiten gefaßt werden.

Nun zur Grundsatzfrage: Soll das Gericht die Interessenabwägung bzw. die Vorrangstellung durch die Verwaltungsbehörde prüfen? Wie es aus den Berichten hervortritt, sind die französischen und englischen Richter etwas zurückhaltend. Der Grund liegt weniger in der Tatsache, daß die Richter dort eine nicht so starke Stellung wie in Deutschland innehaben, als vor allem in der Tatsache, daß die Verwaltungsbehörden in der Regel dort in starkem Maße als demokratisch legitimiert betrachtet werden. Tatsächlich werden die wichtigsten Verwaltungsentscheidungen von Ministern oder sogar, wie öfters in Frankreich, von der ganzen Regierung getroffen, das heißt von Leuten, die eine politische Verantwortung tragen. Insoweit hat es der Richter nicht so leicht, eine demokratisch legitimierte Behörde zu tadeln. Zum Beispiel habe ich gerade in der Zeitung gelesen, daß die Entscheidung der Regierung, die den langen Streik der französischen Lastwagenführer zum Schluß gebracht hatte, vor drei Tagen vom Conseil d'Etat aufgehoben wurde. In solchen Fällen hat der Richter das Demokratieprinzip und das Rechtsstaatsprinzip in praktische Konkordanz zu bringen. Das erklärt, warum der französische Richter nur ausnahmsweise die Abwägung von Belangen durch die Verwaltung überprüft; sonst würde er einfach an der Stelle der politisch verantwortlichen Behörden entscheiden.

Dann zu den Methoden der richterlichen Kontrolle. Hier muß zwischen normaler Kontrolle und Minimalkontrolle unterschieden werden. Bei der normalen Kontrolle werden sowohl das Verfahren und die Form als auch die Subsumtion vom Richter voll geprüft. Es wurde heute gesagt, die Verfahrensrügen würden vom Richter bevorzugt. Es trifft zu, aber es ist leicht zu rechtfertigen: Gerade weil die Verwaltung eine demokratisch legitimierte Behörde ist, kann der Richter leichter einen Verfahrensfehler rügen als einen Subsumtionsfehler (insbesondere einen Abwägungsfehler, soweit der gesetzliche Tatbestand eine Abwägung von Interessen einschließt). Deshalb werden die Verfahren und die Form zuerst geprüft, und erst wenn sie fehlerfrei sind, prüft der Richter die Subsumtion. Hinzu kommt, daß die Beachtung von Verfahrensregeln aus französischer und englischer Sicht besonders wichtig sind: Ein berühmter amerikanischer Jurist, J.N. Hazard, sagte, Anwendung von sowjetischem Recht nach amerikanischem Verfahren sei noch besser als Anwendung von amerikanischem Recht nach sowjetischem Verfahren. Deswegen bedauere ich sehr die 6. Verwaltungsgerichtsordnungsnovelle, nach der die Verfahrensfehler heilbar geworden sind. Dann zur Minimalkontrolle: Auch im Be- 
reich der Minimalkontrolle wird die gerichtliche Nachprüfung immer dichter, gerade weil neuere Arten von Rechtsnormen unmittelbar anwendbar geworden sind, insbesondere völkerrechtliche und verfassungsrechtliche Rechtsnormen. Zum Beispiel wird die Konformität mit völkerrechtlichen Vorschriften immer häufiger vom Richter geprüft, insbesondere im Asyl- und Ausländerrecht (Genfer Konvention, Europäische Menschenrechtskonvention). Auch die verfassungsrechtlichen Grundsätze verengen immer mehr das Ermessen. Nach der Entscheidung "Bléton“ des Conseil d'Etat vom 16. 12. 1988 verbietet zum Beispiel der Artikel 6 der Erklärung der Menschen- und Bürgerrechte von 1789, daß die Verwaltung jemanden zum Beamten ernennt, der überhaupt keine Fähigkeit zur Ausübung des betroffenen Amtes beweisen kann, auch wenn das Gesetz keine besondere Fähigkeit verlangt. Das heißt: Auch im Bereich der Minimalkontrolle prüft der Richter nicht nur Form- und Verfahrensmängel, sondern ebenso die Beachtung materiellen Rechts, soweit Rechtsnormen die Macht der Verwaltung (d.h. das Ermessen) begrenzen und zwar in allen Fällen die Tatsachenfeststellung und die Rechtsfindung, aber auch, allerdings mit Zurückhaltung, die Subsumtion. Es ist klar, daß bei der Minimalkontrolle die Abwägung und die Vorrangstellung von Belangen nur selten geprüft werden; sonst würde der französische Richter das Gefühl haben, er treibe mehr Politik als Jurisprudenz. Danke schön.

Vorsitzender: Herzlichen Dank, Herr Fromont, für diese grundsätzlichen Darlegungen zur gerichtlichen Kontrolle in Frankreich, auch für die Bemerkungen zur Annäherung zwischen den Rechtssystemen, und wenn ich dies richtig sehe, ist Ihre kritische Bemerkung zur 6 . Änderungsnovelle der Verwaltungsgerichtsordnung bei manchen wohl ebenfalls auf fruchtbaren Boden gefallen.

Alexy: Die Formulierung unseres heutigen Beratungsgegenstandes, „Rechtliche Optimierungsgebote oder Rahmensetzungen für das Verwaltungshandeln", erweckt den Eindruck, als ob es sich um eine echte Alternative, ein Entweder/Oder handele. Das möchte ich in Frage stellen. Wenn man das Verhältnis zweier Begriffe bestimmen will, muß man diese zunächst definieren. Optimierungsgebote sind sowohl von Herrn Würtenberger als auch von Herrn Riedel als Prinzipien charakterisiert worden, die gebieten, daß etwas relativ auf die tatsächlichen und die rechtlichen Möglichkeiten in möglichst hohem Maße realisiert wird. Das ist ein Prinzipienbegriff, der an die Struktur ökonomischer Erwägungen anknüpft, aber sich nicht in diesen erschöpft. Er ist auch der juristischen Abwägung zugrunde zu legen. Immer dann, wenn abgewogen wird, werden Prinzi- 
pien im dargelegten Sinne vorausgesetzt. Die Relativierung auf die tatsächlichen Möglichkeiten impliziert die Grundsätze der Geeignetheit und Erforderlichkeit, und diese jene. Das eine folgt logisch aus dem anderen. Der Relativierung auf die rechtlichen Möglichkeiten korrespondiert die Verhältnismäßigkeit im engeren Sinne und damit die Abwägung als solche. Das Gegenstück zum Prinzip ist die Regel. Regeln sind definitive Gebote, unter die zu subsumieren ist. Bevor der Frage nachgegangen wird, ob die "Rahmensetzungen “ in der Formulierung unseres Beratungsgegenstandes Regelcharakter haben, sei noch ein Blick auf die Optimierungsgebote im Sinne des Bundesverwaltungsgerichts geworfen. Das Bundesverwaltungsgericht spricht ihnen ein „besonderes Gewicht ${ }^{\text {" zu. }}$ Das läßt sich dadurch erfassen, daß sie als Optimierungsgebote eingestuft werden, die sich von den normalen Optimierungsgeboten, wie sie in al-

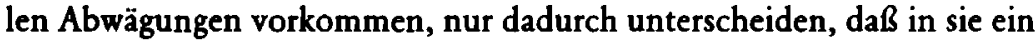
Prima-facie-Vorrang eingebaut ist. Sie sind also normenlogisch nichts Neues, sondern stellen nur eine etwas kompliziertere Figur des allgemeinen Optimierungsgebots dar. Auf der Seite der Optimierungsgebote ist die Sache damit klar. Die entscheidende Frage lautet somit, was ist das, was in unserem heutigen Thema ihnen entgegengesetzt wird, was ist eine Rahmensetzung?

Herr Riedel hat trefflich ausgeführt, daß der Begriff der Rahmensetzung, ich darf aus seinen Leitsätzen zitieren, ein "rechtlich nicht speziell besetzter Begriff“ ist. Wie wahr! Die Dinge wären nun einfach, wenn wir die Rahmensetzungen schlicht als Regeln auffassen könnten. Unser Problem wäre gelöst. Die Spielräume im Rechtssystem könnten allesamt abwägungsfrei durch Subsumtion bestimmt werden. Genau das ist jedoch nicht möglich. In allen schwierigen Fällen lassen sich die Spielräume nicht abwägungsfrei und damit nicht ohne Optimierung bestimmen. Natürlich würde ich gerne wissen, wie Sie, Herr Riedel, zu der Frage stehen, ob die Rahmensetzung sich in Regelsetzung erschöpfen kann.

Wenn Regeln allein aber nicht ausreichen, um den Rahmen zu setzen, was soll es dann sein, wodurch er bestimmt wird? Die These kann nur lauten: Es sind wesentlich Optimierungsgebote. Dabei ist zentral, daß die Idee der Optimierung nicht, wie es häufig anklingt, identisch ist mit der Idee der einzig richtigen Antwort oder der einzig richtigen rechtlichen Lösung. Das Gegenteil ist der Fall. Beide Referate haben dargelegt, daß die Abwägung kein Verfahren ist, das in allen Fällen die richtige Lösung garantiert. Herr Würtenberger hat ausdrücklich die Unbestimmtheit der Abwägung hervorgehoben. Abwägung und damit Optimierung implizieren notwendig Spielräume. Natürlich, und Herr Würtenberger hat diesen Begriff zu Recht ins Spiel gebracht, behält die richtige Antwort den Charakter einer regulativen Idee. Wir erwarten von der Verwaltung, 
daß sie nach der besten Lösung strebt und nicht nach irgendeiner. Was würden wir von einer Behörde sagen, die das folgende erklärt: „Wir haben uns für die Lösung $A$ entschieden, obwohl die Lösung $B$ unter rechtlichen als auch unter $Z$ weckmäßigkeitsgesichtspunkten viel besser ist. Aber die Wahl der Lösung B ist eine hervorragende Möglichkeit, unsere Herr Würtenberger verwendet diesen Begriff - Präferenzautonomie zu demonstrieren." Wir würden das als ungehörig ansehen. Die Behörde hat nach der besten Lösung zu suchen. Das ist ohne weiteres damit vereinbar, daß das Gericht nicht die Kompetenz hat, seine Vorstellung der besten Lösung stets der Vorstellung der Verwaltung von der besten Lösung entgegenzusetzen, und genau dies ergibt sich aus dem Gedanken der Optimierung. Herr Würtenberger hat in seiner 20. These Prinzipien, also Optimierungsgebote, genannt, die für Spielräume sprechen. So ist dort die Rede von der vom Grundgesetz vorausgesetzten Eigenständigkeit der Verwaltung, deren demokratischer Legitimation sowie deren Legitimation durch Verfahren der diskursiven Konfliktlösung. Das sind formelle oder prozedurale Prinzipien. Um zu Spielräumen der Verwaltung zu gelangen, ist es lediglich erforderlich, den materiellen Prinzipien, deren isolierte Betrachtung vielleicht zu einer überzogenen Idee der einzig richtigen Antwort verleiten könnte, die formellen oder prozeduralen Prinzipien zur Seite zu stellen. Zu letzteren gehört auch das Prinzip der Effektivität der Verwaltung, das, wie stets bei Optimierungsgeboten, natürlich nicht grenzenlos, sondern nur im Rahmen der tatsächlichen und rechtlichen Möglichkeiten zu realisieren ist. Wenn man dies alles berücksichtigt, und das ist mein letzter Punkt, kommt man zu einer Theorie der abgestuften Kontrollintensität, und zwar nicht in Entgegensetzung zur Idee der Optimierung, sondern auf ihrer Basis. Die Rahmensetzung erweist sich also als ein Problem der Optimierung.

Ich schließe, nachdem ich soeben von einem abgestuften System der Kontrollintensitäten gesprochen habe, mit einer Frage. Herr Würtenberger, habe ich Sie richtig verstanden, daß Sie in allen Abwägungsfällen nur eine Offensichtlichkeits- oder Evidenzkontrolle zulassen wollen, also für ein einheitliches System der Kontrollintensität plädieren? In diesem Fall müßte ich, unbeschadet der Tatsache, daß ich Ihnen in fast allen Punkten zustimme, doch mit Nachdruck widersprechen.

Isensee: Ich möchte den drei Referaten weithin zustimmen, soweit ich sie verstanden habe. Mein Beifall steht unter Optimierungsvorbehalt. Immer wenn von Optimierung die Rede war, blieb ich mehr oder weniger ratlos. Hier und da versuchte ich, mir den Sinn der „optimierungs" ${ }^{\text {-hal- }}$ tigen Sätze dadurch zu erschließen, daß ich das ominöse Wort einfach ignorierte, also statt „optimierender Abwägung“ schlicht „Abwägung“ re- 
gistrierte - nun meinte ich, zu verstehen, um was es ging. Das Thema der Referate hätte nach herkömmlichem Sprachgebrauch lauten können „Verwaltungsentscheidung $z$ wischen Gesetzesbindung und richterlicher Kontrolle“, vielleicht auch zugespitzt: „Substitution der Gesetzesanwentdung der Exekutive durch Eigenwertung der Judikative ${ }^{\star}$. Doch die drei Referenten müssen die Last der Semantik tragen, machen aus ihrer Not eine Tugend und optimieren, was ihnen vor die rechtstheoretische Flinte kommt. Zu meinem Staunen höre ich, daß die Optimierungsregeln zu verbessern seien, $\mathrm{da} ß$ also dem Superlativ noch ein Komparativ übergestülpt werden kann. Am Ende weiß ich nicht, ob ich stolz oder traurig sein soll, nicht in England oder Frankreich zu leben, jenen Ländern, in denen, wie uns berichtet wurde, die Optimierungsdebatte noch nicht begonnen habe. Glauben wir, daß die Engländer oder Franzosen etwas versäumen?

Vor 25 Jahren erlebte ich so etwas wie eine Generalprobe der heutigen Vortragsveranstaltung, und $\mathrm{zwar}$ beim Habilitationsvortrag eines Betriebswirts, dem ich als Mitglied der Rechts- und Wirtschaftswissenschaftlichen Fakultät der Universität des Saarlandes zuzuhören hatte: Der angehende Habilitand benutzte in auffalliger Häufigkeit das Wort „Optimierung “, auch wenn er nicht annähernd die Optimierungsdichte des heutigen Vormittags erreichte. Ein Strafrechtler, den der ihm fremde Terminus der schon damals amerikanisierten Betriebswirtschaftslehre reizte, bediente sich der Parallelwertung in der Laiensphäre und fragte den Kandidaten, was denn Gegenstand und Maßstab der Optimierung sei; im Referat sei es im wesentlichen um Minimierung der Steuern und um Maximierung des Gewinns gegangen - aus der Sicht der staatlichen Allgemeinheit und aus der Sicht des Kunden bedeute das eher eine Pessimierung. Der Kandidat wußte auf die Frage des Außenseiters keine Antwort. Der Habilitationsvater Kilger räumte ein, es sei zuviel „optimiert ${ }^{\text {s }}$ worden. Die genuin betriebswirtschaftliche Kategorie der Optimierung ist auf dem Umweg angelsächsischer Rechtstheorie und jener Herrn Alexys in die Verwaltungsdogmatik eingedrungen.

Der Sinn des Wortes „Optimierung ${ }^{\alpha}$ changiert. Ich versuche, Bedeutungen, die das Wort in den Referaten des Vormittages angenommen hat, zu unterscheiden und es in die herkömmliche Fachsprache zu übersetzen. „Optimierung" bedeutete zuweilen soviel wie „Rechtsanwendung", zuweilen auch "Wirksamkeit" des Gesetzes. Hier klingt die Unterscheidung an zwischen Geltung und Wirksamkeit des Gesetzes: einerseits der normative Anspruch des Gesetzes auf Geltung, andererseits die reale Einlösung des Anspruchs, seine Wirksamkeit also. Die Normadreassaten haben den Geltungsanspruch mit der Intensität und dem Inhalt zu verwirklichen, wie das Gesetz es vorgibt. Doch sie haben diesen nicht zu op- 
timieren. Das könnte nämlich ein Weniger sein als vorgegeben oder ein Mehr. Das Maß der Optimierung ergäbe sich nicht aus dem Gesetz, sondern aus dem Gusto des Anwenders. Hier und da tritt das Wort Optimierung an die Stelle von „Effektivität ${ }^{\star}$, im Sinn der Auslegungsmaxime, daß Normen im allgemeinen oder nur eine bestimmte Sorte (die Grundrechtsnormen etwa) auf "Effektivität ${ }^{*}$ hin zu interpretieren seien - sei es die im Gesetzesprogramm angestrebte Effektivität, sei es die durch freie Selektion des Gesetzesanwenders bestimmte. „Optimierung" kann aber auch im Sinne von "Richtigkeit" verstanden werden; daß die jeweilige Norm "richtig“ umgesetzt werde. Wiederum erhebt sich die Frage, ob es um die normimmanente Richtigkeit geht oder um eine externe Richtigkeit, wie sie sich aus dem Verfassungs- und dem Europarecht und aus der Idee der Gerechtigkeit ergibt, oder um eine Richtigkeit, die sich nach der Willkür des Interpreten bestimmt. Entsprechende Probleme tauchen auf, wenn die sinnvariable Vokabel auf das Verhältnis des gesetzesakzessorischen zum gesetzesfreien Verwaltungssektor bezogen wird. Im Namen der "Optimierung" verwischen sich die Grenzen zwischen Rechtmäßigkeit und Zweckmäßigkeit, zwischen Legalität und Opportunität.

Angesichts der verwirrenden Semantik erhebt sich die Frage, auf welcher Ebene die Kategorie zu verorten ist. Handelt es sich um Verwaltungsethik, die auf das Zustandekommen möglichst guter Entscheidungen ausgeht, um verwaltungsrechtliche Dogmatik oder einfach um Rechtstheorie? Richtet sich die Kategorie an den Handelnden, also an den Rechtsanwender, oder an den Beobachter, der von der Warte einer Theorie aus auf die Verwaltung hinabschaut, ohne den Ehrgeiz, sich in das Treiben einzumischen? Auch in ihren grundrechtlichen Bezügen erweist sich „Optimierung" als semantischer Wechselbalg, der grundrechtliche Wertordnung bedeuten kann, Ausstrahlung, Wechselwirkung, schonendsten Ausgleich, Vorbehalt des Möglichen, vor allem aber Abwägung.

"Optimale Abwägung“: Norm steht gegen Norm, Rechtsgut gegen Rechtsgut - welche Norm, welches Rechtsgut soll aber optimiert werden? Wenn alles optimiert wird, ergibt sich eine Pattlage. Falls das grammatikalische Unwort erlaubt ist - was ist "optimalex": der offentliche oder der private Belang? Der eine wie der andere läßt sich nicht ohne weiteres als höher oder niedriger einstufen, weil eine Stufenordnung fehlt. Die Grundrechte stehen nicht von vornherein höher als Belange der Allgemeinheit, zumal sie selbst, in ihrer Dimension als objektive Werte und Institutionen, öffentliche Belange darstellen und als solche mit der subjektiven Position des Einzelnen kollidieren können. Was wiegt mehr: das Abwehrrecht des Störers oder der Schutzanspruch des Opfers? Die Fragen führen in das Verwaltungsrecht zurück, zu der Dreierkonstellation Staat - Störer - Opfer, wie sie sich im Polizei- wie im Umweltrecht fin- 
den. Jenseits der Optimierungsbegrifflichkeit werden die kollidierenden Positionen des Störers und des Opfers gewahrt durch das Übermaßverbot auf der einen und das Untermaßverbot auf der anderen Seite; zwischen den zwei Margen bleibt Spielraum für Zweckmäßigkeitserwägungen praktischer Verwaltungsvernunft. Alle juridischen Distinktionen werden jedoch verwischt, indem eine der beiden Positionen oder beide „optimiert" werden. Wenn das Baugesetzbuch der Verwaltung disparate gesetzliche Ziele vorgibt, so verlangt es im konkreten Fall des Zielkonfliktes den Ausgleich der Ziele und statuiert für die jeweils relevanten Ziele einen Mindeststandard an praktischer Wirksamkeit, also ein Anwendungsfall des Untermaßverbotes. Die Formel der Optimierung bietet keine praktische Hilfe. Eher sorgt sie für Verwirrung, wenn alles, was die Dogmatik bisher unterschieden hat, unter den einen semantischen Hut gebracht wird.

Ich möchte von mir aus eine Probe aufs Exempel versuchen für das $\mathrm{Zu}$ sammentreffen von Normen unterschiedlicher Qualität: die Kriterien des Zugangs zum öffentlichen Dienst, der gemäß Art. 33 Abs. 2 GG jedem Deutschen nach Eignung, Befähigung und fachlicher Leistung offensteht. Es gibt Eignungskriterien, die klare Grenzen stecken und der entscheidenden Stelle in der Regel nur ein Ja oder Nein gestatten; das Erfordernis der Staatsangehörigkeit, das Bestehen der laufbahnentsprechenden Eignungsprüfung, das Höchstalter. Neben diesen Kriterien des Entweder/Oder gibt es Kriterien des mehr oder wenigen Guten: Noten des Prüfungszeugnisses, Einstufung der fachlichen Eignung nach dienstlichen Beurteilungen. Die Eignungsauslese für den öffentlichen Dienst soll darauf hinwirken, allen Bewerbern ein faires Verfahren zu sichern, zu verhindern, daß eine ungeeignete Person mit einem öffentlichen Amt betraut wird - das gehört in den Bereich rechtlicher Regeln -, aber auch tunlichst den geeignetsten Kandidaten herauszufinden und ihm das Amt zu übertragen: das allerdings ist ein Prinzip, ein Optimierungsgebot, das über Rechtsanwendung hinausgeht und die autonome Wertung des Inhabers der Personalhoheit fordert. Diesem kommt die Prärogative in der Beurteilung der Bewerber zu. Das Gericht hat die Primärkompetenz der Verwaltung zu respektieren und bescheidet sich mit einer Vertretbarkeitskontrolle. Die Funktion, die dem Begriff der Optimierung in diesem Kontext zufallen kann, ist eher bescheiden, und auch der bescheidene Rest ist verzichtbar, weil sich die Sache, um die es geht, unprätentiös und unmißverständlich ausdrücken läßt.

Gleichwohl übt die Formel heute einen Sog aus. In ihr wirkt die Tendenz, die Richtermacht auf Kosten der Exekutive, aber auch der Legislative zu stärken, weil es letztlich die Richter sind, die kraft ihrer Willkür darüber befinden, ob ein Verwaltungsakt oder ein Gesetz den jeweiligen Optimierungsvorstellungen Genüge tut. In der Formel verwischen sich 
die Kompetenz- und Verantwortungsbereiche. Das Recht wird einerseits entgrenzt, andererseits aufgeweicht, verflüssigt, dynamisiert, verprozessualisiert. Es bildet nicht die feste Ordnung des gesellschaftlichen Lebens, sondern Bewegung, nicht den vorgegebenen Gegenstand der Interpretation, sondern das Stichwort einer permanenten, unabschließbaren Diskussion. Nicht zufällig ist nicht die Rede vom "Optimum" und nicht vom „optimalen Ergebnis“ - das wäre eine vielleicht unerreichbare, doch der Idee nach feste Zielvorgabe. „Optimierung" aber ist dauernde Bewegung, die nicht nach dem Ziel fragt und die des Zieles nicht bedarf: progressus in infinitum.

Die Dogmatik kommt ohne das dynamische Moment nicht aus. Das zeigt die Rechtsfigur der Abwägung. Doch wenn sie wieder festen Boden unter den Füßen zurückgewinnen möchte, sollte sie sich der ersten Funktion des Rechts erinnern, der Abgrenzung. Ceterum censeo: denVorrang der Abgrenzung vor der Abwägung wiederherzustellen. Abwägung (optimierende wie nichtoptimierende) also nur dort, wo sie nicht durch $\mathrm{Ab}$ grenzung ersetzbar und von der Sache her unvermeidlich ist!

Gröschner: Herr Vorsitzender, meine Damen und Herren, gestatten Sie mir die angekündigte methodenkritische Bemerkung, und zwar zum Umgang mit zwei Begriffspaaren: Optimierung und Maximierung einerseits sowie Subsumtion und Abwägung andererseits. $\mathrm{Da}$ ich im wesentlichen an Herm Isensee anschließen kann, glaube ich, eine optimale Nutzung der verbleibenden Diskussionszeit garantieren zu können. "Optimierung" setzt nach meinem Verständnis voraus, daß wir mindestens zwei Größen haben, deren relatives Gewicht zueinander erst und nur im Vorgang der Abwägung bestimmt wird, die also kein Gewicht an sich haben oder deren Ansichgewicht jedenfalls aus Methodenperspektive im Vorgang der Abwägung irrelevant ist. Anders bei der „Maximierung“. Dort, denke ich, setzt ein methodenbewußter Gebrauch des Begriffs voraus, daß wir eine fixe Größe oder eine Größe mit einem ganz genau bestimmten Gewicht haben, dergegenüber dann eine Variable höchstmögliche Wirkung entfalten soll. Ich wage die Behauptung, daß wir es bei der Rechtsanwendung auf allen Gebieten des Rechts niemals mit solchen Begriffen zu tun haben, die quasi apriorisch, also außerhalb des Rechtsfindungsvorgangs, bestimmbar sind. Deswegen wäre aus meiner Sicht der Begriff Maximierung für eine methodenbewußte Jurisprudenz ein verbum prohibitum. Ich würde bei der Optimierung nicht so weit gehen, verbum prohibitum zu sagen, aber gegenüber einer gewissen Optimierungseuphorie doch auch Zurückhaltung im Sinne von Herrn Isensee empfehlen. Darf ich zum zweiten Aspekt ganz kurz kommen: Subsumtion und Abwägung. Ich glaube, die Methodenlehre ist sich heute klar, daß auch die Subsumtion 
unter konditionale Normen - der Luhmannsche Begriff wurde von Herrn Würtenberger heuristisch ja wirklich sehr fruchtbar gemacht - natürlich kein formallogischer Vorgang, keine formallogische Deduktion, sondern Argumentation ist: Auslegung und Anwendung als argumentativer Auswahlprozeß, wie Reinhold Zippelius sehr schön alliterierend formuliert hat. Und aus dieser methodologischen Perspektive scheint mir jene heuristische Unterscheidung von Konditional- und Finalnormen nicht sehr weit zu tragen, und meine Frage wäre, Herr Würtenberger: Würden Sie das im Prinzip, wenn wir uns jetzt wirklich auf Methodenfragen konzentrieren, auch so sehen? Herm Riedel möchte ich sehr zustimmen, weil er uns aus rechtsvergleichender Perspektive klar gesagt hat, letztlich sei alles eine Frage der Kontrolldichte, so daß, ich darf zusammenfassen, es aus meiner dialogischen Sicht des Rechtsfindungsprozesses immer um Argumentationen geht und die Frage allein ist, wie weitgehend wir die Argumente durch die Gerichte überprüfen lassen wollen.

Rossen-Stadtfeld: Herr Vorsitzender, meine Damen und Herren, meine beiden Anmerkungen betreffen überwiegend das Referat von Herrn Würtenberger. Der erste Einwand knüpft bei dem Begriff des Optimierungsgebots an, genauer gesagt, bei der Prinzipienabwägung, auf die dieses Gebot hinzielt. Ich habe nie verstanden, wie Prinzipien abgewogen werden könnten. Rechtsprinzipien haben keine Berührungsflächen. Sie existieren berührungsfrei nebeneinander und stehen alle gleichermaßen unter dem Vorbehalt ihrer Optimierung. Solche Prinzipien können erst in irgendwelchen rechtlichen Operationen eingeführt werden, nachdem sie vorher auf die Ebene der Regeln - Herr Alexy hat diese Begrifflichkeit weit entfaltet - heruntergebrochen worden sind. Anhand welcher normativen Maßstäbe sollten Prinzipien denn auch abgewogen werden können? Es müßten ja Maßstäbe sein, die jenseits dieser Prinzipien existierten, außerhalb ihrer selbst sozusagen. Das scheint mir schwer möglich zu sein. Es sind also immer nur Regeln, die wir abwägen. Und wenn wir dann noch ein wenig genauer hinsehen, dann wird, so glaube ich, ein ganz heterogener Mix von höchst verschiedenen Gesichtspunkten sichtbar, die in eine konkrete Abwägungs- und Entscheidungslage einfließen. Gesichtspunkte, die teils rechtlicher Herkunft und Art sind, teils aber auch Tatsachen betreffen, die situativ gebildet werden, Gelegenheitsstrukturen abgezogen werden usw. Das ist die Situation, in der sich der Verwalter ,vor Ort ${ }^{\alpha}$ meistens befindet. Das ist der Verwaltungsalltag. Recht ist hier ein Gesichtspunkt, aber eben nur ein Gesichtspunkt unter anderen. Vielleicht auch oft kein vorrangiger Gesichtspunkt. Und damit bin ich auf dem Gebiet der Verwaltungslehre und bei meinem zweiten Einwand angekommen. Wer ist das eigentlich, der hier entscheidet und 
für den unter den Gesichtspunkten der Optimierung und der Rahmensetzung Entscheidungsfreiräume geschaffen werden sollen? Die Antwort lautete: Verwaltung. Demgegenüber sagt uns die Verwaltungslehre, daß die Verwaltungsentscheidung vielfach eben gerade nicht mehr, jedenfalls nicht mehr allein, von der Verwaltung, sondern in ihrerseits wiederum einigermaßen unübersichtlichen, vielgestaltigen Netzwerken getroffen wird. In Netzwerken, in denen sich staatliche mit gesellschaftlichen Akteuren verbinden. Wenn die Verwaltungsentscheidung in diesem Geflecht entsteht, dann drängt sich doch die Frage auf, wie das noch gesteuert wird. Kann das überhaupt noch durch Recht gesteuert werden? Wir rechnen immer noch vorwiegend mit gesetzlich angeleiteten staatlichen Akteuren. Wir können ja auch kaum anders verfahren. Die Normen zwingen uns dazu, letztlich die der Verfassung. Aber wir tun das auf schwankendem Boden, denke ich. Selbstverständlich gilt das nicht für alle Bereiche der Verwaltung. Die maßgeblichen und sich dynamisch entwickelnden Referenzbereiche des modernen Verwaltungsrechts aber, so scheint mir, sind von dieser tatsächlichen Unklarheit im Hinblick auf Urheber, Ort und Maßstäbe der Verwaltungsentscheidung geprägt. Vor diesem Hintergrund kann das Wort von der Verantwortungsteilung eigentlich nur als ein Euphemismus verstanden werden. Vielen Dank.

Starck: Herr Vorsitzender, meine Damen und Herren. Es ist jetzt schon viel über das Thema gesprochen worden, und deswegen möchte ich nur noch einmal festhalten, daß die Referate und Diskussionsbeiträge sehr schön gezeigt haben, wie sehr die Gegenüberstellung von Optimierungsgeboten und Rahmensetzung für die Anwendung von Normen, die Abwägungsvorgaben, Finalbestimmungen und Ermessensbestimmungen enthalten, eine fruchtbare Klärung eines verwaltungsrechtlichen Grundproblems wesentlich beiträgt.

Der zweite Gesichtspunkt, der mich veranlaßt hat, mich zu melden, ist, daß unsere Thematik Rechtsvergleichung geradezu herausfordert, und zwar eine Rechtsvergleichung auf der Basis von Rechtsordnungen, die man als rechtsstaatlich und demokratisch bezeichnen kann. Bei dieser Rechtsvergleichung geht es zunächst um die Vergewisserung des eigenen Weges, den wir gehen. Ebenso wichtig und damit verbunden ist aber, daß viele dieser Rechtsordnungen Grundlagen für die Herausbildung eines Verwaltungsrechts der Europäischen Gemeinschaft sind und daß letzten Endes auch in diesem Zusammenhang gemeineuropäisches Verwaltungsrecht entstehen wird, das auf die einzelnen nationalstaatlichen Verwaltungsrechtsnormen einwirken wird.

Dieser Prozeß der Bildung eines gemeinen europäischen Verwaltungsrechts trifft auf ganz erhebliche rechtskulturelle Unterschiede, die Herr 
Riedel, aber auch schon Herr Würtenberger und selbstverständlich auch Herr Haller herausgearbeitet haben. Wenn man die Ergebnisse unter soziologischen Gesichtspunkten kurz zusammenfaßt, kann man sagen, daß in England und Frankreich ein relativ großes Vertrauen in die Verwaltung besteht, während bei uns traditionellerweise eher der Richterschaft vertraut, der Verwaltung aber mißtraut wird. Herr Bullinger hat insoweit auf einen wichtigen Punkt hingewiesen. Wenn auf die Dauer das Vertrauen in die Verwaltung gestärkt werden soll, setzt das geeignete Organisation und personelle Ausstattung insbesondere mit Know-how voraus. Insoweit sind die rechtskulturellen Unterschiede nicht für immer fixiert; vieles kann sich ändern, was zu hoffen ist. Es setzt auch voraus, daß die Richterschaft das Vertrauen in die Verwaltung nicht immer wieder neu zerstört, indem sie $Z$ weckmäßigkeitsfragen über das verfassungsrechtliche Verhältnismäßigkeitsprinzip zu Rechtsfragen hochstilisiert. Das Vertrauen in die Verwaltung kann dadurch gefördert werden, daß in den Urteilsgründen der Rahmencharakter des Rechts stärker betont wird. Selbstverständlich muß das Gericht eingreifen, wenn die Verwaltung von Lobbyismus, von parteipolitischem Einfluß und sachfremden Gesichtspunkten bestimmt wird.

Bei Herrn Riedel hat dann zu Recht der Unterschied der Verfassungsrechtsordnungen der in Vergleich gezogenen Länder eine große Rolle gespielt. Er hat sich mit der Rechtsweggarantie des Art. 19 Abs. 4 GG beschäftigt und die Problematik auf die Frage der Kontrolldichte zugespitzt. Das schien uns bei der Themenstellung in der Tat am wichtigsten. Wie Herr Würtenberger deutlich gezeigt hat, führen Optimierungsgebote zwangsläufig zum Einsickern von Zweckmäßigkeitsfragen in die gerichtliche Rechtskontrolle, d.h. zur Verwischung der Grenzen von Rechts- und Zweckmäßigkeitskontrolle, die die $\$ \S 68$ Abs. 1 S. 1,113 Abs. $1 \mathrm{VwGO}$ so fein säuberlich zu trennen versuchen. Wie kann man diese Trennung in der Praxis erreichen und die Kontrolldichte der Verwaltungsgerichte vermindern, gewissermaßen auf den gemeineuropäischen Stand bringen? Hier sehe ich wenige Möglichkeiten für die Gesetzgebung. Werden die Gesetze deutlicher als Rahmenrecht formuliert, so kommen die Richter über die Grundrechte, über das Verhältnismäßigkeitsprinzip dazu, die einzige richtige Lösung zu verlangen. Die Umkehr muß von der Rechtsprechung ausgehen und vom Bundesverfassungsgericht gebilligt werden. Es muß also eine gerichtliche Umsteuerung vonstatten gehen. Darüber ist ja schon viel gesprochen worden, so über die Änderung oder Neuauslegung des $\S 114$ VwGO, indem man den Ermessensbegriff so faßt, daß auch die unbestimmten Rechtsbegriffe darunter fallen und andere offene Normen, Beurteilungsspielräume usw.

Ein anderer Punkt, der in den Referaten nicht angesprochen worden 
ist, und damit will ich schließen, ist die Frage der Gerichtsorganisation. Wir haben hier eine merkwürdige Situation in Deutschland. Die Unzahl von Prozessen führte zu einer ständigen Vermehrung der Richterschaft. Und wenn man viele Richter hat, kann man die Geschäfte so verteilen, daß sich spezialisierte Fachkammern und Fachsenate bilden. Je mehr spezialisierte Spruchkörper es gibt, und je mehr die Richter über lange Jahre immer nur mit Rechtsfragen aus einem Fachgebiet beschäftigt sind, um so genauere Spezialisten des Baurechts, des Gemeindesteuerrechts und dergleichen werden sie. Die Frage ist, ob man nicht auch über die interne Gerichtsorganisation eine Umsteuerung erreichen kann. Nur wenn die Richterschaft sehr spezialisiert ist, traut sie sich zu, auf die optimale Gesetzesanwendung hinzuarbeiten und dadurch die Optimierungsfrage zur Rechtsfrage zu stilisieren.

Paul Kirchhof: Wenn wir heute die Frage nach den rechtlichen Handlungsaufträgen stellen, bei denen der Entscheidungsmaßstab nur prinzipiell vorgegeben ist, stehen wir im Grunde vor der Frage, was das Recht leisten kann und was das Recht leisten soll. Hier kennen wir die herkömmliche und richtige Antwort: Das Recht schreibt erprobte Rechtserfahrung fest, sichert bewährte Werte, eröffnet verläßliche Entscheidungsund Erneuerungsverfahren und sagt, was unbedingt sein muß und was keinesfalls sein darf. In diesem Rechtsverständnis haben wir eine befriedigende, vielleicht auch eine gute Rechtsordnung hergestellt. Jetzt aber drängt es uns zum Besseren, nein es drängt uns zum Besten, selbst wenn es, Herr Alexy, mehrere beste Lösungen gibt. Mit diesem Streben nach dem Besten bringen wir eine gewaltige Dynamik, aber auch eine Unstetigkeit, eine Unruhe, in unsere Rechtsordnung. Deswegen möchte ich eine am Beispiel des Verfassungsrechts formulierte Frage an die Referenten richten, wobei ich Herrn Würtenberger ein bißchen von seiner eindrucksvollen Theorie ins Konkrete locken und Herrn Riedel bitten möchte, die schöne Brücke, die er von England und Frankreich nach Deutschland geschlagen hat, noch weiter in Richtung Mitteleuropa zu betreten. Das Grundgesetz ist das Gedächtnis unserer Demokratie. Es will das, was unverbrüchliches Recht ist, festschreiben und bewahren. Deshalb hat diese Verfassung im Prinzipiellen stets etwas Beharrendes, etwas Statisches. In dieses bewahrende Verfassungsrecht haben sich nun aber Superlativtatbestände eingeschlichen - der schonendste Ausgleich, der geringstmögliche Eingriff, die kostengünstigste Lösung, das wirtschaftlichste Angebot. Nehmen wir diese Superlativtatbestände beim Wort, so drängen sie die Rechtsanwendung immer auf ein Optimum, auch wenn vielleicht ein Beharren bei der guten die verläßlichere Lösung wäre. Wir verlassen das Gute in der Hoffnung, das Bessere zu erreichen, 
ohne aber zu wissen, wo wir letztlich ankommen. Deswegen genügt der schonende Ausgleich, der maßvolle Eingriff, die sparsame und wirtschaftliche Lösung.

Dieses Bemühen um die gediegene Rechtsordnung, die in ihrer rechtsstaatlichen Stetigkeit und ihrer demokratischen Legitimationsbedürftigkeit nicht stets die beste sein kann, ist nicht nur Inhalt des Verfassungsrechts, das nur das schlechthin unaufgebbare Recht bündelt und deswegen ein besonderes Beharrungselement enthält. Unser Problem läßt sich ebenso am Planungsrecht veranschaulichen, bei dem von vornherein Abwägungsfragen im Mittelpunkt stehen und damit Optimierungsstrategien nicht fernliegen. Nehmen wir als Beispiel den klassischen Plan, den Haushaltsplan: Hat der Haushalt ein Volumen von 600 Milliarden DM, so bieten sich soviele Abwägungslösungen, als diese Summe durch DM teilbar ist. Bei diesen Optimierungsperspektiven schwirrt selbst dem abstraktesten Theoretiker der Kopf, weil er allein von der Zahl her kaum einen Orientierungspunkt gewinnt. Unsere Rechtsordnung reagiert auf diese Entscheidungslast durch Kompetenzzuweisung. Sie sagt zunächst, daß über den Haushalt der Gesetzgeber entscheidet und daß nach der Entscheidung durch das Gesetz die Verwaltung ermächtigt ist. Sie muß den Haushalt nicht vollziehen, sie kann z.B. sparsamer sein als der Gesetzgeber, darf aber von den Ermächtigungen des Haushaltsgesetzes Gebrauch machen. Die haushaltsgesetzliche Ermächtigung enthält die Befàhigung zum finanzwirtschaftlichen Handeln im Rahmen der gesetzlichen Vorgabe als Blankettermächtigung, die von der Verwaltung mit dem Stolz wahrgenommen wird, aus diesem abstrakten Dürfen etwas Konkreteres, etwas Gewichtigeres zu machen, als der Gesetzgeber vorschreiben könnte. Unser Optimierungsauftrag ist also letztlich ein Problem präzise definierter Kompetenzzuweisung und maßvoller Gesetzesbindung. Für die Konkretisierung ist dann entscheidend, ob die Kompetenz der Verwaltung oder zugleich der Rechtsprechung zugewiesen wird. Innerhalb der Rechtsprechung darf dann der Instanzenzug wiederum nicht als Optimierungsabstufung verstanden werden. Anderenfalls spräche die Vermutung dafür - ich wage kaum, dieses zu sagen -, daß die letzte Instanz es stets am besten weiß. Dadurch entstünde eine Sogwirkung, wonach sich alle Entscheidungen schließlich in der letzten Instanz sammeln und diese dann im Optime zusammenbrechen lassen.

Eine letzte Bemerkung verfahrensrechtlicher Art, die auch wieder die Abwägung zwischen gegenläufigen Zielen ins Konkrete wenden will. Wendet sich ein Bürger mit der Urteilsverfassungsbeschwerde gegen eine Gerichtsentscheidung, so verlangt er vom Verfassungsgericht eine andere Ausbalancierung von individueller Freiheit und Gemeinwohl. In dieser Abwägungskonzeption stellt sich die Frage, ob ein solcher Prozeß nicht 
einen Generalanwalt braucht, der das öffentliche Interesse vertritt. Hat die letzte Instanz der Fachgerichte zum Nachteil des Gemeinwohls entschieden und dem Bürger etwas mehr an Rechten gegeben, als ihm von Verfassungs wegen zusteht, so gibt es dagegen keinen Rechtsbehelf. Auch hier tritt das Anliegen zutage, die Ausgewogenheit und Stetigkeit dex gebotenen Abwägungen durch Kompetenzzuweisungen und Verfahrensregeln zu sichern.

Schulze-Fielitz: Herr Vorsitzender, meine Damen und Herren, erlauben Sie mir drei kurze Anmerkungen. Die ersten beiden zur Rechtsvergleichung. Herr Riedel hat festgestellt, daß es so etwas wie einen Annäherungsprozeß unterschiedlicher Verwaltungsrechtskulturen im Sinne eines harmonisierenden Angleichungsprozesses gibt. Soweit das eine empirische Beobachtung ist, bin auch ich davon überzeugt. Sobald dabei aber unterstellt wird, daß wir diesen Prozeß in dem Sinne instrumentell auffassen sollten, daß wir unsere Verwaltungsrechtskultur automatisch anpassen oder ändern sollten, dann würde ich um eine Klarstellung bitten. Ich bin lernbereit und würde auch nicht irgendwelche Status-Quo-Garantien aus Art. 19 Abs. 4 GG zu weitgehend ableiten wollen, aber ich würde doch bitten, daß man die Gründe der unterschiedlichen Verwaltungsrechtskulturen in England, Frankreich und Deutschland mit einbezieht. Unsere extrem legalistisch geprägte Kultur (etwa ablesbar in der Zahl der Richter oder in der Art der Rechtsordnung, der Ausgestaltung) ist doch Antwort auf eine in Jahrzehnten oder Jahrhunderten gewachsene Tradition, und wenn wir jetzt anfangen, an Symptomen zu kurieren und schnell mal umzusteuern, weil wir uns irgendwie „anpassen" wollen, laufen wir Gefahr, solche - wenn man so will - Errungenschaften deutschrechtsstaatlicher Prägung vielleicht mit aufzugeben. Mit anderen Worten: Allein der Vergleich dogmatischer Figuren bringt uns nicht weiter. Dann noch eine Nebenbemerkung: Wenn man Art. 19 Abs. 4 GG hochhält Herr Würtenberger, Sie sprachen von „Verfassungsimperialismus" ${ }^{\alpha}$ - fällt die Technik auf, positiv und negativ besetzte Begriffe in einem Begriff zusammenzuführen, z.B. der „totale Rechtsstaat ${ }^{\text {“ oder } ~ „ M e n s c h e n r e c h t s-~}$ rhetorik". Sie soll den positiv besetzten Begriffsteil kritisieren, aber man läuft so Gefahr, diesen positiven Wert dadurch auch zu entwerten, und deswegen bin ich gegen solche Begriffe. Daher sollte man noch einmal darüber nachdenken, ob man sie gebrauchen soll.

Zweite Bemerkung. Wir haben hier unter den Gesichtspunkten Ermessen, unbestimmter Rechtsbegriff, Planungsdogmatik, Optimierung verglichen. Herr Riedel hat uns das sehr schön vorgeführt, und als Tendenz ist uns der alte Gedanke der Verschiebung der Schwerpunkte der Rechtskontrolle von der materiellen Nachprüfung hin zur Verfahrenskontrolle 
nahegelegt worden. Aber ich meine, man müßte auch zusätzliche Äquivalente in den fremden Rechtsordnungen mit einbeziehen. Zwei Beispiele: Die Rolle der Verwaltungsöffentlichkeit, das Recht auf Verwaltungsinformation, das ja für die Art und Weise, für die Ausgestaltung des Verfahrens erhebliche Bedeutung haben soll, spielt in den anderen Ländern eine ganz andere Rolle. Wie weit muß man dementsprechend unser Verfahrensrecht umgestalten, ehe man den Schritt zur Abkehr von der materiellen Prüfung geht? Zweites Beispiel: Das Verwaltungsorganisationsrecht wurde heute zwar weithin ausgeklammert. Herr Würtenberger hat aber gefordert, aller Sachverstand soll in der Verwaltung gesammelt werden, die dafür zuständig und funktionsadäquat ausgerichtet ist. Aber müssen wir nicht dann auch, ehe wir eine Rücknahme der Kontrolle hinnehmen, z. B. Organisationsgarantien über die Art und Weise der Berücksichtigung des Sachverstandes weit mehr, als wir sie jetzt haben, gleich mit hinzudenken? Das heißt, der Zusammenhang von materiellem und formellem Recht hätte uns zu beschäftigen, bevor wir kurzschlüssig punktuelle Dogmatikfolgerungen ziehen.

Letzte Bemerkung: Warum gibt es eigentlich das Bedürfnis nach Optimierungsklauseln oder Optimierung? Der Kern unseres Themas ist doch der, daß offenbar die Steuerungsfähigkeit von Recht nicht die Kapazität hat, um all diese Prozesse zu lenken oder zu kontrollieren, die eine immer komplizierter werdende moderne Industriegesellschaft auszeichnen. Und die Optimierung ist der Versuch, trotzdem das Recht noch wirken zu lassen, weil es eben nicht mehr mit den klaren eindeutigen Regeln konditionaler Programmierung funktioniert. Wenn das aber so ist, und wenn das Recht oft vergeblich angerufen wird, dann müssen wir, weit mehr als bisher, uns weniger selbst bescheiden auf Rechtsdogmatik, sondern wir müssen, in Anknüpfung an ältere Traditionen, äquivalente Formen der Steuerung und Kontrolle mit in das Verwaltungsrecht aufnehmen, wir müssen die Verwaltungswissenschaft einbeziehen, etwa Effektivitätskontrollen, Kosten-Nutzen-Analysen, alles das, was die traditionellen Verwaltungswissenschaften oder vielleicht Staatswissenschaften mit einbezogen haben, und wir dürfen nicht sagen, das sei kein Recht mehr. Moderne Verwaltung läßt sich möglicherweise eben nicht nur rechtlich steuern, auch wenn wir es versuchen, indem wir etwas als Optimierung etikettieren. Schönen Dank.

Vorsitzender: Wir kommen jetzt zu den Zwischenworten, und zwar in der Reihenfolge der Referate.

Würtenberger: Als erster Punkt sei herausgestellt, daß offenbar Konsens dahin besteht, daß die Betonung des Verfahrensgedankens sehr 
wichtig ist. Vor allem Herr Fromont hat hierauf mit Nachdruck hingewiesen, aber auch in anderen Stellungnahmen ist das angeklungen. In diesem Zusammenhang hat Herr Bullinger die Frage nach dem Personal in der Verwaltung gestellt, das in der Lage ist, ein Verwaltungsverfahren so zu führen, wie es in meinen Ausführungen entwickelt wurde. In diese Richtung gingen ebenfalls die Fragen von Herrn Schulze-Fielitz und Herrn Rossen-Stadtfeld. Die Frage nach dem Personal ist in der schriftlichen Fassung deutlicher angesprochen, als es aus Zeitgründen in dem mündlichen Vortrag möglich gewesen wäre. Es erscheint mir äußerst wichtig, daß das Verwaltungspersonal und das Verwaltungsmanagement den Anforderungen an ein modernes Verwaltungsverfahren gerecht werden. So gehört es bereits seit langem zum Lehr- und Forschungsprogramm der angelsächsischen Universitäten, die Verwaltung, ebenso wie die Anwälte im Umgang mit Konfliktlösungsstrategien zu schulen. Hier geht es nicht nur um die Vermittlung rhetorischer Fähigkeiten beim Umgang mit Einwendern oder Sachverständigen, sondern auch darum, zu lernen, wie das Recht in einer sach- und interessenadäquaten Weise konkretisiert werden kann. Vermittelt wird der Umgang mit Nutzen-Kosten-Analysen, mit wissenschaftlich-technischem Sachverstand, mit der interessierten Öffentlichkeit u. a. mehr. In der Bundesrepublik Deutschland fehlt es bislang wohl weitgehend an einer derartigen fachlichen Schulung.

Unmittelbar im Zusammenhang hiermit steht die ebenfalls angesprochene Frage, ob man nicht auch andere Bürger braucht, die stärker als bislang aus Gemeinsinn heraus darauf hinwirken, daß die sachlich richtige Entscheidung von der Verwaltung getroffen wird. Aus meiner Sicht kann sich der Bürger auf einen liberal orientierten Egoismus beschränken. Wenn die Bürger im Verwaltungsverfahren ihre Interessen gegeneinander und miteinander durchsetzen und wenn die "Egoismen" der Bürger verfahrensmäßig abgearbeitet werden können, kann dies zur relativen Richtigkeit von Verwaltungsentscheidungen wesentlich beitragen. Diese Überlegungen führen zu der bereits angesprochenen Präferenzautonomie zurück, die sich hier fruchtbar machen läßt. Wenn eben jeder seine Präferenzen in das Verfahren einbringen kann, so steht zu erwarten, daß sich ein Optimum an Entscheidungsautonomie verwirklichen läßt.

Von Herrn Rossen-Stadtfeld ist gegenüber dem hier entwickelten Ansatz kritisch angemerkt worden, daß die Verwaltung nach den modernen Verwaltungswissenschaften eher als Netzwerk zu verstehen sei. Solche theoretischen Netzwerkvorstellungen scheinen mir wenig sinnvoll zu sein. Wer die Praxis der Planungs- und Genehmigungsverfahren kennt, muß nicht auf den Begriff Netzwerk zurückgreifen, um zu beschreiben, daß der Antragsteller etwas will, daß die zahlreichen mitbeteiligten Behörden nicht nur Vertreter eines öffentlichen Interesses, sondern vielfältiger un- 
terschiedlicher öffentlicher Interessen sind, daß die Einwender ebenfalls unterschiedliche Interessen in das Verfahren einbringen und daß nicht zuletzt auch der Rückgriff auf den Sachverstand interessengeleitet sein kann. Das Charakteristische an einem Verwaltungsverfahren ist der Diskurs, der $z$ wischen sehr unterschiedlichen Vertretern privater und öffentlicher Interssen geführt wird und aus dem, bei einem gewissen Optimismus, ngute ${ }^{*}$ Entscheidungen hervorgehen.

Sehr ausführlich wurde die Methodenfrage diskutiert. Herr Alexy hat sehr pointiert seinen methodischen Ansatz vorgestellt, der in meinem Referat zum Teil rezipiert worden ist. Herr Isensee hat ebenso pointiert ein Gegenmodell entwickelt, nach dem der Begriff der Optimierung und der damit verbundene methodische Zugriff auf die Abwägung im Recht wenig nützlich seien. Dieser Frontalangriff auf Begrifflichkeit und Methode kann aus meiner Sicht zunächst darum nicht überzeugen, weil der Begriff "Optimierung" ein Begriff ist, der in der Rechtsprechung des Bundesverfassungsgerichts, in der verwaltungsgerichtlichen Rechtsprechung, im Verwaltungsrecht sowie in der Rechtstheorie deutliche Konturen gewonnen hat. Die juristische Dogmatik und das juristische Denken sind also durch diesen Begriff geprägt, wobei sich dann die weitere Frage anschließt, ob dieser Begriff, in einem hegelianischen Sinn, etwas Vernünftiges umschreibt. Hier haben mich Herr Gröschner und andere Diskussionsbeiträge darin bestärkt, daß der Begriff Optimierung deshalb sinnvoll ist, weil er $z$ wischen einer konditionalen Programmierung einerseits und der Vorgabe von Abwägungsspielräumen durch Verfassung und Gesetz andererseits unterscheiden hilft. Auf der einen Seite steht in der alten Tradition der Methodenlehre die Auslegung von Rechtsnormen, auf der anderen Seite steht die Abwägung zwischen gegenläufigen Prinzipien und zwischen gegenläufigen Interessen. Stärker als bei der Auslegung geht es bei der Abwägung um eine rechtschöpfende Tätigkeit. Kommt man um die Kategorie der Abwägung im Recht nicht herum, so stellt sich die wichtige Aufgabe, wo im Bereich der Abwägung die Schnittpunkte zwischen exekutivischem und judikativem Bereich liegen. Davon abgesehen ist die Optimierungsidee im Planungsrecht ausgesprochen oder unausgesprochen eine Leitvorstellung. So will etwa ein Bebauungsplan nicht allein die vielfältigen und in sich heterogenen Vorgaben des Baugesetzbuchs erfüllen, sondern er sucht eine bestimmte bauplanerische Konzeption in optimaler Weise zu verwirklichen.

Haller: Herr Bullinger hat die Frage gestellt: Wie sind die anspruchsvolleren Konzepte mit der bestehenden Verwaltung realisierbar? Ich hatte dieselben Bedenken und habe deshalb den Verzicht auf Regelung, die Vereinfachung von Regelung und die Verbesserung des Bestehenden befür- 
wortet, um für die Bereiche, in denen wir von der Verwaltung durch Rahmensetzung mehr haben wollen als bisher, Freiräume zu geben. Als jemand, der ein wenig in der Beamtenschulung tätig ist, weiß ich, daß die Verwaltung noch nicht immer für allzu hohe Aufgaben reif ist. Ich würde deshalb die Frage von Herrn Bullinger mit einem Ja beantworten, aber auch ich zweifele. Herr Engel hat Demokratieverluste und Rechtsstaatsverluste zur Erwägung gestellt. Wollen wir wirklich verzichten auf Vorhersehbarkeit, auf inhaltliche Kontrolle? Sie haben vielleicht gesehen, daß ich gewisse Bedenken im Rahmen des EU-Rechts geäußert habe. Wollen wir wirklich diese großen Ermessensräume, und wollen wir wirklich diese Verfahrenskontrolle unter Aufgabe inhaltlicher Gesichtspunkte? Ich glaube auch, daß das im Referat von Herm Riedel sehr stark zum Ausdruck gekommen ist. Herr Alexy hat gefragt: Optimierungsgebote und Rahmensetzung ist das ein Gegensatz? Ich habe versucht, dem auszuweichen. Herrn Isensee vorausahnend, habe ich das Wort Optimierung nur ein einziges Mal verwendet, gerade um nicht das Thema zu verfehlen. Weil auch ich hier Bedenken hatte, habe ich mich mehr beschäftigt mit den Fragen "Wie weit ist Determinierung möglich?", „Wie weit ist die Kontrolldichte?" Herr Gröschner es angesprochen hat. Daß die Verwaltung, wenn sie zwischen der Determinierung des Gesetzes und der Kontrolle des Gerichts steht, selbst - ob Netzwerk oder nicht - zwischen politischen Parteien, Parteien, die etwas wollen, und Lobbies steht, habe ich mehrfach angesprochen. Ich glaube, daß das Umfeld neben den schönsten Konzepten eben sehr stark beachtet werden sollte. Herr Starck hat vom Mißtrauen gegenüber der Verwaltung gesprochen. Ich habe das besonders betont: Mißtrauen gegenüber der Politik gegen einer Überlegenheit, gegenüber einer zu starken Machtposition der Verwaltung. Auch bei den Fragen von Herrn Kircbhof nach der Leistungsfähigkeit des Rechts und der Unruhe möchte ich reklamieren, daß ich relativ stark für die Verbesserung des Bestehenden plädiert habe, um das, was erreicht ist, nicht zu gefährden. Ich glaube, daß Fragen der Qualität der Beamten, ihrer Schulung und des Umfeldes wichtig sind und daß hier Verbesserungen liegen sollten. Diesen Fragen kann man natürlich nicht so sehr mit Konzepten und Worten, sondern eher mit der Anerkennung der Realitäten begegnen. Ich glaube also, daß die Fragen, die in der Diskussion angesprochen worden sind, mir ein wenig bestätigen, daß ich versucht habe, das Thema für mich zurechtzurücken, und es nicht ganz verfehlt habe. Danke schön.

Riedel: Da ich heute morgen schon reichlich Gelegenheit hatte, mein Exposé vorzustellen, muß ich mich jetzt knapp fassen und kann deshalb nur einige Punkte der Diskussion aufgreifen. Zunächst ganz kurz eine Bemerkung zu den Ausführungen von Herrn Alexy. Fast alle haben sich ja 
dazu geäußert. Ich habe ihn so verstanden, daß bei der Ausarbeitung von Konditional- und Finalprogrammen die Unterscheidung von Regeln und Prinzipien im Zentrum seines rechtstheoretischen Interesses lag, daß es bei der Optimierung, bei den Prinzipien, primär um Abwägungsoffenheit geht, nicht um Richtigkeit, etwa im Sinne etwa von Larenz' "Richtiges Recht ${ }^{*}$, sondern um Plausibilität, um Nachvollziehbarkeit. Wenn man das so versteht, ist der Einwand oder die Frage von Herrn Isensee gleich mitbeantwortet. Ein Beispiel für Regeln wäre etwa die von Herrn Alexy - allerdings in einer Fußnote - genannte Bestimmung des $\S 5$ der Straßenverkehrsordnung, daß man links überholen müsse und nicht rechts. Der Unterschied zwischen der Regel und dem Prinzip besteht dann ja wohl darin, daß man mit einem Prinzip ohne eine nähere Abwägungs- und Konkretisierungsarbeit keinen einzigen Sachverhalt direkt und sofort subsumieren kann, sondern es bedarf dann stets noch der Normkonkretisierung. Bei einer Regel, etwa dem Gebot links vor rechts, oder rechts vor links in Großbritannien, besteht prinzipiell die Möglichkeit, eine Subsumtion sofort und unmittelbar durchzuführen. Wenn das so ist, dann muß man natürlich auch die Ausnahmen beachten, auf die ich jetzt aber nicht eingehen möchte. Herr Rossen-Stadtfeld hat von Netzwerken gesprochen und davon, daß nicht nur die Verwaltung entscheidet, sondern daß es hier auch gesellschaftliche Strukturen gibt, die Entscheidungen mitprägen. Herr Würtenberger ist schon darauf eingegangen, so daß ich das hier nicht wiederholen möchte. Herr Würtenberger hat dabei den Diskursaspekt hervorgehoben. Auch ich möchte betonen, daß diese Netzwerke, die die gesellschaftlichen Strukturen prägen, sicher bedeutsam sind, und in meiner allerletzten These habe ich versucht, dies auch anzudeuten. Es handelt sich dabei aber um den Bereich vor der eigentlichen Verwaltungsentscheidung. Die eigentliche Entscheidung muß am Ende eines Tages stets voll von der Verwaltung als Exekutive oder Administrative verantwortet werden. Es geht also um das Vorfeld der Entscheidung, und da stimme ich Ihnen insoweit zu. Lassen Sie mich noch die Frage von Herm Kirchbof herausgreifen: „Was kann das Recht leisten, was soll es leisten?" Er sprach von einer Unruhe in der Rechtsordnung, die durch eine solche Fragestellung hervorgerufen wird. Ich hatte ja in der Tat das Bekenntnis unserer Rechtsordnung zum Grundgesetz herausgestellt und über allen Verfassungsvergleich gestellt. So nützlich der Verfassungsvergleich ist, es gibt gewisse Grundparameter, die unverzichtbar, unverhandelbar und auch über Rechtsvergleichung nicht relativierbar sind. Insofern weist unsere Rechtsordnung eine gewisse verharrende und statische Tendenz auf, die durch eine solche Grundgesetzfixierung bewirkt wird. Herr Kirchbof thematisierte dann noch die sogenannten "Superlativtatbestände ${ }^{\alpha}$. In der Tat muß man sich fragen, ob nicht anstelle der Kategorien des schonendsten Ausgleichs, der kostengünstig- 
sten Regelung oder des mildesten Mittels, die stets eine schlechthin richtige Lösung suggerieren, nicht schon ein "schonender ", „kostengünstiger" oder "milder" Ausgleich reicht. Wenn ich Sie recht verstehe, Herr Kirchbof, so darf man diese Bemerkung aber auch als ein Plädoyer für größeren ,judicial self-restraint ${ }^{\alpha}$ des Bundesverfassungsgerichts verstehen. Die Nachvollziehung im Sinne einer Abwägungsnachvollziehung ist das Entscheidende, worauf es mir heute morgen ankam. Nach meiner Einschätzung hat das französische Recht, worauf auch Herr Fromont hingewiesen hat, deutlich gemacht, daß es nicht so sehr um eine Abwägungsalternative geht, die entweder von der Exekutive oder von der Judikative vorgenommen wird, sondern darum, daß die Judikative sich mit guten Gründen jedenfalls in Frankreich auf einen Nachvollzug der Abwägung beschränkt.

Die weitere Frage, ob nicht ein Vertreter des öffentlichen Interesses, ein Generalanwalt europarechtlicher Prägung, vielleicht eine sinnvolle Änderung wäre, halte ich für eine interessante Anregung, die der Vertiefung bedürfte, zumal man darauf hinweisen kann, daß mehr als $80 \%$ der Entscheidungen des $\mathrm{EuGH}$, soweit ich es übersehe, den Empfehlungen der Generalanwälte folgen. Und so sage ich den Studenten immer: Lest das Schlußplädoyer des Generalanwalts. Dort finden sich sehr sorgsam abgewogen alle Argumente, die oftmals in der Urteilsbegründung des EuGH zu kurz kommen.

Das Verhältnis von Freiheit und Gemeinwohl ist zweifellos die große Frage, die hinter allen Fragen der ersten Runde stand. Herr Bullinger hat es mit der Kulturbedingtheit des Rechts angesprochen, und ich finde es bemerkenswert, daß sich etwa Großbritannien mit seiner Rule of Law, die nicht nur prozedural wirkt, hierauf stützt. Es erinnert mich an die Forderungen des formellen Rechtsstaates im Sinne Otto Mayers zu Beginn dieses Jahrhunderts. Diese Forderungen ebneten bekanntlich erst den Weg für die späteren Forderungen des materiellen Rechtsstaats. In Großbritannien ist 1689 durch die Glorious Revolution ein Machtkampf entschieden worden, ich hatte es heute morgen nur angedeutet, in der schriftlichen Version ist es enthalten. Gestritten hatten Parlamentarier und Richter im Verbund gegen die Prärogativrechte der Krone. Gewonnen hat aber nur das Parlament. An die Stelle eines absoluten Monarchen trat 1689 im Ergebnis ein prinzipiell absolutes Parlament, das nur durch den good sense of the British people begrenzt wurde. Jetzt, unter dem Einfluß des EG-Rechts und der dadurch beflügelten Rechtsvergleichung, die in Großbritannien konsequent unternommen wird, ist ein deutliches Umdenken erkennbar, und ich bin Ihnen sehr dankbar, Herr Bullinger, daß Sie darauf hingewiesen haben. Vielen Dank. 
Vorsitzender: Ich möchte nun einen Schnitt machen, wie bereits angedeutet. Die bisherige, sehr grundsätzliche Diskussion hat vielleicht ein wenig in den Hintergrund treten lassen, daß es so etwas wie real existierende Optimierungsgebote gibt, ob man sie nun gutheißt oder nicht. Lassen Sie mich ein praktisches Beispiel nennen, das zugleich zu den europarechtlichen Fragen überleitet. Es gibt bekanntlich eine EG-Richtlinie über die Umweltverträglichkeitsprüfung. Deren Umsetzung hat gerade in der Bundesrepublik Deutschland erhebliche Schwierigkeiten bereitet. Die Richtlinie ist eben geändert worden. Ich fürchte, daß erneute schwierige Prozeduren der Umsetzung ins Haus stehen. Der Europäische Gerichtshof hatte nun vor etwa zwei Jahren darüber zu entscheiden, ob und wie die Bundesrepublik ihren Pflichten genügt hatte. Offensichtlich hat die Umsetzung in Deutschland deshalb so große Schwierigkeiten bereitet, weil diese Richtlinie mit der Umweltverträglichkeitsprüfung und vielen verbal umschriebenen Anforderungen so etwas wie optimalen Umweltschutz aufleuchten ließ. Jedenfalls hat man dies in Deutschland so verstanden. Und deshalb ist die Umsetzung viel zu spät gekommen. Deshalb haben auch die Behörden eine Tendenz erkennen lassen, die Anwendbarkeit dieser Richtlinie so lange zu verneinen, wie es sich irgendwie vertreten ließ, und die Gerichte haben diese Interpretation weitgehend geteilt. In dem Rechtsstreit vor dem Europäischen Gerichtshof kam es nun darauf an, ob die Richtlinie hinreichend und rechtzeitig umgesetzt war und ob ihre Anwendung hinreicht. Im Grundsatz hat der Gerichtshof entschieden, daß die Richtlinie nicht fristgerecht umgesetzt worden ist und daß sie auch in dem entschiedenen Fall entgegen der Meinung der deutschen Behörde hätte angewandt werden müssen. Aber entgegen dem gestellten Klageantrag ist die Bundesrepublik nicht verurteilt worden, weil der Europäische Gerichtshof entschieden hat, es habe ja eine behördliche Ermittlung stattgefunden; die Frage der Vereinbarkeit mit der Umweltsituation sei geprüft worden, und deshalb liege in der Sache kein Rechtsverstoß vor. Salopp formuliert kann man dazu sagen: „Gerade noch einmal Glück gehabt.“ Das Problem scheint mir darin zu liegen, daß nach deutscher Rechtsvorstellung hier ein optimierter Umweltschutz verlangt sein soll. Dagegen hat der Europäische Gerichtshof offenbar aufgrund der Rechtskultur der anderen Mitgliedstaaten entschieden, daß zwar das Umsetzungsgebot und das Anwendungsgebot streng zu handhaben seien, aber in der Sache doch genügend geschehen sei. Natürlich hat diese Entscheidung sofort einen vehementen Protest auf der Seite der deutschen Umweltrechtler ausgelöst. Die unterschiedlichen Philosophien der einerseits optimierten oder angeblich optimierten Vorstellung des Umweltschutzes und der andererseits in der Sache sehr gemäßigten, dafür aber im Umsetzungszwang und im Verfahren strengen Auffassung 
des Europäischen Gerichtshofes ist meines Erachtens anhand dieses Falles so deutlich geworden wie kaum jemals.

Pernice: Meine sehr verehrten Damen und Herren. Ich würde gerne auch zu dieser Frage Stellung nehmen. Aber das war nicht geplant. Es war ja nur ein Beispiel von Ihnen, und alte Dinge sollen nicht wieder ausgegraben werden. Ich hätte gerne zwei Vorbemerkungen und fünf kleine Bemerkungen vorgetragen. Aber zunächst meinen Dank an den Vorstand dafür, daß die rechtsvergleichende Dimension schon heute in den zweiten Beratungsgegenstand dieser Tagung eingeführt worden ist. Ich fand es überaus ertragreich und erhellend, was dann auch Herr Riedel vorgetragen hat. Eine zweite Vorbemerkung zum Thema selbst: ,Optimierung oder Rahmensetzung'. Ich meine in der Tat, das beides gehört zusammen. Eines geht nicht ohne das andere und beides zusammen ist im Grunde ein Abbild dessen, was die Verwaltung in Deutschland auch heute macht und ist. Nämlich, und jetzt komme ich zu meiner ersten Bemerkung: Es geht gar nicht so sehr, wie man herkömmlich immer denkt, um Vollzug. Es geht um eine eigenverantwortliche Gestaltungsaufgabe, die die Verwaltung wahrnimmt anhand bestimmter Optimierungsgebote, die, seit wir von der Wertordnung des Grundgesetzes wissen, vor allem durch Grundrechte gesteuert wird. Also insofern stimme ich voll dem zu, was Herr Würtenberger ausgeführt hat, und ich finde, es trifft den Kern dessen, was unsere Verwaltung heute ist oder vielleicht besser sein sollte. Ein Zweites ist ein Wort von Herrn Würtenberger zum europäischen Einfluß. Ich habe verstanden, daß diese Entwicklung, die er beschrieben hat, primär auf einem europäischen Einfluß beruht, und er sah da wohl auch etwas Kritisches. Ich sehe das, das werden Sie mir nachsehen, wenn es so wäre, gar nicht so kritisch. Aber ich denke auch, der europäische Einfluß ist nicht so eindeutig, und möchte bei der Gelegenheit auf die Richtlinien - vor allem natürlich wieder im Umweltbereich - hinweisen, wo es durchaus sehr umfassende konditionalprogrammierte Regelungen gibt und daneben natürlich auch Optimierungsgebote. Konditionalprogrammierte Regelungen sind z. B. Grenzwertfestsetzungen. Da ist das Ziel klar. Ein Grenzwert darf nicht überschritten werden, er muß innerstaatlich realisiert werden. Wie das gemacht wird, bleibt jedem Staat überlassen. Das würde doch eher unter „Regel“ fallen als unter „Optimierungsgebot". Ein zweites Beispiel konditionalprogrammierter Dinge sind natürlich die Regelungen in Richtlinien über Verwaltungsverfahren. Sie werden in Deutschland zum Teil nicht so gern gesehen. Aber was für mich bedeutsam ist, ist etwa, daß die Kontrollgenehmigung im Umweltbereich etwa bei Abfallanlagen oder Industrieanlagen europaweit erst durch solche Richtlinien eingeführt worden ist. Also die Kontrollgenehmigung oder konditionalpro- 
grammierte Entscheidungsvorgaben gibt es durchaus auch im europäischen Recht. Das europäische Recht nimmt natürlich Elemente auf von verschiedenen Mitgliedstaaten, auch englische und französische, und führt diese zusammen. Aber es ist eben auch deutsches Denken sehr deutlich in den Richtlinien zu finden. Mein vierter Punkt: Herr Würtenberger hat auf die Verfahrensbedeutung seines Verständnisses der Verwaltung aufmerksam und dort einige für mich sehr wertvolle Vorschläge gemacht. Es geht um die Optimierung in einem prozeduralisierten Vorgang durch Partizipation. Besonders wichtig ist dabei die Überlegung, daß sich hier eine andere Art von Legitimation entwickelt. Nämlich: Legitimation - demokratisch parlamentarische Legitimation - bezieht sich auf das Gesetz. Aber ist die Legitimation der Verwaltungsentscheidung, wenn sie in derartigen Verfahren situativ getroffen wird - autonom, lokal autonom - nicht eine ganz andere, eben eine Legitimation durch Diskurs zwischen den Betroffenen? Und darüber, meine ich, sollte man etwas weiter nachdenken. Dies führt mich zu dem letzten Punkt, der etwas grundsätzlicher ist und das Verhältnis von Staat und Gesellschaft betrifft. Verwaltung wird, so meine ich, wenn man Herrn Würtenberger folgt, wie der "Staat" selbst, mehr und mehr ein Element gesellschaftlicher Selbststeuerung. Also: Verwaltung steht nicht mehr dem Bürger gegenüber, sondern ist ein Instrument der Gesellschaft zur Selbststeuerung, nämlich zur Produktion optimaler oder, ich würde sagen, einzelfallgerechter oder billiger Entscheidungen. In diesem Zusammenhang wäre dann die lokale Produktion von Entscheidungen durch die Partizipation der Betroffenen spezifisch oder "prozedural ${ }^{\alpha}$ legitimiert. Legitimitätsgrundlage ist zudem eine staatliche Entscheidung auf der höheren Ebene, nämlich das demokratisch legitimierte Gesetz, und man müßte darüber nachdenken, ob und wie ggf. die europäischen Vorgaben des staatlichen Handelns in einer Kombination demokratischer und weiterer Legitimationsformen ihre Geltungsgrundlage finden. Vielen Dank.

Spannowsky: Der Prozeß der Ausbalancierung der Belange der gestaltenden Verwaltung einerseits und der richterlichen Kontrolle andererseits ist schon schwieriges Geschäft genug. Ich bin den Referenten sehr dankbar, daß sie heute die europäische Dimension in die Thematik miteinbezogen haben. Damit wird es freilich noch etwas komplizierter. Herr Breuer hat bereits einleitend die spezielle Problematik bezüglich der Projekt-UVP dargelegt. Verschärft stellt sich die Frage nach der Systemverträglichkeit, wenn die angebahnte Entwicklung künftig durch die Einführung einer Umweltverträglichkeitsprüfung für Pläne und Programme fortgeführt wird. Die zunehmend notwendige Integration von gemeinschaftsrechtlichen Verfahrens- und Prüfungsanforderungen im planungs- 
rechtlichen Abwägungsprozeß führt zu systemwidrigen Erosionen. Verträglichkeitsprüfungen nach der FFH- und der Vogelschutzrichtlinie, nach der Projekt-UVP- und in absehbarer Zeit möglicherweise auch der Plan-UVP-Richtlinie lassen sich in den Abwägungsvorgang nicht reibungslos integrieren. Die Verträglichkeit von Plänen und Programmen ist aufgrund eigenständiger Verfahrensanforderungen zu prüfen, ist nicht nur reiner Abwägungsvorgang. Vielmehr sind dieser Prüfung eigenständige Verfahrensschritte zugeordnet. Die Planer müssen bei der Rechtsanwendung jeweils gesonderte verfahrensmäßige Prüfungsperspektiven einnehmen. Rechtsanwender sind die Planer und die Entscheidungsträger. Juristen haben mit diesem Vorgang relativ wenig zu tun. Und für die Planer und Gemeinderäte ist die Abstufung der Belange unseres komplizierten, an materiellen Erfordernissen ausgelegten Kontrollsystems noch etwas schwerer zugänglich. Es zeigt sich, daß über das Gemeinschaftsrecht verfahrenssichernde Modelle in das deutsche Recht integriert werden müssen und daß sich diese Integration ohne Systemkorrektur nicht mehr reibungslos vornehmen läßt. Korrekturen zur Entfrachtung des an materiellen Rechtskontrollen ausgerichteten deutschen Rechtssystems sind daher meiner Auffassung nach notwendig. Sie wurden durch Ausweitung der Heilungsmöglichkeiten an den Randzonen bereits vorgenommen. Immer wichtiger wird es aber im europäischen Rechtsetzungsprozeß sein, dafür zu sorgen, daß eine Systemkompatibilität im Vorfeld hergestellt wird. Es erscheint seltsam, daß die Abwägung immer komplexer, inhaltlich immer mehr aufgeladen und die nicht mehr gegebene Praktikabilität dann durch Ausdehnung der Heilungsmöglichkeiten hergestellt werden muß. Notwendig erscheint vor diesem Hintergrund der Abbau überzogener Differenzierungs- und der Abbau inhaltlicher Kontrollanforderungen. Zu viele Optimierungsklauseln lösen die Anforderung an eine gerechte Interessenabwägung nicht auf. Im Gegenteil, sie machen die Rechtsanwendung in der Praxis schwerfällig. Optimierungsklauseln werden auch in ihrem Anspruch auf relativen Vorrang dadurch relativiert, $\mathrm{da} ß$ sie mit anderen im Bund-Länder-Verhältnis normhierarchisch vorrangigen Bundesregelungen und höheres Gewicht beanspruchenden gemeinschaftsrechtlichen Anforderungen in Beziehung gesetzt werden müssen. Deshalb bin ich der Meinung, daß Schritte hin zu einer materiellen Deregulierung, hin zu einer Entfrachtung des Abwägungsvorgangs, getan werden müssen. Meine Frage an die Referenten geht daher dahin, ob und inwieweit sie die Normierung von Optimierungsklauseln, wie wir sie im materiellen Recht vorfinden, z.B. die Bodenschutz-, die Landwirtschaftsklausel im BauGB oder jetzt auch neuerdings die landesrechtlichen Bestimmungen, die die Anordnung der Regenwasserversickerung zum Ziel haben, als verzichtbar beurteilen. 
Oeter: Meine Damen und Herren, ich möchte ein Problem aufnehmen, auf das Herr Sachs gestern in der Diskussion schon kurz hingewiesen hat - nämlich die Frage der bundesstaatlichen Rückwirkung des Dranges zu möglichst detailgenauen Konditionalprogrammen und Optimierungsgeboten mit materieller Steuerungsintention und das Problem dann gedanklich verlängern in die europarechtliche Dimension der Verkoppelung von gemeinschaftlicher Rechtsetzung und mitgliedstaatlichem Vollzug. Ich kann dabei unmittelbar anknüpfen an die These 18 von Herrn Würtenberger. In dieser These lesen Sie: „Die gewaltenteilende föderative Demokratie zieit auf eine funktionsadäquate Steuerungsteilung zwischen zentraler parlamentarischer Steuerung und lokal geprägter Eigensteuerung. Die kommunale Selbstverwaltung kann durch rechtliche Optimierungsgebote ausgehöhlt werden." Das gilt nun nicht nur für die kommunale Selbstverwaltung, sondern das gilt in mindestens genau dem gleichen Umfang auch für das Bundesstaatsprinzip. Um das ganz knapp zu erläutern: Sieht man das deutsche Bundesstaatsmodell, ganz simplifiziert und idealtypisch formuliert, als eine Zuordnung von weitgehend dem Bund zugewiesener Gesetzgebungskompetenz und weitgehend den Ländern zugewiesener Verwaltungskompetenz, dann ist die Frage der Rechtsbindung der Verwaltung bzw. des Ausmaßes der Rechtsbindung der Verwaltung und des komplementären Ausmaßes der Handlungs- und Entscheidungsspielräume der Verwaltung eine Frage der Verkoppelung nicht nur von Gesetzgebung und Verwaltung, sondern auch der Verkoppelung von Bundesstaatsgewalt und von Landesstaatsgewalt. Jede Veränderung des Leitbildes - um es anders zu formulieren: des Ausmaßes der Rechtsbindung der Verwaltung - verändert dann die Statik dieser Zuordnungskonstruktion im Bundesstaatsmodell. Einzelne Autoren haben das schon sehr früh unter dem Grundgesetz gesehen, ohne daß sie dabei große Beachtung gefunden hätten, wie etwa Arnold Köttgen. Wenn man, wie sie sehr früh gesehen haben, von der traditionalen Vorstellung der Verwaltung als einer eigenständigen Gewalt mit sehr weitgehenden Entscheidungsspielräumen abgeht zugunsten eines mit rechtsstaatlichen Erwägungen begründeten Modells möglichst detailgenauer Rechtsbindung der Verwaltung, verschiebt man völlig die Zuordnung dieser beiden Gewalten. Ich möchte es noch einmal ganz kraß formulieren: Wenn man die Systementscheidung des Verwaltungsrechts für eine solche möglichst punktgenaue detaillierte Rechtsbindung der Verwaltung konsequent zu Ende denkt, dann höhlt man letztlich das Bundesstaatsprinzip aus in der Konstruktion, die es unter dem Grundgesetz gefunden hat - mit allen Problemen, die sich bis hin zu Art. 79 Abs. 3 GG dabei ergeben. Es stellt sich dann natürlich, das möchte ich zugeben, automatisch die Frage, die Herr Kirchbof gestern aufgeworfen hat: Wie weit reicht eigentlich das 
$\mathrm{Maß}$ der gesellschaftlich hingenommenen Verschiedenheit und Ungleichheit? Oder anders herum formuliert im Blick dieser Frage: Der Drang zur konsequenten Rechtsbindung der Verwaltung stimmt natürlich völlig überein mit der Präferenz für Einheitlichkeit, die die Bundesstaatsgeschichte der Bundesrepublik gezeichnet hat.

Das führt letzten Endes meines Erachtens zu der Frage, die Herr Fromont gestern aufgeworfen hat: der merkwürdigen Diskrepanz zwischen der Begeisterung für das Subsidiaritätsprinzip im Blick auf das Europarecht und der Skepsis der Verfassungsrechtslehre im internen Gebrauch gegenüber dem Subsidiaritätsprinzip. Man beschwört immer wieder das Phänomen der Überformung des Verwaltungsrechts durch europarechtliche Vorgaben. Sieht man dieses Phänomen, sieht man es zusammen mit dem hier aufgegriffenen Diskussionsstrang des Ausmaßes der Rechtsbindung der Verwaltung, dann verwundert doch immer wieder, mit welcher Vehemenz man die so hoch gehaltene Forderung nach einer möglichst punktgenau gesetzesgesteuerten oder rechtsgesteuerten Verwaltung verteidigt. Ich würde eigentlich meinen, die Konsequenz müßte genau umgekehrt lauten: Eigentlich müßte der pure Selbsterhaltungstrieb das deutsche Verwaltungssystem dazu zwingen, seine Vorstellung von einer möglichst punktgenauen Rechtssteuerung der Verwaltung oder Rechtsdeterminierung der Verwaltung zu überdenken. Denn ich glaube, nur dann kann man überhaupt dem Dilemma, das aus dieser Überformung des Verwaltungsrechtssystems resultiert, entgehen und nationale Entscheidungsspielräume in irgendeiner Form noch bewahren in einem System der Verkoppelung gemeinschaftsrechtlicher Rechtsetzung und mitgliedstaatlichen Vollzuges der Verwaltung. Soviel einfach nur als kurze Bemerkung zu der Frage, die Sie, Herr Breuer, am Anfang der Diskussion aufgeworfen hatten, wieweit die deutsche Systementscheidung für eine möglichst weitgehende Rechtssteuerung der Verwaltung konsequent durchhaltbar ist in der Zukunft.

Vorsitzender: Bisweilen neigen Deutsche, vielleicht auch deutsche Verwaltungsrichter, dazu, sich das Leben sehr schwer zu machen. Dies mag sein. Aber wenn diese Erkenntnis durch Rechtsvergleich in der gebührenden Deutlichkeit gewonnen und das rechte Mittelmaß wieder gefunden wird, wäre schon etwas erreicht.

Zuleeg: Herr Riedel hat für Großbritannien und Frankreich festgestellt, daß die Frage, die das Thema aufwirft, für diese beiden Staaten keine Rolle spielt. Dasselbe ist für die Europäische Union anzunehmen. Ich meine, daß auch Herr Würtenberger und Herr Haller in diese Richtung gehen; denn sie haben ja in der Hauptsache den ersten Punkt betont: die 
Optimierungsgebote. Dazu möchte ich einige Bemerkungen machen. Eine Bemerkung zu Herrn Würtenberger kann ich mir allerdings schenken. Herr Pernice hat schon dazu Stellung genommen, inwieweit konditional gebundene Programme im Gemeinschaftsrecht vorhanden sind. Herr Würtenberger, Sie nehmen bei den Grundrechten ein Kontrolldefizit auf europäischer Ebene an. Ich bin immer wieder erstaunt, in welchem $\mathrm{Maße}$ der Europäische Gerichtshof die europäische Rechtsordnung anreichert, indem er Material aus dem deutschen Recht entnimmt und in das europäische Recht einfügt. Meine Kollegen am Europäischen Gerichtshof haben mich immer wieder gefragt: Wieso besteht in Deutschland oft großer Unmut, ja Empörung, über die Entscheidungen des Europäischen Gerichtshofs? Er hat doch den europäischen Grundrechtsschutz dem deutschen mit dessen Ausgestaltungen angeglichen, etwa mit den Schranken und Schranken-Schranken. Der Grundsatz der Verhältnismäßigkeit war in den anderen Mitgliedstaaten weithin unbekannt. Der Gerichtshof hat ihn übernommen, andere objektive Grundsätze wie den Vertrauensschutz dazu und weitere Institutionen des deutschen Rechts. Aber immer noch wird darüber geklagt, daß in Europa rechtliche Defizite auftreten. Ich glaube, man sollte etwas genauer hinsehen. Dann wird man beobachten, daß die Gemeinschaft in einem großen Ausmaß Anregungen aus Deutschland aufgegriffen hat.

Herr Haller, ich habe den Eindruck, daß Sie die Gesetzgeber der Gemeinschaft und deren Rechtsprechung zu sehr gezaust haben. Zum einen haben Sie der Kommission vorgeworfen, daß sie auf Sachverständige nicht genügend höre. Nach aller Erfahrung, die ich von der Arbeit der Kommission habe, sind eher zu viele Experten für sie tätig. In vielen Ausschüssen und Gutachten wird Fachwissen eingebracht und verwertet. Dies geschieht auf mehreren Stufen. Die Kommission ist ja lediglich vorschlagsberechtigt. Auch der Rat schaltet Sachverständige ein. Zum anderen vermissen Sie auf europäischer Ebene eine systematische Gesetzgebung. Ich möchte aber darauf hinweisen, daß eine diffuse Regelung häufig auf die Mitgliedstaaten zurückzuführen ist, die bestimmte Abrundungen nicht akzeptieren und in ihrer Meinung auseinandergehen. Das Dritte, was ich zu Ihrem Vortrag sagen will, betrifft den Vorbehalt des Gesetzes. Er ist schon seit Jahren in die europäische Rechtsordnung eingeführt. Im Urteil Hoechst hat der Gerichtshof so entschieden. Von da ab habe ich keine Entscheidung angetroffen, die das Gegenteil ausgesprochen hat. Hier haben wir wieder ein Beispiel für die Rechtsfortbildung auf europäischer Ebene vor uns, die eine Anleihe bei der deutschen Rechtsordnung macht.

Zum Schluß möchte ich hervorheben, daß es mehrere Punkte gibt, die in der europäischen Rechtsordnung originär ausgestaltet sind und eng mit 
der Optimierung zu tun haben. Erstens: Der Gerichtshof hat es sich schon seit 1963 bis heute angelegen sein lassen, daß die subjektiven Rechte aus dem Gemeinschaftsrecht Schutz genießen. Insofern ist die Gemeinschaft kein bloßer Staatenverbund. Der Gerichtshof hat ausdrücklich gesagt, daß die Gemeinschaft die Verfassung einer Rechtsgemeinschaft hat, in der die subjektiven Rechte geschützt werden. Zweitens: Die Ziele einer Gesetzgebung müssen nach Gemeinschaftsrecht in der Präambel eines Rechtsakts als Begründung wiedergegeben werden. Das verschafft die Möglichkeit, die teleologische Auslegung daran anzuknüpfen, weil die Ziele bekannt sind. Es wäre vielleicht sehr gut, wenn in Deutschland und anderswo die Gesetze zwangsweise mit der Angabe der Ziele verbunden würden. Dritter und vorletzter Punkt: Der Gerichtshof ist darauf aus, daß die Rechtsordnung nicht nur in der Rechtsprechung vorkommt, sondern auch effizient verwirklicht wird. Die Effizienz des Gemeinschaftsrechts wird durch verschiedene Instrumente gewährleistet, die ich aus Zeitgründen hier nicht aufzählen kann. Schließlich hat der Gerichtshof stets betont, daß die einheitliche Geltung des Gemeinschaftsrechts in allen Mitgliedstaaten sichergestellt sein muß. Es bedeutet eine Optimierung des Rechts, wenn aus der europäischen Rechtsordnung keine Teile herausgeschossen werden dürfen, sei es durch Gesetzgebung der Mitgliedstaaten, sei es durch nationale Rechtsprechung. Auch die bloße Unanwendbarkeit des Gemeinschaftsrechts aufgrund eines Spruchs eines nationalen Gerichts durchkreuzt die Einheit der Rechtsordnung. Effiziente und einheitliche Geltung des Gemeinschaftsrechts ist ein Stück Optimierung.

Dörr: Herr Vorsitzender, meine Damen und Herren, ich möchte nur zwei Punkte herausgreifen, die mich am Referat von Herrn Riedel besonders interessieren, und zwar im Zusammenhang mit Ihrem faszinierenden Blick auf das englische Rechtssystem. Sie haben uns dieses Rechtssystem vorgestellt, die unterschiedlichen Traditionen deutlich gemacht und deshalb auch vor einer vorschnellen Ubertragung auf die deutsche verwaltungsgerichtliche Kontrolle gewarnt, aber in der Tendenz für etwas weniger gerichtliche Kontrolle plädiert. Ich glaube, Sie haben einen sehr wichtigen Punkt angesprochen, den ich noch etwas vertiefen und zu dem ich auch eine Frage stellen will. Sie haben nicht nur dafür plädiert, die gerichtliche Kontrolle entsprechend dem englischen System in Deutschland ein wenig zurückzunehmen, sondern auch die Prognose gewagt, daß sich das englische System ein wenig unserem System annähern wird und annähern muß und haben dabei auch die Menschenrechte angesprochen. Ich meine, daß diese Prognose zutreffend und auch zwingend ist. Denn die Menschenrechte der EMRK, die ja bisher die englischen Gerichte nicht veranlaßt haben, eine vertiefte Kontrolle vorzunehmen, werden die 
englischen Gerichte dazu zwingen, weil man immer sehen muß, daß diese Menschenrechte der EMRK, an die kraft völkerrechtlichen Vertrages Großbritannien gebunden ist, auch Gemeinschaftsgrundrechte sind. Insoweit knüpfe ich an die Bemerkung von Herr $Z$ uleeg an und weise darauf hin, daß sie nunmehr auch durch ausdrückliche Bezugnahme im Vertrag selber Gemeinschaftsgrundrechte darstellen. Schon im MaastrichtVertrag war dies der Fall, wenn auch mit einer Schwäche, daß nämlich die Bestimmung des Art. F Abs. 2 EUV formal nicht der Kontrolle des EuGH unterlag. Aber das hat der Amsterdamer Vertrag geändert, und damit ist der Menschenrechtskatalog ausdrücklich Bestandteil der Gemeinschaftsgrundrechte geworden. Dies führt, gerade wenn man der englischen Systematik folgt, wonach der Vorrang des Gemeinschaftsrechts durchaus anzuerkennen und bei der Kontrolldichte zu berücksichtigen ist, dazu, daß diese Menschenrechte als materielle Schranken von Verwaltungsentscheidungen zwingend zu beachten sind. Aber trotzdem führt dies nicht etwa zur gleichen Kontrolldichte wie in Deutschland. Zwar ist es beim Europäischen Gerichtshof für Menschenrechte durchaus so, daß er das Verhältnismäßigkeitsprinzip prüft. Aber er prüft es, wenn ich es richtig analysiere, doch deutlich anders als deutsche Gerichte. Es ist vielleicht eine Schwäche bei den bisherigen Entscheidungen des Europäischen Gerichtshofs für Menschenrechte, daß er dies nicht hinreichend deutlich gemacht hat. Leider liegen detaillierte Entscheidungen zu den Menschenrechten bisher nur vom Europäischen Gerichtshof für Menschenrechte vor, insoweit muß ich Herrn Zuleeg widersprechen. Der EuGH bekennt sich ebenfalls zu den Menschenrechten in ihrer Eigenschaft als Gemeinschaftsgrundrechte und zur entsprechenden Menschenrechtsdogmatik. Aber er führt bisher in seinen Entscheidungen keine im einzelnen systematisierte Grundrechtsprüfung anhand dieser Maßstäbe durch, und ich glaube, dies erzeugt ein wenig Unbehagen in manchen Mitgliedstaaten und meines Erachtens nicht ganz zu Unrecht.

Obwohl bisher keine ganz klare Dogmatik besteht, kann man sagen, $\mathrm{da} \dot{\beta}$ der Europäische Gerichtshof für Menschenrechte bei der Verhältnismäßigkeit im engeren Sinne die Prognose-, Beurteilungs- und Abwägungsspielräume wesentlich stärker betont, wenn es in diesem Zusammenhang auch widersprüchliche Entscheidungen gibt. Es wird allerdings, glaube ich, dafür zu sorgen sein, daß man dabei eine gewisse Systematik entwickelt, wie sie im englischen Recht tendenziell vorhanden ist, also Bereiche anerkennt, wo die Kontrolle stärker vorzunehmen ist, und Bereiche, wo sie zurückzuschrauben ist. Daher frage ich Sie, Herr Riedel, ob Sie glauben, daß man eine solche Systematik vielleicht entwickeln und daraus dann für die deutsche Rechtsordnung gewisse weiterführende Rückschlüsse erzielen kann. 
Zweitens möchte ich kurz bemerken, daß ich nicht glaube, daß die Vorschrift des Art. 19 Abs. 4 GG im Hinblick auf die Kontrolldichte entscheidende Aussagen trifft, wenn man sie sachgerecht auslegt. Die Bestimmung des Art. 19 Abs. 4 GG enthält nach meiner Auffassung entscheidende Aussagen nur darüber, daß gerichtliche Kontrolle sein muß. Wie weit die Abwägungsprozesse wirklich von den Gerichten kontrolliert werden müssen, entscheidet sich m.E. nicht am Maßstab des Art. 19 Abs. 4 GG.

Öhlinger: Anknüpfend an die europarechtliche Debatte möchte ich eine Frage an Herrn Riedel richten: Herr Riedel, Sie haben für eine allenfalls vorsichtige Annäherung des deutschen Kontrollsystems, der deutschen Kontrolldichte an den europäischen Standard oder an den Standard, wie er von anderen europäischen Nationen vorgegeben wird, plädiert, aber doch im wesentlichen für eine Beibehaltung des deutschen Systems gesprochen. Ich stelle die Frage zugespitzt: Wie verhält es sich, wenn die deutsche Verwaltung unmittelbar Europarecht anzuwenden hat, sei es, daß Einzelfallentscheidungen aufgrund von Verordnungen der Gemeinschaft zu treffen sind, sei es, daß sie Normkonkretisierungen in Ausführung von Richtlinien der Gemeinschaft zu treffen hat? Mir ist bewußt, daß die Anwendung des europäischen Rechtes im Kontext nationaler Dogmatik und nationalen Verfahrensrechtes zu erfolgen hat, aber es gibt doch auch gemeinschaftsrechtliche Grenzen. Und bedeutet nicht eine unterschiedliche Kontrolldichte letztlich auch eine unterschiedliche Anwendung mit Rückwirkung auf den Gehalt der Norm? Herr Haller hat das angedeutet, wenn auch unter einem spezifisch österreichischen Aspekt. Er meinte, es gebe auf österreichischem Territorium zwei unterschiedliche Normenkomplexe, die unter dem Gesichtspunkt der gesetzlichen Bestimmtheit, der Entscheidungsfreiheit der Verwaltungsorgane, des Abwägungsgebotes, das Verwaltungsorgane zu befolgen haben, zwei unterschiedliche Komplexe bilden: das traditionelle österreichische Recht und das europäische Recht, die eben unter diesen $\mathrm{Ge}$ sichtspunkten unterschiedlichen Prinzipien unterliegen. Er hat das mit großem Unbehagen gesehen. Es gibt viele Gründe für dieses Unbehagen. $\mathrm{Ob}$ es allerdings die richtige Strategie ist, mit diesem Problem fertig zu werden, ist eine andere Frage.

Und damit noch einige Bemerkungen zum Referat von Herm Haller. Ich stimme dem Ausgangspunkt zu, und es ist dies im ersten Teil dieser Diskussion ja vielfach ausgeführt worden, daß „Optimierungsgebot ${ }^{*}$ und „Rahmensetzung" keine scharfen Gegensätze bilden. Ich bin nur wiederum auch nicht der Meinung, daß sie völlig identisch sind und daß man daher das Kapitel Optimierungsgebote eigentlich aus dem Thema 
eliminieren könnte. Zumindest graduelle Unterschiede bestehen, und Sie haben ja Ansätze aufgezeigt, die man nur vielleicht unter dem Aspekt dieser Thematik doch etwas vertiefen könnte. Ich stimme dem Ansatz zu, daß diese Problematik auch eine Frage der Gesetzgebung ist und daß es unter beiden Gesichtspunkten, Optimierung wie Rahmensetzung, letztlich um die Frage geht, welche Freiräume der Gesetzgeber der Verwaltung überlassen kann und darf. In Österreich ist dies auch ein spezifisches verfassungsrechtliches Problem. Es gibt allerdings Ansätze eines differenzierten Verständnisses des damit angesprochenen Legalitätsprinzips. Die Frage ist, inwieweit diese unter dem Aspekt der Optimierung ausbaufähig sind.

Diese Begriffe spielen aber, auch das ist in der Diskussion schon oft angesprochen worden, vor allem für die richterliche Nachkontrolle des Verwaltungshandelns eine große Rolle, und da hätte es mich doch interessiert, inwieweit man in der österreichischen Verwaltungsgerichtsbarkeit eine Respektierung der vom Gesetzgeber legitimerweise der Verwaltung eingeräumten Freiräume - wie immer man diese versteht: als Rahmen der Verwaltung oder als Optimierungsgebote - findet. Immer noch ist doch die These herrschend, daß bei unbestimmten Gesetzesbegriffen der Verwaltung keine Abwägungsfreiräume eingeräumt werden, sondern daß hier eine einzig richtige Entscheidung zu finden ist. Und diese Entscheidung weiß das Gericht, sehr oft sagt es aber nicht, inwieweit es gerade seine Gesetzesauslegung als die einzig mögliche begründen kann. Mich würde interessieren, inwieweit zu dieser Frage in der österreichischen Rechtsprechung auch schon etwas differenziertere Ansätze entwickelt wurden. Danke.

Vorsitzender: Ich bin sicher, daß Ihre Frage nach den differenzierteren Ansätzen gleich von den Referenten beantwortet wird. Als nächsten Diskussionsredner bitte ich Herrn Autexier, das Wort zu nehmen. Wir kommen noch einmal zum französischen Recht zurück und sind gespannt darauf, was Sie uns über die Determinanten des Verwaltungsrechts in Frankreich sagen können.

Autexier: Herr Vorsitzender, meine Damen und Herren. Herrn Riedel kann ich zu seiner Darstellung des französischen Rechts nur beglückwünschen. Im Grundsätzlichen stimme ich ihm zu. Leider fehlt mir die Zeit, die angesprochenen Aspekte im einzelnen Revue passieren zu lassen. Daher wende ich mich sofort dem Ergebnis zu. Herr Fromont wies bereits darauf hin, daß es in Frankreich und England keine Optimierungsdebatte gebe. Warum? Herr Riedel antwortete darauf, daß die dortigen Rechtskulturen nicht dazu führten, diese Frage zu stellen. Bereits Herr Würtenberger 
hat in seiner letzten These den Finger auf diesen Punkt gelegt. Korrelativ ließe sich fragen: Warum löst die deutsche Rechtskultur eine Optimierungsdebatte aus? Warum aber stellt sich im französischen Rechtssystem die Frage nach der Optimierung nicht? Meines Erachtens hat sich der Blick auf die Ermittlung von Determinanten zu richten. Hier würde ich pointiert sagen: Eine der Hauptdeterminanten der deutschen Rechtsordnung könnte lauten: Im Anfang war das Wort - das Wort des Grundgesetzes selbstverständlich. Im französischen Verwaltungsrecht heißt die Determinante: Im Anfang war der Richter. Es ist ein Gemeinplatz, daß es in Frankreich zuerst Verwaltungsgerichte gab (Gesetz vom 24. Mai 1872), bevor das von den Richtern geschaffene spezifische Recht der Verwaltung entstand. Diese Richter haben das Verwaltungsrecht entwickelt - ein Prozeß, der unweigerlich die Frage nach der Akzeptanz der Verwaltungsgerichtsbarkeit und der verwaltungsgerichtlichen Rechtsprechung durch die aktive Verwaltung aufwirft. Eine Entwicklung, die auch Deutschland nicht fremd ist, denken wir nur an die Ausfuihrungen von Gneist oder an die Zeiten des Preußischen Oberverwaltungsgerichts. Die damals in Preußen und Frankreich vorgeschlagenen Lösungswege waren sich im übrigen sehr ähnlich: Erstens ging es um die Nähe der Verwaltungsgerichtsbarkeit zur aktiven Verwaltung - ein Stichwort, das noch heute Gültigkeit für den Conseil d'Etat beansprucht; zweitens wurde self-restraint gefordert und umgesetzt, d.h. die Kontrolle der Verwaltung auf ein Minimum reduziert. Die verwaltungsgerichtliche Überprüfung konnte sich zunächst nur auf die Feststellung grober und evidenter Fehler beschränken; erst im Laufe der Zeit ging man auch zu einer Verhältnismäßigkeitsprüfung über. Der gemeinsame Nenner dieser beiden Bestrebungen ist, daß wir zu einer Globalisierung der Optimierung gekommen sind, zu einer Reduzierung der Optimierung auf bloße Abwägung. Insofern folge ich gerne Herm Isensee.

Dogmatisch gesehen führt dies zu einer Minimierung der Fälle, in denen die Verwaltung in ihrem Eigenbereich gerichtlicher Kontrolle unterliegt. Minimierung der potentiellen Überprüfungsfälle - diese Möglichkeit besteht nach deutschem Recht aufgrund von Art. 19 Abs. 4 GG nicht! Trotz der referierten Einschränkungen der Rechtsschutzgarantie meine ich, daß Art. 19 Abs. 4 GG eine Maximierung von Nachprüfungsmöglichkeiten zur Folge hat. Währenddessen bewirken Entstehungs- und Entwicklungsgeschichte der französischen Verwaltungsgerichtsbarkeit eine Minimierung der Nachprüfbarkeit von Verwaltungsentscheidungen durch die Verwaltungsgerichte.

Dennoch kommen weder Optimierung noch Abwägung im französischen Recht zu kurz. Lassen Sie mich an dieser Stelle den Gedankengang von Herm Riedel weiterführen. Besinnen wir uns auf die Leitentscheidung Benjamin aus dem Jahre 1933. Sie stellte zwei Grundsätze auf: Zum einen, 
und diesen Gesichtspunkt hob der Referent deutlich hervor, das Gebot der Abwägung, die Adäquation. Die Kontrollfrage lautet hier: Ist der konkrete Sachverhalt geeignet, die von der Verwaltung getroffene Maßnahme zu rechtfertigen? Besieht man dieses Gebot von näherem, so fällt auf, daß die von der französischen Rechtsprechung verwendeten Kriterien der Trias des Übermaßverbotes sehr nahe kommen. Zum anderen, und dies betonte Herr Riedel weniger deutlich, sprachen sich die Richter in der Entscheidung Benjamin für ein Verbot allgemeiner und absoluter Maßnahmen aus. Die Kontrollfrage stellt sich hier wie folgt: Wäre es nicht möglich gewesen, das Ziel auch durch andere mildere Mittel zu erreichen? Wäre es nicht möglich, das Ziel auch auf andere Weise zu verwirklichen? Diese Aussage bedeutet meines Erachtens nichts anderes, als daß die französische Rechtsprechung bereits im Jahre 1933 den Vorrang der Freiheit herausstellte und zum Gegenstand ihrer ständigen Rechtsprechung machte. Mit anderen Worten: Der Rechtsgedanke des Art. 19 Abs. 4 GG wird zwar im französischen Recht nicht expressis verbis zum Ausdruck gebracht, seine Existenz ist aber unbestreitbar. Das beweist die Richtigkeit des von Herrn Riedel gezogenen Schlusses, daß trotz bestehender - unter Umständen sogar unüberbrückbarer - Unterschiede diese nicht überwertet werden dürfen, sondern daß letztlich zwischen beiden Rechtssystemen, wenn auch versteckt, zahlreiche Konvergenzen festzustellen sind. Diese Schlußfolgerung kann nur von einem Rechtsvergleicher stammen. Nur einen Rechtsvergleicher schreckt es nicht, Grundzüge des nationalen Rechts für einen heuristischen Moment zurückzustellen - ein Schritt, den Rechtsgelehrte sonst nicht so leicht wagen, wie es die Intervention von Herrn Schuke-Fielitz zeigte. Das Ergebnis vermag nur Juristen aufzufallen, die nicht mehr eindimensional, d.h. nicht mehr eingebunden in das enge Korsett ihrer eigenen Rechtsordnung, denken. Ich freue mich, daß unser Vorstand das Thema des heutigen Sitzungstages um diese rechtsvergleichende Dimension erweitert und bereichert hat. Ich meine, daß wir diese Entwicklung vorantreiben müssen, und zwar aus einem zwingenden Grund, den wir bislang noch nicht richtig wahrgenommen haben: Unsere Studenten stehen vor einer qualitativen Veränderung ihres Berufes. Der Jurist von heute und morgen wird, im Unterschied zu dem Juristen, den wir bis heute bzw. vor 10 Jahren ausgebildet haben, immer häufiger mit der Situation konfrontiert werden, mit Juristen anderer Rechtskulturen in Berührung zu kommen oder gar verhandeln zu müssen. Auf diese Aufgabe müssen wie sie vorbereiten. Vielen Dank.

Vorsitzender: Herzlichen Dank, Herr Autexier, für diese wichtigen Bemerkungen nicht nur zum französischen Recht, sondern auch zur Rechtsvergleichung und für die Conclusio, die Sie daraus gezogen haben. 
Sieckmann: Ich möchte auf die Frage eingehen, ob wir eine Optimierungskonzeption brauchen oder ob sie vielleicht eine deutsche Besonderheit ist, wie Herr Riedel sagte, die vielleicht eher überflüssig ist. Zunächst eine begriffliche Vorbemerkung: Ich sehe keinen Gegensatz zwischen Optimierungsgeboten und Rahmensetzungen. Beides ist natürlich zu unterscheiden, aber es gehört auch zusammen, denn Optimierungsgebote zielen ja gerade auf die Begründung konkreter Festsetzungen. Das heißt, beides muß zusammen gesehen werden, man kann das nicht trennen. Begrifflich natürlich schon, aber praktisch nicht. Worum geht es dann bei dem Gegensatz von Optimierungsgeboten und Rahmensetzungen? Der Unterschied ist, ob wir eine begründete Festsetzung haben wollen oder ob beliebige Festsetzungen ausreichen. Optimierungen dienen dazu, eine möglichst gute Begründung zu solchen Festsetzungen zu geben und beliebige Festsetzungen auszuschließen. Und wenn man nun weiter fragt, was eine gute Begründung ist, dann kommt man zu den Theorien rationaler Entscheidungen, die insbesondere in der Wohlfahrtsökononie entwickelt worden sind, aber seit einigen Jahren auch auf rechtliche Probleme angewandt werden. Die Frage ist: Brauchen wir eine solche Theorie der Optimierung als Theorie rationaler Entscheidungen im Bereich des Rechts? Herr Würtenberger hatte schon teilweise eine Antwort darauf gegeben. Wir haben Abwägungen im Recht, wir kommen ohne sie nicht aus, und wenn wir sie rational-wissenschaftlich durchdringen wollen, brauchen wir eine Optimierungskonzeption. Ich möchte das ergänzen durch einen anderen Aspekt, einen rechtsvergleichenden Aspekt in Anknüpfung an die Aussage von Herrn Riedel, daß Optimierung, jedenfalls der Ausdruck, im englischen und französischen Recht nicht vorkommt. Das ist sicher so richtig; als Rechtsterminologie gibt es das nicht, aber das bedeutet nicht, daß wir diese Strukturen und diese Rationalitätskonzeption nicht in den Rechtssystemen haben. Ich möchte mich auf das englische Rechtssystem beziehen. Natürlich haben wir dort keine solchen theoretischen Konzeptionen, aber implizit kann man sie auch dort feststellen. So werden vielleicht Optimierungüberlegungen nicht explizit gemacht, sie sind vielleicht nicht justitiabel, aber wenn man sich das englische Recht näher ansieht, kann man solche Strukturen feststellen. Aber ich möchte beginnen mit einer Analyse: „Was brauchen wir in einer Optimierungskonzeption?" Wir brauchen drei Elemente, erstens muß festgelegt werden, was optimiert werden soll. Das geschieht durch Rechtsprinzipien; es ist wichtig, daß es sich um rechtliche Prinzipien handelt, damit wir nicht in eine allgemeine nicht-rechtliche Abwägung geraten. Das zweite Element der Optimierung ist das der Abwägung, der rechtliche Maßstab ist hier im deutschen Recht der der Verhältnismäßigkeit, und das dritte Element ist die Frage der Entscheidungskompetenz zum 
einen des parlamentarischen Gesetzgebers gegenüber der Verwaltung, dann aber auch die Kontrollkompetenz der Gerichte gegenüber der Verwaltung. Das haben wir im deutschen Recht sehr stark ausdifferenziert; wir haben die grundrechtlichen Prinzipien extrem weit gefaßt, wir haben den Verhältnismäßigkeitsgrundsatz als allgemein anwendbaren Maßstab, und wir haben schließlich die Diskussion z.B. um die Kontrollkompetenzen der Gerichte, wo wir allerdings Probleme haben, klare Kriterien anzugeben. Wie sieht es nun im englischen Recht aus? Da finden wir auch alle drei Elemente, nur, sie werden eben nicht unterschieden, sondern man sieht am Ergebnis, daß in bestimmten Bereichen Gerichte durchaus substanzielle Erwägungen anstellen, in anderen Bereichen wiederum nicht. Und wenn man das etwas näher analysiert, dann kann man etwa materielle Prinzipien feststellen, wenn man fragt, wo Anhörungsrechte im Verwaltungsverfahren gewährt werden. Im englischen Recht gibt es kein allgemeines Anhörungsrecht, sondern in bestimmten Bereichen, z. B. wenn Berufsfreiheit oder Vertrauensschutz betroffen ist, wird ein Anhörungsrecht gewährt. Das heißt, wir finden hier eine ganz ähnliche Struktur zu unserem Grundrechtskatalog oder rechtsstaatlichen Prinzipien. Der zweite Punkt: Verhältnismäßigkeitsgrundsatz. Im englischen Recht haben wir natürlich traditionell nur das Kriterium der reasonableness, das ist formal schwächer, aber es gibt durchaus Tendenzen zu einer Verstärkung hin zu einer proportionality-Prüfung, auch beeinflußt durch das europäische Recht. Aber in einzelnen Bereichen haben wir durchaus auch substanzielle Abwägungen. Schließlich der dritte Punkt: Die Kontrollkompetenzen. Auch da haben wir durchaus unterschiedliche Kontrollmaßstäbe in der gerichtlichen Rechtsprechung. Nur, das alles wird nicht explizit gemacht. Man sieht es am Ergebnis, aber es wird nicht explizit gemacht. Und nun ist die Frage: Was ist besser? Wollen wir diese stark ausdifferenzierte deutsche Systematik, oder wollen wir diese eher implizite Prüfung im englischen Recht? Mir scheint weder in wissenschaftlicher Sicht noch in sachlicher Hinsicht viel für die englische Konzeption zu sprechen. In wissenschaftlicher Hinsicht muß Klarheit im Vordergrund stehen, und in sachlicher Hinsicht haben wir natürlich im englischen Recht weniger Kontrollkompetenzen der Gerichte. Sollen wir das deutsche Recht dem angleichen? Ich möchte das gar nicht in der Sache diskutieren, aber um was für ein Problem geht es denn hier? Es wurde darauf hingewiesen, Optimierung würde zu Einbußen an Demokratie und Rechtstaatlichkeit führen, wenn zu anspruchsvolle Ziele gestellt werden, aber das ist doch wiederum ein Optimierungsproblem. Das heißt, wir können diese Thematik der Kontrollkompetenzen überhaupt nicht anders erörtern als in einer Optimierungskonzeption, und insofern ist sie eindeutig überlegen auch gegenüber der Konzeption des englischen Rechts. 
Ronellenfitsch: Ich muß entschuldigen, daß ich nach den Höhenflügen der Rechts- und Verfassungstheorie jetzt auf die Ebene des Verwaltungsrechts herabsteige. Ich habe Herrn Würtenberger den kategorischen Imperativ für alle Verwaltungsrechtler entnommen, wir sollten das Verwaltungsrecht nicht verfassungsrechtlich aufladen. Ein entsprechender kategorischer Imperativ bezieht sich auf die Rechtstheorie: Wir sollten aufpassen, daß wir nicht durch falsche Begrifflichkeiten zu Konsequenzen auf der verwaltungsrechtlichen Ebene beitragen, die nicht erwünscht sein können. Das Abwägungsgebot wurde ganz banal im Bauplanungsrecht entwickelt, also auf der Ebene der Gesamtplanung und Angebotsplanung. Dort kommt es darauf an, die öffentlichen und privaten Belange zu gewichten und zu sichten. Bestimmte Belange hat man nun mit einer Vorrangstellung versehen. Und das hat man Optimierung genannt. Es ging somit um eine stärkere Gewichtung bestimmter Belange. Das war im Rahmen der Gesamtplanung bei der Findung des Gemeinwohls, Herr Bullinger hat mit diesem Gesichtspunkt die Diskussion begonnen, adäquat und angebracht. Bei der Findung des Gemeinwohls auf lokaler Ebene ist es völlig legitim und richtig, wenn der Gesetzgeber bestimmte Belange für wichtiger erklärt als andere. In diesem Sinne ist die Optimierung akzeptabel und bereitet kaum Probleme. Schon schwieriger wird es, wenn man diesen Aspekt auf die Fachplanung überträgt. Ich greife den prekärsten Belang heraus. Das ist der Umweltschutz. Den Umweltschutz als Vorrangbelang bei der Bauleitplanung auszugestalten, ist akzeptabel. Bei der Fachplanung geht das nicht. Demgegenüber wurde gesagt, daß auch dort eine Abwägung stattfindet. Aber was wird hier abgewogen? Ein konkretes Projekt! Was muß jetzt also optimiert werden, das Projekt oder der Umweltschutz? Das ist der entscheidende Punkt. Wer jetzt immer noch den Umweltschutz optimieren will, liegt schief. Plötzlich werden Umweltbelange, sektorale Belange, der Fachplanung entgegengehalten, und die Fachplanung tritt zurück. Das ist falsch. Bei der Fachplanung kommt es vielmehr nur darauf an, das Projekt zu optimieren. Eigentlich ist das Optimierungsgebot hier ein Minimierungsgebot, nämlich das $\mathrm{Ge}$ bot, bei Realisierung des Projekts den geringstmöglichen Eingriff in die Umwelt vorzunehmen. Es ist also schon problematisch, eine Kategorie der Gesamtplanung auf die Fachplanung zu übertragen. Ganz schlimm wird es dann bei der Kontrollerlaubnis mit planungsrechtlichem oder ohne planungsrechtlichen Einschlag. Optimierung der Kontrollerlaubnis klingt harmlos. In Wirklichkeit soll jedoch eine Unternehmergenehmigung optimiert werden. Was soll nun genau optimiert werden? Nicht der Umweltschutz, sondern das Vorhaben eines konkreten Unternehmers. Dieser muß bei gegenläufigen öffentlichen und privaten Belangen mit Restriktionen rechnen, das ist ganz klar. Aber Optimierung kann nicht 
bedeuten, einen sektoralen Belang zu Lasten des Unternehmers, der ein Projekt durchfuihrt, zu maximieren. Also ist auch hier das Optimierungsgebot allenfalls ein Gebot, möglichst geringe Eingriffe in die Umwelt und Natur vorzunehmen unter Optimierung des Projekts aus der Sicht des Projektträgers und des Unternehmers. Das ist der erste Aspekt. Zweiter Aspekt: Ich stimme mit Herrn Würtenberger völlig überein, daß die Kontrollerlaubnis nicht durch Mechanismen des Optimierungsgebots bei der planerischen Abwägung verwässert werden darf. Wenn aber optimiert wird, gilt es die beste Lösung zu finden. Daran knüpft die Frage an: Wie finde ich das beste Ergebnis? Darüber streiten wir seit den 80er Jahren. Stellen wir auf die Verfahrensgestaltung ab, oder schauen wir auf das Ergebnis selbst - was ist als Ergebnis herausgekommen? Ich hatte gehofft, daß diese Diskussion endlich zur Ruhe gekommen ist, nachdem der Bundesgesetzgeber im letzteren Sinn die richtigen Regelungen getroffen hat. Aber da wir jetzt einen anderen Gesetzgeber haben, gehe ich davon aus, daß diese Regelungen wieder aufgehoben werden. Dann kommen die $80 \mathrm{er} \mathrm{Jahre} \mathrm{in} \mathrm{einem} \mathrm{anderen} \mathrm{Gewand} \mathrm{zurück.} \mathrm{Das} \mathrm{schadet} \mathrm{nichts.} \mathrm{Ich} \mathrm{bin}$ immer noch der Überzeugung, daß das Ergebnis das Entscheidende ist und nicht das zum Selbstzweck betriebene Verfahren. Da sind Sie mir, Herr Würtenberger, zu blauäugig. In Deutschland ist es nicht wie in Frankreich oder sonstwo: „Am Anfang war das Wort". Für Deutschland gilt: „Am Anfang war der Verein“. Sobald irgendein Verfahren zur Zulassung eines größeren Vorhabens durchgeführt wird, wird irgendein Verein gegründet, und alle möglichen Einwender werden beteiligt und müssen angehört werden. Idealtypisch ist das aber für die Optimierung richtig. Wenn wirklich alle angehört werden, alle Vereine, Gruppierungen und Interessenvertreter - das war auch in der Diskussion angeklungen -, wenn alle Belange repräsentiert sind, ist das in Ordnung. Nur ist das in unseren Genehmigungsverfahren eben nicht der Fall. Es findet kein idealtypischer diskursiver Prozeß statt; es kommen nur die zum Zug, die am lautesten schreien; es gilt der Grundsatz: „Qui clamat, optimat “. Dadurch wird im Ergebnis nicht optimiert. Optimiert wird nur dann, wenn wir unsere Verfahrensgestaltung ändern. Wenn bei der Fachplanung und Kontrollerlaubnis nicht nur Einwendungen gehört werden, sondern auch Anregungen und Beschwerden über die vorhandene Situation. Ich sage es ganz kraß: Wenn Naturschutzverbände - womit zu rechnen ist - noch intensiver beteiligt werden, weil dadurch der Erfahrungshorizont der Behörde und deren intellektuelles Verständnis wächst, dann sollten gefälligst auch die Handwerkskammer, Industrie- und Handelskammern, die Arbeitnehmer- und Arbeitgebervertreter, der ADAC und wer auch immer beteiligt werden, um einen korrekten Optimierungsprozeß durchzuführen. Wenn Sie das machen, Herr Würtenberger, bestreite ich nicht mehr, 
daß durch die Verfahrensgestaltung ein optimales und korrektes Ergebnis herbeigefuihrt werden kann. Wenn Sie das aber nicht machen und auch noch die Dichte der Ergebniskontrolle relativieren, dann stimme ich mit Herm Riedel überein, dann relativieren wir den Rechtsschutz. Und da halte ich immer noch das deutsche System hoch. Wir müssen weiterhin beim Ergebnis ansetzen und darauf schauen: Ist das für den Vorhabenträger ein optimales Ergebnis im Interesse aller Belange, oder wurde nur unzulässigerweise ein sektoraler Belang optimiert?

Masing: Ich möchte auf ein Moment zu sprechen kommen, das die Polarität zwischen Optimierungsgeboten und Rahmensetzungen noch einmal in einem anderen Licht erscheinen läßt, nämlich auf das Spannungsverhältnis von Einzelfallgerechtigkeit und Typisierungsnotwendigkeit. Mir scheint, daß sich nicht zuletzt auch hieraus die Attraktivität der Optimierungsgebote zunächst erklärt. Denn wie kommt es, daß die Optimierungsgebote solche Anziehungskraft haben? Man will dem einzelnen Fall möglichst optimal Rechnung tragen - und die Kosten, die eine Typisierung mit sich bringt, so vermeiden. In der Idee des Optimierungsgebots liegt es, daß man am Einzelfall mit seinen spezifischen Sachproblemen ansetzt und dabei alle Umstände berücksichtigen und $z u$ einer optimalen, da maßgeschneiderten Entscheidung zusammenführen kann. Diesem Wunsch zur Optimierung im Einzelfall entspricht eine Angst vor Typisierung, d.h. vor Verallgemeinerung. Meines Erachtens ist diese Angst auch in vielen Entscheidungen des Bundesverfassungsgerichts zu erkennen, sie kommt also nicht etwa erst und allein aus dem Europarecht. Wenn es insoweit darum geht, dem jeweiligen Einzelfall Rechnung zu tragen und sich zugleich vorzubehalten, im nächsten Fall angesichts etwaiger Besonderheiten anders zu entscheiden, bricht sich das notwendig mit der Vorstellung des Rechts als verbindliche Rahmenvorgabe. Denn ein Rahmen kann natürlich stets nur typisierend allgemein wirken er setzt eben gerade vor dem Einzelfall an. Bevor der Einzelfall da ist, wird durch ihn mit notwendigerweise einzelfallblinden, d.h. allgemeinen und groben Vorgaben verbindlich eine Grundsteuerung vorgegeben. Dabei wird man zunächst erkennen müssen, daß mit der Entwicklung zu den Optimierungsgeboten z. T. nur eine Reaktion gesucht wird, das Recht überhaupt den komplexen Vernetzungen der Sachgegebenheiten nachrücken zu lassen. Von daher ist ein Stück Attraktivität dieser Optimierungsgebote gut verständlich. Ich denke allerdings, daß gerade in dieser einzelfallbezogenen Struktur auch die besondere Problematik solcher Optimierungsgebote sichtbar wird, und zwar eine Problematik, in deren Folge im Extremfall das eigentliche Ziel, nämlich die Einzelfallgerechtigkeit, gerade verfehlt werden kann. In der Frage „Optimierungsgebot oder 
Rahmensetzung?“" geht es nämlich - gerade Herr Würtenberger hat dies in seinem Referat deutlich gemacht - auch um die Steuerungsfähigkeit des Rechts. Sofern die Entscheidung in den Einzelfall gelegt wird, läßt sich eine demokratische Steuerung kaum mehr vornehmen. Damit verbunden ist zugleich, daß die gesamte Entscheidungsstruktur in den Sachverhalt als Sachverhalt verlegt wird und so deren politische Dimension zunächst, zumindest scheinbar, eliminiert wird. Der Rechtsfindung liegt keine Satzung mehr zugrunde, sondern das Problem wird, sachangemessen, so wie es sich aus der Natur der Sache ergibt, möglichst optimal gelöst. Das Moment der Entscheidung des Politischen ist damit zunächst zurückgedrängt und minimalisiert - allerdings nur scheinbar. Denn letztlich kommt es - und da liegt die Problematik - als Politisierung der Einzelfallentscheidung an anderer Stelle doch wieder zum Vorschein und führt jetzt dazu, daß im Einzelfall der gesamte politische Ausgleich der vielschichtigen Entscheidungen getroffen werden muß und dabei der einzelnen Behörde obliegt. Die zuständige Behörde muß nun allein die aus der Natur der Sache sich ergebende Präferenzentscheidung in einem unter Umständen hochpolitischen Umfeld fällen. Ohne den Schutz einer verbindlichen gesetzlichen Vorgabe kann eine Behörde hiermit erheblich überfordert sein. Ausgesetzt den Pressionen der konkret Interessierten, kann dies zu Entscheidungen führen, die sich mehr an wirtschaftlichem Einfluß oder an kurzfristigen Vorteilen sonstiger Sachgegebenheiten orientieren als an der optimalen Lösung des Einzelfalls. Gerade die Entwicklung, die durch den integrierten Umweltschutz z.T. in der Europäischen Union stattfindet, kann, wenn sie nicht durch verbindliche Rahmensetzungen sinnvoll ergänzt und aufbereitet wird, dazu führen, daß die Behörden in den verschiedenen Ländern letztlich ohne bzw. jedenfalls nur mit wenigen strikten Maßstäben arbeiten müssen und somit ein verbindlicher Standard kaum gewährleistet erscheint. Darüber hinaus schlägt die vermeintlich optimierende Einzelfallentscheidung leicht auch dann gegen die Einzelfallgerechtigkeit, wenn es im Einzelfall um vielleicht anstöBiges Verhalten von Außenseitern geht, das das Recht gerade schützen soll. Wenn dieses unter Abwägungsvorbehalte je nach Maßgabe der individuellen Situation gestellt wird, kann man sich vorstellen, daß eine politische öffentliche Meinung hier den Minderheitsschutz sehr viel schwerer macht, als wenn man sich auf etwas weniger differenzierte, aber allgemeine Rahmensetzungen zurückzieht. Das heißt natürlich nicht, und das ist mir gerade auch aus dem Referat von Herrn Würtenberger noch einmal deutlich geworden, daß es die eine Form generell gegenüber der anderen zu präferieren gälte. Optimierungsgebote und Rahmensetzung sind zwei Formen der Entscheidungsfindung, zwischen denen man bereichsspezifisch wird unterscheiden müssen. Hierbei scheint mir wichtig, 
was Herr Schulze-Fielitz betont hat: In den Fällen, in denen eine Steuerung gar nicht mehr möglich ist, sind Optimierungsgebote der Versuch, den Entscheidern zumindest doch überhaupt etwas an die Hand zu geben. Von daher darf man nicht das Kind mit dem Bade ausschütten und in Optimierungsgeboten nur noch eine Auflösung des Rechts erkennen wollen. Gerade im Umweltschutz bleibt im übrigen noch auf ein weiteres hinzuweisen: Es gibt ja auch Möglichkeiten, beide Elemente ein Stück weit zu verschränken. Denkbar ist es etwa, möglichst weitgehende Rahmenvorgaben mit strikten Grenzwerten zu verbinden mit einem darüber hinausgehenden Bewirtschaftungskonzept, das - dann freilich nur noch begrenzt - Optimierungsmaximen zum Einsatz bringen kann. Hier wären beide Aspekte möglicherweise sinnvoll verbunden. Ich danke Ihnen.

Geis: Herr Würtenberger, einige Anmerkungen zu Ihren Thesen, konkret zu F.I. Da sprechen Sie von einer Neuorientierung des Verwaltungsverfahrens. Nun, wenn man es genau nimmt, so neu sind ja die Thesen nicht. Genau genommen sind sie eigentlich schon ziemlich alt, eigentlich schon über 20 Jahre. Das war im Grunde die Diskussion im Vorfeld des VwVfG, und auf der Konstanzer Tagung 1982 sind ja ähnliche Forderungen auch schon erhoben worden: das Verfahren als Korrelat zu einer materiellen Inhaltsprüfung des Verfassungsrechts. Der Ansatz, dem ich ja eigentlich auch zuneige, ist für sich genommen als Theorie schlüssig. Aber im einzelnen muß man sich fragen: Jagen wir dann nicht zusammen einem Phantom nach? Denn - es ist jetzt auch schon angesprochen worden, und in Threr These 27 kommt es zum Ausdruck - durch ein Verwaltungsverfahren, das durch exzessive Heilungsvorschriften als Entscheidungsprozeß entwertet wird, kann Verfahrensgerechtigkeit, wie Sie sie ansprechen, nicht mehr adäquat garantiert werden. Der Verfahrensgedanke wird dadurch entwertet. Beim Widerspruchsverfahren wird es noch deutlicher. Das sollte ja sozusagen auch noch eine Inhaltskontrolle ermöglichen. Es ist noch nicht ausdrücklich nachgeforscht, wie sich in der Rückkopplung diese Heilungsvorschriften auf die verschiedenen Gestaltungen der Verfahren empirisch auswirken werden. Ich glaube eher, daß dabei nichts Gescheites herauskommt. Sie monieren auch in These 27 eine diskursive Konkretisierung als Forderung. Da fragt man sich, wo der Diskurs bleibt, wenn die Verwaltung im krassesten Fall, im GaA sozusagen, erst einmal so richtig einseitig obrigkeitlich handeln kann, also gegen Verfahrensrechte verstoßen kann, um dann abzuwarten, ob der Betroffene genug Geld und Nerven hat, um zu klagen, und dann im Zweifel immer noch den Joker des $§ 45$ Abs. 2 VwVfG ziehen kann. Also ich glaube, die Wirklichkeit ist von dem einstigen Ideal des Verwaltungsverfahrensgesetzes und der damaligen Diskussion mehr denn je entfernt. Ein zweiter Punkt noch ganz kurz: In Ihrer These 26 plä- 
dieren Sie dafür, im Idealfall Elemente der repräsentativen und der partizipativen Demokratie miteinander zu verknüpfen, und Sie setzen das mit einer Verantwortungsteilung zwischen Staat und gesellschaftlichem Bereich gleich, wenn ich das richtig verstanden habe. $\mathrm{Da}_{2}$ denkt man natürlich, daß auf diese Art und Weise alte Geister beschworen werden, insbesondere durch den Begriff der partizipativen Demokratie, wenn dies, wie hier es zu sein scheint, mit dem gesellschaftlichen Bereich assoziiert wird. Nachdem ich nicht annehme, daß Sie hier die Speerspitze grüner Politik darstellen wollen, wïrde ich hier fragen, wie Sie sich das mit der partizipativen Demokratie etwas präziser vorstellen. Handelt es sich da nicht um die funktionale Beteiligung, also um den Gedanken aus dem Grundrechtsschutz heraus und weniger um den aus der staatstheoretischen Demokratie?

Götz: Unser heutiger Beratungsgegenstand betrifft die Normstruktur des Verwaltungsrechts. Aber dahinter steht doch letztlich und vor allem das Verhältnis der Verwaltung zur Verwaltungsgerichtsbarkeit, eine Thematik, die in der Vereinigung Tradition hat. Herr Starck hat heute bei der Eröffnung auf die früheren Tagungen '75, '80, '82 und '84 hingewiesen. Mir scheint, daß zu dieser Tradition der Vereinigung auch gehört, daß sie in diesem Zusammenhang stets den Begriff der Verwaltungsverantwortung positiv besetzt, während die richterliche Kontrolle unterschwellig dem Verdacht ausgesetzt wird, sie übertreibe bei dieser Kontrolle und bringe durch solche Ubertreibungen eben die Verwaltungsverantwortung in Gefahr. Ich ergreife das Wort, um dieser Tendenz deutlich entgegenzutreten, und beziehe dabei meine Legitimation mit aller Bescheidenheit aus einer jetzt fast 30jährigen aktiven Tätigkeit in der Verwaltungsgerichtsbarkeit. Ich habe dabei gründlich die Baurechtspraxis kennengelernt. Das ist zugegebenermaßen nur ein kleiner Kosmos des Verwaltungsrechts. Aber man kann vieles darin erkennen. Die Gesetzmäßigkeitskontrolle der Bauleitpläne wird anhand einer gesetzlichen Rahmenregelung vorgenommen, und es findet die Anwendung einer bewährten Abwägungskontrolldogmatik statt. Dies ermöglicht, wie ich meine, in perfekter Weise auch die Gestaltungsfreiheit der Verwaltung, der planenden Verwaltung, zu wahren. Nun sind in der jüngsten Zeit die Optimierungsgebote im Baurecht aufgetreten, aber sie bringen überhaupt nichts grundstürzend Neues. Selbstverständlich kann man das Gebot, mit dem Boden schonend umzugehen oder die Eingriffe in den Naturhaushalt zu vermeiden, als Optimierungsgebote verstehen. Aber diese Gebote sind nicht derart, daß sie, um es auf eine Kurzformel zu bringen, das Bauen letztlich verhindern. In der Baurechtspraxis stoßen wir auf einen weiteren Gegenstand, die Zulässigkeit der Vorhaben. Hier wenden wir unbestimmte Rechtsbegriffe an, und allen, die irgendwie eine Herabsetzung der Kontrolldichte favorisieren, 
möchte ich entgegenrufen: An der vollständigen gerichtlichen Anwendbarkeit der die Zulässigkeit von Vorhaben bestimmenden Normen ist überhaupt nicht zu rütteln, auch wenn es sich dabei um unbestimmte Rechtsbegriffe handelt.

Die drei Referenten haben durch eine Rechtsvergleichung das Gebäude unserer Kontrolldogmatik durchleuchtet und auch durchlüftet. Sie haben, wenn ich sie recht verstehe, nicht dafür plädiert, daß die deutsche Verwaltungsgerichtsbarkeit bewährte Errungenschaften aufgibt. Ich meine deshalb, daß Herr Schulze-Fielitz bei den Referenten offene Türen einrennen müßte mit seinen Sorgen und Forderungen, solche rechtsstaatlichen Errungenschaften nicht aufzugeben. In den europäischen Dialog und Wettbewerb ist der deutsche Beitrag einzubringen. Die Optimierungsgebote sind nach allem, was wir gehört haben, trotz der vorsichtigen Annäherung von Herrn Sieckmann, keine Exportschlager. Auf sie können wir weitgehend verzichten. Aber es gibt gottlob Qualitätsartikel unseres Verwaltungsprozeßrechtes, die wir vorweisen können: Ich denke an den einstweiligen Rechtsschutz und vor allem die Verpflichtungsklage, die in Europa nicht vorhanden ist, die aber - ich wiederhole mich - ein Qualitätsartikel ist. Wir verdanken überhaupt die Entwicklung großer Teile unseres materiellen Rechtes der Existenz dieser Verpflichtungsklage. Es gäbe kein Schulrecht, es gäbe bestimmte Teile des Polizeirechts, Hochschulrechts usw. ohne diese Klage nicht. Ich glaube, daß es den Referenten hervorragend gelungen ist, das deutsche System in den europäischen Rechtsvergleich, in die europäische Dimension hineinzustellen.

Raschauer: Zunächst eine Vorbemerkung: Ich möchte unterscheiden zwischen dem Umfang der verwaltungsgerichtlichen Kontrolle und dem Umfang der rechtlichen Bindungen der Verwaltung. Die zweiteren sind wesentlich umfangreicher. Ich sage das deshalb, weil man leicht den Gedanken "Optimierungsgebot" durch Hinweise auf Überforderung der Verwaltungsgerichtsbarkeit umbringen könnte. Sehen wir das Gebot als Handlungsauftrag an die Verwaltung, so möchte ich eben die These vertreten, daß das zumindest kontraproduktiv ist. Herr Alexy hat uns eingeräumt, daß das Optimierungsgebot nicht dahin zu verstehen ist, daß es auf die optimale im Sinn von einzig richtige Entscheidung hinzielt. Nur, wenn das nicht der Fall ist, wenn es nicht um die optimale Entscheidung geht, dann sollte man das Verfahren auch nicht als Optimierungsverfahren bezeichnen. Zum zweiten merke ich zur Zeit im Umweltrecht den Kampf um Begriffe und damit auch den Kampf um die Besetzung der "Optimierung“ im Umweltschutzrecht, die immer wieder dazu führt, daß materielle Umweltstandards abgebaut werden. Wie funktioniert das, was unter Optimierung figuriert, in der Praxis? Dazu ein ganz banales Bei- 
spiel, das es sicher auch im deutschen Forstrecht gibt: Die Rodungsbewilligung hat zur Voraussetzung, daß das öffentliche Interesse an dem Projekt das öffentliche Interesse an der Walderhaltung überwiegt. Ganz banal, entweder überwiegt es, oder es überwiegt nicht. Zu optimieren ist da nichts. Und das ist das Grundstrukturmodell eines Abwägungsvorgangs, und das finden wir im Naturschutzrecht wieder, im Denkmalschutzrecht, bei allen Abstandnahmebewilligungen. Ich will damit nur sagen, die Masse der Abwägungen hat überhaupt nichts mit Optimierungen zu tun. Jetzt zu Beispielen, welche die Referenten gebracht haben. Es waren ja leider sehr wenige Beispiele, an denen man diese zum Teil sehr abstrakten Theorien hätte überprüfen können. Aber Herr Würtenberger hat zum Beispiel das Anlagenrecht angesprochen. Da würde ich sagen, die Masse der anlagenrechtlichen Fallkonstellationen geht dahin, ob etwa bei einer Spritzlackiererei eine bestimmte Abluftreinigung Stand der Technik ist. Da gibt es nichts zu optimieren. Entweder kann sie dem Betreiber vorgeschrieben werden, oder sie kann ihm nicht vorgeschrieben werden. Das führt mich gleich weiter zum zweiten Beispiel, nämlich zum Umweltoptimierungsprinzip. Zur Zeit läuft es ja im ganzen deutschsprachigen Raum im Lichte der IPPC-Richtlinie darauf hinaus, den "Stand der Technik“ abzuschaffen und durch die best available technologies zu ersetzen, durch die best practice, wie sie in These 7 angesprochen ist. Nur, das ist weniger als der Stand der Technik, und der ist schon weniger als der Stand der Wissenschaften. Kurz, im Anlagenrecht kann von einem Optimierungsgebot keine Rede sein. Dann haben Sie, Herr Würtenberger - nicht als Vorwurf, sondern nur, um es zu exemplifizieren - die Nachbesserung angesprochen. Wir haben auch in Österreich einen Trend - $\$ 79$ Gewerbeordnung - hin zur Nachbesserung, was impliziert, daß man am Anfang zu großzügig bei der Erstgenehmigung war. Das heißt aber, daß in der Rechtsordnung von vornherein einprogrammiert ist, daß Suboptimales beginnt und dann ergänzende Auflagen vorgeschrieben werden. In diesem Zusammenhang erleben wir den spezifischen Konflikt "Optimierung contra Verhältnismäßigkeit", denn den nachträglichen Vorschreibungen steht der Verhältnismäßigkeitschutz des Anlagenbetreibers entgegen. Mit Nachbesserungsmodellen ist also nie das optimale Projekt zu erzielen. Das waren ein paar Beispiele, wie sich nach meiner Sicht die Frage aus der Perspektive der Verwaltung darstellt. Das einzige, wo ich schwankend werden würde, ob es so etwas wie „Optimierung" gibt, und von dort dürfte ja auch der Begriff herkommen, ist das Planungsrecht. Trotzdem scheint es mir auch dort ein unangemessener Begriff zu sein. Überlegen Sie sich einmal, wie es zu einer Eisenbahntrasse kommt. Wie man in jahrelanger Arbeit Gewässerschutzgebiete, schützenswerte Wälder, Naturschutzbereiche, Denkmalobjekte, Straßen- 
züge, Jagdgebiete usw. erhoben hat und unter mühsamen Geburtswehen eine Trasse geboren hat, ist es undenkbar, ganz praktisch unvorstellbar, $\mathrm{da}$ man der einen Trasse eine andere Trasse als besser gegenüberstellt. Man kann nur etwas, was in solchen jahrelangen Mühen geboren ist, punktuell falsifizieren, indem man sagt, ihr habt ja übersehen, daß da Naturdenkmäler sind, die kommen in eurem Umweltbericht nicht vor. Aber eine Optimierung von Großprojekten in dem Sinn, als gäbe es da mehrere Varianten, wobei dann der Richter sagt, das wäre eigentlich die optimale gewesen, ist nach meiner Überzeugung weltfremd. Daher komme ich zu dem Ergebnis, man sollte diesen Begriff in der Verwaltungsrechtsdogmatik unbedingt vermeiden. Er löst Erwartungshaltungen aus, die in der Verwaltung nicht vorgesehen sind, die nicht eingelöst werden können und, wie ich skizziert habe, auch gar nicht eingelöst werden sollen. Herr Isensee hat gesagt, die Verwaltung hat das Recht anzuwenden, und das ist eine gute Formulierung. Denn Handlungsauftrag der Verwaltung ist eben ein anderer.

Selmer: Ein kurzer Blick zurück noch auf den europarechtlichen Beitrag von Herrn Zuleeg: Ich stimme ihm in der Anerkennung der großartigen Integrationsleistung des Europäischen Gerichtshofes durchaus zu. Was speziell allerdings den durch diesen gewährleisteten Grundrechtsschutz gegen Akte der Gemeinschaftsgewalt betrifft, so kann ich ihm in der These, der Gerichtshof habe sich hier gegenüber Äußerungen aus der Bundesrepublik überaus offen gezeigt, nicht beipflichten. Denn bei aller Bewunderung der Gesamtleistung des EuGH: Dieser ist dem Vertrauensvorschuß, den ihm das BVerfG 1986 in seiner Solange II-Entscheidung (BVerfGE 73, 339, $383 \mathrm{ff}$.) insoweit entgegengebracht hatte, in den nachfolgenden Jahren keineswegs in überzeugender Weise gerecht geworden. In dieser Beurteilung sehe ich mich einig mit einer zunehmenden Zahl von Beobachtern, dabei keineswegs nur, wenn auch vorwiegend solchen aus der Bundesrepublik. Im einzelnen kann ich insoweit auf die Äußerungen von Herrn Dörr sowie auf eine eigene jüngere Darlegung Bezug nehmen. Interesse verdient hier freilich die durch den sogenannten Bananen-Streit, seine Entscheidung durch den EuGH sowie eine einschlägige Vorlage an das BVerfG veranlaßte Äußerung des Richters am EuGH Günter Hirsch anläßlich des Verwaltungsrichtertages in Mainz, grundrechtskritische Warnsignale aus Karlsruhe würden gegebenenfalls in Luxemburg größte Aufmerksamkeit finden. Sie vermittelt den Eindruck, daß sich der EuGH der grundrechtsdogmatischen Schwächen seiner Judikatur bewußt und bereit ist, in grundrechtsrelevanten Entscheidungen die Zügel künftig etwas straffer anzuziehen.

Jetzt zu meiner eigentlichen Fragestellung: Ausgangspunkt ist der Be- 
fund, daß die beiden ersten Referenten, wenn sie die Optimierung als eine der Gerechtigkeit verpflichtete Idee würdigen, dabei offenbar vor allem die Gerechtigkeit des konkreten Einzelfalles vor Augen haben. Ich verweise insoweit auf die von Herrn Würtenberger vor Leitsatz 15 verwendete Formel vom „Zwang zur situativen Konkretisierung des Rechts" und die von ihm in Leitsatz 15 genannten "konkreten Lebensverhältnisse", die in hohem Maß den Entscheidungsprozeß der Verwaltung steuerten. In einem gewissen Gegensatz hierzu sehe ich allerdings den immer wieder deutlichen Typisierungs- und Generalisierungshunger der Verwaltung auch dort, wo der Gesetz-oder Verordnungsgeber durch die Einräumung von Ermessen oder Beurteilungsspielräumen gerade auf die Möglichkeit einer einzelfallgerechten Lösung verweist. Die Gründe hierfür und damit für die Fülle ermessensleitender und normkonkretisierender Verwaltungsvorschriften liegen gewiß einmal in dem Drang der Exekutive nach abgesicherter Entscheidungserleichterung, daneben und nicht zuletzt aber auch in ihrem Bedürfnis nach Gewährleistung einer standardisierten Gleichbehandlung im Typus gleichartiger oder ähnlicher Fälle. Herr Haller hat auf diesen Aspekt, wenngleich in einem etwas anderen Zusammenhang, in Leitsatz 9 seiner Thesen verwiesen. Das BVerwG hat die darin liegende Verengung der durch den Gesetzgeber an sich eingeräumten situativen Konkretisierungsbefugnis durch Verwaltungsvorschriften bekanntlich hingenommen, solange nur der spezifischen Bewältigung gänzlich atypischer Fälle Raum gelassen sei. Meine Frage an die Referenten geht dahin, wie sich ihre Optimierungsvorstellungen zu der von mir kurz skizzierten Problematik verhalten.

Wallerath: Ich möchte zurückkommen auf die unterschiedlichen begrifflichen Grundlagen in den Referaten von Herrn Haller und Herrn Riedel. Herr Haller formuliert in These 1: „Der Gesetzgeber gebietet immer Optimierung." Diese Formulierung umgreift ersichtlich einen weiteren Optimierungsbegriff, der sich an dem Effizienzgedanken oder an der Effektivität, also der Steuerungskraft, des Gesetzes mißt. Demgegenüber verwendet Herr Riedel - ebenfalls in These 1 - einen engeren Begriff, wenn er auf die Auflösung von Kollisionen abstellt. Ich meine nun, daß beide Begriffe ihren Sinn haben, aber in unterschiedlichen Zusammenhängen, weil sie je verschiedene Funktionen erfüllen. Der enge Begriff ist vor allen Dingen ein dogmatischer Begriff; der weite Begriff ist ein Begriff, der insbesondere auf Gesetzgebungslehre und Verwaltungswissenschaft zielt. Um dies mit einer Überlegung zu verdeutlichen: Primäres Ziel eines jeden Gesetzes ist die Steuerung von gesellschaftlicher Wirklichkeit, deren Veränderung oder Stabilisierung. Aber es ist nicht ausgeschlossen, daß im Gesetz die Selbstdarstellung der Akteure mitschwingt. 
Und je mehr diese dominiert, um so mehr wird das Problem der Effektivität virulent. Sie führt nämlich dazu, daß wir hier defizitäre Normverwirklichung oder gar programmiertes Vollzugsdefizit viel eher feststellen können als bei sonstigen Gesetzen. Hier ist vor allem die Perspektive der Effektivität, also praktisch der Optimierung in einem weiteren Sinne, zur Geltung zu bringen. Wenn es dagegen um die dogmatische Griffigkeit geht, scheint mir der engere Begriff, wie er von Herrn Riedel formuliert wurde, sehr viel adäquater zu sein. Er hat auch den Vorteil, daß er juristische Selbstbeschränkung anmahnt, daß die Juristen - es war eben die Rede davon, daß ,im Anfang “ das Wort war - nicht immer das letzte Wort zu allem und jedem haben.

Dies gibt mir das Stichwort für die zweite Überlegung, bei der ich an These 17 von Herrn Würtenberger anknüpfen möchte. Herr Würtenberger stellt die Optimierung in einen Zusammenhang mit dem Grundsatz der Proportionalität. Ich halte das für völlig richtig. Worauf ich nur hinweisen möchte, ist, daß wir gleichsam vorgelagert eine "Sollbruchstelle“ haben. Es ist der Grundsatz des Gebotes des mildesten Mittels oder des Interventionsminimums. Diese Bruchstelle versperrt uns den Rückgriff auf eine andere Figur, die wir als Verwaltungsrechtler inzwischen weithin vernachlässigen, nämlich die der „Unzweckmäßigkeit" als Gegenbegriff der Zweckmäßigkeit. Was aber ist Zweckmäßigkeit? Zweckmäßigkeit ist die optimale Verwirklichung von Verwaltungszwecken. Freilich, wenn wir sie ausgrenzen wollen, müssen wir sie ausgrenzen von der gebotenen ,rechtlichen" Optimierung, denn deren Verfehlung bedeutete Rechtswidrigkeit. Mir liegt daran, daß die negative Fassung des Gebots des mildesten Mittels zur Geltung kommt, wie dies überwiegend auch in der Rechtsprechung geschieht, um die Rechtsfigur der Unzweckmäßigkeit nicht zu einem historischen Relikt werden zu lassen. Tatsächlich markiert nicht zuletzt diese den Raum, den wir der Verwaltung als eigenständiger Staatsgewalt zubilligen müssen. Vielen Dank!

Vorsitzender: Wir sind damit am Ende der Liste der Diskussionsredner angelangt, und ich darf nun die Referenten bitten, am Schluß dieser Aussprache in komprimierter und vielleicht auch selektiver Form zu den gestellten Fragen und den Anregungen Stellung zu nehmen. In umgekehrter Reihenfolge darf ich nun zuerst Herrn Riedel um das Schlußwort bitten.

Riedel: Vielen Dank, Herr Vorsitzender, und ich bitte gleichzeitig um Nachsicht, daß ich nicht alle Diskussionsbeiträge der Reihe nach durchgehen werde und angesichts der Zeit nur einige wenige herausgreifen kann. Zunächst einmal möchte ich aber den Gedanken aufgreifen, den 
Herr Pernice ganz zu Beginn unserer zweiten Runde ins Spiel gebracht hat, den Gedanken der Partizipation, der bei unserer Diskussion eine relativ geringe Rolle gespielt hat. Ich kann da nur noch einmal bekräftigen, was er dazu gesagt hat. In der Tat gibt es auf europarechtlicher Ebene eine andere Art von Legitimation. Es geht nicht so sehr um die Legitimation durch parlamentarische Gesetzgebung. Wie der Rechtsetzungsprozeß in der Europäischen Gemeinschaft zeigt, sind hier vielmehr die Gedanken der Vernetzung, der vielfältigen verfahrensmäßigen Beteiligungsformen, ja der Legitimation durch Diskurs, doch viel intensiver ausgestaltet, als das im innerstaatlichen Bereich der Fall ist. Deshalb stimme ich Ihrer Analyse, Herr Pernice, insofern zu. Mehrere Redner haben die Frage der Umsetzung des EG-Rechts im innerstaatlichen Recht thematisiert und die Frage der Rahmensetzung oder Optimierung daran festgemacht. Ich kann nur wiederholen, daß weder das englische Recht noch das französische Recht - und Herr Fromont sowie Herr Autexier haben dies für das französische Recht ausdrücklich bestätigt - den Optimierungsgedanken aufnehmen, es sei denn, man begreift ihn als Umschreibung für notwendige Abwägungsgebote ohne Fixierung auf ein einziges, richtiges Ergebnis. Herr Zuleeg und Herr Dörr haben sodann mögliche Divergenzen in der Rechtsprechung des EuGH und des EGMR thematisiert und die innerstaatliche Akzeptanz dieser Rechtsprechung erörtert. Soweit Großbritannien betroffen ist, binden Straßburger Menschenrechtsentscheidungen einstweilen nur völkerrechtlich, nicht unmittelbar innerstaatlich. Erst nach Erschöpfung des Rechtsweges können Beschwerdeführer das EMRK-Regime nutzen. Dies wird sich nach Inkrafttreten der neuen britischen Bill of Rights wohl ändern. Anders verhält es sich mit Urteilen des EuGH. Über die Grundrechtsrechtsprechung aus Luxemburg werden gemeineuropäische Grundrechts- und Verfassungsstandards unter Einbeziehung der Rechtsvergleichung gewonnen, in das innerstaatliche Recht übernommen, und sie genießen im Konfliktfall sogar Vorrang. Auf dem Umweg über Luxemburg gelangen so Grundrechtspositionen der Straßburger Institutionen als unmittelbar geltendes Recht in die britische Rechtsordnung und können deshalb auch schon in unteren Instanzen berücksichtigt werden. Man ist sich dabei aber voll bewußt, daß hier echter Konfliktstoff zwischen demokratisch legitimierten Entscheidungen des Parlaments und grundrechtsschützenden gegenläufigen Entscheidungen der Gerichte vorprogrammiert ist, wie es ihn seit 1689 nicht mehr gab. Und doch gehen die britischen Gerichte diesen Weg, aber mit großen Zahnschmerzen. Die Richter tun es nicht gerne, denn die Souveränität des Parlaments steht bei den Engländern nach wie vor sehr stark im Vordergrund. Ich hatte das heute morgen $\mathrm{ja}$ ausführlich dargestellt. Die EMRK und die Gemeinschaftsgrundrechte und vor allen Dingen die 
Neuerungen der Gemeinschaftsgrundrechte im Vertrag von Maastricht, die abgewandelte Artikel F Abs. 2-Version, die gemeineuropäische Standards herausstellt, werden in Großbritannien sehr ernst genommen. Art. F Abs. 2 EUV war ja mit Art. L EUV verbunden, der keine direkte gerichtliche Überprüfung des Art. F zuließ. Die Überprüfung durch den EuGH konnte nur dadurch bewerkstelligt werden, daß dem Art. F Abs. 2 deklaratorische Wirkung zugesprochen wurde. Somit war ein dogmatisch sauberer Weg zur Anwendung der gemeineuropäischen Verfahrensstandards und -traditionen der Mitgliedstaaten gefunden, der im Vertrag von Amsterdam in den Art. 6 und 46 AV weitergehend fortgeschrieben wurde. Die Auseinandersetzung darüber ist von Herrn Pernice, Herrn Schwarze, Herm Frowein und anderen ja ausführlich behandelt worden.

In Großbritannien ist die Diskussion um die Einführung der Bill of Rights, wie Sie wissen, nie verstummt, und es kann mit der baldigen Verabschiedung einer solchen Grundrechtscharta, gestützt auf die Formulierungen der EMRK, gerechnet werden. Die neuere Rechtsprechung dort nimmt im übrigen zunehmend auf diese europäischen Entwicklungen Rücksicht, vor allen Dingen auf Entwicklungen, die aus Straßburg kommen. Und der Vorrang des Gemeinschaftsrechts wird ernstlich befolgt, ja man übernimmt sogar die Frankovich-Entscheidung in viel größerem $\mathrm{Maße}$, als das in einigen anderen Mitgliedstaaten der Fall ist.

Herr Dörr hatte dann das Verhältnismäßigkeitsprinzip als Beispiel für den europäischen Gerichtshof für Menschenrechte herangezogen, um zu zeigen, daß wir dort einen unterschiedlichen Standard haben. Das ist in der Tat so. Die Diskussion um den Verhältnismäßigkeitsgrundsatz auf Luxemburger und Straßburger Ebene ist zwar stark von deutschen Rechtsvorstellungen geprägt, aber in concreto dann doch sehr viel enger gefaßt. Woran liegt das? Weil es zwei Tendenzen in der Rechtsprechung in Straßburg gibt; einmal die Harmonisierungstendenz, und zum anderen die Pluralitätstendenz. Und das führt dann in der Praxis häufig zur Respektierung einzelstaatlicher Regelungen über die Figur der staatlichen Einschätzungsprärogativen (marges d'appréciation). Bei der Harmonisierungstendenz gibt es gewisse unveräußerliche, unantastbare, überall in Europa gleichermaßen durchzusetzende Grundsätze wie etwa, daß Prügelstrafe als Gerichtsstrafe und Schulstrafe verboten ist. Demgegenüber steht das Pluralitätsinteresse, das verschiedene, kulturell bedingte Unterschiede der Rechtsordnungen bewußt respektiert, in England etwa Verurteilungen wegen contempt of court (Mißachtung der Gerichtsbarkeit) bei Vorveröffentlichung von Verhandlungsabläufen, obwohl es in keinem anderen Mitgliedstaat der Europäischen Menschenrechtskonvention den Strafgrund contempt of court in dieser Form gibt. Der nationalen Rechtsordnung müsse deshalb eine marge d'appréciation, eine Einschätzungsprä- 
rogative im weitesten Sinne, verbleiben. Das schafft Unterschiede und Schwierigkeiten, und dieses Spannungsverhältnis zwischen Harmonisierung und Pluralitätssicherung ist letztlich ungelöst und wird noch lange die Gemüter bewegen, in Straßburg und letztlich auch in Luxemburg. In bezug auf den Beitrag von Herrn Oblinger möchte ich nur kurz darauf hinweisen, daß das Vorabentscheidungsverfahren nach Art. 177 EGV, demnächst $234 \mathrm{AV}$, von den unteren Instanzen der deutschen Gerichte durchaus ernstgenommen wird, nicht jedoch in gleichem Maße von den Obergerichten. Ich erinnere nur daran, daß einige Entscheidungen des Bundesfinanzhofs sich mit der Umsetzung von EuGH-Urteilen sehr schwertun. Soviel zu konkreten Beiträgen.

Gestatten Sie mir an dieser Stelle, vielleicht noch einmal meine Kernthese ganz kurz zu benennen. Der Blick in benachbarte Rechtsordnungen zeigte mir, daß es keiner grundlegenden Umwandlung unserer Rechtsordnung bedarf, daß dies wegen Art. 19 Abs. 4 GG weder erforderlich noch angezeigt scheint. Die Ausführungen von Herrn Schulze-Fielitz haben das meines Erachtens bestätigt. In der Tat, Art. 19 Abs. 4 GG ist keine carte blanche, sondern muß im Zusammenhang mit den dahinterstehenden Grundrechtsgewährleistungen gesehen werden, aber auch im $\mathrm{Zu}$ sammenhang mit Art. 80 Abs. 1 Satz 2 GG sowie mit einer stärkeren Rückbesinnung auf die Rolle der Dritten Gewalt als kontrollierende Gewalt ohne Gestaltungsauftrag. Optimierungsgebote sind, wie Herr Götz es treffend formulierte, folglich auch kein Exportschlager. Optimierung ist deshalb eher eng als Abwägungsgebot, als Einstellungsgebot zu begreifen, wie dies auch Herr Wallerath sieht. Dann rücken automatisch Verfahrensaspekte stärker in den Vordergrund, ohne dadurch die materiellrechtlichen Aspekte des Rechtsstaatsprinzips zu vernachlässigen, von denen wir uns im Kern nicht trennen können.

Was bleibt, ist ein Appell an judicial self-restraint, wie es englische und französische Richter in ihren Entscheidungen immer wieder betonen, aber nicht nur unter Vergießen von Krokodilstränen, um dann doch etwas anderes zu tun, sondern sie halten sich auch daran. Das sollte man vielleicht den Untergerichten stärker vor Augen führen. Im Vorfeld der eigentlichen Verwaltungsentscheidung ist der Blick in die anderen Rechtsordnungen meines Erachtens besonders ertragreich. Tribunals, inquiries oder enquêtes publiques liefern dort sehr interessante Beispiele, wie man die ganze Skala der Beteiligungsmöglichkeiten durch Vergleich schärfen kann.

Der Beitrag von Herrn Starck, und damit komme ich zum Schluß, hat mich angeregt, eine zusätzliche Bemerkung zur Rolle der Rechtsvergleichung anzuschließen, was sie letztlich leisten und was sie nicht bewirken kann. Sie liefert keine blue prints, keine Patentlösungen für innerstaatliche 
Probleme. Die jeweilige Rechtsordnung produziert ihre eigenen Antworten, die nicht schlechthin gelten können und sollen, sondern meist zeitgebundene Antworten auf konkrete historisch-kulturelle Gegebenheiten darstellen. Aber Rechtsvergleichung schärft uns den Blick, typische Vorund Nachteile einzelstaatlicher Lösungsversuche klarer herauszustellen, allerdings stets unter dem ceteris paribus-Vorbehalt. Die großen Rechtsvergleicher haben deshalb immer sehr sorgsam die Vorverständnisse im Sinne Josef Essers mitberücksichtigt und Rechtsvergleichung entweder vor dem Hintergrund des Kulturvergleichs, des Vergleichs der Rechtsstile, des Vergleichs der Institute oder als Vergleich der Sachregeldifferenzen betrieben. Nicht zuletzt, und darauf hat Herr Starck ja heute nachmittag zu Recht hingewiesen, dient Rechtsvergleichung der Vergewisserung des eigenen Weges. Für jeden Völkerrechtler und Europarechtler ist Rechtsvergleichung absolut unverzichtbar, schon weil im Rechtsquellenkanon nach allgemeinen Rechtsgrundsätzen gesucht wird, und das geht ohne Rechtsvergleichung nicht. Diese Rechtsvergleichungsdimension zwingt uns vor allem im Europarecht, mehr Rechtsvergleichung zu betreiben. Und damit möchte ich jetzt ganz zum Schluß meinen Dank an den Vorstand aussprechen, daß Sie dieses Thema gewählt haben und daß Sie den Mut hatten, dabei die Dimension der Rechtsvergleichung aufzugreifen. Ich hatte Angst, daß der Blick in die anderen Rechtsordnungen im Raume verharren und niemand sich angesprochen fühlen könnte. Ich bedanke mich für die dann doch sehr große Beteiligung an der Diskussion, die klar bewies, wie groß die versammelte Sachkompetenz der Vereinigung auch in Fragen der Rechtsvergleichung ist und daß in Zukunft, darum würde ich herzlich bitten, Rechtsvergleichung immer wieder einmal miteinbezogen wird. Vielen Dank.

Vorsitzender: Herr Riedel, ich danke Ihnen ganz herzlich für Ihr Referat und auch für die ergänzenden Ausführungen in der Diskussion. Ich glaube, daraus ist sehr deutlich geworden, wie wichtig die Rechtsvergleichung ist und daß es Ihnen vorzüglich gelungen ist, uns die Welt der Rechtsvergleichung und insbesondere das französische und das britische Recht vorzustellen. Herr Haller, Sie haben als nächster das Wort.

Haller: Zu Herrn Pernice, der auf das sehr unterschiedliche europarechtliche Material hingewiesen hat: Ich darf kurz auf einen Fall verweisen, den Herr Öblinger dargestellt hat. Eine sehr präzise, ins Detail gehende EG-Richtlinie wird in Österreich durch ein bei weitem nicht so präzises Gesetz durchgeführt. Sie wird in einer dieses Gesetz durchführenden Verordnung wiederholt, so daß, wenn die Richtlinie, wie zu erwarten ist, sehr bald wieder verändert wird, wir nicht unser Gesetz verän- 
dern müssen, sondern mit dem schnelleren Instrument der Verordnung, auf dieses Gesetz formal gestützt, nachziehen können. Das Material ist wirklich sehr unterschiedlich. Zu Herrn Spannowsky, der die Frage gestellt hat, ob wir uns furr eine materielle Deregulierung auf Europaebene aussprechen: Ja, im Sinne des Beispieles von Herrn Breuer sicherlich; im Rechtsetzungsprozeß viel Komplexes zu verlangen und in der Rechtsprechung dann davon Abstand zu nehmen - das ist sicherlich nicht ein der Rechtsklarheit dienendes Vorgehen. Lieber sind mir Mindesterfordernisse, die bewältigbar sind und deren Vollziehung man auch verlangt. Herr Zuleeg hat mir vorgeworfen, daß ich die Kommission zu sehr gezaust hätte. Ich habe mich hier sehr vorsichtig hinter der Kritik des Rechnungshofes versteckt und habe auch gesagt, daß das sicherlich ein Extremfall ist. Dort steht aber, daß die Kommission ohne Sachverstand und auch ohne Sachverständige in diesem Fall agiert hätte. Ich stehe auch voll und ganz zu meiner Aussage, daß das europäische Recht vielfach unsystematisch ist, und die Argumentation von Herm Zuleeg, daß eben die Mitgliedstaaten dies oder jenes nicht zuließen, verstehe und kenne ich. Das ändert aber nichts daran, daß immer wieder schrittweise, wo man sich eben im Formelkompromiß einigt, nicht allzu systematisch vorgegangen wird, wie es ja bisweilen auch innerstaatlich geschieht. Ich habe darauf hingewiesen, daß es für einen Gerichtshof eben schwierig sein mag, bei diesem Material das Recht zur Wirkung zu bringen und gleichzeitig eine systematische Judikatur pflegen zu sollen. Zur Frage von Herrn Öblinger, ob ich mir vorstellen kann, unter den speziellen Anforderungen der österreichischen Verfassung noch weitere Freiräume der Verwaltung zu öffnen: Ich habe versucht, etwa durch das Beispiel einer Verordnung mit längerem Inkrafttretenszeitraum und anschließendem Individualakt, der relativ leicht mit aufschiebender Wirkung versehen werden kann, anzudeuten, daß ich mir weitere Erweiterungen vorstellen kann, und ich glaube, daß die Judikatur dem auch folgen wird. Zur Frage, wie weit ich meine, daß der Verwaltungsgerichtshof Freiräume der Verwaltung respektiert: Ich habe auf das eingeschliffene Niveau der Nachprüfung beim unbestimmten Gesetzesbegriff und beim Ermessen und bei den Beurteilungsspielräumen hingewiesen, aber gleichzeitig gesagt, daß die Judikatur unterschiedlich ist bei 20 Senaten, die sich verändern. Sie betrifft zum Teil unterschiedliche Rechtsgebiete, die wieder unterschiedlich normiert sind. Ich habe erwähnt, daß Gerichte bisweilen die Verwaltung führen, wenn ein Senat zu sehr in die Entscheidungsvorgänge hineinsteigt. Wer besonders viel davon versteht, ist geneigt, genauer zu prüfen. Der Verwaltungsgerichtshof ist geneigt, genauer zu prüfen, wenn aus dem kontrollierten Akt hervorgeht, daß die Verwaltung mehr getan und mehr argumentiert hat. Dabei stellt man nicht immer auf die Richtigkeit ab, sondern man begnügt sich damit zu 
sagen, hier ist einiges geschehen, lassen wir es gut sein. Es ist also doch zum Teil eine Verfahrenskontrolle, was auch den Aufhebungsgründen des Verwaltungsgerichtshofsgesetzes entspricht. Dabei ist das Maß im Einzelfall sehr schwer nachzuvollziehen. Denn der Begründungsstil des Verwaltungsgerichtshofes ist nicht immer so, daß er Gegenargumente widerlegt und die eigenen darlegt, sondern vielfach begründet er die Entscheidung nur aus seiner Sicht, und die Argumente sind vielfach nur aus dem kompletten Akt, der ja nicht zugänglich ist, zu ersehen. Ich habe bisweilen schon Akten angefordert und daraus diesen Befund ziehen können. Zuletzt zu Herm Raschauer und Herm Wallerath. Herr Raschauer hat sehr stark den Begriff der Optimierung der Abwägung gegenübergestellt. Wenn wir die Abwägung verschiedener Werte als eine Optimierung bezeichnen, dann wäre auch die Abwägung bei der Rodungsbewilligung nach $\S 17$ Forstgesetz eine Optimierung des Werts des Projekts gegenüber der Walderhaltung oder auch bei der Nachbesserung nach $\S 79$ Gewerbeordnung. Es sind eben neue Umstände hinzugekommen, es muß nachgebessert werden, und die Werte, die vom Gesetzgeber angegeben sind, sind abwägend zu optimieren nach ihrem vom Gesetzgeber vorgesehenen Gewicht, was natürlich Schwierigkeiten bereitet. In diesem Sinne habe ich Optimierung in These 1 verwendet. Zuletzt gibt es den Typisierungshunger der Verwaltung, selbstverständlich. Ich wollte die konventionelle Art der Regelung, weitgehende Vorgaben des Gesetzgebers aufrechterhalten und nur verbessern und durch Beispiele zeigen, daß mir das durchaus ein Anliegen ist. Dazu dient etwa ein demonstrativer Katalog für die Verwaltung mit einer escape-Klausel für den Fall, daß es dann in concreto mit den Katalogvorgaben doch nicht stimmen sollte. Damit möchte auch ich mich bedanken, auch beim Vorstand. In einer Linie Nachfahre von Hugenotten, die in Preußen Aufnahme fanden, danke ich, daß ich wieder als Ausländer, aus Österreich kommend, in Potsdam aufgenommen wurde. Danke schön.

Vorsitzender: Herr Haller, haben auch Sie ganz herzlichen Dank für Ihr Referat und für die ergänzenden Stellungnahmen in der Diskussion. Es war uns natürlich klar, daß es für einen österreichischen Referenten besonders schwierig sein würde, mit dem Begriff der Optimierungsgebote umzugehen. Sie haben dazu zum Schluß in ihren Antworten die Begriffe der eingeschliffenen Judikatur und der konventionellen Prozeduren verwandt; vielleicht ist dies auch nicht das Schlechteste, der Begriff der Optimierungsgebote stellt eine Herausforderung dar, die zu kritischer Überprüfung Anlaß geben sollte. Sie haben uns die österreichische Sicht dazu vorgestellt, und hierfür sind wir Ihnen besonders dankbar. Herr Würtenberger, Sie haben als letzter das Schlußwort. 
Würtenberger: Ich möchte zunächst auf die europarechtlichen Bemerkungen zu meinem Referat eingehen. Herr Pernice und Herr Zuleeg haben darauf hingewiesen, daß das Europarecht nicht nur mit best practice-Lösungen steuern würde, sondern auch einen beachtlichen Bereich konditionaler Steuerung aufweise. Dies findet natürlich meine Zustimmung. Gleichwohl zeigt die von mir als Beispiel herangezogene IVU-Richtlinie, $\mathrm{da} ß$ das Europarecht zu gewissen Veränderungen in der nationalen Verwaltungskultur führen kann. Herr $Z$ uleeg muß mich wohl mißverstanden haben, wenn er der Meinung war, daß ich den EuGH wegen mangelnder Grundrechtsrechtsprechung kritisiert hätte. Hierzu war im Referat nichts ausgefuihrt. In der Sache hat Herr Selmer zu dieser Frage soeben Stellung genommen.

In der ersten Diskussionsrunde hatten Herr Engel und Herr Alexy gefragt, wo der Rechtsschutz in meiner Konzeption der Abschichtung von Verwaltungsverfahren und Gerichtsverfahren bleiben würde. Sicherlich läßt sich hier eine abgestufte Theorie der Kontrollintensität entwickeln und nach der normativen Steuerungskraft der verwaltungsrechtlichen Begriffe fragen. Mir ging es jedoch um einen grundsätzlicheren Perspektivenwechsel: Das Verwaltungsverfahren sollte so angelegt sein, daß in ihm alle Streitpunkte in einer rechtlich vertretbaren Weise gelöst werden können. Dann bedarf es im Gerichtsverfahren lediglich einer Vertretbarkeits- und Plausibilitätskontrolle, nicht aber einer umfänglichen Richtigkeitskontrolle. Diese Vertretbarkeits- und Plausibilitätskontrolle würde dadurch stattfinden, daß das Gericht sich Gewißheit darüber verschafft, ob das Verwaltungsverfahren fair abgelaufen ist, der wissenschaftlichtechnische Sachverstand, auch durch Gegengutachten, in das Verfahren einbezogen wurde, alternative Möglichkeiten der Gestaltung bewertet wurden etc. Herr Ronellenfitsch und Herr Geis gehen teilweise von einer anderen Philosophie des Verwaltungsverfahrens und seiner gerichtlichen Kontrolle aus. Wenn man von der Beteiligung interessierter Bürger und von einer diskursiven Verfahrensgestaltung nicht viel an Ergebnisrichtigkeit erwartet, so wäre es in der Tat besser, daß die Verwaltung in traditioneller Manier in Distanz zu den interessierten Bürgern und zur kritischen Öfentlichkeit ihre Entscheidungen fällt. Diese Konzeption freilich zwingt den Bürger in das Klageverfahren. Nach meiner Konzeption dagegen sind das Verwaltungsverfahren und das Gerichtsverfahren ein System kommunizierender Röhren. Wenn die wichtigen Fragestellungen, Probleme der Gewichtung, Würdigung des wissenschaftlich-technischen Sachverstandes etc. im Verwaltungsverfahren mit den Betroffenen abgearbeitet worden sind, wenn also im Verwaltungsverfahren die Betroffenen mit der Verwaltung um das Richtige gerungen haben, so kann im Gerichtsverfahren der Rechtsschutz weitgehend auf eine Kontrolle des Ver- 
fahrens zurückgenommen werden, also auf die Frage, ob aufgrund eines fairen Verfahrens eine rechtlich vertretbare Entscheidung gefunden wurde. Wenn jedoch die interessierten Bürger im Verwaltungsverfahren nur gehört werden, man sich mit ihnen aber nicht mit der erforderlichen Gründlichkeit auseinandersetzt, wenn die Erörterungstermine in der alten Manier verlaufen, daß man zwar das Wort erteilt, aber keine Diskussion ermöglicht, wenn es im Erörterungstermin abgelehnt wird, Sachverständige der Einwender zu hören, wenn man also mit dieser alten Verfahrenskultur fortfährt, führt dies zu einer Überlastung der Verwaltungsgerichte. Im verwaltungsgerichtlichen Verfahren muß all das nachgearbeitet werden, was im Verwaltungsverfahren nicht geleistet wurde.

Herr Rascbauer hat mit einigen durchaus plausiblen Beispielen das optimierende Abwägen kritisch beleuchtet. Einem Beispiel möchte ich jedoch dezidiert widersprechen: Im Planungsrecht kann man durchaus dazu veranlaßt sein, auch alternative Trassen zu prüfen und zu erwägen. Gerade bei der UVP werden mehrere Planungsvarianten durchgespielt, um sodann eine optimierende Summe im Hinblick auf die Umweltbelastung zu ziehen.

Der rechtskulturelle Vergleich erscheint mir als ein äußerst wichtiger Punkt, der in den Diskussionen immer wieder angesprochen wurde. Herr Riedel hat mit Recht darauf hingewiesen, daß die Rechtsvergleichung auch im öffentlichen Recht wegleitend sein muß. Ich möchte dies nicht nur unterstützen, sondern um den folgenden Gedanken ergänzen: Ebenso wichtig ist eine Art historischer Rechtsvergleichung, die zu unseren rechtskulturellen Fundamenten führt und deren kritische Diskussion ermöglicht, aber uns gleichzeitig auch erkennen läßt, auf welchen rechtskulturellen Fundamenten andere Staaten ihr Rechtssystem bauen. Dies ist in einer Zeit besonders wichtig, in der an der Einheit Europas gearbeitet wird, die auch zu einer Vereinheitlichung in der Rechtskultur führt, zugleich aber auch im Sinne der Subsidiaritätsidee die Fundamente der Rechtskultur der Mitgliedstaaten der Europäischen Union zu berücksichtigen hat.

Abschließend möchte ich für die anregenden und weiterführenden Diskussionsbeiträge meinen Dank sagen. Zugleich möchte ich auch dem Vorstand danken, daß er mich mit der Thematik des heutigen Tages betraut hat.

Vorsitzender: Herr Würtenberger, ich danke Ihnen ebenfalls sehr herzlich für Ihr Referat, das uns in einer sehr tiefreichenden Weise bis in die historischen Grundlagen hinein, dann aber auch bis zu den aktuellen rechtlichen Fragen deutlich gemacht hat, daß man offensichtlich differenzieren muß zwischen Bereichen, in denen Optimierungsgebote mit 
einer bestimmten Funktion einen Sinn haben, und anderen Bereichen, wo strikte rechtliche Rahmensetzungen wohl nach wie vor das Richtige sind. Es wäre vermessen, am Ende einer solchen Diskussion ein Resumee ziehen zu wollen. Diesen untauglichen Versuch werde ich nicht unternehmen, Sie können beruhigt sein. Gleichwohl scheint es mir richtig zu sein, drei Punkte am Schluß hervorzuheben. Das Thema mit einem ungewohnten Begriff und einer ungewohnten Gegenüberstellung enthielt natürlich eine Provokation. Dies war beabsichtigt. Und so ist es auch nicht verwunderlich, daß manche am Begriff der Optimierungsgebote Ansto $\beta$ genommen haben und $d a ß$ andere versucht haben, die Optimierungsgebote in jeweils spezifischer Weise zu interpretieren oder fortzuentwickeln. Es ging dem Vorstand auch weniger um Begrifflichkeiten als vielmehr um ein Phänomen, das sich gerade in der deutschen Rechtsordnung mehr unterschwellig eingeschlichen hat, aber international und rechtsvergleichend eher auffällig ist. Es macht in der Tat einen Unterschied aus, ob man etwa auf der verfassungsrechtlichen Ebene ein positives Gebot der Verhältnismäßigkeit als angeblich verfassungsrechtliches Gebot versteht oder ob man lediglich ein Verbot der Unverhältnismäßigkeit verlangt. Letzteres scheint mir jedenfalls in den ausländischen Rechtsordnungen, die wir betrachtet haben, der Fall zu sein. Es dürfte auch im europäischen Recht weitgehend so verstanden werden, und im Prinzip schien mir das Ergebnis dieser Debatte darin zu bestehen, daß man auch im deutschen Recht eher Selbstbescheidung des Juristen pflegen und nicht in den Sternenhimmel im Sinne eines positiven Optimierungsgebotes der Verhältnismäßigkeit greifen sollte. Auf der verwaltungsrechtlichen Ebene kann man dies alles fortsetzen. Man kann beobachten, daß die Gesetzgeber in den einzelnen Staaten, insbesondere auch in Deutschland, und der Richtliniengeber der Europäischen Gemeinschaft sich in sehr ehrgeizigen, anspruchsvollen und fragwürdigen Wendungen im Sinne der Optimierung verlieren. Etwa im Bereich des Umwelt- und des Verfahrensrechts läßt sich dies aufzeigen. Insoweit scheint das rechte $\mathrm{Maß}$ der Dinge durch diese Diskussion jedoch wieder gefunden zu sein. Es macht, und da kann ich an die Schlußworte von Herrn Würtenberger anknüpfen, auch einen erheblichen Unterschied aus, ob man die Postulate der Gesetze und der europäischen Richtlinien als justitiable Rechtsbegriffe versteht, ob man sie also gerichtsadressiert interpretiert und insoweit den Gerichten das letzte Wort zuspielt, oder ob man diese Begriffe eher im Sinne eines Auftrages an die Exekutive versteht. Eine starke Tendenz schien mir in die zuletzt genannte Richtung zu gehen. Zum zweiten: Wir haben Rechtsvergleichung in dieser Aussprache miteinander betrieben; die Grundlage dafür bestand in den ausgezeichneten Referaten. Mir scheint, wenn ich der weiteren Bewertung etwas vorgreifen darf, daß 
dieses Experiment gelungen ist. Was Herr Riedel zum Schluß angedeutet hat, dürfte wohl ebenfalls zum Resumee dieser Veranstaltung gehören. Otto Mayer hat bereits in seiner berühmten Theorie des französischen Verwaltungsrechts von 1886 darauf hingewiesen, daß es notwendig sei, Rechtsordnungen anderer Staaten originär $\mathrm{zu}$ vermitteln; und seine Theorie des französischen Verwaltungsrechts ist nichts anderes als eine Darstellung des französischen Verwaltungsrechts in deutscher Sprache. Insbesondere Herr Riedel als Referent, aber auch mehrere Diskussionsteilnehmer sind insoweit in die Fußstapfen von Otto Mayer getreten, indem sie uns wieder diese Innensicht anderer Rechtsordnungen in Europa vermittelt haben. Zum dritten: Die Konvergenz ist wiederholt angesprochen worden. Herr Würtenberger, Herr Riedel und auch Herr Haller haben dies getan. Konvergenz ja, hier sind deutliche Linien erkennbar. Ich möchte aber auch im Sinne der Worte von Herrn Götz darauf hinweisen, daß die Konvergenz nicht darin bestehen kann, zu kopieren, was in anderen Mitgliedstaaten der Europäischen Gemeinschaft oder sonst in anderen Staaten dieser Welt gemacht wird, sondern daß es darum geht, die spezifisch deutsche Tradition des Rechtsstaates, der Gesetzmäßigkeit und der gerichtlichen Kontrolle einzubringen. Auch dazu hat aber die Debatte, wie ich meine, gute Ansätze geboten, die es fortzuführen gilt. Zum Schluß danke ich noch einmal den drei Referenten sehr herzlich für die Referate, die, wie gesagt, die Basis waren. Ich danke auch allen Diskussionsrednern für die Anregungen, die uns vermittelt worden sind, und schließe damit den wissenschaftlichen Teil dieser Staatsrechtslehrertagung. 